\title{
Informe Anual del Sector de los Contenidos Digitales en España 2018
}

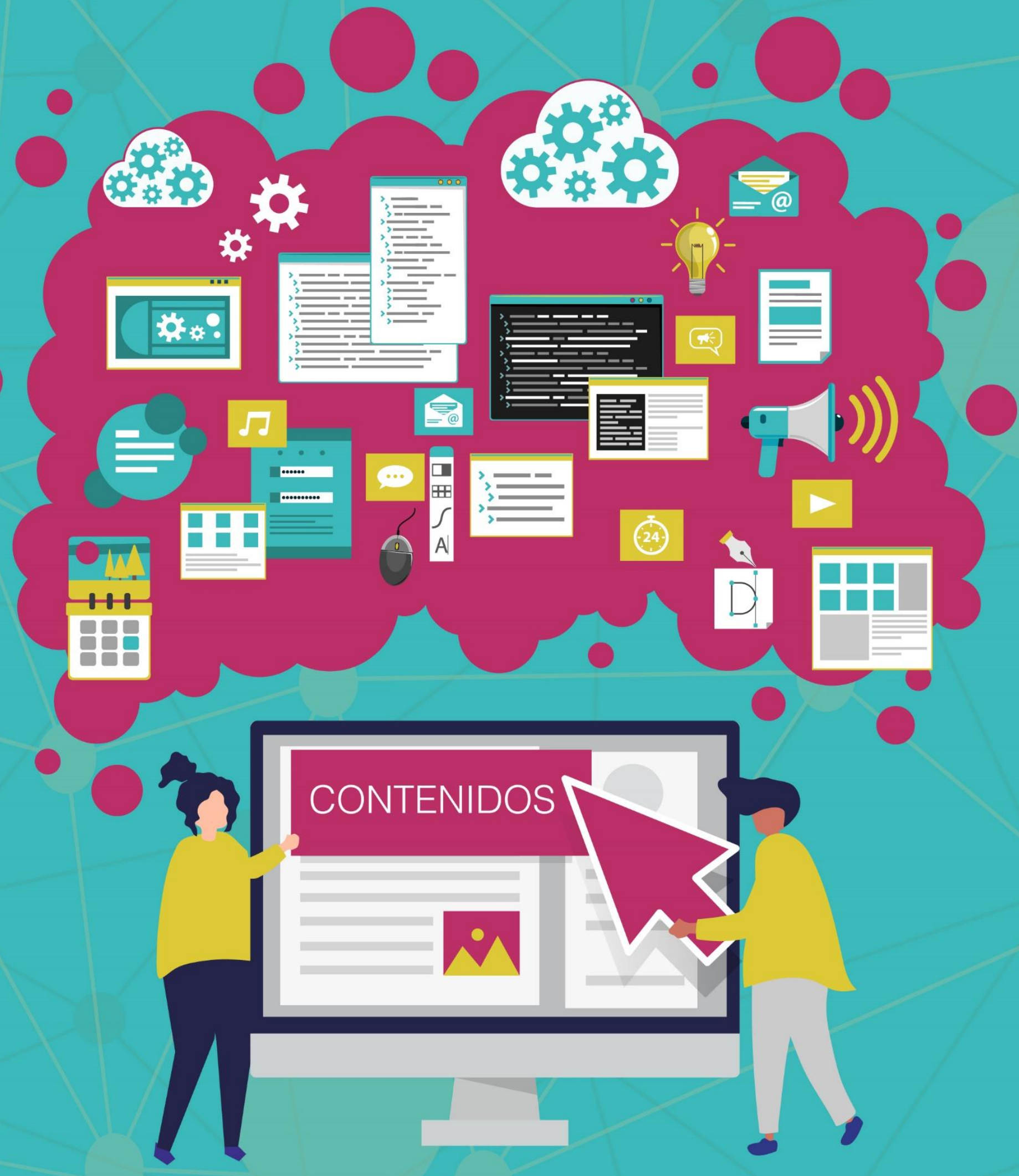

ontsi $\begin{gathered}\text { observatorio } \\ \text { nacional del as } \\ \text { telocol }\end{gathered}$ elecomunicaciones

$\begin{array}{lll}\star & \\ \star & \text { MINISTERIO } \\ \text { DE ECONOMIA }\end{array}$ Y EMPRESA 
El estudio anual del Sector de los Contenidos Digitales en España 2018 ha sido elaborado por el equipo del ONTSI:

Luis Muñoz López (Director Técnico)

Pedro Antón Martínez

Para la elaboración de este informe se ha contado con los servicios de apoyo de ACAP, Asesores y Consultores en Administraciones Públicas S.L. y de Oesía Networks.
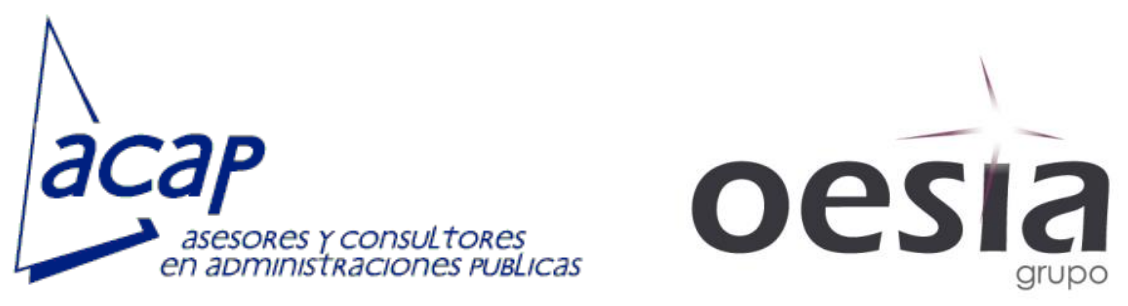

DOI: $10.30923 /$ SECCONDIGESP2018

Reservados todos los derechos. Se permite su copia y distribución por cualquier medio siempre que se mantenga el reconocimiento de sus autores, no se haga uso comercial de las obras y no se realice ninguna modificación de las mismas. 


\section{ÍNDICE}

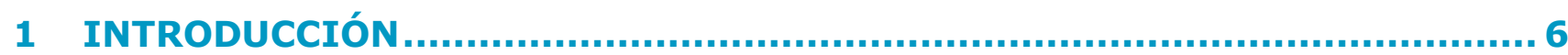

2 TENDENCIAS DEL SECTOR DE LOS CONTENIDOS DIGITALES ................ 10

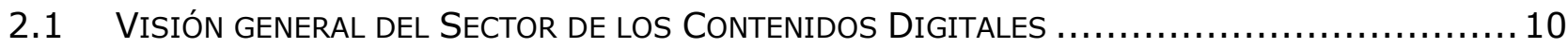

2.2 EL PAPEL DE LOS OPERADORES DE TELECOMUNICACIONES EN LA TRANSFORMACIÓN DEL MERCADO

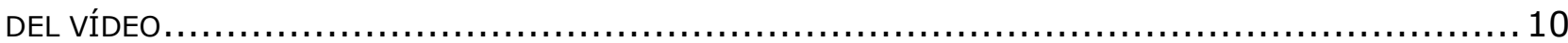

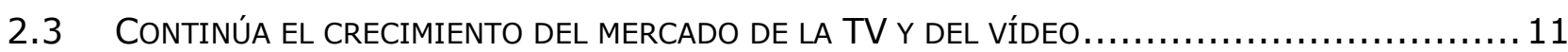

2.4 TV Y PUBLICIDAD: REINVENCIÓN DEL MODELO DE NEGOCIO DE LA TV $\ldots \ldots \ldots \ldots \ldots \ldots \ldots \ldots \ldots \ldots \ldots \ldots \ldots \ldots \ldots \ldots$

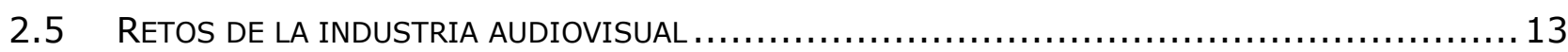

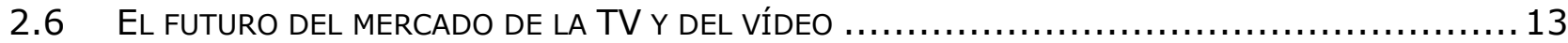

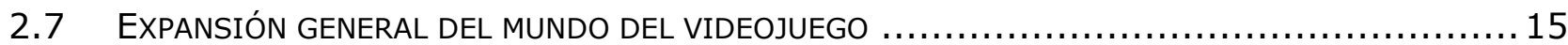

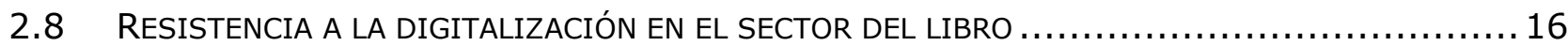

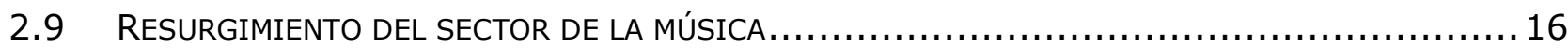

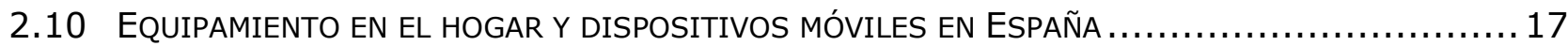

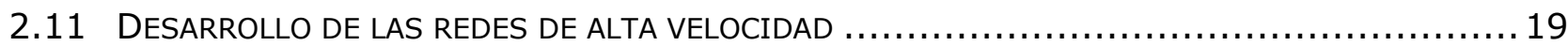

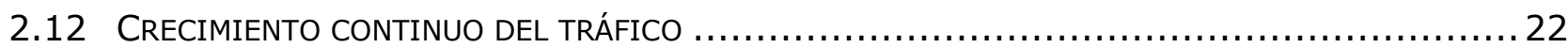

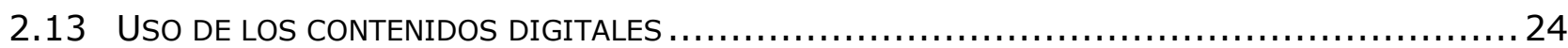

3 LA INDUSTRIA DE LOS CONTENIDOS DIGITALES EN ESPAÑA.................. 27

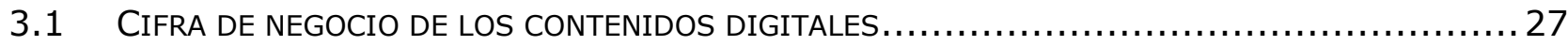

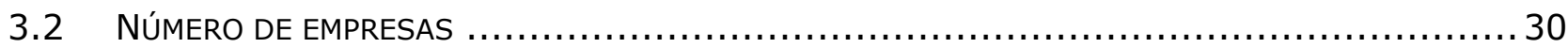

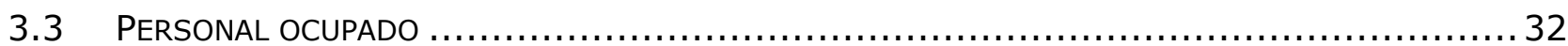

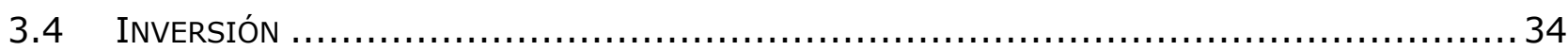

4 EL SECTOR DE LOS VIDEOJUEGOS … 38

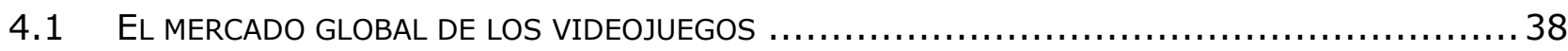

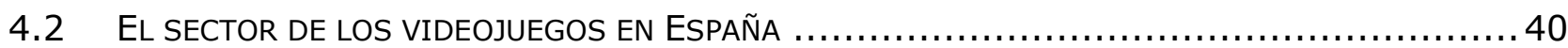

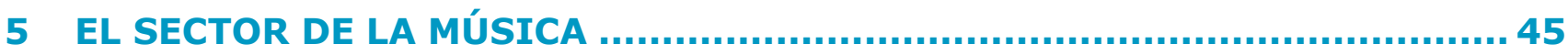

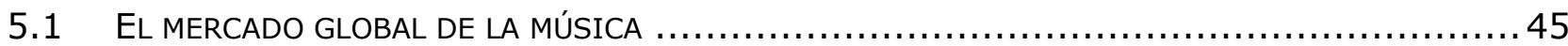

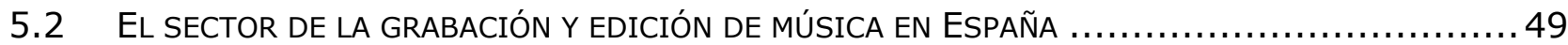

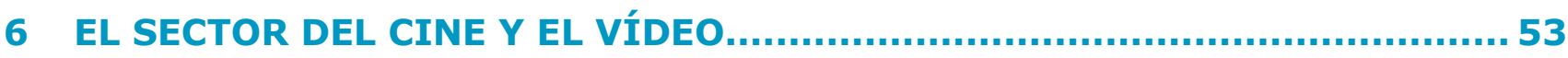

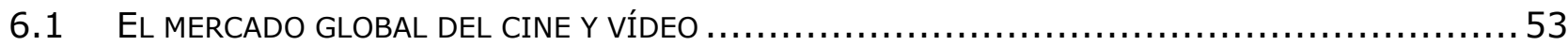

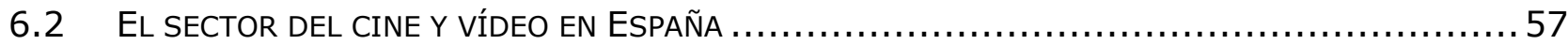

7 EL SECTOR AUDIOVISUAL.............. 73

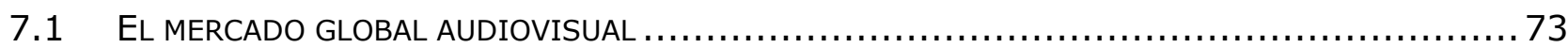

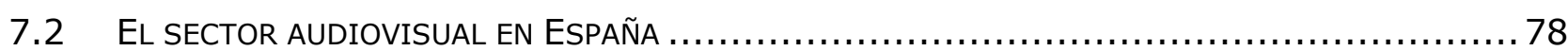

8 EL SECTOR DE LAS PUBLICACIONES .................................. 83

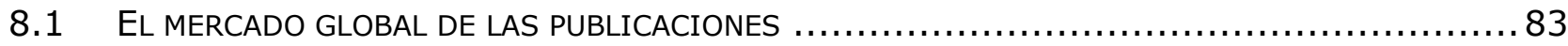

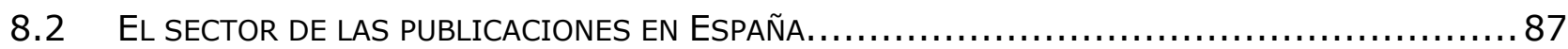

9 EL SECTOR DE LA PUBLICIDAD DIGITAL

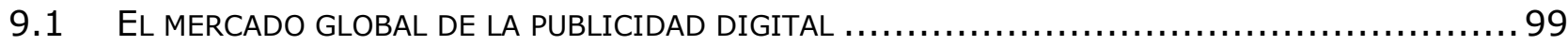

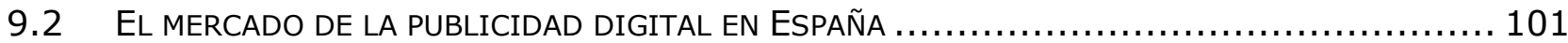

10 OTROS SECTORES DE CONTENIDOS DIGITALES

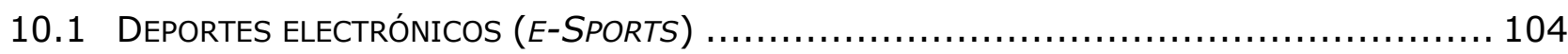




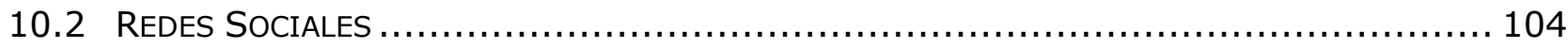

11 CONCLUSIONES .........................................................

12 NOTA METODOLÓGICA

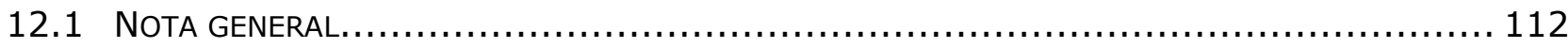

12.2 FICHA TÉCNICA Y METODOLOGÍA DE LA ENCUESTA A LAS EMPRESAS DEL SECTOR DE CONTENIDOS 112

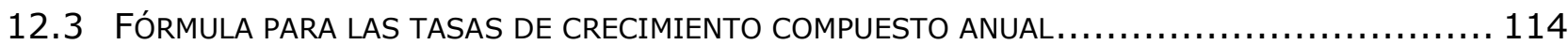

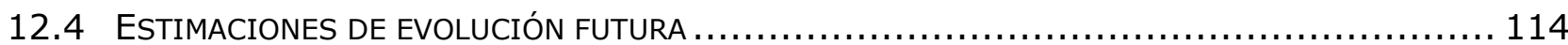

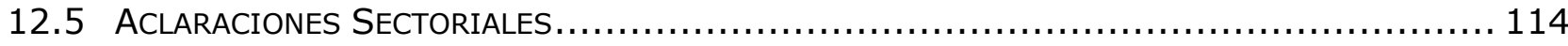

13 GLOSARIO DE TÉRMINOS .......................................... 116

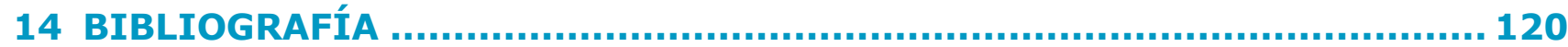

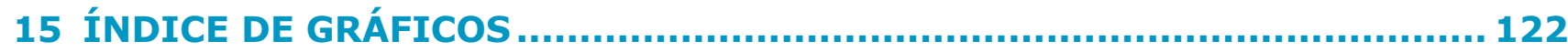




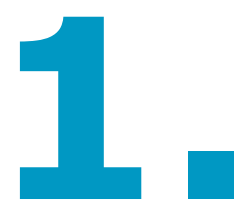

\section{INTRODUCCIÓN}

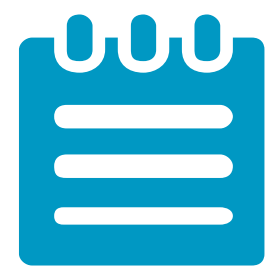




\section{Introducción}

El Observatorio Nacional de las Telecomunicaciones y la Sociedad de la Información (ONTSI) saca a la luz la décima edición del Informe Anual sobre el Sector de los Contenidos Digitales en España, con el objetivo de analizar las tendencias principales que experimenta la industria de los contenidos digitales en la actualidad, así como la evolución futura de las principales variables económicas tanto en el ámbito nacional como internacional.

En este apartado introductorio se realiza una breve descripción de los marcos regulatorio, económico e institucional, en los que se encuadra el desarrollo del sector de los contenidos digitales. Igualmente, se expone la estructura de contenidos del presente documento; así como las principales fuentes de información utilizadas para la elaboración del mismo.

El marco básico regulatorio sobre el que se plantea el desarrollo del sector de los contenidos digitales en España es la Estrategia para el Mercado Único Digital que adoptó la Comisión Europea el 6 de mayo de 2015. Sus objetivos principales son lograr que la economía, la industria y las sociedades europeas aprovechen plenamente la nueva era digital, en definitiva, la creación de un entorno libre y seguro en el que los ciudadanos puedan comprar en línea a través de las fronteras y las empresas puedan vender online en toda la UE. Ya en el año 2017 se produjeron logros en el marco de la Estrategia como el final de las tarifas de roaming o de itinerancia de datos, la modernización de la protección de datos, la portabilidad transfronteriza de contenidos en línea, y la liberalización del comercio electrónico a través de la eliminación del bloqueo geográfico injustificado. Estos logros constituyen hechos importantes para el desarrollo del sector de los contenidos digitales: por ejemplo, el final de las tarifas de roaming y la portabilidad transfronteriza de contenidos online permite a los europeos desde principios de 2018 viajar con sus productos de contenido digital (películas, vídeos, música, etc.) a los que se han suscrito.

Igualmente, en el marco de la Estrategia de Mercado Único Digital, desde mayo de 2018 se aplica el Reglamento General de Protección de Datos europeo que deroga parte de la Ley Orgánica de Protección de Datos. Este nuevo reglamento impactará de manera muy significativa en el sector de la publicidad digital, transformando la forma de recoger y tratar los datos (IAB Spain, 2016). De manera simultánea a la entrada en vigor de este Reglamento, entra también en vigor el Reglamento de e-privacy para la regulación de las comunicaciones comerciales, la regulación de cookies y la regulación de los servicios OTT (IAB Spain, 2018b).

También, constituye un hecho relevante para el sector de la publicidad digital la aprobación del Memorando de Entendimiento (MoU) sobre publicidad en línea y violación de propiedad intelectual impulsado por la DG GROW de la Comisión Europea, con objeto de reducir la colocación de publicidad en sitios que violan los derechos de autor o venden productos falsificados y reducir la fuente de ingresos de tales sitios ${ }^{1}$.

Además, un hecho muy importante para el sector de los contenidos digitales es la negociación que se está produciendo actualmente en Bruselas con respecto a la controvertida Directiva de Contenidos Digitales, que plantea el concepto del dato como contraprestación monetaria, o lo que es lo mismo, que los usuarios puedan pagar con sus datos en lugar de con dinero, lo cual contradice las bases del derecho fundamental, entre ellos, el de la protección de datos. Además, el Supervisor Europeo de Protección de Datos rechaza la idea de que el dato personal se pueda considerar una contraprestación por los servicios que se disfrutan de forma gratuita

\footnotetext{
${ }^{1}$ https://iabspain.es/iab-europe-firma-el-memorando-de-entendimiento-sobre-publicidad-en-linea-y-violacion-
} de-la-propiedad-intelectual-mou/ 
por las profundas implicaciones que tendría en un derecho fundamental como la privacidad (IAB Spain, 2018b).

En el ámbito nacional, el Gobierno de España aprobó la Agenda Digital para España en febrero de 2013, como hoja de ruta para el cumplimiento de los objetivos de la Agenda Digital para Europa para el período 2015-2020 en materia de TIC y Administración Electrónica. La Agenda Digital para España contaba con un plan específico en materia de impulso de la economía digital y los contenidos digitales.

En otro orden de cuestiones, la presente edición del informe para el año 2018 se estructura en los siguientes capítulos:

- Un primer capítulo, que corresponde a esta introducción.

- Un segundo capítulo en el que se exponen la visión general y las tendencias principales que viene experimentando el sector de los contenidos digitales y los subsectores que lo configuran, así como las principales claves para su desarrollo en los próximos años.

- En el capítulo tercero se ofrece un análisis de la evolución durante los últimos años hasta la actualidad del sector de los contenidos digitales en su conjunto en relación con las siguientes magnitudes principales: la cifra de negocio o volumen de ingresos, el número de empresas, las cifras de empleo o de personal ocupado, y las cifras de inversión.

- Los capítulos siguientes, desde el cuarto hasta el noveno, corresponden a la descripción de la evolución de cada una de las industrias o sectores que configuran o caracterizan al sector de los contenidos digitales: videojuegos, música, cine y vídeo, audiovisual (en este caso sólo en lo que se refiere a la parte de televisión), publicaciones y publicidad digital. Cada uno de estos capítulos se inicia con una descripción de la evolución del mercado en el ámbito mundial o global, y de las previsiones de evolución para los próximos años; a continuación, se describe la situación actual de cada una de las industrias de contenidos digitales, así como la de las ramas de actividad asociadas a éstas (cuando corresponde), en el ámbito nacional, prestando atención a la evolución de la cifra de negocio, del número de empresas, del personal ocupado y de las cifras de inversión.

- El capítulo décimo se refiere a la evolución y tendencias generales de otras industrias de contenidos digitales especialmente relevantes.

- El undécimo capítulo contiene las principales conclusiones del estudio.

- Los capítulos restantes se refieren a las notas metodológicas, glosario de términos, referencias bibliográficas e índice de gráficas.

En la elaboración del presente informe, en lo que se refiere a la evolución de la industria de los contenidos digitales y de los sectores de contenidos que la caracterizan, se ha utilizado como principal fuente de información la encuesta que realiza con carácter anual el ONTSI a las empresas del Sector TIC y de los Contenidos, para la realización del Informe Anual del Sector TIC y de los Contenidos en España. Dicha fuente, sirve para caracterizar la evolución de la cifra de negocio y de inversión. Las cifras relativas al número de empresas y al personal ocupado son suministradas al ONTSI por la Tesorería General de la Seguridad Social. 
Igualmente, se han utilizado para el caso de España otras fuentes de información externas para la caracterización de algunos sectores de contenidos digitales. En el caso del sector de videojuegos, los datos correspondientes a la facturación del sector proceden, por un lado, de la Asociación Española de Empresas Productoras y Desarrolladoras de Videojuegos y Software de Entretenimiento (DEV) y, por otro lado, de la Asociación Española de Videojuegos (AEVI), en este último caso también para el número de copias de videojuegos vendidas en España. En el caso de la industria del cine, los datos referidos al número de salas de cine digitales en España proceden de la Asociación para la Investigación de Medios de Comunicación (AIMC). Con respecto al sector de la televisión, los datos referidos a los ingresos proceden de la Comisión Nacional de los Mercados y de la Competencia (CNMC); y los que se refieren a las cifras de inversión publicitaria de la televisión, proceden de InfoAdex. En el caso del sector de la publicidad digital, los datos correspondientes a inversión proceden de Interactive Advertising Bureau (IAB Spain).

De otro lado, los datos e información relacionados con la caracterización a nivel global de la industria de los contenidos proceden del Institut de l'audiovisuel et des télécommunications en Europe (IDATE) a través de su informe Media Strategies: The content industry's fundamentals and new trends, elaborado en exclusiva para Red.es. Igualmente, para la caracterización a nivel mundial de cada uno de los sectores de contenidos, se han utilizado fundamentalmente los datos que proporciona IDATE al respecto, además de otras fuentes internacionales. 


\section{2. \\ TENDENCIAS DEL SECTOR DE LOS CONTENIDOS DIGITALES}

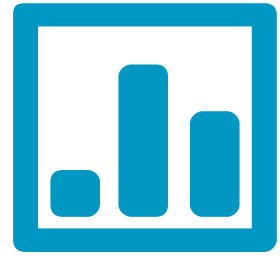




\section{Tendencias del Sector de los Contenidos Digitales}

A modo de contextualización inicial, en este apartado se expone la radiografía general del sector de los contenidos digitales a nivel global, tomando como principal fuente de información la que facilita IDATE a través de su último informe Media Strategies: The content industry's fundamentals and new trends, elaborado en exclusiva para Red.es, tal y como se ha dicho en el apartado introductorio.

El modelo de suscripción mensual se ha convertido en el nuevo modelo de acceso universal a los contenidos

\subsection{Visión general del Sector de los Contenidos Digitales}

En términos generales, los sectores de contenidos se encuentran actualmente en diferentes etapas del proceso de digitalización, aunque en todos ellos se percibe el impacto que están teniendo los cambios en los comportamientos de consumo de los usuarios, y la aparición de nuevos agentes en la agregación y distribución de contenidos en línea, con el surgimiento de nuevos modelos de negocio.

Si bien la publicidad es una fuente integral de financiación para la televisión y los medios impresos tradicionales, también se ha convertido en un componente de la nueva economía digital para los sectores de la música, los videojuegos e incluso los libros. Pero es el modelo de suscripción mensual el que realmente se ha convertido en el nuevo modelo de acceso universal a los contenidos, reemplazando la compra de singles, PPV y alquileres.

La digitalización de los sectores de videojuegos, del vídeo y de la música a nivel mundial sigue su tendencia creciente. Las tasas de digitalización para estos sectores en 2017 son del $88 \%$, del $68 \%$ y del $66 \%$, respectivamente. Por el contrario, el sector de las publicaciones y de la prensa siguen resistiéndose en la transición hacia el mundo digital, cuyas tasas de digitalización son del $11 \%$ y del $10 \%$ respectivamente. La tasa de digitalización global del sector de los contenidos es del 41\%. (IDATE, 2018b).

\subsection{El papel de los operadores de telecomunicaciones en la transformación del mercado del vídeo}

La forma en que los usuarios consumen los contenidos de vídeo se está transformando, mientras que el tiempo de pantalla sigue aumentando y las capacidades de monetización continúan siendo muy fuertes. Para los operadores, es decir, las compañías de telecomunicaciones y de cable, según su situación, los servicios de televisión o de vídeo pueden permitirles generar ingresos medios por usuario adicionales, asegurar la lealtad del cliente, y atraer nuevos suscriptores a medida que compiten por una cuota de mercado de acceso super rápido. Ningún operador en la actualidad puede permitirse el no disponer de una estrategia de televisión o de vídeo. 


Los operadores
deben enfrentar el
desafío de la
innovación y
ofrecer soluciones
de publicidad
dirigida y
personalizada,
ante el riesgo de
verse desplazados
por los gigantes
de Internet

El sector de la TV continúa siendo el mayor generador de ingresos de la industria de los contenidos
Esto significa la convergencia entre los medios de comunicación y los operadores de telecomunicaciones, cuyo objetivo final es mantener el valor allá donde pueda encontrarse, ya sea en acceso, monetizando las plataformas, o diversificando en servicios de medios. Además, cada vez es más difícil para las empresas de telecomunicaciones ignorar la oportunidad de monetizar transacciones o servicios de medios financiados mediante publicidad.

El proceso de transformación que está experimentando el mercado de la televisión incluye un conjunto de intereses compartidos para empresas de telecomunicaciones y medios de comunicación, ante la creciente influencia del uso de las tecnologías IP. Estas tecnologías no hacen sino incrementar el papel del streaming y la orientación al cliente. Ante esto, los agentes del mercado deben anticipar las futuras plataformas de video, y el proceso será largo. Los operadores deben enfrentar el desafío de la innovación y ofrecer soluciones de publicidad dirigida y personalizada, ante el riesgo de quedarse fuera del circuito, siendo desplazados por los gigantes de Internet (IDATE, 2018b).

\subsection{Continúa el crecimiento del mercado de la TV y del vídeo}

El sector de la televisión continúa siendo el mayor generador de ingresos de toda la industria de los contenidos, representando el $55 \%$ a nivel mundial. El sector de la televisión en su conjunto continúa creciendo, a pesar de las amenazas que pesan sobre el lado tradicional del negocio (la televisión lineal), que, no obstante, generará el $80 \%$ de los ingresos del sector en 2021, frente al $88 \%$ de 2017. El vídeo bajo demanda (VoD) impulsa el crecimiento, pues crece a ritmos muy superiores a la televisión lineal, aunque se espera que la competencia de los OTT (over the top, en sus siglas en inglés) obstaculice considerablemente el impulso del mercado general de televisión en el próximo año debido a la creciente popularidad de este tipo de servicios.

Con respecto a la televisión de pago, tanto el VoD como los servicios de OTT están obligando a bajar sus precios y se prevé que el crecimiento del segmento caiga a un $+1,8 \%$ anual, en promedio, desde ahora hasta 2021, mientras OTT se prevé represente para entonces el $90 \%$ de los ingresos de VoD.

En términos de acceso, el número de hogares con TV en el planeta continúa creciendo, de 1,64 mil millones en 2017 a 1,72 en 2021. Para entonces, prácticamente todas las líneas de acceso a TV se habrán digitalizado $(96 \%)$ y dos tercios de la población estará suscrito a algún servicio de pago de televisión. Se espera que el cable y el satélite estén más o menos a la par en términos de tasa de penetración (respectivamente $33 \%$ y $31 \%$ ), al igual que terrestre e IPTV (ambas en torno al 18\%). Se prevé que la ubicuidad del 
acceso por cable (cable e IPTV) sea incluso ligeramente mayor que la inalámbrica (terrestre y satelital), lo que facilita el acceso a VOD directamente en la televisión del hogar (IDATE, 2018b).

\subsection{TV y publicidad: reinvención del modelo de negocio de la TV}

Según IDATE (2018b), ante un paulatino descenso en los últimos años del consumo de televisión lineal debido a la competencia que ejerce Internet, no solo en lo que se refiere al tiempo dedicado por los usuarios, también y consecuentemente a los ingresos por publicidad, la televisión se está reinventando para ofrecer a los anunciantes ventajas similares a las que ofrece Internet.

La TV

programática crece rápidamente en Estados Unidos, pero también está haciendo grandes avances en Reino Unido, Australia y Alemania.
En este sentido, cobra especial importancia la televisión programática, la cual permite la aplicación de tecnología a la publicidad para encontrar audiencias y perfiles más sofisticados y efectivos, es decir, ofrece los mismos anuncios publicitarios a todos los espectadores que ven el mismo programa de televisión, pero permite a los anunciantes apuntar a aquellos programas cuyos espectadores coinciden más con su consumidor objetivo ideal. (IAB Spain, 2018b; IDATE, 2018b).

Con respecto a la expansión de la televisión programática, que crece rápidamente en Estados Unidos pero también está haciendo grandes avances en el Reino Unido, Australia y Alemania, juegan un papel central, por un lado, los decodificadores STB (Set-Top-Box) y las plataformas implementadas por compañías de cable, operadoras de telecomunicaciones y de satélite; así como, por otro lado, el desarrollo de análisis de datos para la recopilación de información sobre los hábitos de consumo de los usuarios, que en definitiva constituyen las herramientas fundamentales para el desarrollo de la televisión programática. Las cadenas de televisión son más reticentes, preocupadas de que algunos de sus valiosos ingresos por publicidad se pierdan ante terceros, y especialmente preocupadas de que pesos pesados como Google o Facebook se aseguren un papel importante en la recopilación y análisis de datos de los consumidores.

Igualmente, IDATE (2018b) identifica una serie de condiciones necesarias para el desarrollo y despegue de la televisión programática: (1) el incremento de las tasas de penetración de la TV de pago (por lo tanto, de los STB), así como los niveles de adopción de diferentes dispositivos que permiten conectar la TV a Internet; (2) la capacidad de los agentes interesados en llegar a acuerdos sobre estándares tecnológicos y nuevas herramientas para la medición de audiencias, así como para idear nuevos modelos de negocio que se adapten a la nueva relación entre los actores del mercado; (3) el desarrollo de normativa regulatoria; (4) mayores grados de transparencia en la utilización de los datos; (5) los requisitos reales de los anunciantes en términos de publicidad 
televisiva dirigida, dado que la publicidad masiva satisface ciertas necesidades específicas que serían más caras de lograr con la publicidad dirigida.

En la actualidad Estados Unidos abarca casi la totalidad de este mercado y se espera que en 2021 se haya incrementado por nueve su volumen, llegando a alcanzar los 19,1 miles de millones de euros (IDATE, 2018b).

\section{La rápida adopción del acceso a Internet de alta velocidad, la TV conectada y las STB, se ha traducido en un crecimiento para los ingresos generados por el consumo de vídeo OTT}

\subsection{Retos de la industria audiovisual}

La televisión lineal continúa perdiendo terreno en favor del vídeo online (OTT - over the top, en sus siglas en inglés). La rápida adopción del acceso a Internet de alta velocidad (tanto fijo como móvil), la TV conectada y las STB, se ha traducido en un crecimiento para los ingresos generados por el consumo de vídeo OTT. Desde 2013, el mercado ha crecido a un ritmo del 36,9\% al año en promedio, y se espera que continúe creciendo a una tasa promedio de $20,5 \%$ al año entre 2018 y 2021 , como parte de un mercado general de televisión cuya tasa de crecimiento anual promedio se pronostica al 4,2\%. Para 2021, se espera que el vídeo OTT represente el $18 \%$ del mercado total de TV, en comparación con el $10 \%$ en 2017. Los ingresos por publicidad y suscripción son vitales para el futuro del mercado y las principales fuentes de crecimiento del sector. En 2021, se pronostica que la publicidad representará dos tercios de los ingresos de OTT.

Aparte del peso económico de este mercado, su desarrollo está teniendo un efecto enorme y rápido en todo el sector audiovisual, obligando a la industria tradicional no solo a incorporar servicios de OTT y bajo demanda como partes completas de su línea de negocio, sino también a diseñar estrategias de consolidación nacionales o regionales. Los proveedores de televisión de pago están trabajando para incorporar la producción de contenidos en sus negocios y desarrollar colaboraciones internacionales. Cada vez más, las empresas de telecomunicaciones están explorando oportunidades para comprar propiedades de medios (IDATE, 2018b).

\subsection{El futuro del mercado de la TV y del vídeo}

Sobre la base de una combinación de hipótesis sobre consumo, suministro, tecnología, monetización y normativa, IDATE (2018b) ofrece cuatro escenarios para el futuro del sector de la televisión, cada uno de ellos con un distinto agente beneficiario principal: las cadenas de televisión, las compañías de cable y las operadoras de telecomunicaciones, y las compañías de servicios OTT.

El primer escenario que se contempla se caracteriza por la hipotética prevalencia de la convergencia de las tecnologías de difusión y transmisión fijas y móviles, en el que las compañías de cable y las operadoras de telecomunicaciones jugarían un papel central, 


\author{
En todos los \\ escenarios futuros \\ que se \\ contemplan, el \\ tiempo de \\ visionado de TV \\ lineal disminuiría a \\ medida que \\ aumenta el de VoD
}

ofreciendo un amplio conjunto de servicios que incluye TV lineal y visualización OTT a la carta, orientada a cada miembro del hogar y disponible en una amplia variedad de dispositivos, tanto dentro como fuera del hogar. En este escenario, los ingresos por suscripciones seguirían siendo una fuente clave de ingresos, al igual que la publicidad dirigida que se desarrollaría considerablemente gracias a los datos recogidos por los proveedores del servicio.

El segundo escenario (escenario de ruptura o rupturista), se caracteriza por el hipotético dominio de las compañías OTT, que impulsan la oferta estructurándola en torno a derechos globales y vídeos virales. En este escenario, la individualización de los contenidos de vídeo se lleva al extremo, donde los hábitos de visualización de cada persona ayudan a determinar los videos sugeridos, a la par que la distribución mediante streaming se convierte en norma general. Igualmente, el uso de datos personales en este escenario constituiría una pieza fundamental para la capacidad de personalizar productos y monetizar servicios. La publicidad dirigida ocuparía un papel central junto con las suscripciones de bajo coste y PPV.

El tercero de los escenarios estaría caracterizado por el papel central de la sindicación o redifusión de contenidos televisivos, en el que las cadenas de TV tendrían la oportunidad de entrar de nuevo en el juego. En este caso, la oferta se estructuraría en torno a un conjunto de poderosas marcas de TV que crearían paquetes de contenidos para su distribución lineal y bajo demanda. La televisión lineal, financiada por publicidad, se convertiría en un escaparate para el contenido de la videoteca a la carta, que es más rico y ofrece una gama más amplia de características, algunas de las cuales los usuarios tendrían que realizar pagos extra. Este escenario se fundamentaría en la hibridación de sistemas, permitiendo un enlace entre la visualización lineal y no lineal.

El cuarto y último de los escenarios contemplados por IDATE, se caracterizaría por la ausencia de cambios, es decir, se trataría de un escenario continuista en lo que se refiere al modelo de mercado actual. En este escenario cada uno de los tres tipos principales de actores que entran en el juego tienen un papel que desempeñar junto con los otros dos. En él, los canales de televisión lineales y los servicios de VoD cohabitan, al igual que las tecnologías de retransmisión de TV y de streaming. La televisión seguiría siendo en gran parte gratuita, mientras que las tarifas de suscripción de televisión de pago estarían en línea con los precios de las compañías OTT.

Por último, IDATE señala que en todos los escenarios contemplados el tiempo de visionado de TV lineal disminuiría a medida que aumenta el visionado bajo demanda, mientras que la visualización en un televisor tradicional se reemplazaría por la visualización mediante dispositivos alternativos. Sin embargo, los modos de visualización tradicionales seguirían siendo muy populares en el 
escenario continuista, pero mucho menos en el escenario rupturista. Las estimaciones de crecimiento para el horizonte 2025 en la facturación del mercado global de la televisión serían distintas para cada uno de los escenarios. De este modo, en 2025, ante un escenario de sindicación, el mercado global de la TV generaría un volumen mucho mayor de ingresos (superior a los 650 miles de millones de euros) en comparación con el escenario rupturista dominado por las compañías OTT (donde apenas se alcanzarían los 550 miles de millones de euros). Ante un escenario bien de convergencia o bien de continuidad con el modelo actual, el mercado global de la TV generaría unos ingresos que superarían los 600 miles de millones de euros. Por su parte, en todos los escenarios, se produciría un incremento de los ingresos generados por los servicios de $\mathrm{VoD}$ iguales o superiores al $15 \%$ anual; los ingresos generados por la televisión lineal también crecerían, aunque a un ritmo inferior del $5 \%$ anual en promedio. Solo ante un escenario rupturista, la televisión lineal vería reducir sus ingresos a un ritmo de casi el $10 \%$ anual en promedio (IDATE, 2018b).

En 2018 se estima que las ventas digitales representen más del $90 \%$ de los ingresos del sector de los videojuegos

\subsection{Expansión general del mundo del videojuego}

Los juegos para dispositivos móviles y tablets poco a poco se van convirtiendo en el segmento líder del sector del videojuego (el único cuya distribución se produce exclusivamente a través de medios y soportes digitales), a la vez que los desarrolladores y fabricantes de videoconsolas están desarrollando su estrategia de distribución de software hacia un modelo completamente digital (a través de sus propias plataformas digitales de venta como, por ejemplo, PlayStation Network, Nintendo eShop y Xbox Marketplace); factores que explican la creciente digitalización general del sector. En 2018 se estima que las ventas digitales representen más del $90 \%$ de los ingresos.

Se prevé que el mercado mundial de videojuegos genere 94,2 miles de millones de euros en 2018, y alrededor de 134,3 miles de millones de euros en 2022. Se espera que los ingresos por ventas de software de juegos superen los 100.000 millones de euros en 2019. Este fuerte crecimiento ( $9,3 \%$ anual, en promedio, hasta 2022), según IDATE, se puede atribuir a tres factores: un sector de juegos móviles muy fuerte en Asia, el aumento de la ubicuidad de las ventas digitales para juegos de consolas domésticas y el desarrollo de dispositivos para juegos de realidad aumentada y virtual.

Igualmente, se prevé que los juegos para móviles generen unos 43.600 millones de euros a finales de 2018. Dicho segmento seguiría creciendo, alcanzando los 60.700 millones de euros en 2022, en parte, debido a su popularidad en los países emergentes, especialmente en el continente asiático. 


\section{La venta de libros en papel a través de e-commerce se incrementa de forma masiva a expensas de la venta tradicional en librería}

Por el contrario, se prevé que las ventas físicas continúen evolucionando negativamente (IDATE, 2018b).

\subsection{Resistencia a la digitalización en el sector del libro}

El sector del libro continúa resistiéndose al proceso de digitalización, al contrario de lo que sucede con el resto de los sectores de contenidos. Aun así, sus cifras de ingresos siguen una tendencia al alza durante los últimos años, aunque a un ritmo de crecimiento bastante bajo.

Las razones que explican la tendencia que experimenta el sector del libro, según las argumentaciones de IDATE, se deben a la fidelidad al libro en papel que persiste entre los lectores, a pesar de los esfuerzos de las editoriales para entregar una versión electrónica de un porcentaje creciente de libros nuevos. Otra de las razones, se encontraría en la escasa competitividad de los precios si se compara entre la modalidad de distribución (física o digital), además de la ausencia en la industria editorial de equivalentes a Spotify o Netflix en comparación con la industria de la música o el vídeo. No obstante, aunque existen modalidades de suscripción, muy pocas se han desarrollado a nivel internacional, con la excepción de Amazon's Kindle Unlimited Plan. Además, la mayoría de ellas establecen límites en la cantidad de libros a los que se puede acceder mensualmente (IDATE, 2018b).

Por otra parte, cabe destacar que, a pesar de que las ventas digitales continúan siendo escasas, la venta de libros en papel a través de comercio electrónico se incrementa de forma masiva a expensas de la venta tradicional en librería.

Comparada al nivel de países, la tasa de digitalización en ningún caso supera el $30 \%$. Las tres primeras posiciones en cuanto a digitalización del sector del libro las ocupan China, Colombia y Japón cuyas tasas se encuentran entre el $17,5 \%$ y el $28 \%$ (IDATE, 2018b).

\subsection{Resurgimiento del sector de la música}

El sector de la música atraviesa un buen momento en la actualidad, lejos del declive constante sufrido años atrás, especialmente gracias al desarrollo de los servicios de streaming para su distribución.

En 2017, el 58\% del volumen de negocio del sector de la música corresponde a las suscripciones a servicios de streaming, habiendo crecido con respecto al año anterior casi un $60 \%$.

Según IDATE, el impacto tan positivo que está teniendo la penetración de los servicios de streaming, se debe fundamentalmente a la buena predisposición de los consumidores a pagar por acceder a servicios de música, al mismo tiempo que se viene produciendo un incremento de la competencia en dicho 


En 2017, el
$58 \%$ del
volumen de
negocio del
sector de la
música
corresponde a las
suscripciones a
servicios de
streaming

segmento gracias a la llegada de nuevos actores, más allá de los tradicionales Spotify o Deezer, como Google, Apple Music o Amazon.

Además, las perspectivas de crecimiento para los servicios de streaming son favorables, aunque IDATE advierte de la persistencia de dos incertidumbres: en primer lugar, la capacidad de la industria de la música para traducir en ingresos el tiempo que los usuarios pasan en las plataformas de streaming; y, en segundo lugar, la forma en que los sistemas de reconocimiento de voz (por ejemplo, Alexa de Amazon o Google Home) estimularán el uso de sus servicios de transmisión asociados, afectando considerablemente a actores como Spotify, que podría verse superada en el futuro por sus competidores norteamericanos (IDATE, 2018b).

En la actualidad más de la mitad de los ingresos totales del sector proceden de las ventas digitales.

\subsection{Equipamiento en el hogar y dispositivos móviles en España}

En lo que se refiere al equipamiento y dispositivos para acceder a contenidos digitales, según los últimos datos de la Encuesta sobre Equipamiento y Uso de TIC en los Hogares Españoles ${ }^{2}$ del Instituto Nacional de Estadística (INE) indican que prácticamente la totalidad de los hogares con, al menos, un miembro de entre 16 y 74 años en 2018 dispone de teléfono móvil (98\%); el segundo dispositivo más frecuente es el ordenador (de cualquier tipo) presente en el 79,5\% de los hogares españoles. Completa el podio la tablet, que está presente en más de la mitad de los hogares $(54,5 \%)$.

Aunque la televisión, en general, es el dispositivo con mayor presencia en los hogares españolas (prácticamente la totalidad de ellos, el $99,1 \%)$, los datos que presenta el INE no permiten distinguir el porcentaje de Smart TV, las cuales posibilitan el acceso a contenidos digitales. Lo mismo ocurre con los libros electrónicos o ebooks (no todos estos dispositivos integran la funcionalidad para conectarse a Internet), que son el dispositivo menos frecuente en los hogares españoles (24\%).

\footnotetext{
2 Datos publicados el 7 de noviembre de 2018 .
} 
Gráfico 1. Equipamiento de productos TIC en los hogares españoles, 2018 (\% de hogares)

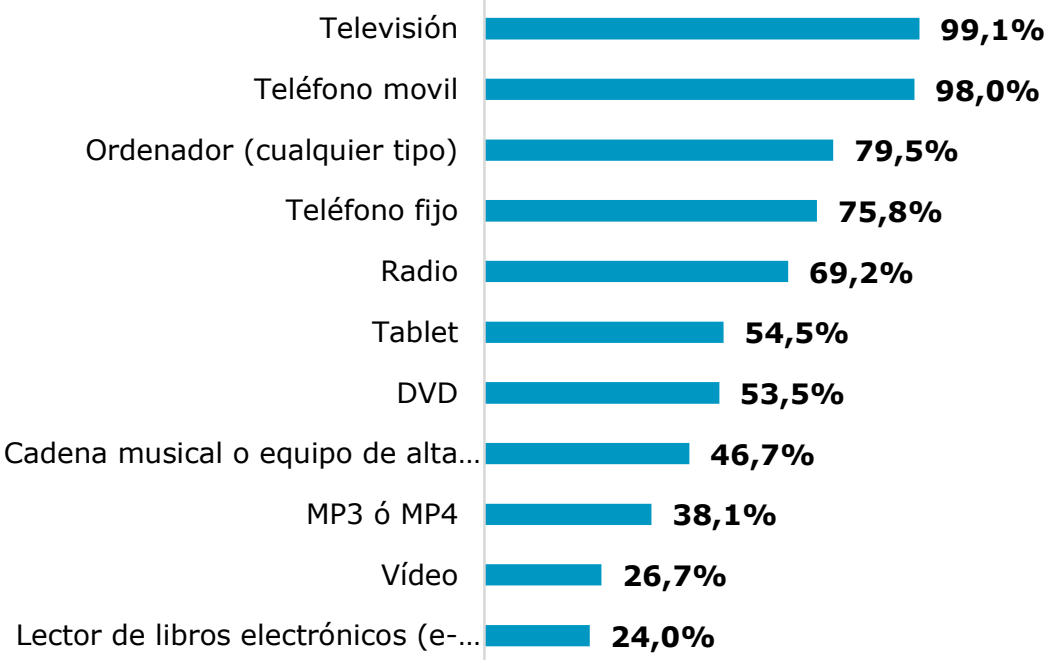

Fuente: INE, Encuesta sobre equipamiento y uso de TIC en hogares 2018

A principios de 2018, en España, el $85,2 \%$ de los

\section{usuarios utiliza el teléfono móvil para acceder a Internet}

De acuerdo con los últimos datos disponibles procedentes de la LIX Oleada del Panel de Hogares del ONTSI, el teléfono móvil (smartphone) continúa siendo el dispositivo más utilizado para acceder a Internet por los usuarios $(85,2 \%)$. El ordenador es otro dispositivo que los internautas emplean a menudo para conectarse a la red, el 55\% utiliza un ordenador portátil, mientras que el $45,1 \%$ hace lo propio con un ordenador de sobremesa. Otros dispositivos que también utilizan los usuarios para conectarse a Internet son la tablet $(36,7 \%)$, la Smart TV $(17,5 \%)$ y la videoconsola $(6,7 \%)$.

Gráfico 2. Principales dispositivos de acceso a Internet (\% de internautas)

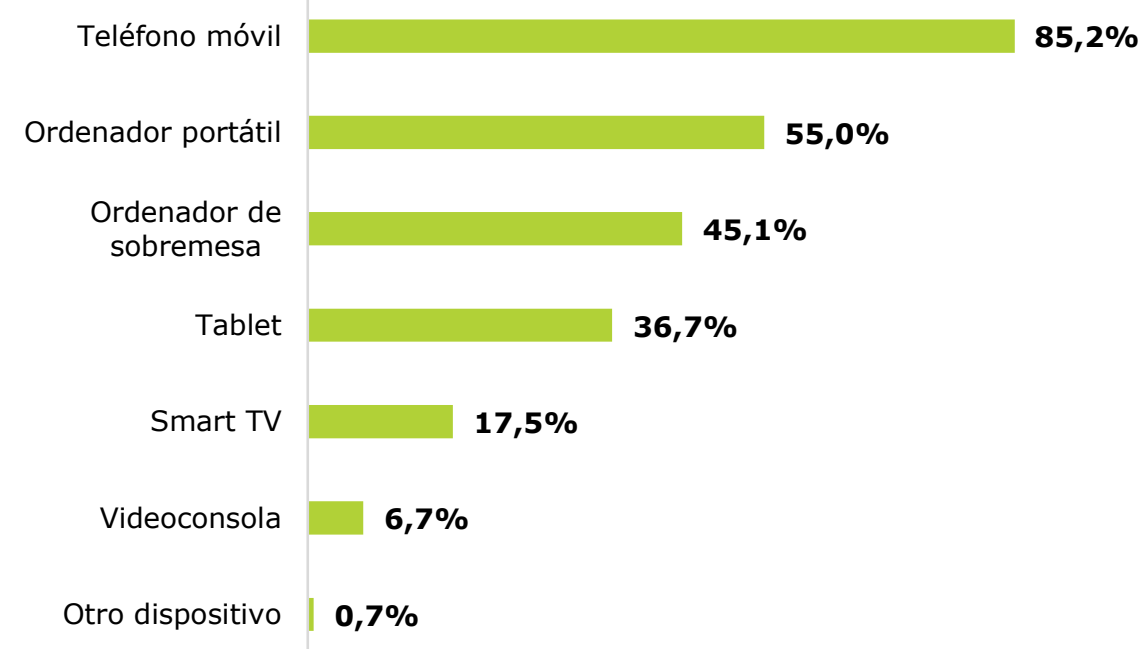

Fuente: Panel de hogares ONTSI (LIX Oleada, Enero-Marzo 2018)

Igualmente, en relación con el uso de dispositivos para acceder a contenidos digitales, IAB Spain, en su último estudio sobre vídeo online, señala que el dispositivo preferido por los usuarios para ver los contenidos de vídeo en Internet es el ordenador de sobremesa o 
el ordenador portátil (83\%), seguidos de los smartphones (61\%). Por su parte, la TV conectada estaría ganando peso en las preferencias para ver vídeo online (38\%). En cuarto lugar, aparece la tablet, utilizada por el $34 \%$ de los usuarios.

Gráfico 3. Principales dispositivos para el consumo de vídeo online ( $\%$ de usuarios de vídeo online)

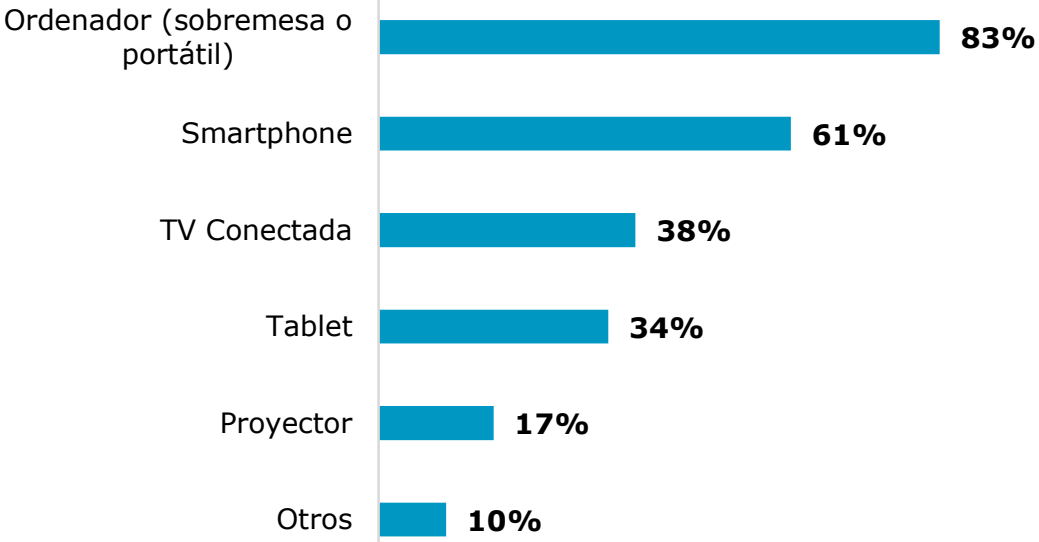

Fuente: IAB Spain, $2018 \mathrm{C}$

\subsection{Desarrollo de las redes de alta velocidad}

\subsubsection{Desarrollo de redes de alta velocidad en el mundo}

La cifra de suscriptores a redes LTE en el mundo ha ido creciendo durante los últimos años a pasos agigantados
En este subapartado, se distingue, en primer lugar, cómo ha evolucionado el desarrollo de las redes fijas atendiendo al número de suscripciones existentes en el mundo y en las principales regiones. En segundo lugar, se hace lo mismo con respecto a la evolución de las redes móviles (LTE), añadiéndose, además, las previsiones relativas al desarrollo de las redes $5 \mathrm{G}$.

En relación con la evolución de las redes fijas, IDATE proporciona información relativa al número de suscriptores a redes FTTH/B (redes de fibra óptica hasta el hogar o el edificio), y a redes VDSL.

La cifra total de suscripciones a redes FTTH/B en el mundo en el año 2017 ronda los 469 millones, habiendo experimentado un crecimiento con respecto al año anterior del 24,3\%. Durante los años anteriores a 2016 las suscripciones a esta tipología de redes venían incrementándose a ritmos superiores al 50\%. Asia Pacífico abarca más del $80 \%$ de las suscripciones totales en el mundo; muy lejos de Europa que representa un 11,3\%. Además, es Asia Pacífico la región con el ritmo más veloz de crecimiento durante los últimos años (casi del 50\% entre 2014 y 2017 en promedio). Las previsiones de cara al futuro indican crecimientos más ligeros para todas las regiones.

En relación con las redes VDSL, la cifra total de suscriptores en el mundo en el año 2017 es de 71,6 millones (un 17,4\% más que en 2016). En este caso, es Europa la región del mundo que abarca 
proporcionalmente el mayor número de suscripciones (42,8\%), seguido de Norteamérica $(28,9 \%)$ y Asia Pacífico $(20,4 \%)$. Las previsiones, según IDATE, de cara a los próximos años indican un crecimiento generalizado en todas las regiones, incluida Europa ${ }^{3}$ (IDATE, 2017c).

Por otro lado, con respecto a las redes móviles LTE, la cifra de suscriptores a este tipo de redes en el mundo ha ido creciendo durante los últimos años a pasos agigantados. En 2017, la cifra de suscriptores asciende a 2.692 millones (un $41 \%$ más que en 2016).

Las proyecciones estimadas por IDATE con respecto al desarrollo de las redes 5G indican que para el año 2025 se habrán alcanzado, por lo menos, los $1.650,8$ millones de suscriptores a servicios de redes $5 \mathrm{G}$, siendo Europa el continente que crecerá a mayor velocidad. Asia Pacífico representará en torno al $58 \%$ del total de suscriptores en el mundo (IDATE, 2017d).

\section{El $\mathbf{8 5} \%$ de los} hogares españoles dispone de algún tipo de red NGA en 2017

\subsubsection{Desarrollo de redes de alta velocidad en España y UE}

Uno de los objetivos primordiales de la UE es el despliegue de infraestructuras de comunicaciones de alta velocidad como elemento impulsor y diferenciador de la Economía Digital. Con el paso del tiempo, cada vez más hogares europeos pueden acceder a esta tipología de redes.

Los operadores de telecomunicaciones han apostado de manera clara por las redes NGA, cuya característica principal es la alta velocidad, como medio de conexión a Internet en detrimento de las redes DSL y las redes de cable tradicionales.

Con respecto a la cobertura de redes de nueva generación (NGA) la evolución está siendo muy favorable, tal y como indican los resultados expresados en la siguiente ilustración. El $85 \%$ de los hogares españoles en 2017 dispone, al menos, de algún tipo de red de nueva generación con conexión de 30Mbps o más de bajada. Desde el año 2013, el incremento del despliegue de este tipo de redes ha sido de 13,8 puntos porcentuales. En comparación con la Unión Europea, España se sitúa por encima de la media, en torno a unos cinco puntos porcentuales en el período 2014-2017.

\footnotetext{
${ }^{3}$ Cabe indicar sobre este aspecto que los datos aportados por IDATE son mucho más optimistas que los aportados por otras fuentes relacionados con el despliegue de infraestructuras VDSL. En el caso de España, por ejemplo, indican crecimientos de esta infraestructura importantes durante los últimos años siendo las previsiones de cara a 2021 también relevantes, mientras que la SEAD, como se puede apreciar más adelante, indican que el porcentaje de hogares que disponen de dicha tecnología permanece estable.
} 
Gráfico 4. Cobertura de redes NGA en España vs. UE28 (\% hogares)

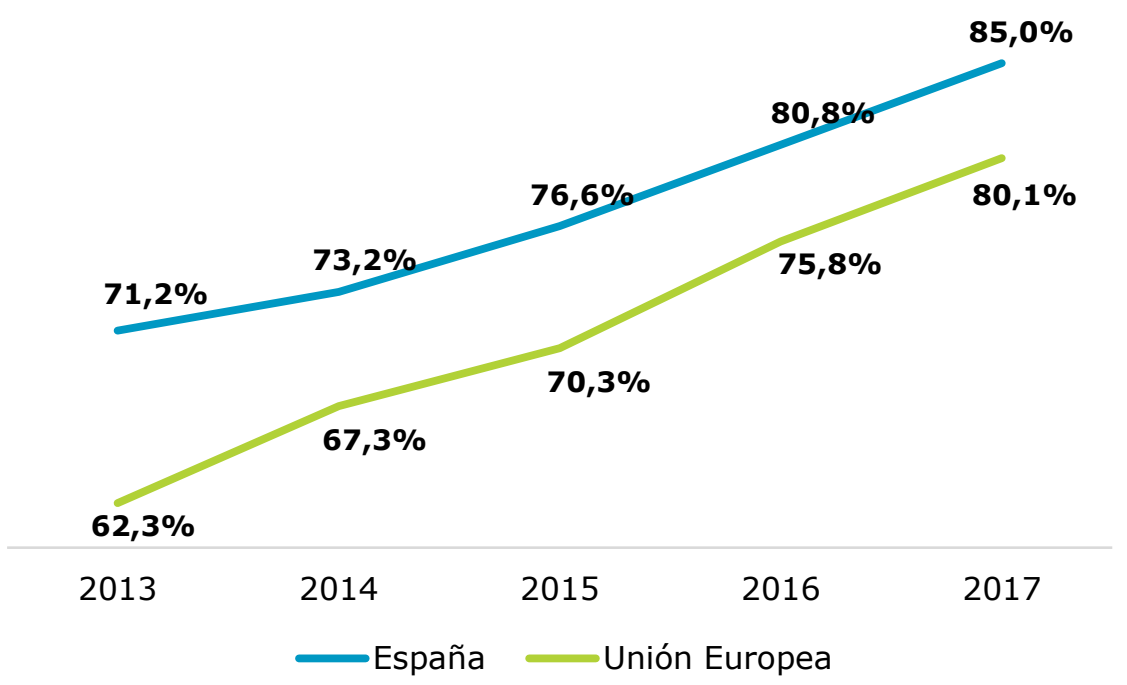

El $97 \%$ de los hogares españoles dispone de cobertura LTE en 2017

Fuente: Comisión Europea, 2018

En relación con el tipo de tecnología, aquellas que han experimentado un mayor crecimiento en los últimos cuatro años son la fibra directa al hogar (FTTH) y la cobertura LTE. A finales del segundo trimestre de 2017 el porcentaje de hogares españoles con cobertura FTTH alcanza el $71 \%$, mientras que el porcentaje de hogares con cobertura LTE es del $97 \%$. Con respecto a las tecnologías VDSL y HFC, apenas han experimentado cambios significativos en el período 2014-2017, manteniéndose el porcentaje de hogares españoles que disponen de dichas tecnologías en torno al $11-12 \%$ y el $49 \%$ respectivamente (SEAD, 2018).

Gráfico 5. Cobertura de redes de banda ancha ultrarrápida en España por tecnología (\% hogares)

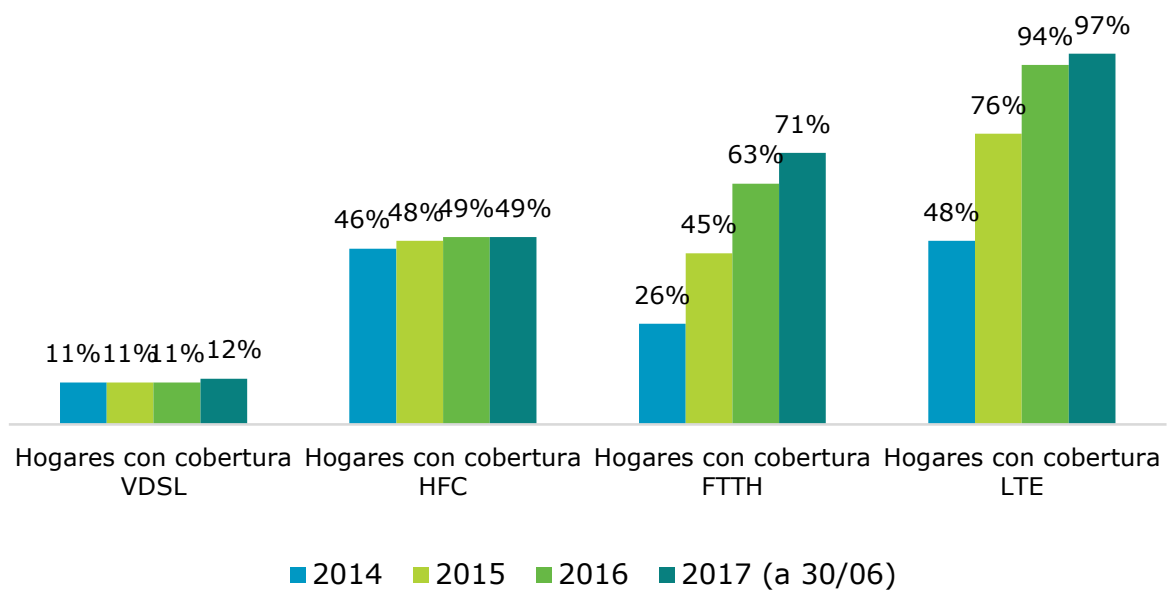

Fuente: SEAD, 2018

Con respecto a la velocidad de conexión, durante el segundo trimestre del año 2017 el $81 \%$ de los hogares españoles tienen 
El $\mathbf{8 1} \%$ de los hogares españoles dispone de accesos con velocidades de bajada iguales 0 superiores a 30 Mbps disponibles accesos con velocidades de bajada iguales o superiores a $30 \mathrm{Mbps}$ pero menores de $100 \mathrm{Mbps}, 6$ puntos porcentuales por encima que en 2016. En el caso de los accesos de $100 \mathrm{Mbps}$ o superiores, la cobertura es del $76 \%$. En este caso, este tipo de acceso experimenta un crecimiento, también, de 9 puntos porcentuales con respecto a 2016 (SEAD, 2017).

De otro lado, tal y como se señalaba en el informe del año anterior de acuerdo con los últimos datos disponibles de la CNMC para España, la fibra óptica está teniendo un mayor desarrollo y una penetración más elevada que en el conjunto de la Unión Europea. La principal tecnología de conexión en los hogares españoles que disponen de redes NGA es la FTTH, que acumulaba el $61,9 \%$ del total de accesos. Seguidamente se sitúa el cable, que comprendía el $32,7 \%$ del total. Por su parte, la tecnología vDSL para redes NGA en España es residual, aunque en el resto de la Unión Europea tiene una elevada penetración.

Volviendo al caso de la Unión Europea, en lo relativo a la demanda de estas infraestructuras de conexión, durante el segundo trimestre de 2017 se registraron aproximadamente 172 millones de suscripciones de banda ancha fija. De ellas, el 48\% (83 millones aproximadamente) se consideran accesos de redes NGA (al menos 30 Mbps de bajada). En relación con la distribución de accesos de estas redes de nueva generación por tecnología en Europa, el 37\% de los accesos es de cable y el 35\% proviene de la tecnología VDSL. La conexión mediante fibra óptica (hasta el hogar o hasta el edificio) engloba el 27\% de los accesos (Comisión Europea, 2018).

\subsection{Crecimiento continuo del tráfico}

Uno de los indicadores más habituales para medir el uso de los contenidos digitales es el impacto en el tráfico cursado a través de las redes de comunicaciones, ya que el consumo de contenidos digitales está relacionado con el tráfico cursado (Internet fijo, Tráfico IP gestionado y Datos móviles). La fuente disponible más reciente sobre este aspecto es el Visual Networking Index de CISCO de 2018.

Según los datos aportados por este informe, los tres tipos de tráfico seguirán creciendo hasta 2022. Se prevé que en 2017 se confirme un incremento del tráfico de datos móviles cercano al $60 \%$. Igualmente, se prevé un crecimiento del Internet fijo y del Tráfico IP gestionado de, aproximadamente, un $26 \%$ y $19 \%$ respectivamente. En 2017, el Internet fijo aglutina aproximadamente el $70 \%$ del tráfico IP mundial. Las estimaciones de crecimiento que arroja CISCO de cara a los próximos años señalan una tendencia positiva para las tres tipologías, especialmente para los datos móviles, que registraría una tasa compuesta de crecimiento agregado entre 2017 y 2022 del 58\%. 
Gráfico 6. Evolución esperada del tráfico IP 2017-2022 (exabytes/mes)

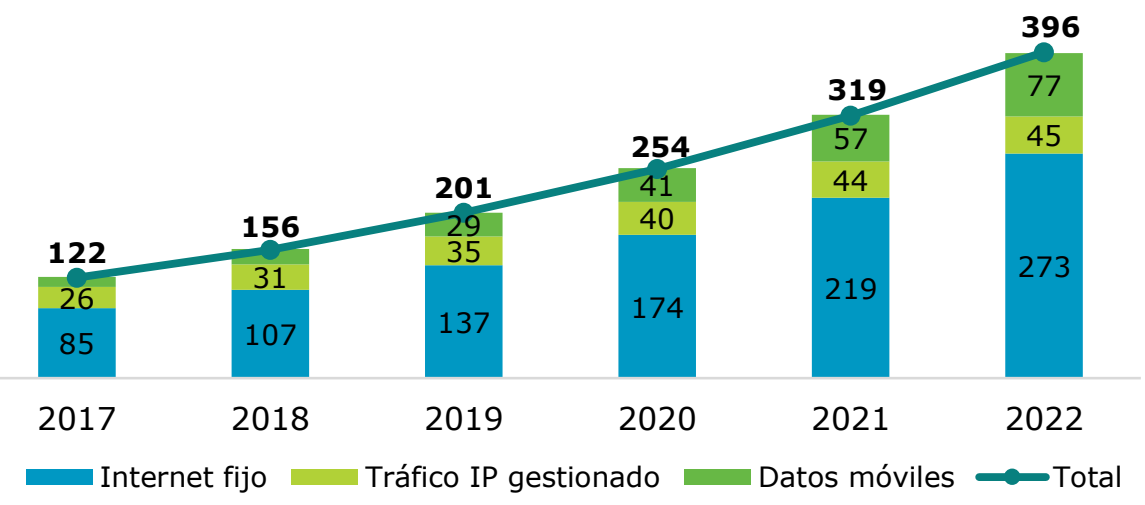

Fuente: CISCO, 2018

Con respecto a los tipos de contenidos digitales, CISCO indica que el vídeo online es el que más tráfico IP genera, ocupando en $2017 \mathrm{el}$ $73 \%$ de todo el tráfico IP generado por los consumidores. Del mismo modo, se proyectan crecimientos sólidos en el periodo comprendido entre 2017 y 2022 tal y como indica la tasa de crecimiento medio anual que asciende al $31 \%$. La web, e-mail y datos $(15,6 \%)$ y el intercambio de archivos $(10,4 \%)$ generan prácticamente el mismo tráfico, aunque las previsiones de futuro varían considerablemente. Así pues, entre 2017 y 2022, el tráfico que generará la web, e-mail y datos crecerá a un ritmo del $22 \%$ anual en promedio, aunque irá perdiendo peso; mientras que las cifras para el intercambio de archivos se mantendrán sin cambios. Los juegos online solo representan el $1,3 \%$ de todo el tráfico IP, aunque se esperan elevados crecimientos para los próximos años. La tasa de crecimiento medio anual para los juegos online en el periodo comprendido entre 2017 y 2022 es del $59 \%$.

Gráfico 7. Distribución del tráfico IP generado por los consumidores por tipo de contenido 2017-2022 (exabytes/mes)

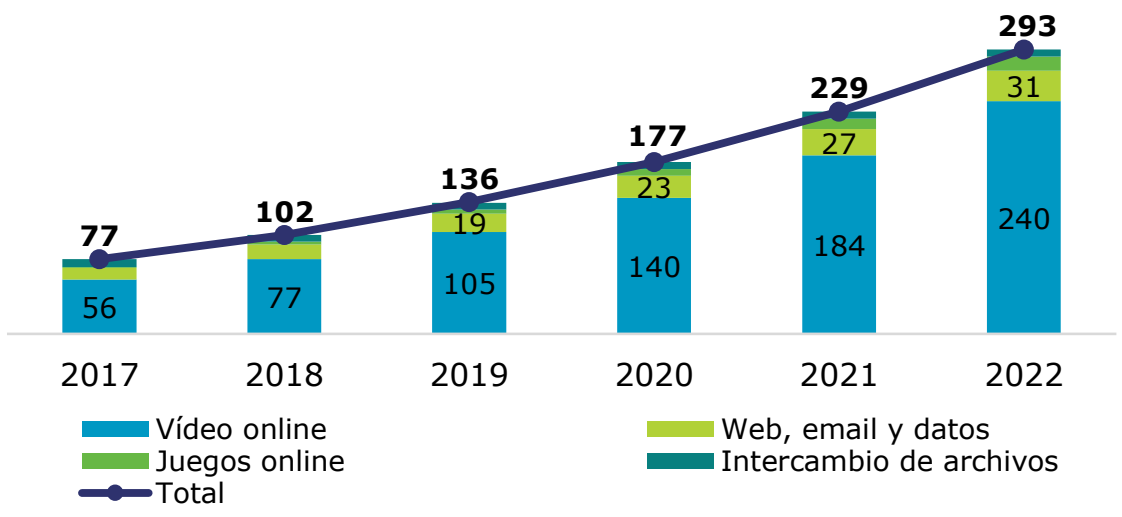

Fuente: CISCO, 2018 


\section{El $72 \%$ de los}

usuarios europeos

se conecta a

Internet

diariamente
En 2017 , el $72 \%$ de los internautas europeos lee noticias de periódicos 0 revistas online

\subsection{Uso de los contenidos digitales}

Durante los últimos años se han apreciado cambios en los hábitos de consumo de los usuarios, cada vez más conectados a Internet. El crecimiento del tráfico IP es consecuencia de la evolución de los usuarios que acceden a Internet. El número de usuarios europeos que utilizan Internet diariamente aumenta todos los años. En 2012, el $58 \%$ de todos los usuarios se conectaban a Internet diariamente. Ese porcentaje se ha incrementado en 14 puntos porcentuales en apenas 5 años hasta llegar a 72\% de usuarios en 2017.

Gráfico 8. Evolución de los usuarios europeos que utilizan diariamente Internet

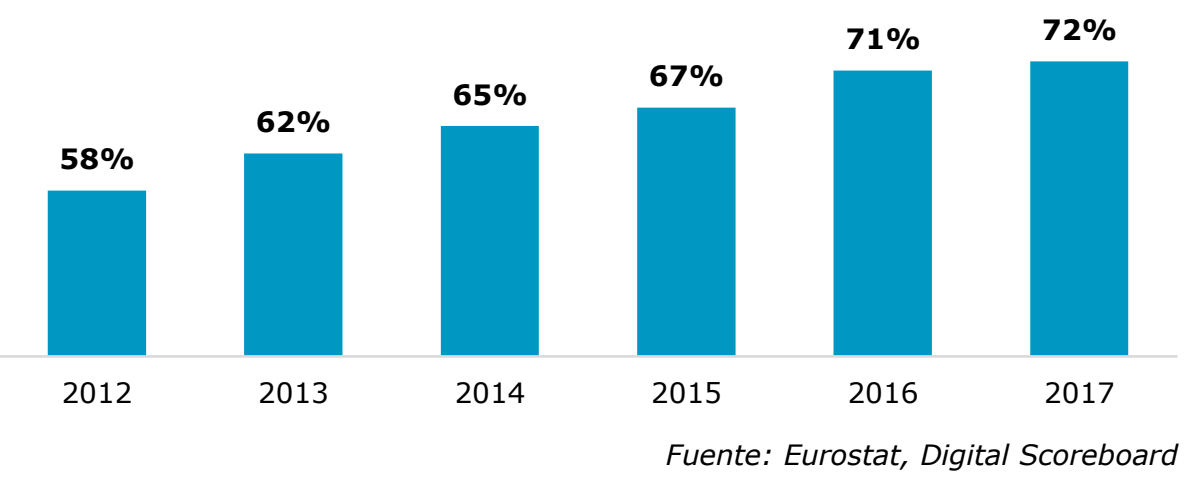

Igualmente, los internautas europeos que realizan actividades relacionadas con los contenidos digitales también aumentan notoriamente. Según Eurostat, en 2017, el 72\% de los internautas europeos que accedió a la red en los últimos 3 meses, lo hizo para leer noticias de periódicos o revistas online; el $65 \%$ participó en redes sociales, el $46 \%$ realizó llamadas o videollamadas a través de Internet, y el $40 \%$ subió contenido de elaboración propia a webs para compartir.

Gráfico 9. Evolución de los principales usos de Internet relacionados con el consumo de contenidos digitales en la UE-28, 2013-2017 (\% usuarios que han accedido a Internet en los últimos 3 meses)

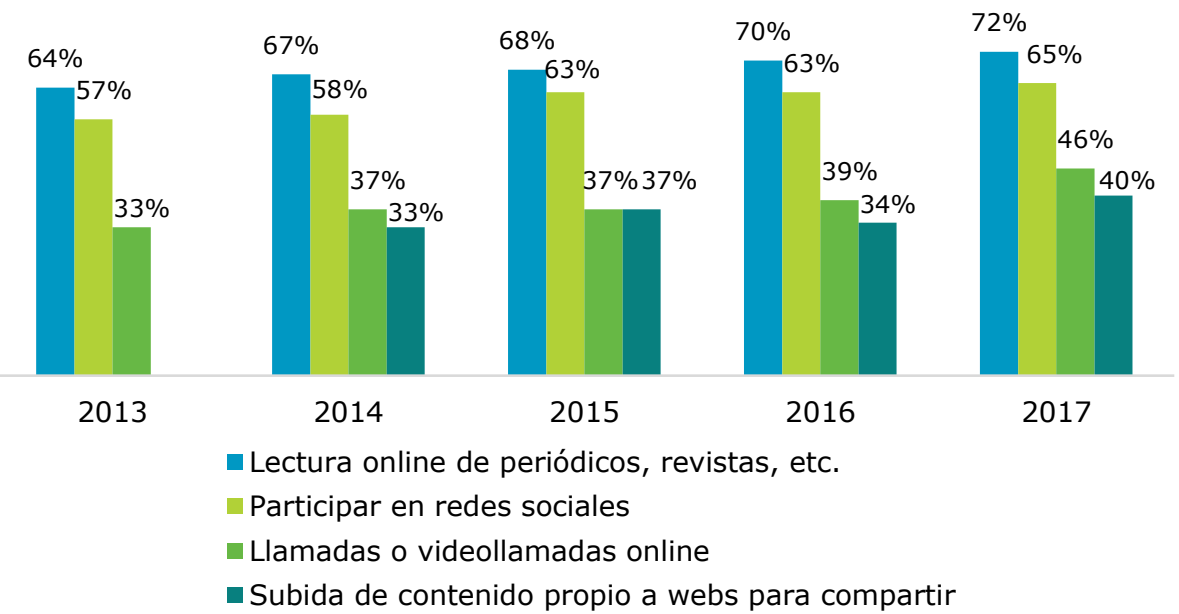

Fuente: Eurostat 
Además de estos, Eurostat dispone de información relativa de otros indicadores relacionados con el consumo de contenidos digitales, en este caso, únicamente para el año 2016. De este modo, el 68\% de los internautas que accedieron a Internet en los últimos tres meses con respecto al momento en el que se recogió la información ven la televisión por internet o vídeos. Un $59 \%$ ve vídeos a través de plataformas abiertas; el 50\% escucha música por Internet; mientras que un $36 \%$ ve TV online procedente de emisoras de televisión. Por otra parte, un $34 \%$ juega o descarga videojuegos a través de internet. Tan sólo un $21 \%$ de los internautas europeos hace uso de servicios de VoD a través de plataformas de pago.

Gráfico 10. Principales usos de Internet relacionados con el consumo de contenidos digitales en la UE-28 (\% usuarios que han accedido a Internet en los últimos 3 meses, 2016)

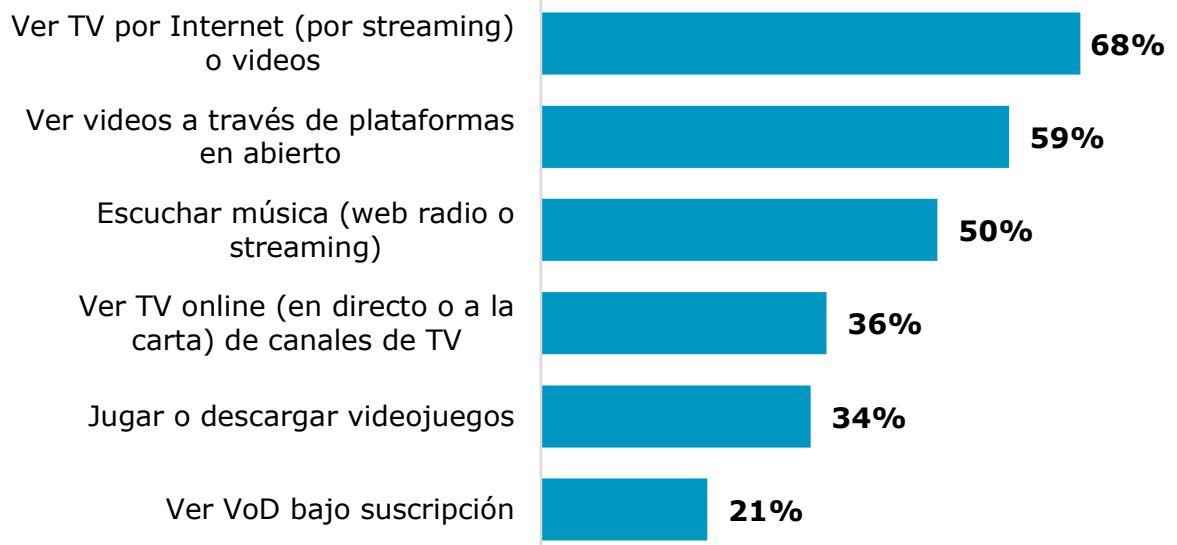

Fuente: Eurostat 


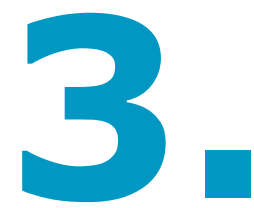

\section{INDUSTRIA DE LOS CONTENIDOS DIGITALES EN ESPAÑA}

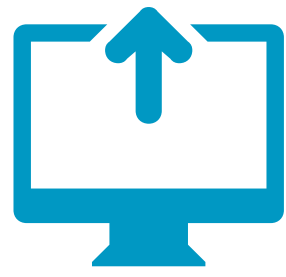




\section{La industria de los Contenidos Digitales en España}

En este capítulo se describe la evolución experimentada por el sector de los contenidos digitales en su conjunto en España durante los últimos seis años. Los subsectores de actividad en los que se recogen las empresas que conforman el sector de los contenidos son:

- Publicación de libros, periódicos y otras actividades de publicación.

- Actividades cinematográficas, de vídeo y de programas de televisión.

- Actividades de grabación de sonido y edición musical.

- Actividades de programación y emisión de radio y televisión.

- Videojuegos.

- Publicidad online.

- Otros servicios de información.

En los siguientes subapartados se detalla la evolución del sector en una dimensión general, en lo que respecta a su volumen de negocio digital, al número de empresas, al número de empleados y a las cifras de inversión.

\section{CIFRA DE NEGOCIO DIGITAL}

En 2017, la cifra de negocio de la industria de los Contenidos

Digitales en España asciende a

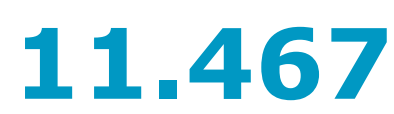

millones de euros

\subsection{Cifra de negocio de los contenidos digitales}

En el año 2017 el sector de los contenidos digitales en España alcanza un volumen de negocio cifrado en 11.467 millones de euros, lo que supone un $16,3 \%$ más con respecto al año 2016. Desde 2014 hasta 2017 la cifra de negocio del sector viene creciendo a un ritmo del $12,8 \%$ por ciento anual.

Distinguiendo en función de los subsectores o ramas de actividad que conforman el sector de los contenidos se observa la misma tendencia. Todas ellas crecen igualmente con respecto al año 2016. El subsector que más ha crecido ha sido el de la publicación de libros, periódicos y otras actividades de publicación en un $74,3 \%$, registrando un nivel de ingresos en 2017 de 1.260 millones de euros, y siguiéndole en intensidad de crecimiento las actividades de grabación de sonido y edición de sonido $(50,3 \%)$ y otros servicios de información (49,5\%), con unas cifras de negocio de 247 y 126 millones de euros respectivamente, muy inferiores en comparación con el resto de las ramas de actividad. Por su parte, las ramas de actividades cinematográficas, de vídeo y de programas de televisión (3.443 millones de euros) y de videojuegos (713 millones de euros) han crecido, con respecto al año anterior, con una intensidad similar a la del sector en su conjunto ( $17,6 \%$ y $15,6 \%$ respectivamente). Las ramas de publicidad online y de actividades de programación y emisión de radio y televisión han crecido más moderadamente, presentando unas tasas de crecimiento de $9,1 \%$ y $7,2 \%$ respectivamente. 
Gráfico 11. Cifra de negocio de la industria de los contenidos digitales en el periodo 2012-2017 (Millones de euros)

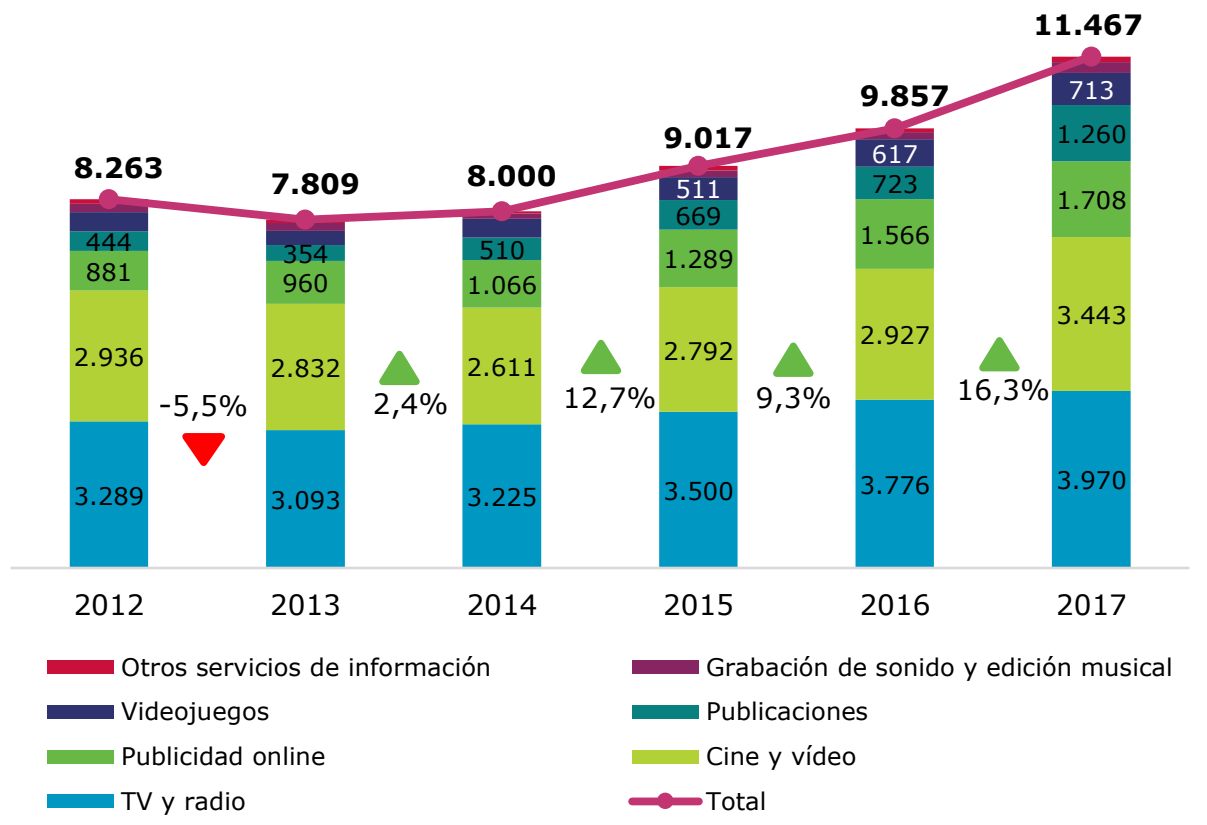

Fuente: ONTSI

La rama de programación y emisión de radio y televisión representa el $34,6 \%$ de la facturación
Con respecto al peso de cada una de las ramas de actividad sobre la facturación total del sector de los contenidos digitales, en 2017 continúan manteniendo las tres primeras posiciones las actividades de programación y emisión de radio y televisión $(34,6 \%)$, las actividades cinematográficas, de vídeo y de programas de televisión (30\%) y la publicidad online $(14,9 \%)$. La rama de publicaciones de libros y periódicos representa el $11 \%$ de la facturación total de sector de contenidos digitales, seguida de la rama de videojuegos $(6,2 \%)$. Las dos últimas posiciones las ocupan las ramas de actividades de grabación de sonido y edición musical y otros servicios de información, ambas con una aportación casi residual al total de facturación del sector de los contenidos digitales $(2,2 \%$ y $1,1 \%$ respectivamente). 
Gráfico 12. Desglose de la facturación de la industria de los contenidos digitales por sectores en el año 2017 (\%/total)

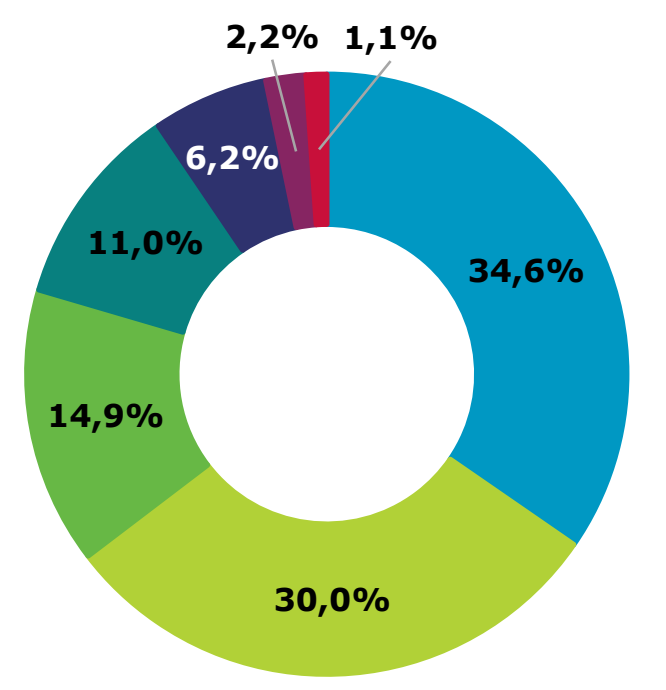

Fuente: ONTSI
TASA DE DIGITALIZACIÓN

La tasa de digitalización del sector de los Contenidos en España asciende al

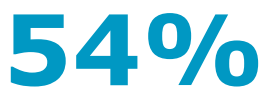

Por otra parte, se calcula la tasa de digitalización del sector de los contenidos, la cual mide el porcentaje de los ingresos que procede de la realización (desarrollo, edición, distribución, comercialización) de actividades digitales (productos, sean bienes o servicios).

En 2017 la tasa de digitalización del sector de los contenidos fue del $54 \%$ ( 4,1 puntos porcentuales más que el año anterior), aunque vuelve a situarse en valores similares a los registrados antes de 2016. No obstante, si se hace una distinción entre los sectores que lo configuran, las diferencias son evidentes. De este modo, cabe destacar el sector de las publicaciones que a pesar de continuar con una de las tasas más bajas en 2017 (22,9\%) en comparación con el resto de los sectores, se incrementa en más de 10 puntos porcentuales con respecto a 2016.

Igualmente, se incrementa con respecto al año anterior la tasa de digitalización del sector de las actividades cinematográficas, de vídeo y de programas de televisión, situándose en un 71,5\%. Concretamente el aumento ha sido de 8,1 puntos porcentuales.

El mayor de los incrementos en la tasa de digitalización se produce en las actividades de grabación de sonido y edición musical, logrando en 2017 una tasa del 64\% (15,8 puntos porcentuales más que en 2016).

Al contrario, las actividades de programación y emisión de radio y televisión ven reducidas en 6,3 puntos porcentuales su tasa de digitalización, que se sitúa en 2017 en el 53,3\% ${ }^{4}$.

\footnotetext{
${ }^{4}$ La reducción de la tasa de digitalización para el sector audiovisual se debe a que la CNMC, organismo que proporciona los datos relativos a la evolución de la cifra de negocio del sector, ha incluido en los ingresos los servicios mayoristas de contenidos
} 
La más baja de todas corresponde a otros servicios de información (18,9\% en 2017).

Por su parte, el sector de los videojuegos español y el de la publicidad digital, como es evidente en este último caso, logran una tasa del $100 \%$.

Gráfico 13. Tasa de digitalización por sectores. Año 2017
(\%/total)

NÚMERO DE EMPRESAS

\section{El número de empresas del sector de los Contenidos asciende a

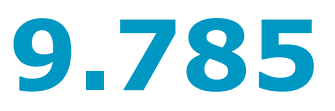

en 2017

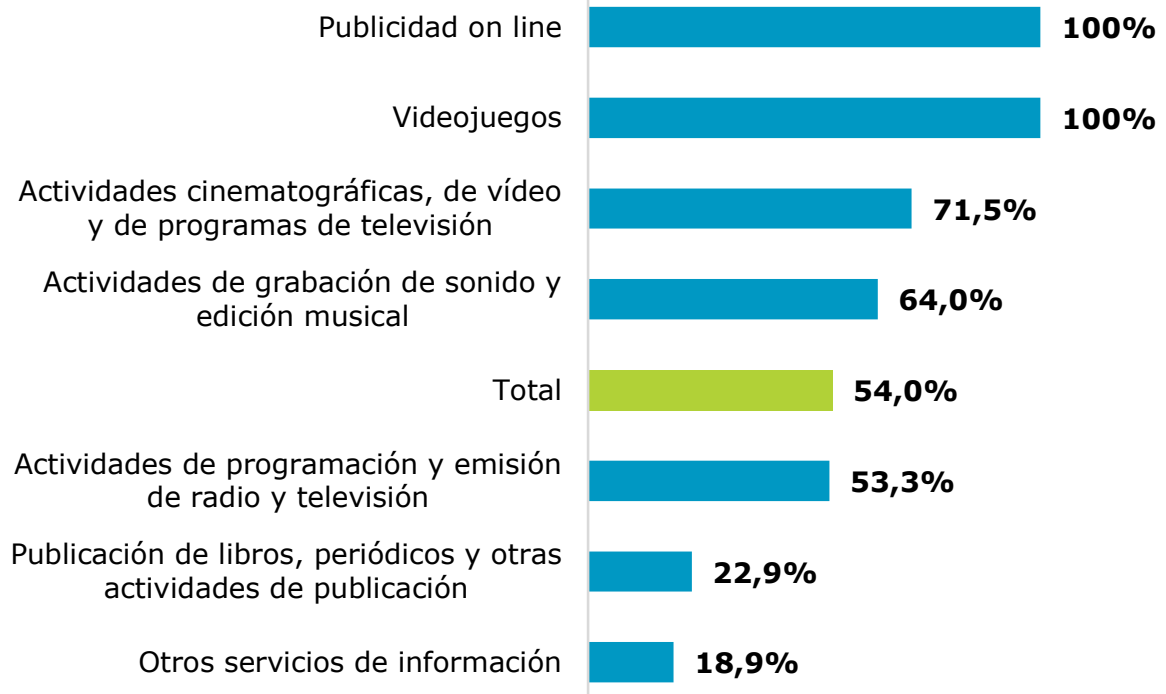

Fuente: ONTSI

\subsection{Número de empresas}

El número total de empresas que pertenecen al sector de los contenidos continúa creciendo, aunque muy ligeramente, desde el año 2014. En 2017, la cifra asciende a las 9.785 empresas, un 0,4\% más con respecto al año 2016.

Diferenciando en función de los subsectores que configuran el sector de los contenidos, solamente se incrementa el número de empresas en las actividades cinematográficas, de vídeo y de programas de televisión que cuenta en 2017 con 2.817 (un 4,3\% más que en el año anterior). Igualmente, crecen en número las empresas del subsector de grabación de sonido y edición musical, un 4,8\% más que en 2016, aunque representan una porción muy pequeña del total del sector de los contenidos (154 empresas en 2017).

Continúa descendiendo el número de empresas del subsector de las publicaciones, con una pérdida del $-1,9 \%$, contando en 2017 con 3.182 empresas. Igualmente sucede en el caso de las actividades de programación de emisión de radio y televisión, que cuenta con

que no han sido considerados como digitales. La tasa de digitalización para el sector audiovisual normalmente rondaba el $90 \%$. 
1.192 empresas ( $-0,8 \%$ con respecto al año anterior), y en el de los otros servicios de información que alcanza las 2.440 .

Gráfico 14. Número de empresas de la industria de los contenidos. 2012-2017

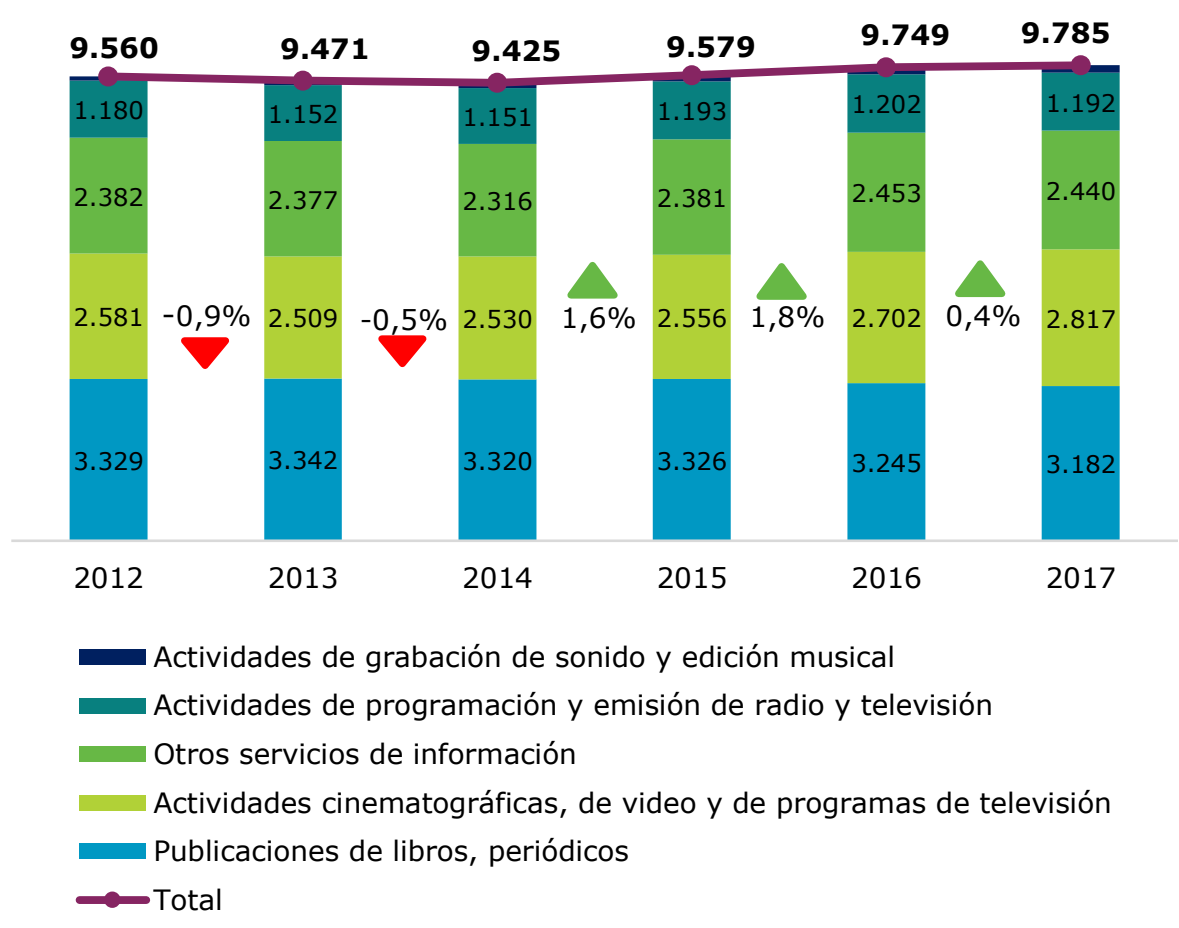

Fuente: ONTSI

El subsector de las publicaciones concentra el $32,5 \%$ del total de empresas del sector de los contenidos 
Gráfico 15. Desglose del número de empresas de la industria de los contenidos por sectores en el año 2017 (\%/total)

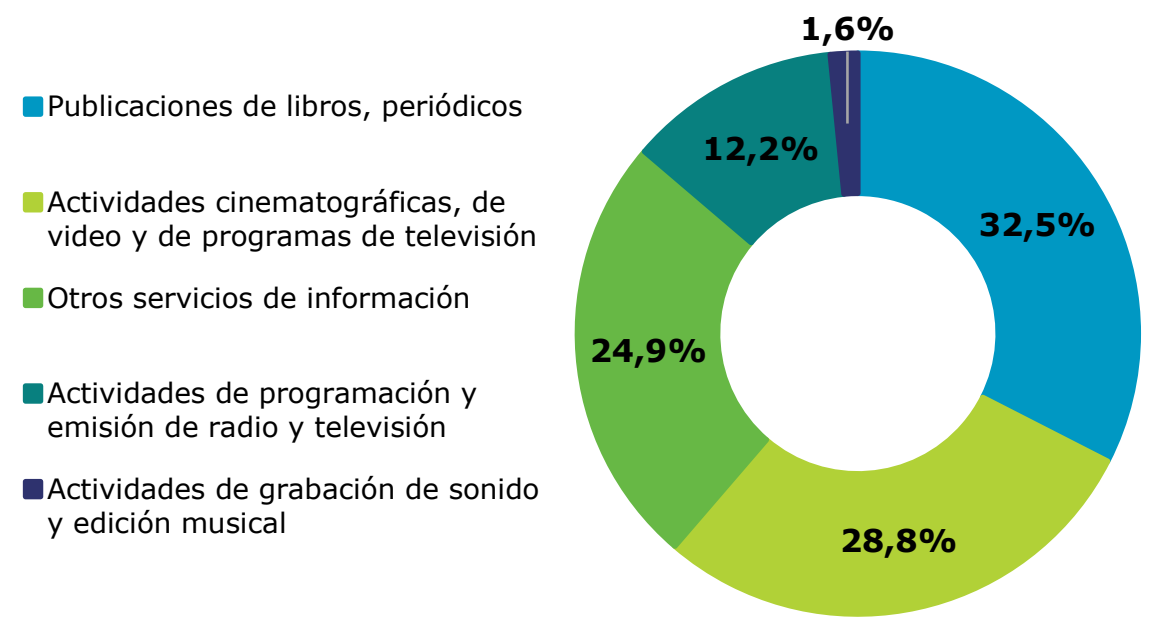

Fuente: ONTSI

\section{No DE EMPLEADOS}

El personal ocupado de la industria de los Contenidos Digitales asciende a

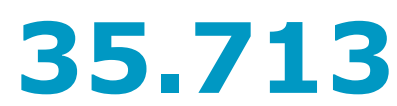

empleados en el año 2017

\subsection{Personal ocupado}

En el año 2017, el sector de los contenidos en su conjunto alcanza unas cifras de empleo que se sitúan en los 105.760 trabajadores, lo que supone un incremento del $1,7 \%$ con respecto al año 2016 . Por tercer año consecutivo, el empleo en este sector crece, lo que supone una clara señal de recuperación del empleo pasados los años más duros de la crisis económica.

Del total del empleo del sector de los contenidos, el 33,8\% se asocia a la parte de negocio digital, lo que corresponde en términos absolutos a 35.713 empleados, un $24,1 \%$ más con respecto al año anterior.

En 2017, todas las ramas de actividad asociadas al sector de los contenidos digitales incrementan el número de empleados, destacando significativamente la rama de otros servicios de información cuya tasa de crecimiento anual es de un 123,6\%.

Igualmente, crecen notablemente con respecto al año anterior en número de empleados las ramas de grabación de sonido y edición musical $(41,8 \%)$; la de publicación de libros, periódicos y otras actividades de publicación $(40,6 \%)$ y, aunque en menor intensidad, la de actividades cinematográficas, de vídeo y de programas de televisión $(16 \%)$; y la de programación y emisión de radio y televisión ( $8 \%)$. 
Gráfico 16. Número de empleados en la industria de los contenidos digitales. 2012-2017

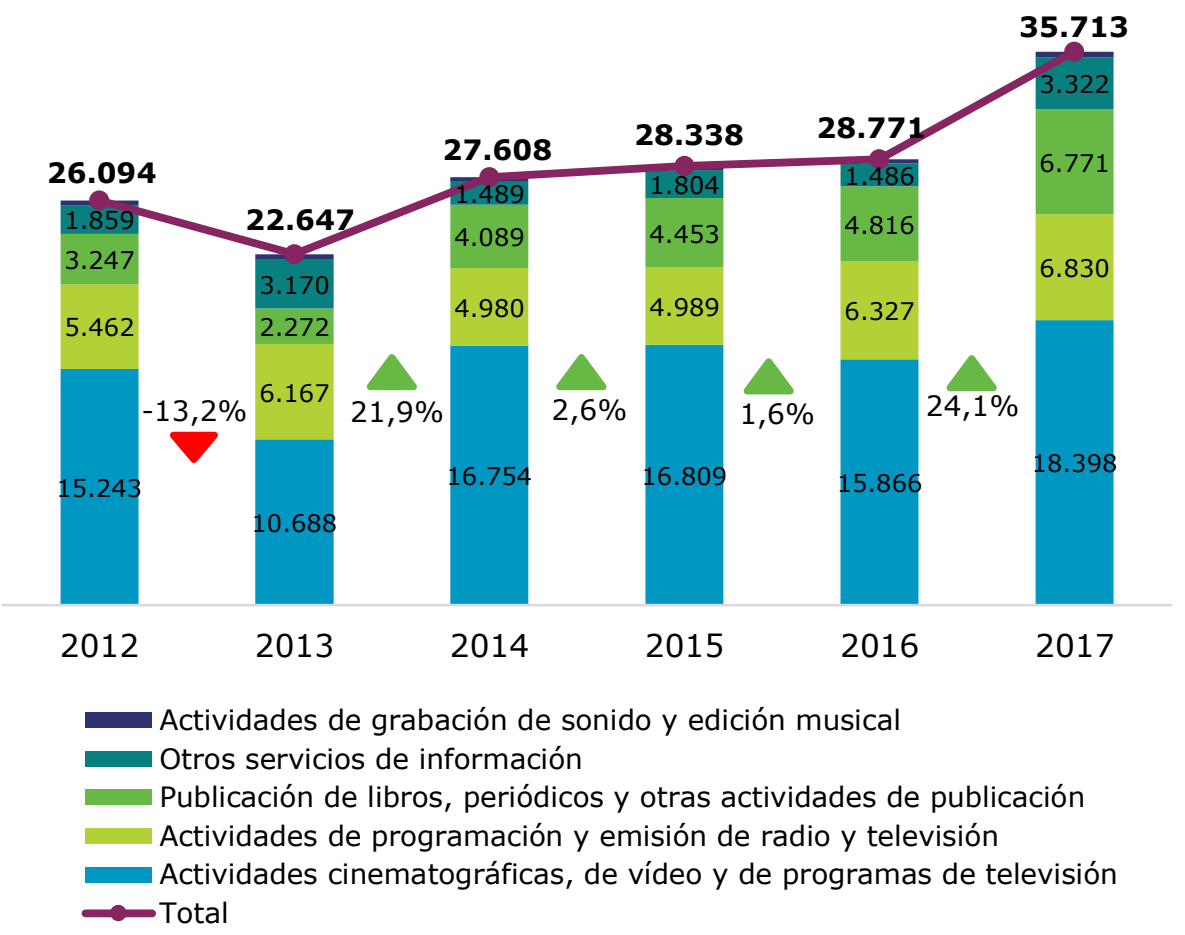

Fuente: ONTSI

La rama de cine, video y programas de TV representa el $51,5 \%$ del total del personal ocupado
Por otro lado, en términos porcentuales, la rama de actividad de cine, vídeo y programas de televisión concentra más de la mitad del empleo del sector de los contenidos digitales (51,5\%), seguido de la rama de programación y emisión de radio y televisión $(19,1 \%)$ y las actividades de publicación de libros y periódicos (19\%). Por su parte, la rama de otros servicios de información logra concentrar el 9,3\% del empleo total de la parte de negocio digital del sector de los contenidos. El 1,1\% restante corresponde a las actividades de grabación de sonido y edición musical.

Gráfico 17. Empleo dedicado a la industria de los contenidos digitales por rama. 2017 (\%/total)

\footnotetext{
Actividades cinematográficas, de vídeo y de programas de televisión

Actividades de programación y emisión de radio y televisión

Publicación de libros, periódicos y otras actividades de publicación

D Otros servicios de información

Actividades de grabación de sonido y edición musical
} 


\section{INVERSIÓN EN NEGOCIO DIGITAL}

La inversión de la

industria de los

Contenidos Digitales asciende a

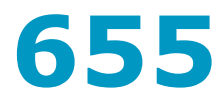

millones de euros en 2017

\subsection{Inversión}

Por segundo año consecutivo crece la cifra de inversión total del sector de los contenidos, situándose en valores superiores a los alcanzados cinco años atrás, e invirtiéndose la tendencia negativa que experimenta desde 2012. En 2017, la cifra de inversión del sector de los contenidos alcanza los 3.072 millones de euros, un $12,8 \%$ más con respecto a 2016 .

De esta cifra, el 21,3\% corresponde a la inversión en el modelo de negocio digital, que se traduce en términos absolutos en una cifra de 655 millones de euros. Al contrario de lo que sucede con la evolución de la invsersión total del sector de los contenidos, la evolución desde 2012 hasta 2016 de la inversión digital sigue una tendencia negativa con descensos en algunos años de hasta el $29,6 \%$ y del $-18,2 \%$, especialmente bruscos para el sector de las actividades cinematográficas, de vídeo y de programas de televisión. Por primera vez, en 2017, la inversión en negocio digital crece con respecto al año anterior en un 9,2\%, gracias al aumento de la inversión digital en el sector del cine y el vídeo. El resto de sectores sigue una tendencia negativa.

Gráfico 18. Inversión en el negocio digital de la industria de los contenidos. 2017 (millones de euros)

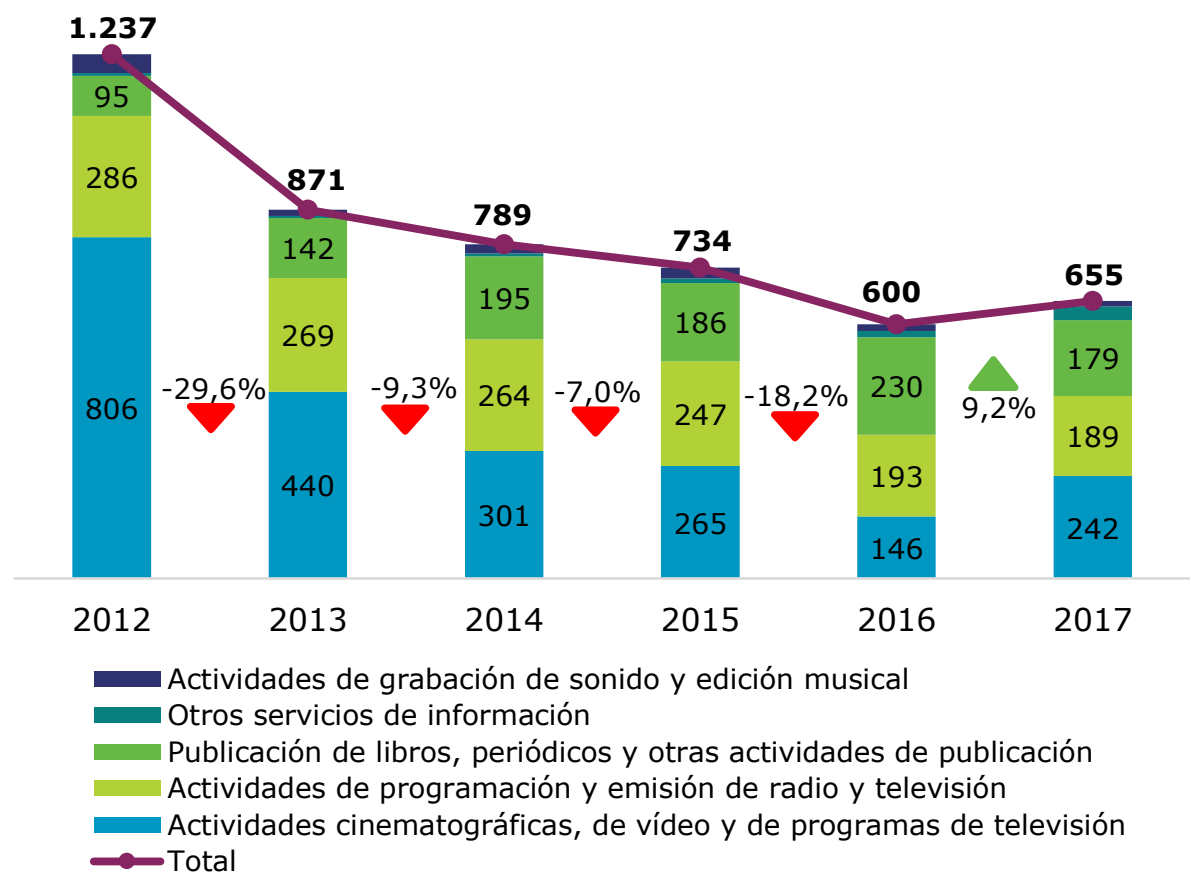

Fuente: ONTSI

Distinguindo entre los subsectores que configuran la industria de los contenidos digitales, el total de inversión digital se reparte de manera más o menos equitativa entre tres de ellos: la rama de actividades cinematográficas, de vídeo y de programas de televisión concentra el 36,9\% de la inversión, seguida de las activiades de programación y emisión de radio y televisión $(28,9 \%)$, y de la rama 
de publicación de libros, periódicos, etc. que concentra en proporción similar el 27,3\% de la inversión.

Por su parte, la rama de otros servicios de información apenas logran representar el $5 \%$ de la inversión total en la parte de negocio digital; mientras que el subsector de la música solamente llega a representar en 2017 un 1,9\%.

Gráfico 19. Inversión en el negocio digital de la industria de los contenidos digitales por ramas. 2017 (\%/total)

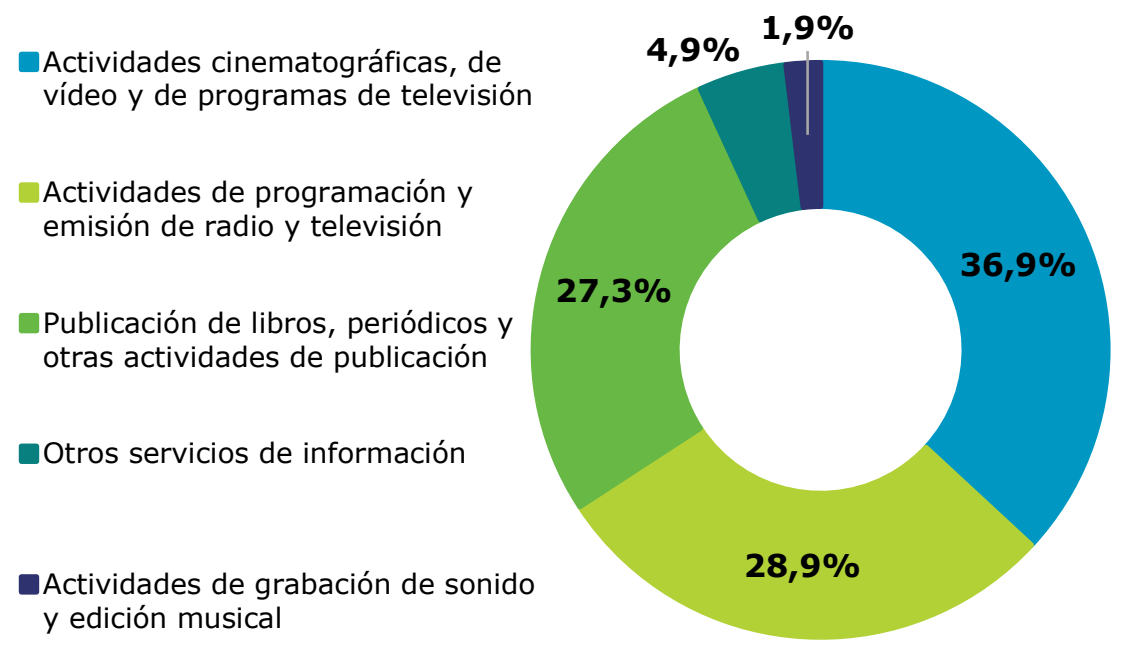

Fuente: ONTSI 



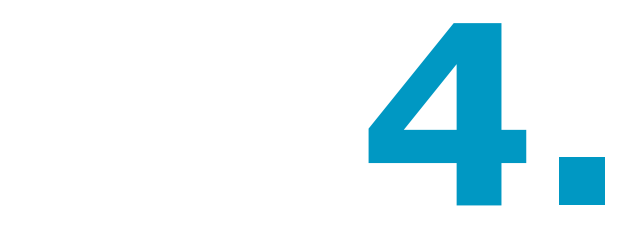

\section{EL SECTOR DE LOS VIDEOJUEGOS}
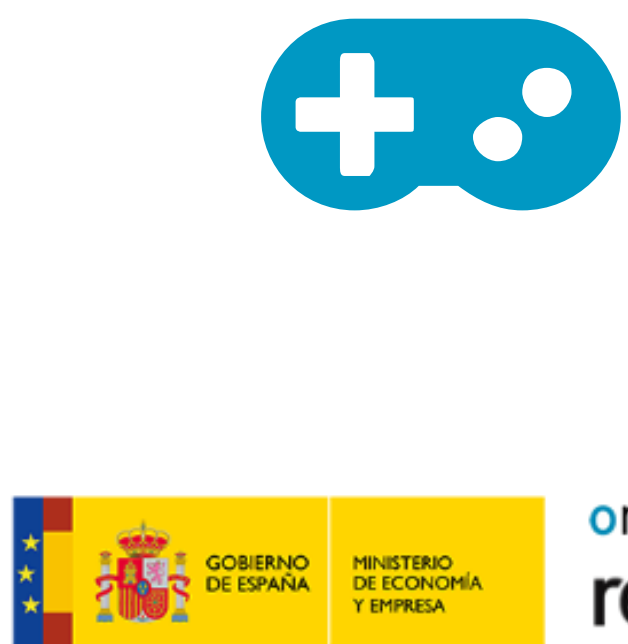

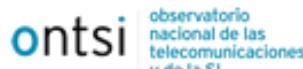
red.es 


\author{
En 2017, el \\ mercado global de \\ videojuegos \\ (excluida la venta \\ de hardware) \\ alcanza una cifra \\ de negocio de \\ 86,5 miles de \\ millones de \\ euros
}

\section{El sector de los videojuegos}

\subsection{El mercado global de los videojuegos}

La distribución de los videojuegos puede llevarse a cabo en soporte físico y en soporte digital, aunque es en la modalidad digital donde se concentra la mayor parte del volumen de negocio.

En 2017, el sector de videojuegos ha alcanzado un volumen de negocio a nivel mundial de 86,5 miles de millones de euros, creciendo un $10,8 \%$ con respecto al año anterior, y se prevé que para 2019 la cifra de ingresos del sector se aproxime a los 100.000 millones de euros. Del total de ingresos, el $87,7 \%$ proviene de las ventas digitales mientras que el $12,3 \%$ restante proviene de ventas físicas. Durante los próximos años se espera que estas diferencias se acentúen. Así pues, las ventas físicas irán perdiendo peso (se prevé que para el año 2022 tan sólo lleguen a representar un 3,9\% del total de ingresos). Se estima que los ingresos provenientes de las ventas digitales en videojuegos serán superiores al $90 \%$ ya en 2018, alcanzando el $96,1 \%$ en 2022 . La tasa de crecimiento medio anual entre 2018 y 2022 será del $-11,7 \%$ para las ventas físicas y de $11,1 \%$ para las ventas digitales.

Gráfico 20. Ingresos por venta de videojuegos en el mundo (miles de millones de euros)

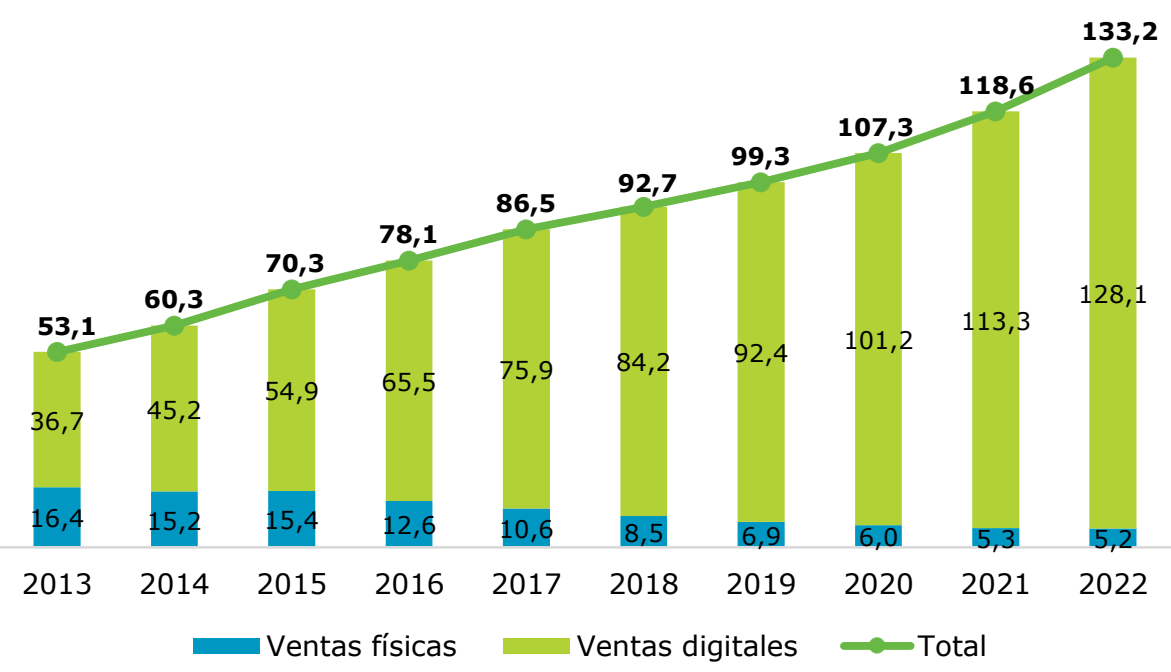

Fuente: IDATE, 2018a

Dentro del campo de las ventas digitales existen dos modalidades de ingresos: venta individual y suscripciones. Apenas los ingresos procedentes de suscripciones llegan a representar un $1 \%$ del total de ingresos de videojuegos por venta digital, tanto en la actualidad como en el futuro. 


\section{En 2017 el $94 \%$ de los ingresos del sector de videojuegos de Asia-Pacífico procede de las ventas digitales}

Desde el punto de vista de las principales regiones geográficas, casi la totalidad de los ingresos por ventas de videojuegos en el mundo provienen de Asia Pacífico, Norteamérica y Europa. Asia Pacífico se convierte en la región con mayor volumen de negocio en 2017 acumulando un total de 37,8 miles de millones de euros. Norteamérica y Europa registran cifras similares, 18,9 y 15,7 miles de millones de euros respectivamente. Estas tres regiones crecen con respecto a 2016 con incrementos del 17,6\% (Asia Pacífico), $14,1 \%$ (Europa) y $11,3 \%$ (Norteamérica). Las estimaciones calculadas por IDATE (2018a) para el periodo 2018-2022 indican que continúa el crecimiento, aunque a ritmos mucho más moderados.

Adicionalmente, comparando los pesos proporcionales que tiene la venta digital de videojuegos con respecto al total de ingresos del sector en cada una de las regiones, Asia-Pacífico destaca en primer lugar. En esta región el $94 \%$ de los ingresos del sector de los videojuegos procede de las ventas digitales. Le siguen América Latina ( $87 \%$ ) y Norteamérica (86\%). En Europa y en Oriente Medio y África la proporción de las ventas digitales de videojuegos representa el $77 \%$ y el $73 \%$ sobre el total de ingresos del sector en las respectivas regiones. Las previsiones de cara a los próximos años indican que las ventas de videojuegos en formato digital representarán más del $90 \%$ en todas las regiones.

Si se relacionan las cifras relativas a los ingresos procedentes de la venta de videojuegos en formato digital con la población de cada una de las regiones del mundo, Norteamérica sobresale notoriamente con respecto a las demás, siendo su cifra de ingresos per cápita de 52,1 millones de euros en 2017. Europa tan solo logra una cifra de 18,8 millones de euros per cápita, mientras que Asia Pacífico apenas alcanza los 10 millones de euros.

Por otra parte, no ha resultado posible para la edición del presente informe la identificación de datos actualizados con respecto al número de copias de videojuegos distribuidas en el mundo. Por este motivo, se especifican los datos que se reflejaron en la edición del informe del pasado $a n ̃ o^{5}$. De este modo, el número de copias de videojuegos distribuidas en el mundo vivió una situación delicada entre los años 2011 y 2014 debido a las importantes bajadas experimentadas. En el año 2011 se distribuyeron 648,2 millones de copias de videojuegos por los 448,4 millones de copias que se registraron en 2014. Esta tendencia negativa se revirtió en el año 2015 con el primer incremento de copias de videojuegos distribuidas tras varios años de caídas. En 2016 se confirmaba la tendencia alcista iniciada en 2015 con un crecimiento del 17,6\%, habiéndose distribuido un total de 556,7 millones de copias. Las previsiones de futuro estimadas por IDATE evidenciaban un comportamiento

\footnotetext{
${ }^{5}$ La cifra de copias de videojuegos vendidas reflejadas en la edición del informe del pasado año procedían de IDATE World Digital Content Markets (2016).
} 
similar hasta el año 2020, donde se apreciaba un ligero retroceso, aunque la tasa de crecimiento medio anual para el período 20162020 era positiva $(3,8 \%)$ (ONTSI, 2017).

Distinguiendo entre las principales regiones geográficas del mundo, Norteamérica destacaba con más copias de videojuegos vendidas agrupando el $46,5 \%$ de la cuota de mercado en 2016 con un total de 258,7 millones de copias. Le seguía Europa con un total de 177,6 millones de copias representando el $31,9 \%$ de la cuota de mercado. Ambas regiones crecieron, pero a un ritmo distinto. Así pues, Norteamérica destacaba con un $27,2 \%$ de crecimiento mientras que en Europa el incremento era de un 4,7\% para el periodo 2015-2016. Asía Pacífico también destacaba debido al rápido crecimiento que experimentó en los últimos años. En 2016, esta región aumentó en un $23 \%$ las copias de videojuegos distribuidas y se estimaba una tasa de crecimiento medio anual para el periodo 2016-2020 más alta en comparación con el resto de las regiones, concretamente de un $8,8 \%$ (ONTSI, 2017).

En definitiva y a modo de conclusión a este subapartado las consideraciones de IDATE con respecto a las tendencias a nivel global del sector de los videojuegos. Según esta fuente, las previsiones de crecimiento del sector de los videojuegos hasta 2022 son a un ritmo del 9,3\% anual en promedio. $Y$, especialmente, las previsiones relativas al crecimiento de las ventas digitales, se atribuyen, en primer lugar, al fuerte empuje que está experimentando el sector de los juegos para móviles, especialmente en el continente asiático; en segundo lugar, a la estrategia orientada hacia la venta digital de videojuegos a través de las propias plataformas o tiendas online de los fabricantes de videoconsolas (en un contexto donde el $95 \%$ de los jugadores de videoconsola están conectados a la web); y, en tercer lugar, al creciente desarrollo de juegos de realidad virtual y realidad aumentada (IDATE, 2018b).

\subsection{El sector de los videojuegos en España}

\section{CIFRA DE NEGOCIO}

El volumen de

ingresos del sector de

Videojuegos en

España asciende a

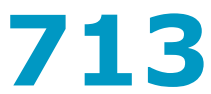

millones de euros en 2017, según DEV
El sector de los videojuegos en España continúa evolucionando positivamente. Así lo confirman las dos principales asociaciones de empresas del sector español de los videojuegos.

En primer lugar, la Asociación de Desarrollo Español de Videojuegos (DEV) indica un incremento en los ingresos del sector del $15,6 \%$ con respecto al año 2016. En 2017, la cifra de negocio ${ }^{6}$ alcanza los 713 millones de euros. Desde 2013, el sector del videojuego no hace más que crecer a un ritmo en promedio del $22,8 \%$ anual para el periodo 2013-2017. Además, las estimaciones que elabora DEV en su última edición del Libro Blanco del Desarrollo Español de los

\footnotetext{
${ }^{6}$ DEV distingue nueve tipologías de ingresos de las empresas del sector: venta física, venta digital, F2P (free to play) + publicidad, F2P + compras in game, desarrollo para terceros, venta de servicios, formación, venta de assets y otros.
} 
Videojuegos indican que el sector seguirá creciendo notablemente, previéndose que se alcance en 2020 una facturación de 1.440 millones de euros (DEV, 2018).

Gráfico 21. Facturación de la industria española de desarrollo de videojuegos, 2012-2017 (Millones de euros)

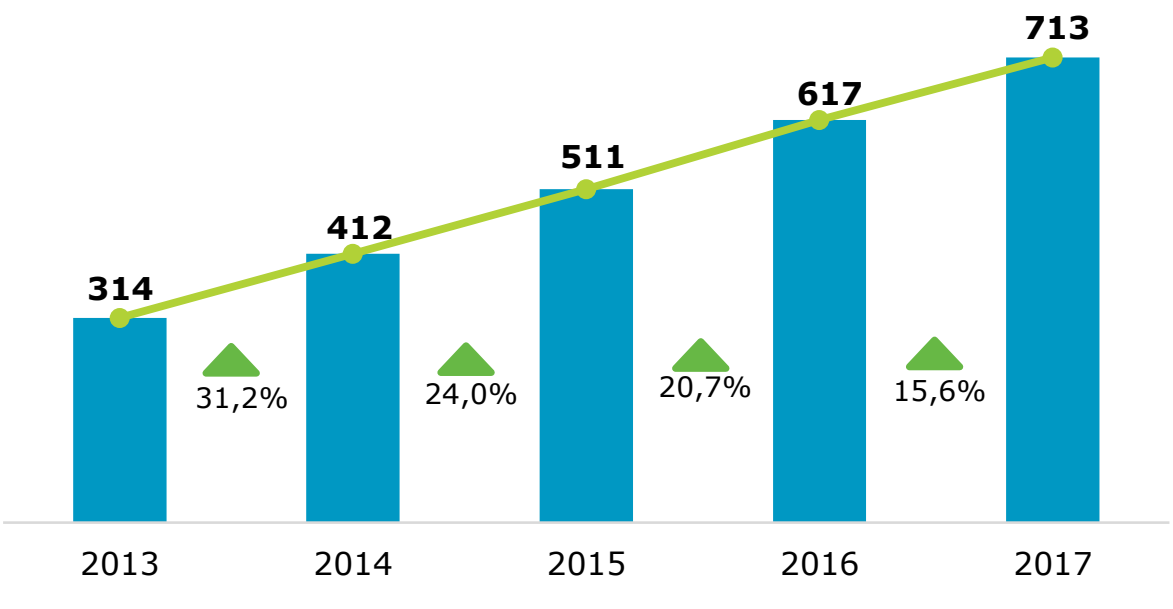

Los videojuegos continuarán evolucionando positivamente durante los próximos años

Fuente: DEV, 2018

En segundo lugar, la Asociación Española de Videojuegos (AEVI), a través de su último Anuario de la Industria del Videojuego (2018), también confirma la tendencia creciente que experimentan los ingresos del sector español del videojuego. De este modo, en 2017 este sector habría alcanzado una facturación total ${ }^{7}$ de 1.359 millones de euros (un 16,9\% más con respecto al año anterior), de los cuales el $65,1 \%$ procederían de la facturación física, y el 34,9\% de la facturación online.

De la facturación procedente de las ventas físicas en 2017, AEVI indica que 376 millones de euros proceden de la venta de hardware, 389 de la venta de software y 120 millones de euros de la venta de accesorios (AEVI 2018).

A pesar de la tendencia general negativa que vienen experimentando los ingresos por parte de la venta física de videojuegos (software) desde los últimos años, por segundo año consecutivo se incrementan, alcanzando en 2017 los 389 millones de euros (un $7,8 \%$ más con respecto a 2016) (AEVI, 2018).

\footnotetext{
${ }^{7}$ La cifra de facturación total del sector calculadas por AEVI se refieren, por un lado, a la facturación física total por la venta de hardware, software y accesorios; y, por otro lado, a la facturación online total (ingresos procedentes de la venta de aplicaciones para móviles y procedentes de plataformas digitales).
} 
Gráfico 22. Ingresos por venta física de videojuegos (software) en España. Evolución 2012-2017 (Millones de euros)

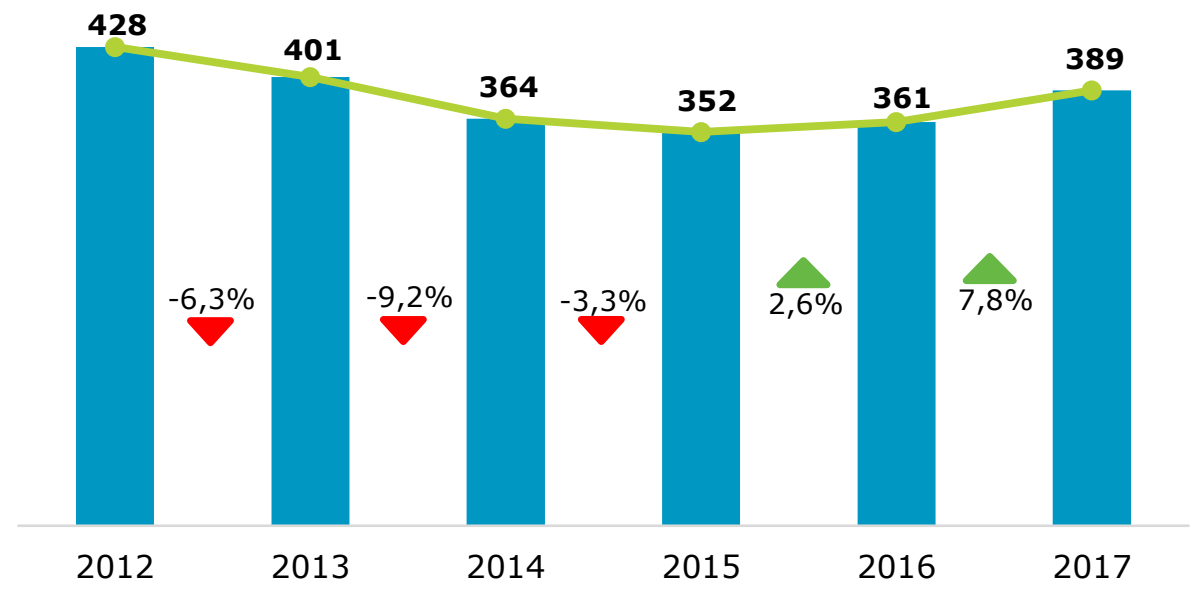

Las copias de videojuegos vendidas en 2017 aumentaron un $0,4 \%$, hasta los 9,2 millones
Por su parte, el número de copias de videojuegos (software) vendidas en España durante los últimos años sigue la misma tendencia. En 2017, por segundo año consecutivo la cifra se incrementa, en este caso hasta los 9,2 millones de unidades (un $0,4 \%$ más con respecto a 2016), muy lejos de las alcanzadas diez años atrás (AEVI 2017).

Gráfico 23. Videojuegos (software) vendidos en España. Evolución 2012-2017 (Millones de unidades)

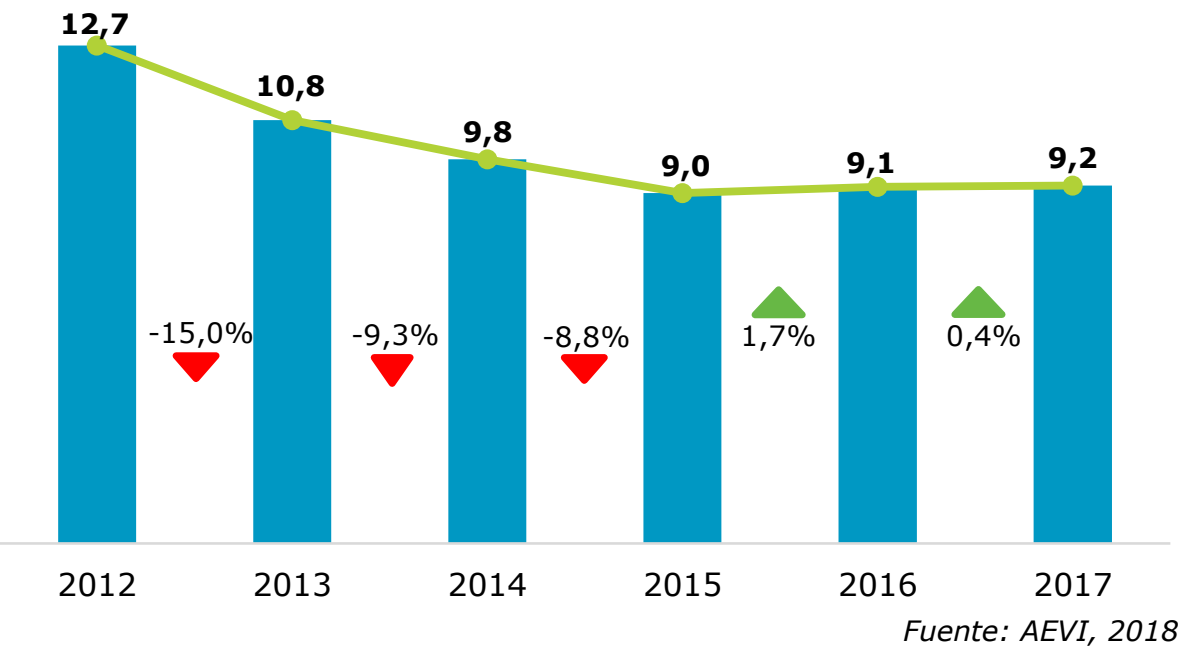

Por otro lado, el ONTSI a través de su encuesta a las empresas del Sector de las TIC y de los Contenidos dispone de información relacionada con los productos que las empresas del sector de los videojuegos desarrollan o comercializan. En este caso, sin contar los ingresos procedentes de la venta de hardware, el $45,8 \%$ de la facturación del sector del videojuego procede la venta de juegos para consola en soporte físico; seguido de la venta de juegos para dispositivos móviles descargables, que abarca el 37,4\% de los ingresos. Lejos de estos dos últimos, aparecen los juegos online de 
acceso desde PC, los juegos para consola descargables, los servicios de cesión de los derechos de videojuegos y los juegos de ordenador en soporte físico que representan respectivamente el 5,9\%, 4,9\%, $2,9 \%$ y $2,4 \%$ de la facturación total del sector. Por su parte, la aportación al total de ingresos del sector de los juegos online de acceso desde consola, los juegos para ordenador descargables y los casual games o juegos para móviles desde el aplicativo, apenas alcanza un $1 \%$ en su conjunto.

Gráfico 24. Distribución de la cifra de negocio de productos relacionados con el sector de los videojuegos en España, 2017 (\% sobre el total) ${ }^{8}$

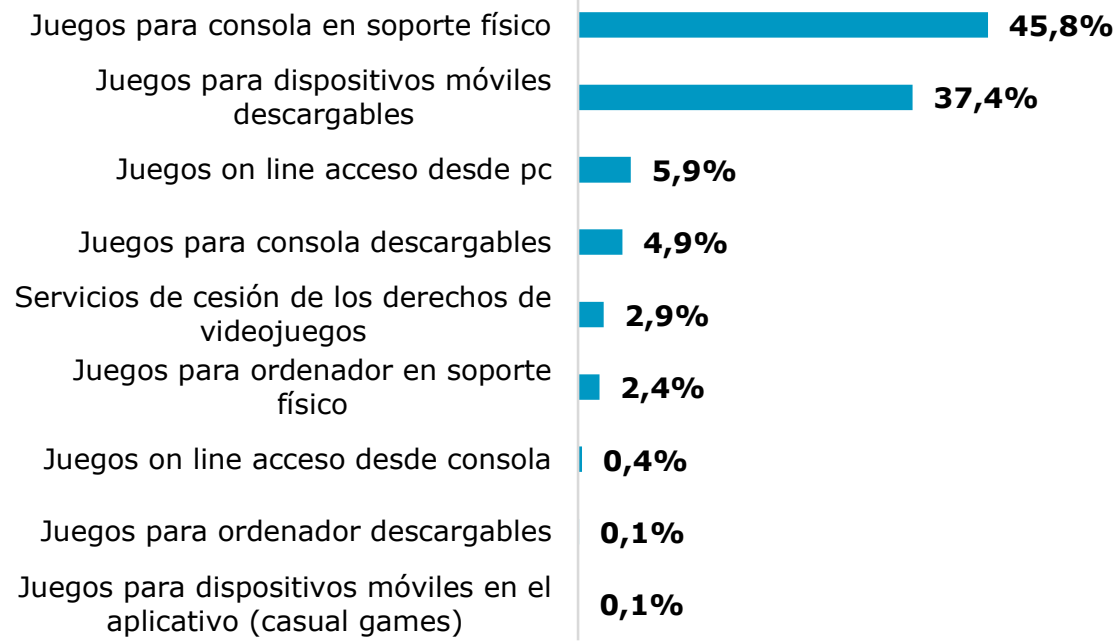

Fuente: ONTSI

Los juegos descargables para móviles representan el $76,5 \%$ de los ingresos por venta de videojuegos por medios digitales
Si se tienen en cuenta únicamente los ingresos generados por la venta de videojuegos distribuidos a través de medios o canales digitales, los juegos para dispositivos móviles descargables representarían en 2017 el 76,5\% de los ingresos. Muy lejos de este porcentaje aparecerían los juegos online de acceso desde PC y los juegos para consola descargables, que representarían el $12,1 \%$ y el $10,1 \%$ de los ingresos procedentes de la venta digital de videojuegos, respectivamente.

${ }^{8}$ No incluye la cifra de negocio procedente del hardware 


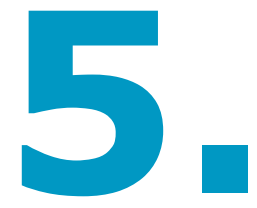

\section{EL SECTOR DE LA MÚSICA}
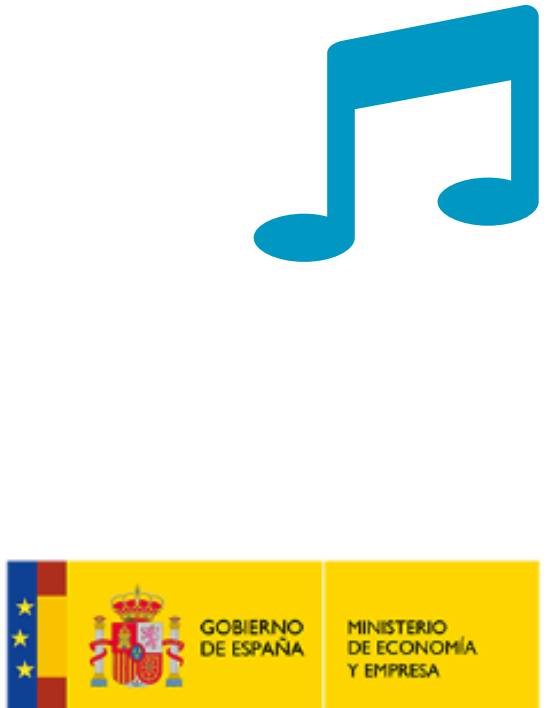

ontsi red.es 


\section{CIFRA DE NEGOCIO}

En 2017 la facturación del sector de la música en el mundo es de

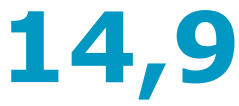

miles de millones de euros

\section{$5 \quad$ El sector de la música}

\subsection{El mercado global de la música}

La digitalización es un proceso que afecta de forma diferente a los contenidos. En el caso del sector de la música su proceso de digitalización se encuentra en una situación muy favorable. Además, la música es uno de los sectores donde se aprecia en mayor medida lo que ha supuesto el impacto de Internet. Hace varios años, las ventas digitales de álbumes superaron a las físicas, iniciando así una revolución en el sector nunca vista antes. Uno de los efectos de la digitalización del sector ha sido la aparición de nuevos agentes en la cadena de valor como, por ejemplo, las plataformas de venta online mediante descarga o streaming.

Desde el punto de vista del volumen de negocio del sector de la música en el mundo, durante los últimos años, concretamente en el período 2013-2016, los ingresos procedentes de la venta de discos se han mantenido estables. Los ingresos en 2013 fueron de 11,8 miles de millones de euros mientras que en 2016 la cifra de negocio aumentaba hasta los 12,8 miles de millones de euros. En 2017 se incrementa hasta casi los 15 miles de millones de euros, un 16,7\% más que en el año anterior. No obstante, esta tendencia es diferente en función del origen de las ventas. Así pues, los ingresos provenientes de las ventas online aumentan considerablemente, sobre todo a partir de 2016, alcanzándose en 2017 unos ingresos de 9,9 miles de millones de euros (un $32 \%$ más con respecto a la cifra del año anterior).

Con respecto al volumen de ingresos de las ventas físicas del sector de la música, la tendencia, como es evidente, es negativa. Hasta el año 2014 las ventas físicas suponían más de la mitad del volumen de negocio total de este sector $(52,6 \%)$. Las previsiones de cara a los próximos indican que este porcentaje se haya reducido al 15,6\% en el año 2022. En 2017, el 66,3\% del total de ingresos del sector de la música procede de las ventas digitales.

Gráfico 25. Ingresos por venta de discos en el mundo (miles de millones de euros)

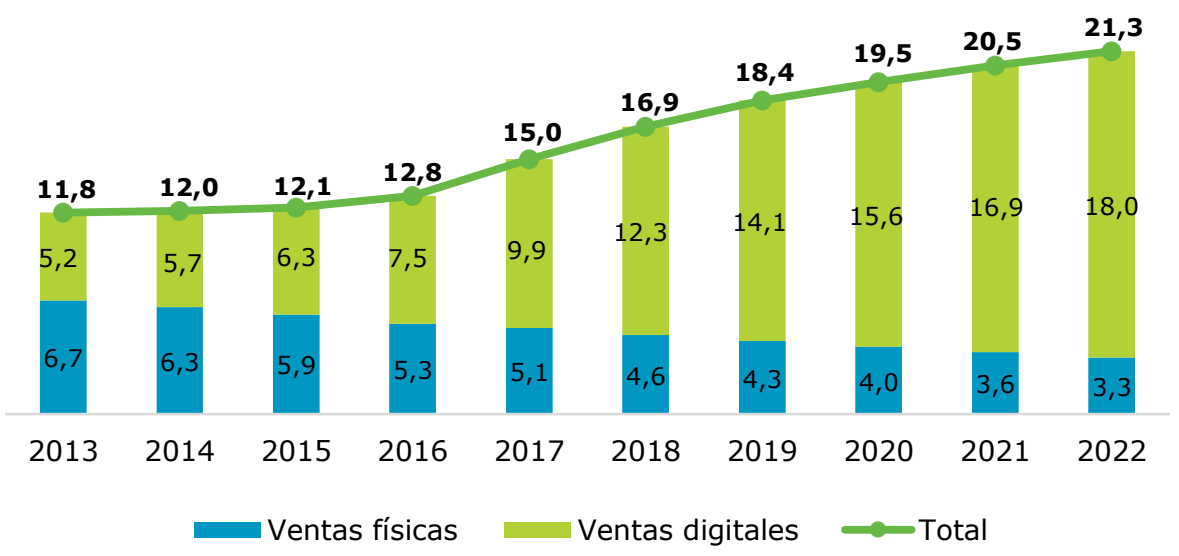

Fuente: IDATE, $2018 a$ 
En 2017, el $66,3 \%$ de los ingresos totales del sector de la música procede de las ventas digitales
De otro lado, en relación con la evolución de los ingresos del sector de la música, la International Federation of the Phonographic Industry (IFPI), en su último informe con carácter global sobre el sector, incorpora otras tipologías que contribuyen al total de ingresos, más allá de las ventas físicas y digitales. Así pues, según IFPI, en el año 2017 el 38\% de los ingresos proceden de los servicios de streaming, el $30 \%$ de la venta física, el $16 \%$ de la venta digital (excluyendo streaming), el $14 \%$ de los derechos de autor, y el $2 \%$ restante de las licencias de sincronización. La música en formato digital, en su conjunto, representa el $54 \%$ de los ingresos. La modalidad de ingresos que más ha crecido ha sido los servicios de streaming en un 45,5\% con respecto al año 2016.

Gráfico 26. Ingresos por venta de discos en el mundo según IFPI (miles de millones de euros)

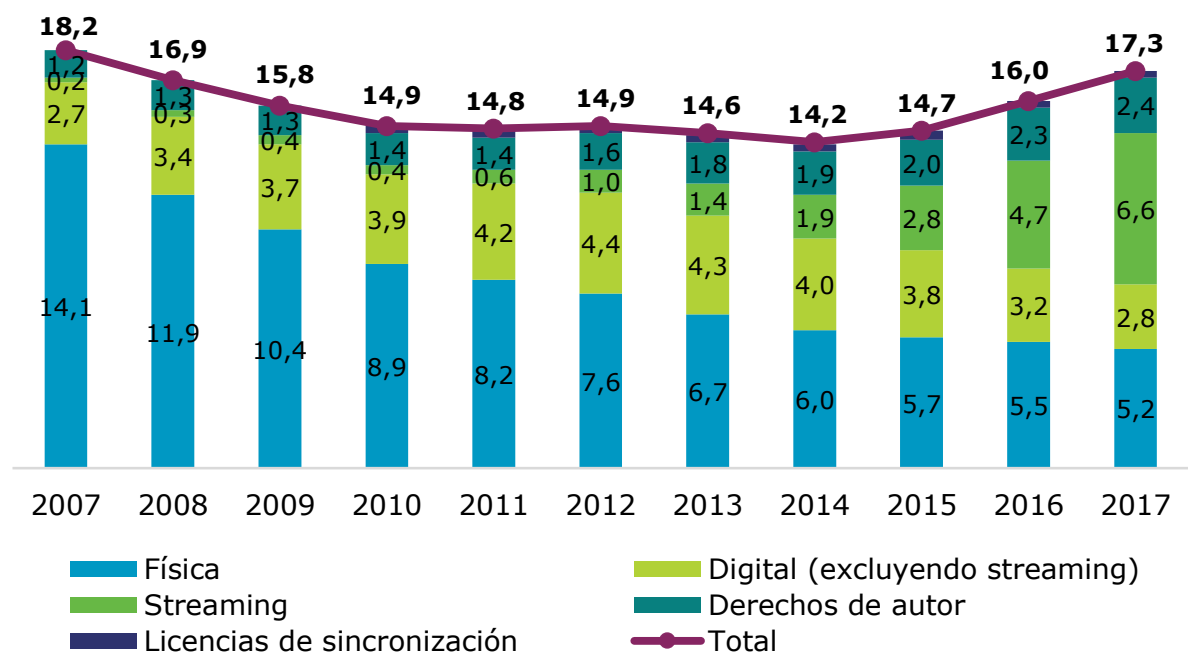

Fuente: IFPI, 2018

Volviendo a la información que proporciona IDATE, fijándonos en el sector de la música online, hasta el año 2015 su fuente de ingresos principal lo constituían la venta de álbumes online y la venta de singles (o pistas individuales), representando en su conjunto el $52,2 \%$.

En 2017 la tendencia cambia considerablemente en favor de las suscripciones online, que ya representa el $57,9 \%$ de los ingresos del sector de la música en Internet. La cifra de negocio de las suscripciones online es la que más ha crecido en el último año en términos proporcionales ( $58,1 \%$ con respecto a 2016), y se prevé que lo siga haciendo, aunque a un ritmo más pausado (con una tasa de crecimiento medio anual para el período 2018-2022 del 10,7\%).

También ha experimentado un crecimiento muy importante la música online apoyada por publicidad, que en la actualidad representa el $20,8 \%$ de los ingresos y será la que proporcionalmente más lo haga durante los próximos años (con una tasa promedio de crecimiento del $16,6 \%$ ). Por el contrario, las previsiones para la 
venta de álbumes y singles indican que no llegarán a alcanzar el $8 \%$ del total de ingresos en 2022 en todo el mundo.

Gráfico 27. Ingresos del sector de la música (ventas digitales) según origen (miles de millones de euros)

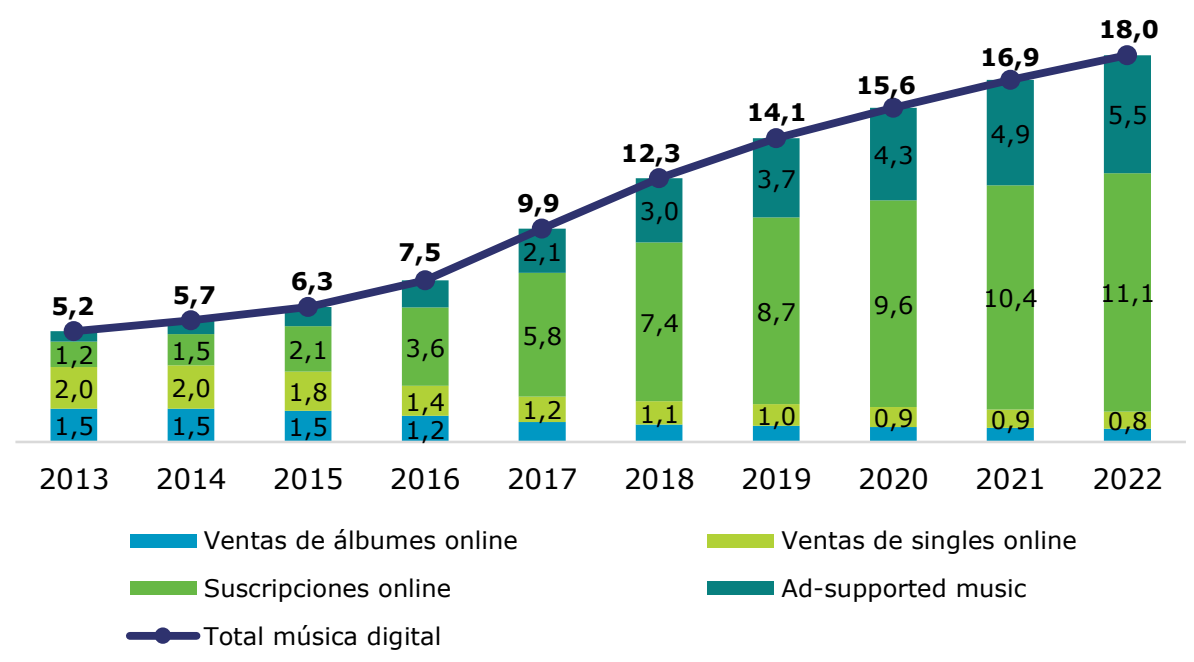

Fuente: IDATE 2018a

Norteamérica se posiciona como la región con más ingresos per cápita procedentes de la música digital
Diferenciando por regiones geográficas, Norteamérica destaca con la cifra de negocio más alta en 2017, de 6 mil millones de euros, un $42,8 \%$ más que en el año 2016. Esta región logra abarcar el 60,8\% de toda la música digital a nivel global. Se posicionan a continuación Europa y Asia Pacífico con unos ingresos de 2,2 y 0,9 miles de millones de euros, respectivamente. Ambas regiones consiguen aumentar sus ingresos en comparación con el año 2016. Las previsiones de futuro son optimistas para todas las regiones geográficas, especialmente para América Latina cuya tasa de crecimiento medio anual entre 2018 y 2022 se estima que será del $20,4 \%$.

Además, en los últimos cuatro años la proporción de los ingresos procedentes de las ventas digitales comparando entre las principales regiones del mundo indican que en Norteamérica la penetración de este modelo ha sido mayor. Es en Asia Pacífico donde aún las ventas físicas siguen teniendo una importancia relevante con respecto al resto de regiones, representando aun cerca del $60 \%$ del total de ventas de música. Las previsiones para Oriente Medio y África y América Latina señalan una importante penetración del modelo de negocio de las ventas digitales.

En términos relativos a la población de cada una de las regiones geográficas, Norteamérica destaca considerablemente con respecto al resto en cuanto a ingresos por parte de la venta de música en formato digital, con una cifra de ingresos per cápita de 16,7 millones de euros en 2017. Muy lejos se posiciona Europa con 2,7 millones de euros per cápita. El resto de las regiones apenas llegan a alcanzar el millón de euros por habitante. 
Spotify continúa siendo el líder indiscutible dentro del sector de las plataformas de streaming, contando con 71 millones de suscriptores a finales de 2017
Con respecto a la evolución de las ventas de álbumes de música a nivel mundial no se han identificado datos actualizados en el momento de la realización del presente informe. Por este motivo se refleja la información contenida en el informe del pasado año, del mismo modo que se ha hecho en el capítulo respectivo al sector de los videojuegos. De este modo, durante el transcurso del año 2016, se vendieron aproximadamente 3.093 millones de álbumes en todo el mundo, de los cuales el $78,5 \%$ han procedido de ventas digitales y el $21,5 \%$ de ventas físicas. El número de álbumes vendidos en 2016 descendió un -2\% respecto al año 2015 (ONTSI, 2017a).

Las previsiones de futuro auguraban un gran recorrido para los álbumes digitales que crecerían entre 2016 y 2020 un 3,7\%. De igual forma, se esperaba que en 2020 los álbumes digitales abarcaran casi el $90 \%$ de la cuota de mercado a nivel mundial. Lo contrario ocurría con los álbumes físicos, esperándose descensos en el número de álbumes vendidos y la consecuente pérdida de cuota de mercado (ONTSI, 2017a).

No obstante, a pesar de la caída de las ventas físicas de álbumes de música, formatos casi olvidados como el vinilo estarían experimentando un incremento de sus ventas. Así lo confirma el último informe realizado por la empresa BuzzAngle sobre la industria musical en Estados Unidos, donde la venta de vinilos en 2017 se ha incrementado un $20,1 \%$, representando actualmente el $10,4 \%$ del total de las ventas físicas. Cabría pensar que dicha tendencia puede ser similar en continentes como el europeo o incluso a nivel global.

Finalmente, se debe destacar el exitoso recorrido en los últimos años que vienen experimentando las plataformas de servicios de música streaming, con un crecimiento en promedio desde 2014 del $60 \%$ anual. Spotify continúa siendo el líder indiscutible dentro del sector de este tipo de plataformas, contando con 71 millones de suscriptores a finales de 2017. Deezer, el principal rival de Spotify hasta mediados del año 2015, ha pasado a ocupar la última posición en número de suscriptores ( 10 millones a finales de 2017) debido al enorme éxito que han tenido plataformas de reciente creación como Apple Music (creada en junio de 2015), con 38 millones de suscriptores en marzo de 2018, y Amazon Music con una cifra que ronda los 30 millones de suscriptores a finales de 2017 (IDATE, 2018b). 


\subsection{El sector de la grabación y edición de música en España}

CIFRA DE NEGOCIO DIGITAL

La facturación del sector de la Música

Digital asciende a

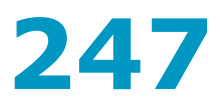

millones de euros en 2017
De todo el período representado en la siguiente gráfica, 2017 es el año en el que el sector de la grabación de sonido y edición musical alcanza la cifra de negocio más alta, con 247 millones de euros (un $50,3 \%$ más con respecto al año 2016), señal de la clara y satisfactoria recuperación que viene experimentando desde los últimos tres años (en 2014 experimentó unas pérdidas del $-33 \%$ con respecto al año 2013, habiéndose situado la cifra de negocio en 122 millones de euros).

Gráfico 28. Facturación del negocio digital de la música en España: 2012-2017 (Millones de euros)

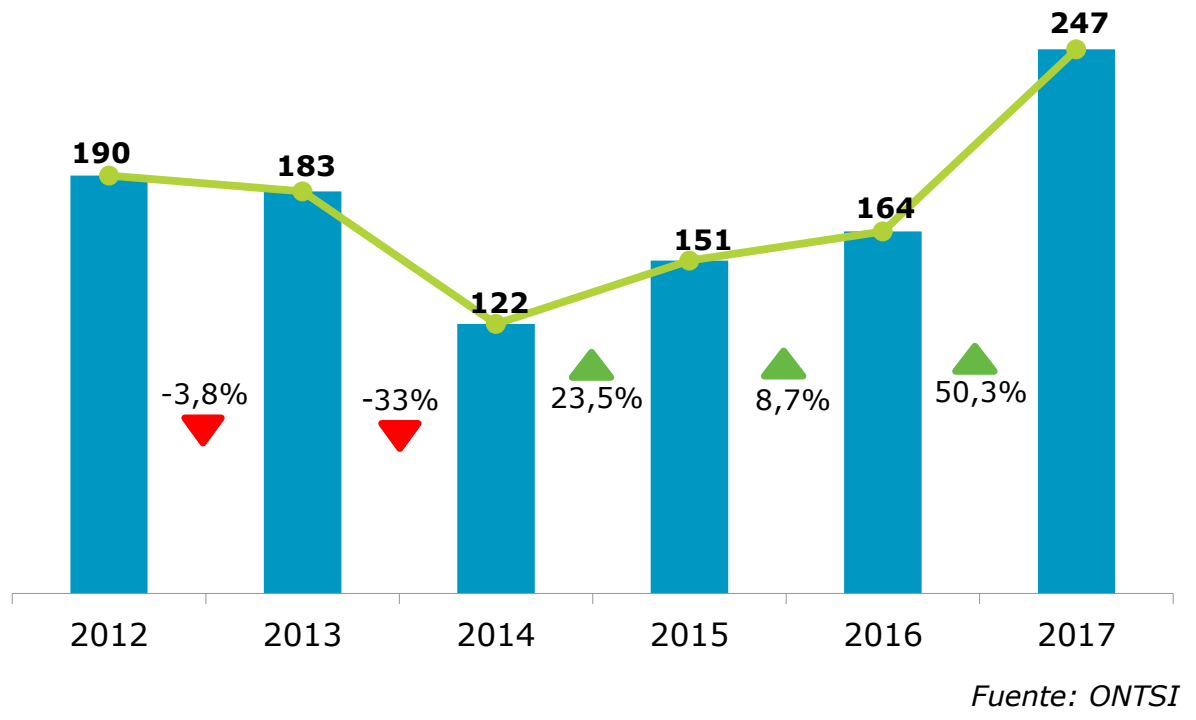

Igualmente, con respecto a 2017, distinguiendo la cifra de negocio total del sector de las actividades de grabación de sonido en función de su tipología de productos asociada, el 20,3\% de los ingresos proceden de la venta de productos catalogados como "otros productos relacionados con la grabación y la edición musical". Le sigue la venta de productos en formato tradicional (soporte físico $C D$, DVD, etc.), que representa el $19,2 \%$ de los ingresos del sector. En tercer lugar, se posicionan los servicios de grabación de sonido $(17,7 \%)$. La música en streaming también adquiere un papel significativo en la contribución al total de ingresos del sector $(14,2 \%)$. Con unos porcentajes algo superiores al $10 \%$ aparecen los servicios de cesión de los derechos de originales sonoros, así como la música descargable de pago. Con una aportación residual aparecen las suscripciones de música descargable $(3,2 \%)$ y la música para móviles $(1,9 \%)$. 
Gráfico 29. Distribución en productos de la facturación del sector de la música en España 2017 (\%/total)

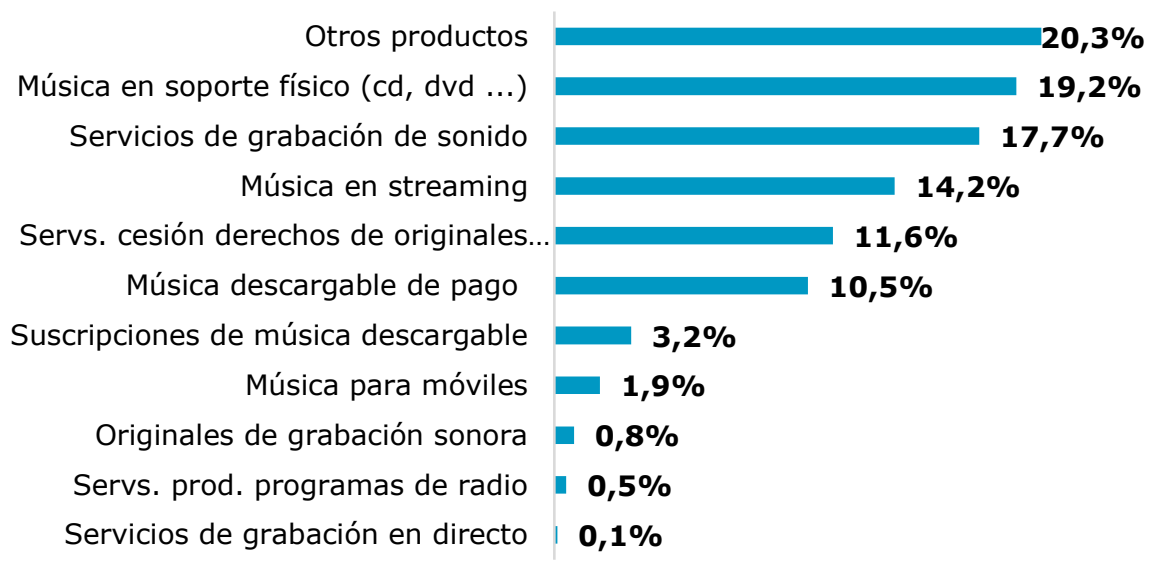

Fuente: ONTSI

La música en streaming aporta el $47,5 \%$ de los ingresos sobre el total de la facturación de la música digital

Para completar la fotografía del sector de la música digital, en su dimensión de negocio, se presta atención a lo que representan en términos proporcionales los ingresos de productos que se distribuyen a través de Internet sobre el total de la facturación de la distribución online de música. De este modo, en 2017, la música en streaming aporta el 47,5\% de los ingresos, seguido de la música descargable de pago con 35,4\%. Menor aportación, al total de ingresos de la distribución online de música, ofrecen las suscripciones de música descargable y la música para móviles con unos porcentajes de $10,7 \%$ y $6,4 \%$ respectivamente.

Gráfico 30. Distribución de la facturación por comercialización online de música en España 2017 (\% sobre el total de la facturación por comercialización online)

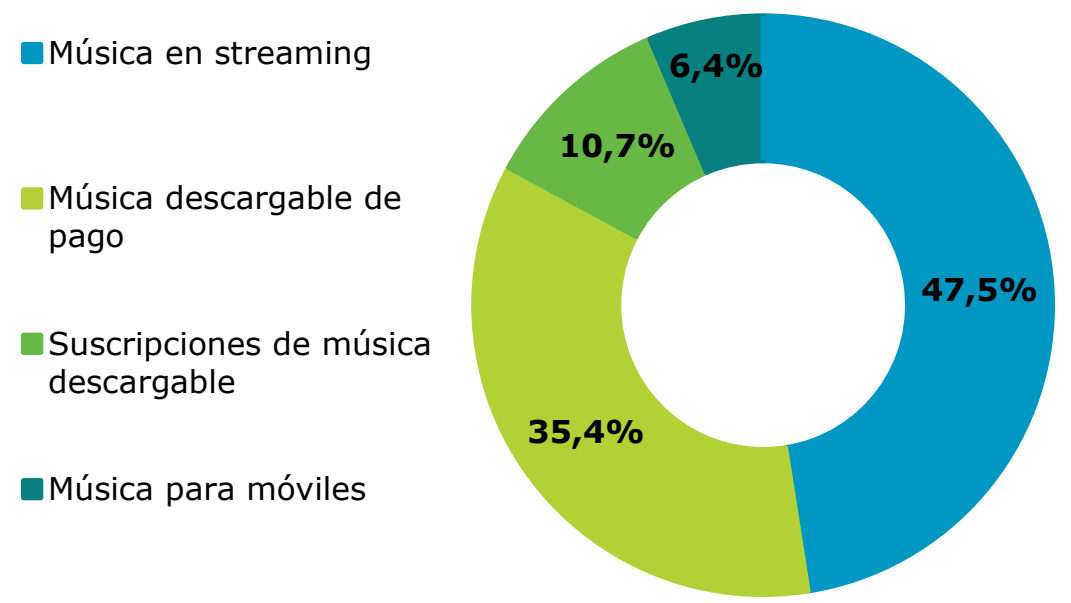

Fuente: ONTSI

Sin embargo, si se tiene en cuenta el total de facturación de la venta de música (tanto física como a través de Internet), la música en soporte físico ( $C D, D V D$, etc.) constituiría la principal fuente de 
ingresos (representando un 39,2\%). Le seguirían la música en streaming $(28,9 \%)$ y la música descargable de pago $(21,5 \%)$. Sólo un $6,5 \%$ le correspondería a las suscripciones de música descargable, y un 3,9\% a la música para móviles. No obstante, la suma de todas las modalidades de comercialización o de distribución a través de medios digitales supera con distancia a la tradicional, llegando a representar casi el $61 \%$ de las ventas de música.

En otro orden de cuestiones, más allá de la evolución del volumen de negocio del sector de la música, se hace referencia a continuación a la evolución del número de empresas del sector, así como a la evolución del personal ocupado y de la inversión.

Con respecto al número de empresas, la evolución desde 2012 continúa con una tendencia ascendente. En 2017 se ha registrado un total de 154 empresas dedicadas a actividades de grabación de sonido y edición musical (un 4,8\% más que en 2016). Hasta ahora, la tasa compuesta de crecimiento agregado ha sido del $11,8 \%$ anual.

La cifra total de empleados que ejercitan su profesión en este sector continúa su tendencia ascendente, alcanzando los 747 trabajadores en 2017 (un 3,9\% más que en el año anterior), de los cuales más de la mitad (el 52,4\%) corresponde a la parte de negocio digital, registrándose una cifra de 392 empleados, un $41,8 \%$ más que en 2016.

Finalmente, en lo que se refiere a la inversión total de las empresas del sector de la música, la cifra asciende en 2017 a los 105 millones de euros (un $52,1 \%$ más con respecto al ejercicio anterior), la más alta registrada desde 2012. Del total de la inversión, solo 13 millones de euros corresponden a la parte de negocio digital (12\% del total de inversión), cifra que desciende por tercer año consecutivo y lejos de la registrada cinco años atrás en 2012. 


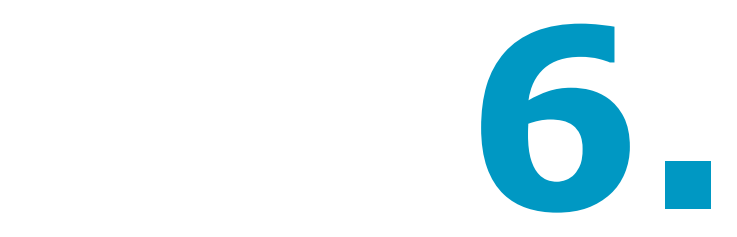

\section{EL SECTOR DEL CINE Y DEL VÍDEO}
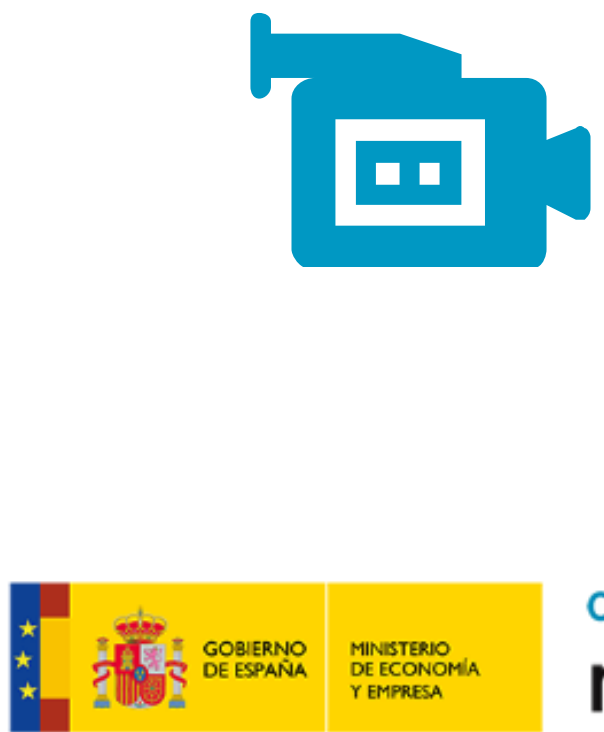

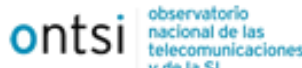

red.es 


\section{El Sector del cine y el vídeo}

\subsection{El mercado global del cine y vídeo}

Este apartado sobre la situación del mercado del cine y del vídeo a nivel mundial se divide en dos subapartados: el primero, en relación con la situación en el mundo del sector de vídeo; y el segundo, en relación con la evolución a nivel global del sector de vídeo bajo demanda (VoD).

\subsubsection{Situación del sector del vídeo en el mundo}

En 2017, los ingresos de vídeo

en soporte digital representan el $67,6 \%$ del total del sector del vídeo en el mundo
En el año 2015, por vez primera, los ingresos de vídeo en soporte digital abarcan más de la mitad del total de los ingresos del sector del vídeo. Ya en 2017, los ingresos de vídeo en soporte digital (30,4 miles de millones de euros) suponen el 67,6\%, 17 puntos porcentuales más que en 2015. La tasa de crecimiento anual fue en 2017 del 22\% con respecto a 2016. Las previsiones para los próximos años (2018-2022) indican igualmente un notable crecimiento con una tasa de crecimiento medio anual del $12,7 \%$ con respecto a los ingresos de vídeo en soporte digital. Se estima que en 2022 englobará aproximadamente el $87 \%$.

Por su parte, los ingresos procedentes del soporte físico continúan con una tendencia muy negativa y no se vislumbran ni mucho menos señales de una recuperación en los próximos años vista la estimación de la tasa de crecimiento medio anual que se sitúa en el $-9,1 \%$ (IDATE, 2018a).

Gráfico 31. Evolución de ingresos de vídeo en soporte físico y digital a nivel mundial (miles de millones de euros)

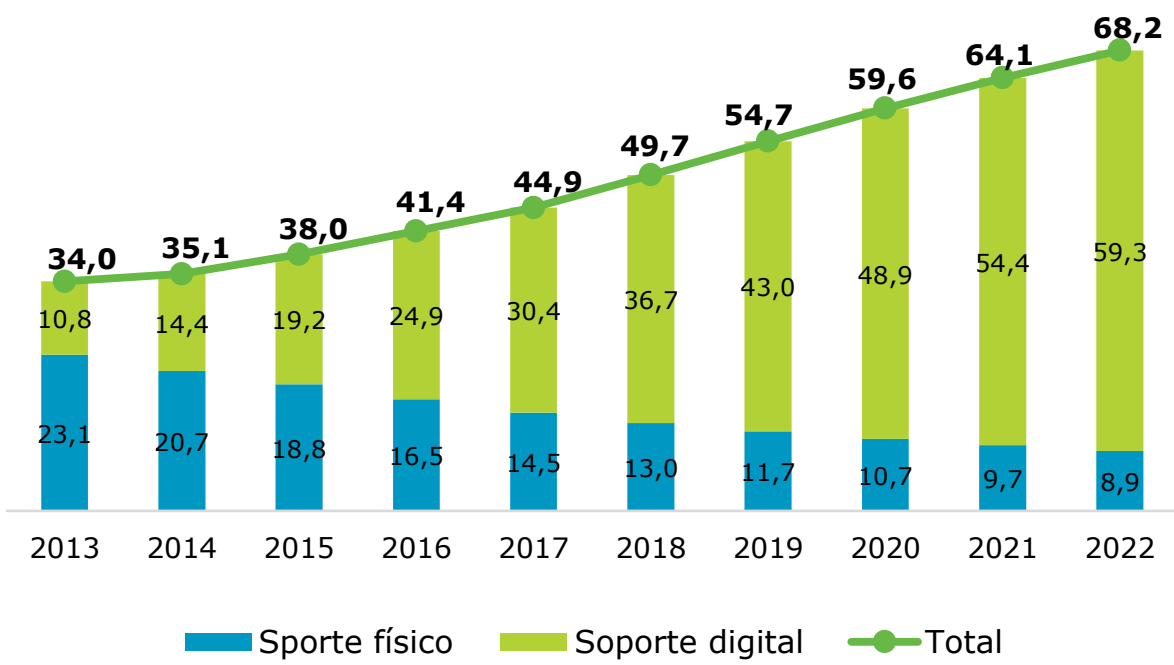

Fuente: IDATE, 2018a

El crecimiento exponencial de los ingresos del sector del vídeo en su dimensión de negocio digital se debe fundamentalmente al importante papel que tienen las suscripciones a servicios de vídeo en comparación con las restantes modalidades de ingresos (venta, alquiler y publicidad). En 2017, los ingresos que proceden de las 


El crecimiento
exponencial de los
ingresos del sector
del vídeo en su
dimensión de
negocio digital se
debe al importante
papel que tienen
las suscripciones
a servicios de
vídeo

suscripciones en formato digital engloban el $57,8 \%$ del total, alcanzando una cifra 17,5 miles de millones de euros. Con respecto al año anterior, esta fuente de ingresos se incrementa en un 30,6\% y se esperan importantes crecimientos durante los próximos años, tal y cómo indica la tasa de crecimiento medio anual para el período 2018-2022 calculada por IDATE del 15\% anual.

Hasta 2013, la principal fuente de ingresos eran los procedentes del alquiler en soporte digital, encontrándose ligeramente por encima en términos porcentuales con respecto a las suscripciones. Al contrario, ya en el año 2017 el alquiler en soporte digital supuso solo el $21,1 \%$ de los ingresos en formato digital $(6,4$ miles de millones de euros) previéndose que, en 2022, a pesar de incrementar la facturación, represente apenas el $15,6 \%$ del mercado.

Por otra parte, los ingresos provenientes de las ventas en formato digital todos los años experimentan crecimientos considerables, aunque insuficientes para llegar a representar más del $15 \%$ del sector digital de vídeo. En el año 2017, los ingresos por venta digital fueron de 4,5 miles de millones de euros.

Por último, cabe mencionar que, en la actualidad, los ingresos provenientes de la publicidad dentro de este sector representan un escaso $6,3 \%$ con unos ingresos de 1,9 miles de millones de euros en 2017. A pesar de que las previsiones en los próximos años (20182022) señalan un crecimiento del $13,8 \%$ anual para esta fuente de ingresos, en el futuro no representará más del $7 \%$ con respecto al total, según datos de IDATE (2018a)

Gráfico 32. Evolución de los ingresos por venta, alquiler y suscripciones de vídeo en soporte digital a nivel mundial (miles de millones de euros)

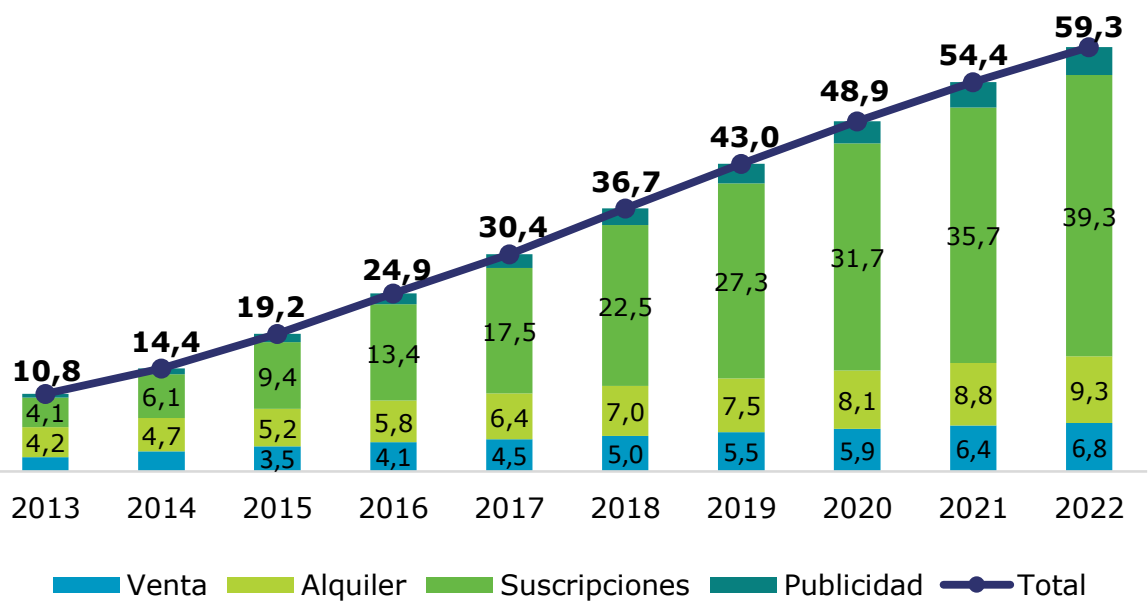

Fuente: IDATE, 2018a

Haciendo una comparación entre las distintas regiones geográficas, Norteamérica destaca por encima del resto con unos ingresos por servicios de vídeo online de 14,1 miles de millones de euros, 


\section{El 79,2\% de los ingresos del sector del vídeo de Asia- Pacífico procede de las ventas digitales}

representando cerca de la mitad de todos los ingresos de vídeo online $(46,4 \%)$. En comparación con 2016 , la cifra de negocio de Norteamérica crece un $21,6 \%$.

Asia Pacífico y Europa consiguen unos ingresos de 8,9 y 5,1 miles de millones de euros respectivamente. Asia Pacífico crece de manera destacada con respecto a $2016(26,4 \%)$, mientras que Europa también lo hace, aunque más moderadamente (14,2\%).

Las previsiones para los próximos cuatro años son positivas para todas las regiones geográficas, especialmente para Oriente Medio y África que obtendrían una tasa compuesta de crecimiento agregado entre 2018 y 2022 del 28,5\%.

Si se relacionan las cifras de ingresos del vídeo en formato digital y la realidad demográfica de cada región, Norteamérica destaca notoriamente con respecto al resto de regiones geográficas, con una cifra en 2017 de 38,9 millones de euros per cápita. Además, según las proyecciones de cara al horizonte 2021, se espera que se duplique esta cifra en dicha región. Muy por debajo aparecen Europa, Latinoamérica y Asia Pacífico, con unos ingresos per cápita en 2017 de 6,$1 ; 2,8$; y 2,2 millones de euros respectivamente. Todo ello indica que los ingresos derivados del vídeo digital no se derivan de la población local, sino que tienen un carácter global. Igualmente pone de relieve que en Norteamérica se encuentra la mayor oferta de contenidos vinculados al vídeo digital, que se consume en la totalidad de las regiones.

Para concluir este subapartado, se debe señalar que el porcentaje que representan los ingresos procedentes del vídeo en soporte digital con respecto al total de ingresos del sector en relación con cada una de las regiones geográficas es mayor en Asia Pacífico (donde representa un $79,2 \%$ en 2017). Le sigue Norteamérica $(68,7 \%)$ y América Latina $(59,1 \%)$. Las previsiones para los próximos años indican un incremento general para todas las regiones del peso proporcional que tienen las ventas de vídeo en soporte digital. 
Gráfico 33. Evolución de los ingresos por venta, alquiler y suscripciones de vídeo en soporte digital a nivel mundial (miles de millones de euros)

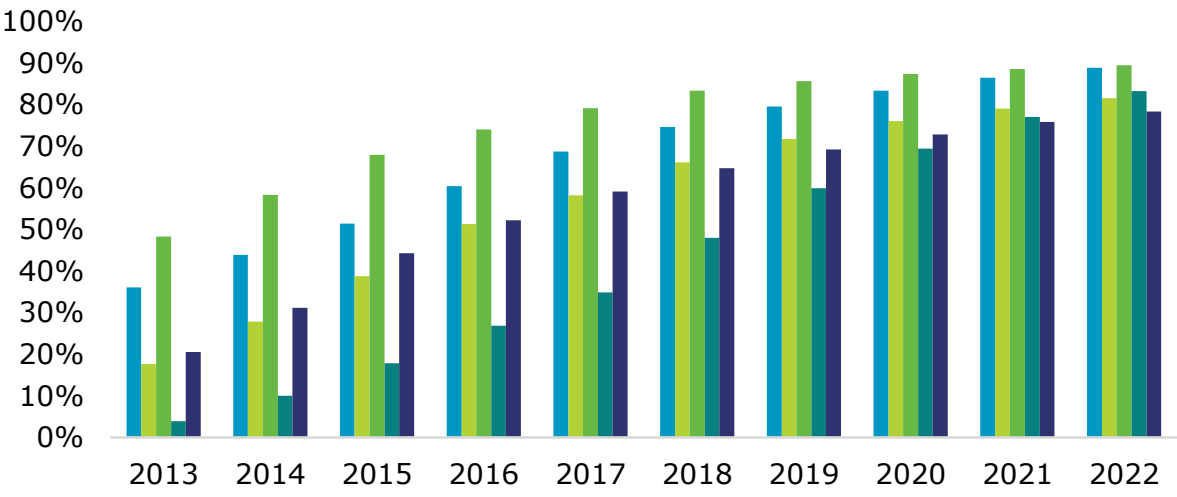

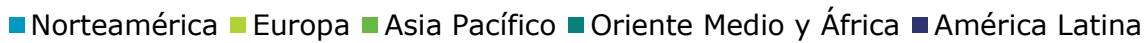

Fuente: Elaboración propia a partir de datos de IDATE

\subsubsection{Situación del vídeo bajo demanda (VoD) en el mundo}

La principal característica de las plataformas de VoD es que permiten al usuario el acceso a un amplio catálogo de producciones renovable periódicamente, con la posibilidad de reproducirlos sin ningún tipo de restricción. Otra de sus características es la doble modalidad de suscripción a sus servicios: a través de proveedores OTT (Netflix, HBO, etc.), o a través de paquetes ofertados por los operadores de telecomunicaciones con servicios de TV de pago (Movistar, Vodafone, etc.)

Además, estos proveedores no solo ofrecen contenidos de terceros, sino que están incrementando la inversión en producciones propias, con el fin de asegurarse un catálogo diferenciado y exclusivo frente a la competencia. De este modo, las plataformas de servicios de video bajo demanda VoD se están convirtiendo en los mayores inversores de la industria audiovisual.

Los ingresos por parte de los servicios de VoD OTT crecerán durante los próximos años a un ritmo en promedio del $25,1 \%$ anual
Ya en el nivel de los datos, la evolución de los ingresos a nivel mundial de los servicios de $\mathrm{VoD}$ es de un incesante crecimiento desde 2013 hasta la actualidad. La cifra de negocio asciende a 54,1 miles de millones de euros en el año 2017. Desde 2013 vienen experimentando un crecimiento a un ritmo, en promedio, del $32,7 \%$ anual. Del total de ingresos, el $86,1 \%$ procede de los servicios de VoD OTT. Los ingresos procedentes de los operadores de telecomunicaciones o servicios de televisión de pago sólo representan un 13,9\%. Las previsiones de cara a los próximos años indican que los ingresos de estos últimos irán perdiendo peso, llegando a representar menos del $10 \%$ en 2021 . Los ingresos por parte de los servicios de VoD a través de proveedores OTT crecerán a un ritmo más elevado, siendo su tasa de crecimiento medio anual para el período 2017-2021 del 25,1\% (IDATE, 2017b). 
Gráfico 34. Evolución de los ingresos de los servicios de vídeo bajo demanda en el mundo (miles de millones de euros)

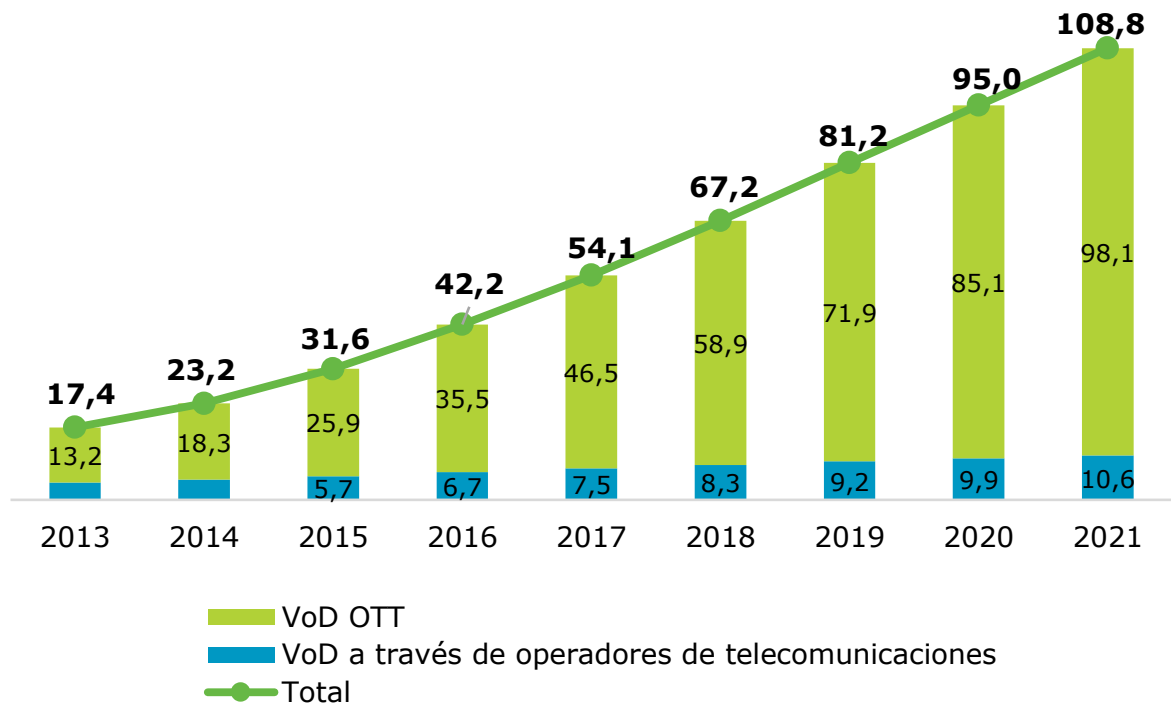

Fuente: IDATE, 2017b

Distinguiendo entre las principales regiones geográficas de mundo Norteamérica acumula el 43,1\% de los ingresos en 2017 con 23,3 miles de millones de euros, seguido de Asia Pacífico que representa el $31,8 \%$ del total de los ingresos mundiales con 17,2 miles de millones de euros, y Europa con 9,7 miles de millones de euros. Las previsiones para los próximos años indican que será Europa la región que en mayor intensidad incrementará los ingresos procedentes de los servicios de $\mathrm{VoD}$ con una tasa de crecimiento del 23,6\% anual para el período 2017-2021.

En términos per cápita, Norteamérica es la región que mayor cifra de ingresos obtiene (64,3 millones de euros per cápita). Bastante inferiores son las cifras de ingresos por servicios de VoD en Europa y América Latina con 11,6 y 5,8 millones de euros per cápita respectivamente para el año 2017 . Todo ello muestra la importancia relativa de la industria norteamericana con respecto al resto de la industria y su capacidad de generar ingresos fuera de sus fronteras.

\section{CIFRA DE NEGOCIO} DIGITAL

La facturación digital del sector del Cine y

Vídeo alcanza en 2017 los

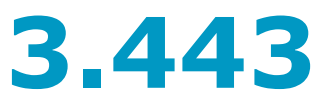

millones de euros

\subsection{El sector del cine y vídeo en España}

En 2017 la cifra de negocio total del sector de las actividades cinematográficas, de vídeo y de programas de televisión en España crece por tercer año consecutivo, ascendiendo a 4.815 millones de euros (un 4,3\% más con respecto a 2016). De esta cifra, el $71,5 \%$ corresponde al negocio digital, lo que equivale a 3.443 millones de euros de volumen de negocio digital de las empresas del sector de cine y de vídeo, lo que supone una evidente señal de la importancia que tiene la digitalización en este sector. En términos porcentuales, la cifra de negocio digital ha crecido en un $17,6 \%$ con respecto al año anterior, lo que hasta la fecha supone el mayor de los 
crecimientos desde el inicio de la serie histórica representada en la siguiente gráfica.

Gráfico 35. Facturación digital del cine y vídeo en España: 2012-2017 (Millones de euros)

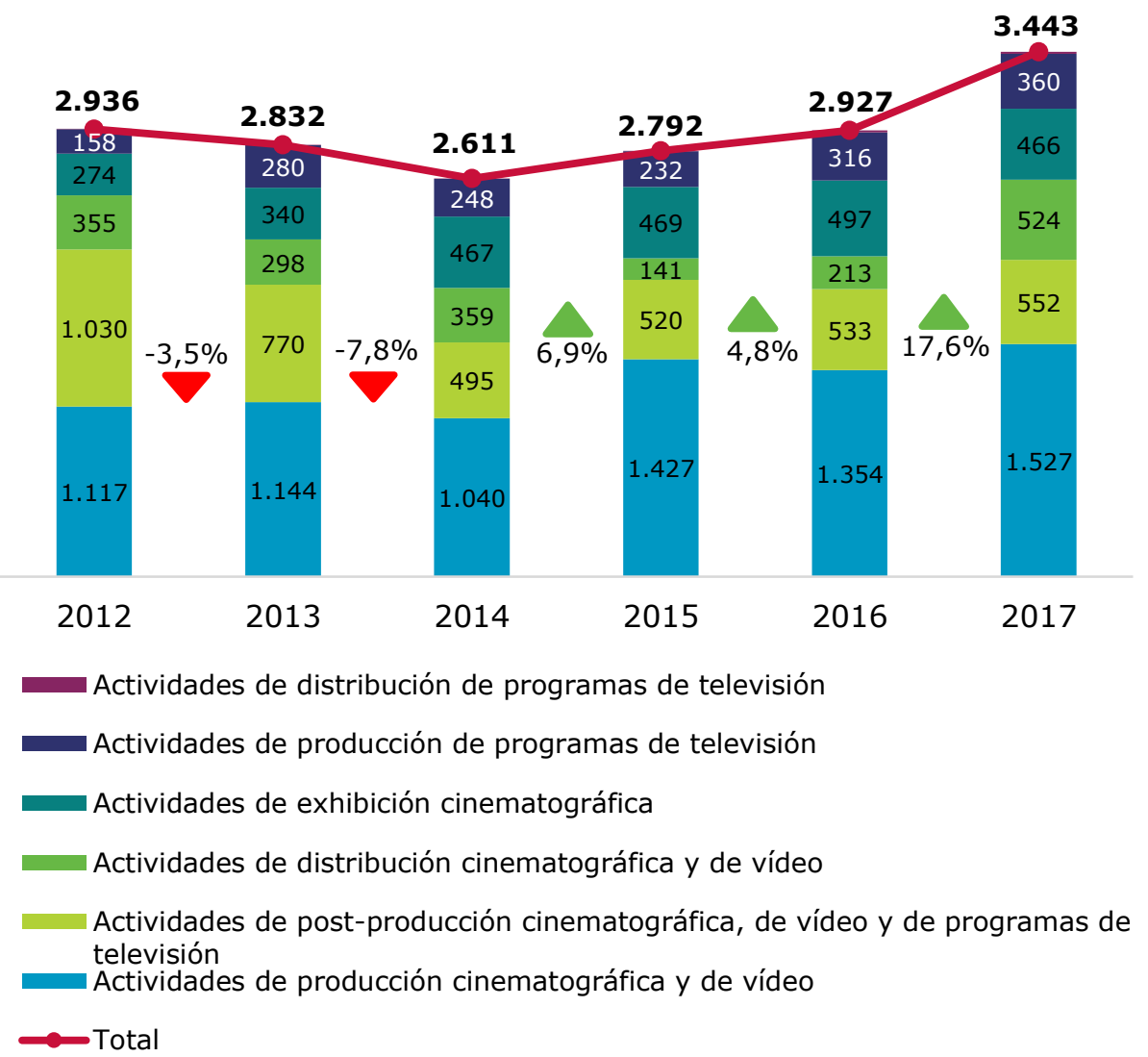

El 44,3\% de la cifra de negocio digital procede de las actividades de producción cinematográfica y de vídeo

Fuente: ONTSI

Por otra parte, distinguiendo entre las diferentes ramas o subcategorías de actividad asociadas al sector del cine y del vídeo, cabe señalar que el $44,3 \%$ de la cifra de negocio digital procede de las actividades de producción cinematográfica y de vídeo. Le sigue en segunda posición las actividades de post-producción cinematográfica, de vídeo y de programas de televisión (16\%). En una proporción similar, las actividades de distribución cinematográfica y de vídeo representan el 15,2\% del volumen de ingresos digital del sector. Por su parte, las actividades de exhibición cinematográfica aportan un $13,5 \%$ de los ingresos, mientras que las actividades de producción de programas de televisión lo hacen en un $10,4 \%$. Por último, las actividades de distribución de programas de televisión representan una parte insignificante de la cifra de negocio digital del sector del cine y el vídeo $(0,4 \%)$. 
Gráfico 36. Facturación del negocio digital de actividades cinematográficas, de vídeo y de programas de televisión en España. 2017 (\% sobre la facturación digital del sector)

Actividades de producción
cinematográfica y de vídeo
Actividades de post-producción
cinematográfica, de vídeo y de
programas de televisión
Actividades de distribución
cinematográfica y de vídeo
Actividades de exhibición
cinematográfica
Actividades de producción de
programas de televisión
Actividades de distribución de
programas de televisión

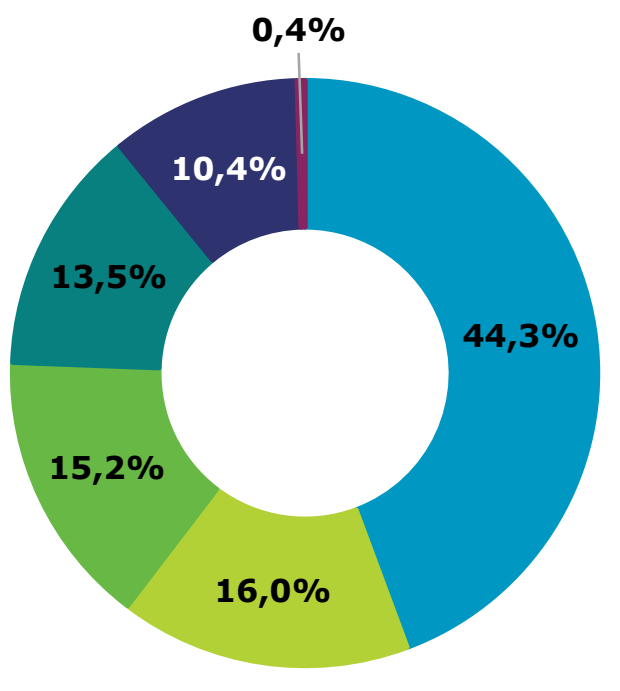

\section{El 51,9\% de las empresas del sector de cine y vídeo se dedican a actividades de producción cinematográfica}

Fuente: ONTSI

Dejando a un lado la cuestión de la cifra de negocio, se debe señalar que la evolución del número de empresas del sector de cine y de vídeo continúa su tendencia positiva, aumentando por cuarto año consecutivo. Con respecto a 2016, ha aumentado en un $4,3 \%$, pasando de 2.702 a 2.817 en 2017.

En términos porcentuales, en la actualidad, más de la mitad de las empresas del sector del cine y del vídeo se dedican a actividades de producción cinematográfica $(51,9 \%)$. Le siguen en importancia las empresas de actividades de exhibición cinematográfica, que llegan a representar el 16,1\%. La tercera posición la ocupan las empresas de actividades de producción de programas de televisión, llegando a representar un $14,5 \%$ del total. Las tres últimas posiciones corresponden a las empresas dedicadas a actividades de postproducción cinematográfica; de distribución cinematográfica y de vídeo; y de distribución de programas de televisión, que abarcan respectivamente el $8,8 \%, 7,2 \%$ y $1,5 \%$ del total de empresas registradas del sector del cine y del vídeo. 
Gráfico 37. Porcentaje de empresas por rama de actividad del sector de cine y de vídeo en España en 2017 (\% sobre el total de empresas del sector)

Actividades de producción
cinematográfica y de vídeo
Actividades de exhibición
cinematográfica
Actividades de producción de
programas de televisión
Actividades de post-producción
cinematográfica, de vídeo y de
programas de televisión
Actividades de distribución
cinematográfica y de vídeo
Actividades de distribución de
programas de televisión

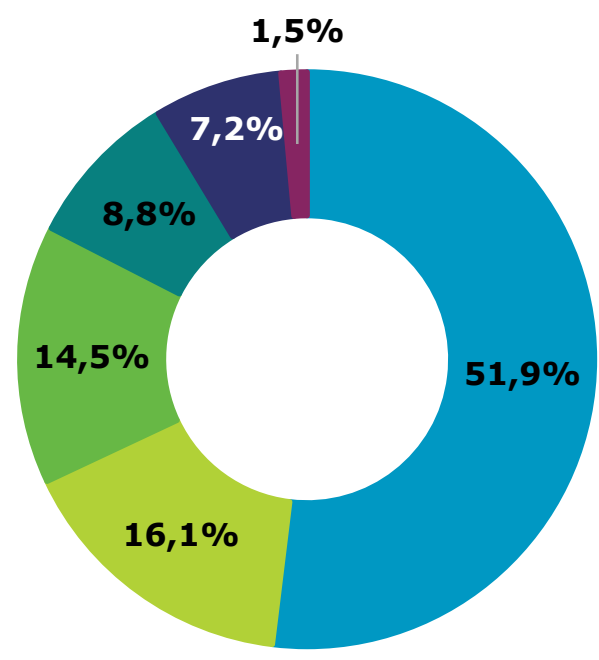

Fuente: ONTSI

Por otra parte, igualmente se puede confirmar el incremento general del empleo en el sector de las actividades cinematográficas y de vídeo pasados los peores años de la crisis económica. Con respecto al año 2016, el sector ha generado 1.113 nuevos empleos, alcanzándose en 2017 la cifra de 28.786 empleados, de los cuales el $63,9 \%$ pertenece al negocio digital, es decir, 18.398 empleados.

Además, alrededor del $90 \%$ del personal ocupado en la parte de negocio digital del sector del cine y del vídeo se concentra en tres subsectores de actividad: en primer lugar, en el de producción cinematográfica y de vídeo, que abarca el $31,1 \%$ del empleo; seguido del subsector de producción de programas de televisión, que concentra el $31 \%$ del empleo; y en el de las actividades de exhibición cinematográfica, que agrupa el $28,1 \%$ del empleo en la parte de negocio digital del sector. Por su parte, la rama de actividades de post-producción cinematográfica apenas logra representar el $6 \%$ del personal ocupado; y en bastante menor medida las actividades de distribución cinematográfica y de distribución de programas de televisión englobando tan solo un $2,4 \%$ y un $1,6 \%$ respectivamente. 
Gráfico 38. Porcentaje de personal ocupado en la parte de negocio digital por rama de actividad del sector de cine y de vídeo en España en 2017 (\% sobre el total de empleados del sector en la parte de negocio digital)

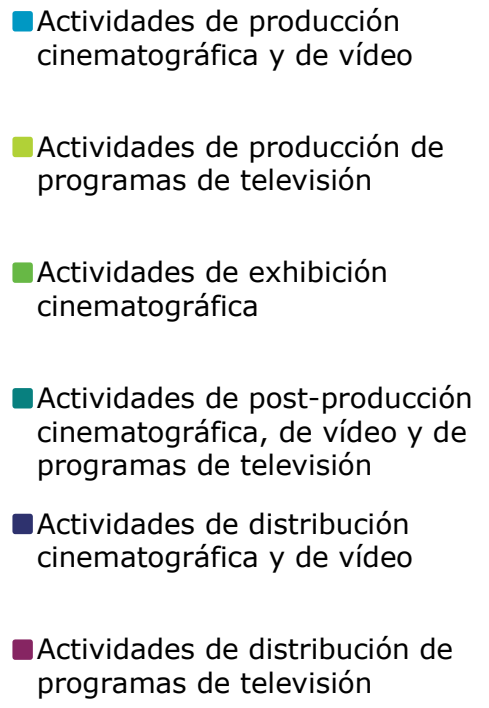

Actividades de producción cinematográfica y de vídeo

Actividades de producción de programas de televisión

Actividades de exhibición cinematográfica

Actividades de post-producción cinematográfica, de vídeo y de programas de televisión

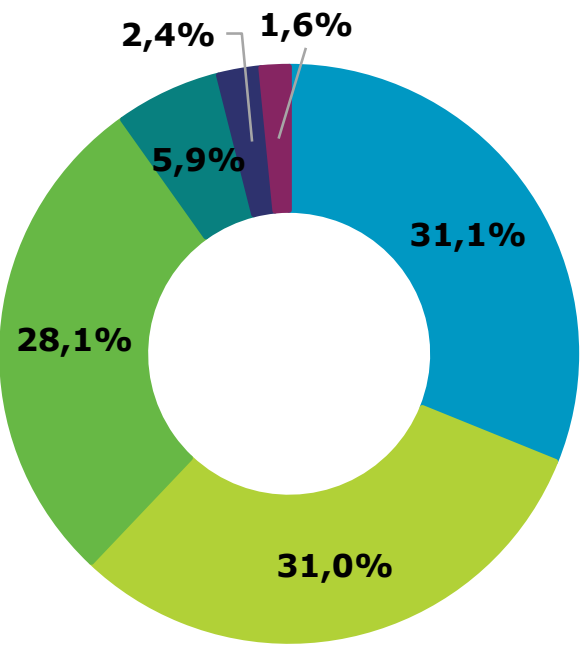

Fuente: ONTSI

\section{INVERSIÓN EN} NEGOCIO DIGITAL

La inversión del sector del Cine y Vídeo alcanza los

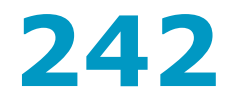

millones de euros en 2017
Por último, para completar la radiografía general del sector del cine y del vídeo en España se hace referencia a la evolución de la inversión orientada al negocio digital. Por primera vez desde el año 2012, la tendencia de la inversión del sector dedicada al negocio digital cambia de signo. En 2012 la cifra se situaba en los 806 millones de euros alcanzándose el mínimo en 2016 con 146 millones de euros. Ya en 2017, la cifra de inversión en negocio digital se incrementa en un 65,1\% llegándose a los 242 millones de euros. De la cifra total de inversión del sector de cine y vídeo (873 millones de euros) el $27,7 \%$ le corresponde al negocio digital.

Desagregando el volumen de inversión en negocio digital del sector de cine y vídeo en función de sus ramas de actividad, en 2017 el $38 \%$ de la inversión digital se concentra en las actividades de postproducción cinematográfica, de vídeo y de programas de televisión. En una proporción similar, las actividades de exhibición cinematográfica concentran el $33,6 \%$ de la inversión digital del sector. Un poco más de la cuarta parte de la inversión digital se concentra en las actividades de producción cinematográfica y de vídeo $(14,4 \%)$ y en las actividades de distribución cinematográfica y de vídeo $(11,7 \%)$. De manera residual, las actividades de producción y las actividades de distribución de programas de televisión representan un $1,3 \%$ y un $1 \%$ de la inversión total en negocio digital respectivamente. 
Gráfico 39. Inversión digital del sector de cine y vídeo, 2017 (\% sobre el total de la inversión del sector dedicada al negocio digital)

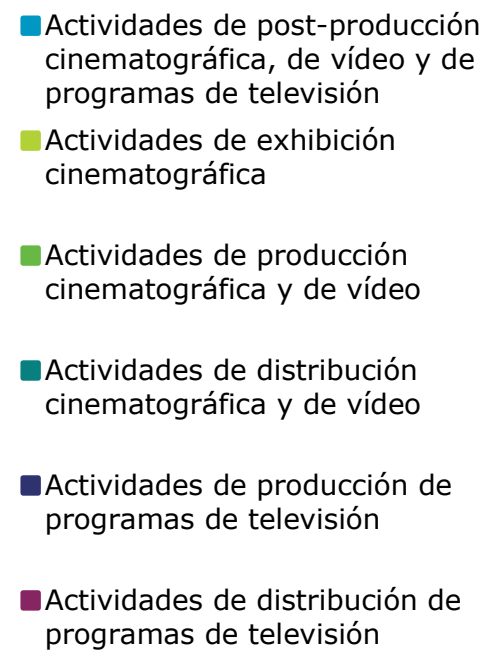

Actividades de post-producción cinematográfica, de vídeo y de Actividades de exhibición cinematográfica

Actividades de producción cinematográfica y de vídeo

Actividades de distribución cinematográfica y de vídeo

Actividades de producción de Actividades de distribución de programas de televisión

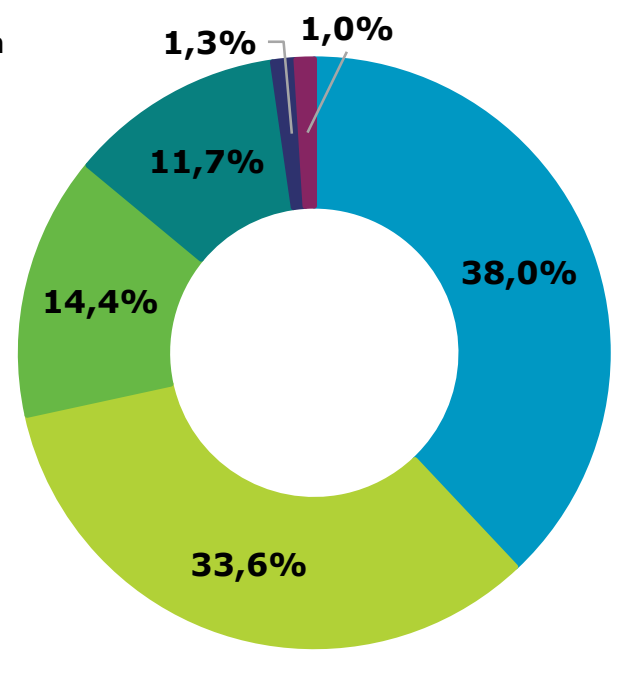

Fuente: ONTSI

\section{CIFRA DE NEGOCIO}

La facturación digital de la rama de

Producción

cinematográfica y de vídeo se sitúa en

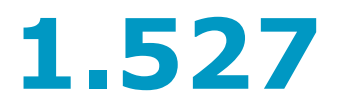

millones de euros en 2017

\subsubsection{Producción cinematográfica y de vídeo}

La cifra de negocio total de la rama de actividad relacionada con la producción cinematográfica alcanza en 2017 los 1.901 millones de euros (un 7,3\% más que en 2016), de los cuales el $80,3 \%$ corresponde a la parte de negocio digital de la rama de actividad (1.527 millones de euros).

Gráfico 40. Cifra de negocio digital de la rama de actividad de producción cinematográfica y de vídeo 2012-2017 (millones de euros)

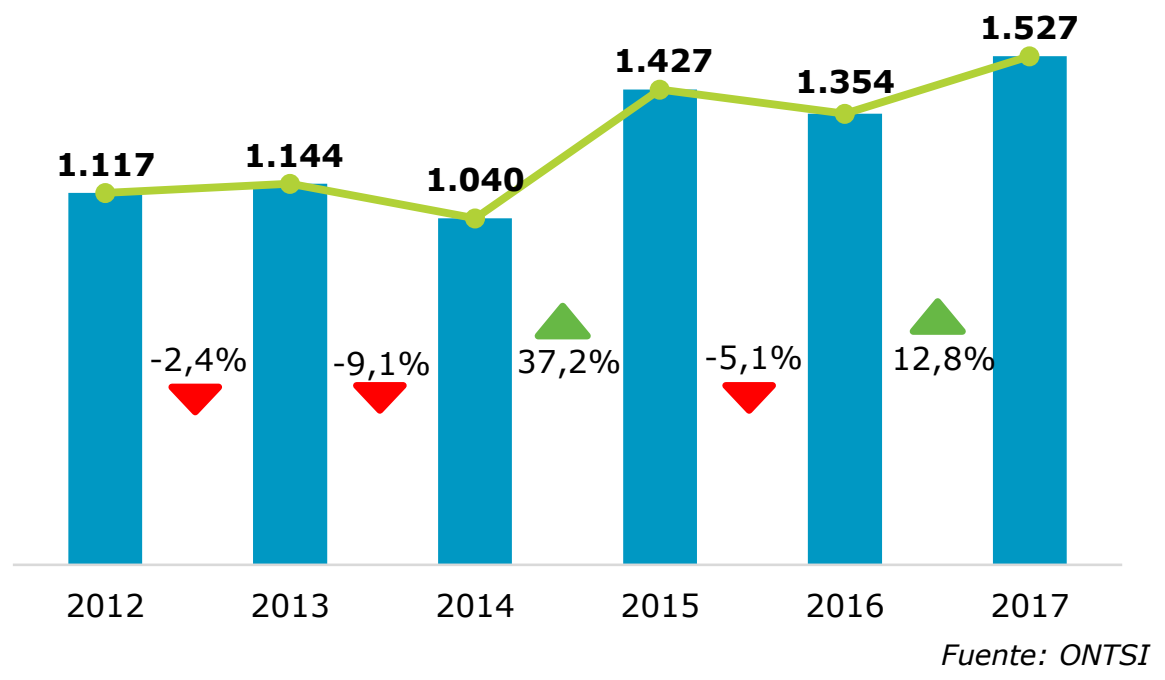

Desglosando la cifra de negocio total de la actividad de producción cinematográfica y de vídeo en función de su tipología de productos 
y servicios asociada, cabe destacar que la prestación de servicios de producción de películas y de vídeos publicitarios abarca la mayor parte de los ingresos de la rama de actividad $(67,2 \%)$. Muy por debajo, aparecen representando en unas proporciones similares otros productos relacionados con la producción cinematográfica y de vídeo $(13,8 \%)$ y la venta de películas cinematográficas $(10,3 \%)$. Los ingresos procedentes de la venta de películas u otros contenidos en soportes físicos tan sólo representan el 5,5\% del total de la cifra de negocio de la rama de actividad. Por su parte, la venta de películas u otros contenidos descargables sólo representa una pequeñísima porción $(2,2 \%)$.

Gráfico 41. Distribución del volumen de facturación por productos de las actividades de producción cinematográfica y de vídeo en España. 2017 (\% sobre la facturación de la rama de actividad)

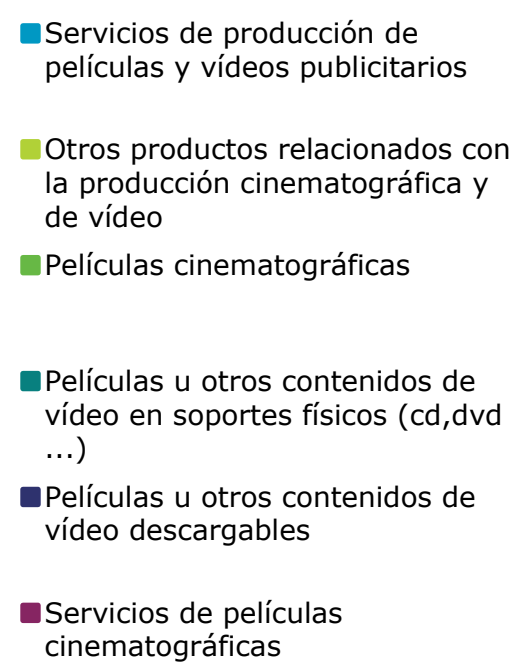

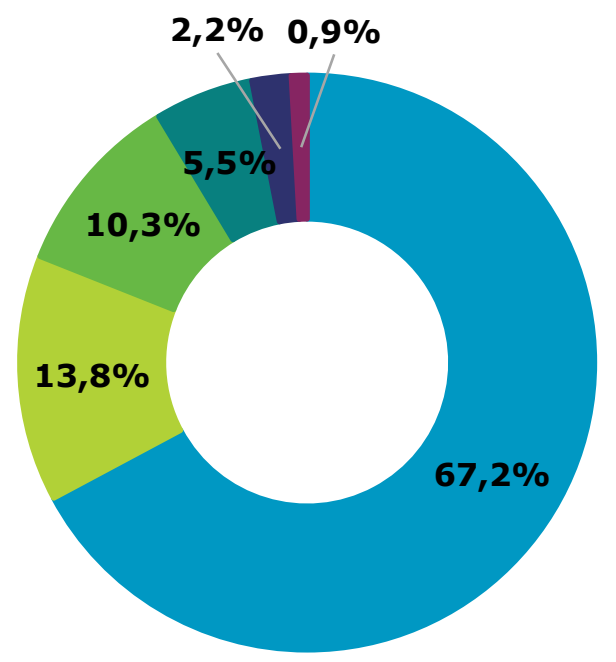

Fuente: ONTSI

En 2017, El número de empleados de la parte de negocio digital de la producción cine y del vídeo crece un $41 \%$, alcanzándose los 5.727 empleados.
Si se tiene en cuenta solamente la parte de los productos relacionados con la venta de películas, el $71,6 \%$ se sigue realizando a través de los medios tradicionales, es decir, en soporte físico (DVD, Blu-ray, etc.), mientras que el $28,4 \%$ se realiza a través de descarga.

De otro lado, se debe señalar que en 2017 el número de empresas de la rama de actividades de producción cinematográfica y de vídeo alcanza una cifra de 1.463 (un 7,7\% más que en 2016).

Igualmente, el personal ocupado de esta rama de actividad aumenta considerablemente con respecto a 2016 (41\%), alcanzando los 5.727 empleos en 2017, por lo que se invierte la tendencia de crecimiento negativo iniciada en 2015.

Por último, la cifra de inversión en negocio digital dentro de la rama producción cinematográfica y de vídeo desciende a los 35 millones 
de euros ( $-12,5 \%$ con respecto al año anterior), representando el $14,9 \%$ de la cifra total de inversión de la rama de actividad.

\subsubsection{Post-producción cinematográfica, de vídeo y de programas de televisión}

\section{CIFRA DE NEGOCIO} DIGITAL

\section{En 2017, la facturación digital del sector Post- producción cinematográfica, de vídeo y de programas de televisión se sitúa en

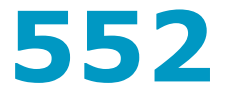

millones de euros
En 2017, la cifra de negocio total de la rama de post-producción cinematográfica alcanza los 859 millones de euros, de los cuales el $64,3 \%$ corresponden a la parte de negocio digital.

Desde 2014 el volumen de negocio digital de esta rama lentamente va recuperándose. Su cifra de negocio lejos está de la alcanzada cinco años atrás. En 2017, el volumen de negocio digital asciende a 552 millones de euros, un 3,5\% más que en 2016.

Gráfico 42. Cifra de negocio digital de la rama de actividad de post-producción cinematográfica, de vídeo y de programas de televisión 2012-2017 (millones de euros)

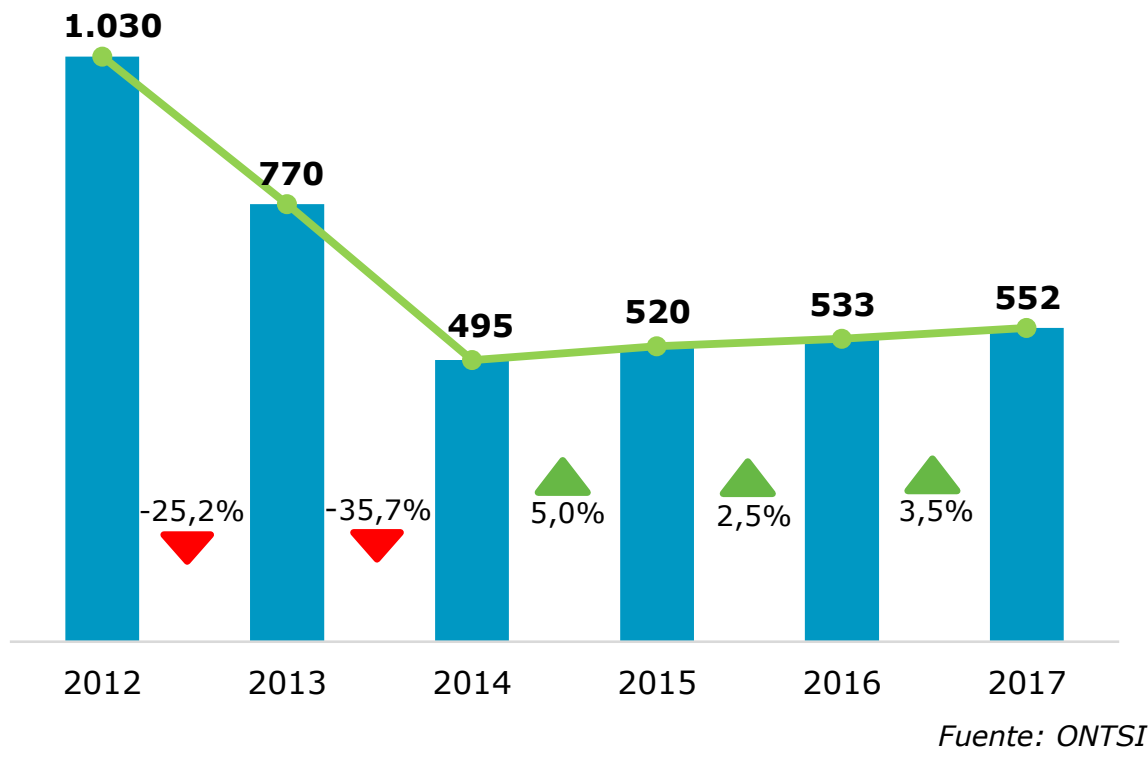

Del total de ingresos de la rama de post-producción cinematográfica, distinguiendo por productos, el 58\% procede de los servicios de montaje audiovisual. Le sigue, representando tan solo un $17 \%$ de los ingresos, los productos clasificados como "otros servicios de post-producción cinematográfica". 
Gráfico 43. Distribución del volumen de facturación por productos de las actividades de post-producción cinematográfica, de vídeo y de programas de televisión en España. 2017 (\% sobre la facturación digital de la rama de actividad)

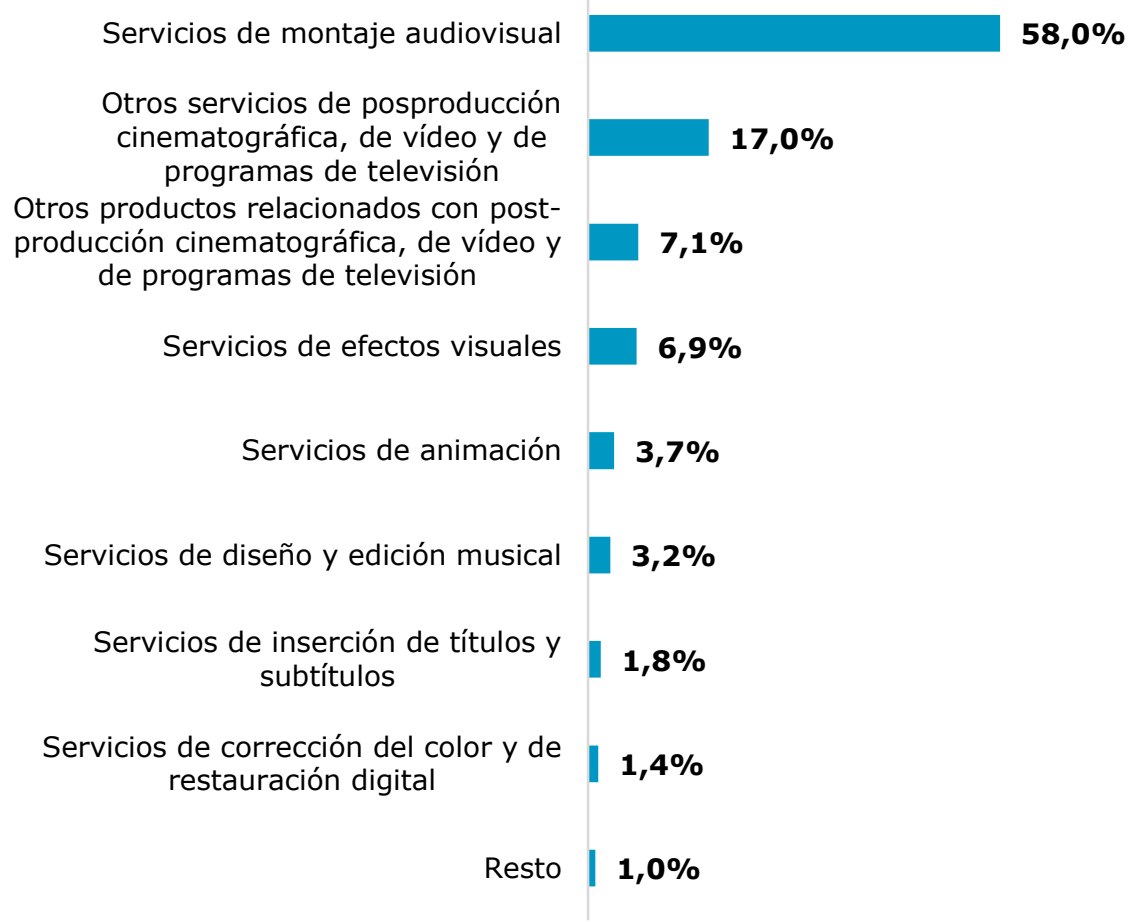

Fuente: ONTSI

Por otra parte, el número de empresas relacionadas con las actividades de post-producción cinematográfica se mantiene desde los últimos cinco años a un ritmo constante, con ligeras variaciones. Desde 2014 viene incrementándose, aunque en magnitudes pequeñas. En 2017, asciende la cifra a 248 empresas (un 4,2\% más que en 2016).

Con respecto al personal ocupado total de esta rama de actividad, se contabilizan en 20171.900 empleados (un 19\% más que en 2016). De este total, el $57 \%$ corresponde al personal ocupado del negocio digital de las actividades de post-producción cinematográfica, con 1.083 empleados, cifra que también crece con respecto a 2016 en un $35,3 \%$.

Finalmente, se debe destacar que la inversión total en el subsector de las actividades de post-producción cinematográfica continúa disminuyendo por sexto año consecutivo habiéndose reducido a la mitad en 2017, alcanzando los 228 millones de euros frente a los 472 del año 2012. Sin embargo, si se tiene en cuenta la inversión correspondiente al negocio digital del subsector, en 2017 llega a representar el $40,2 \%$ de la inversión total. Además, por primera vez desde 2012 la inversión se incrementa hasta alcanzar los 92 millones de euros (un $235,6 \%$ más que en 2016). 


\section{CIFRA DE NEGOCIO DIGITAL}

La cifra de negocio

digital de la Exhibición cinematográfica

desciende a los

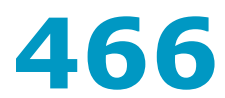

millones de euros en 2017

\subsubsection{Exhibición cinematográfica}

En lo que se refiere al volumen de ingresos totales, el subsector de actividad de la exhibición cinematográfica no ha experimentado grandes cambios desde los últimos tres años, manteniéndose las cifras de negocio relativamente constantes. En 2017, los ingresos totales se incrementan en un $0,8 \%$ con respecto al año anterior, alcanzándose los 632 millones de euros, de los cuales el 73,7\% corresponden a la parte de negocio digital.

Hasta 2016, los ingresos del negocio digital de este subsector venían creciendo a un ritmo anual en promedio del $16,1 \%$. Sin embargo, por primera vez, la cifra de negocio digital desciende a los 466 millones de euros $(-6,2 \%$ con respecto a 2016).

Gráfico 44. Cifra de negocio digital de la rama de actividad de exhibición cinematográfica, 2012-2017 (millones de euros)

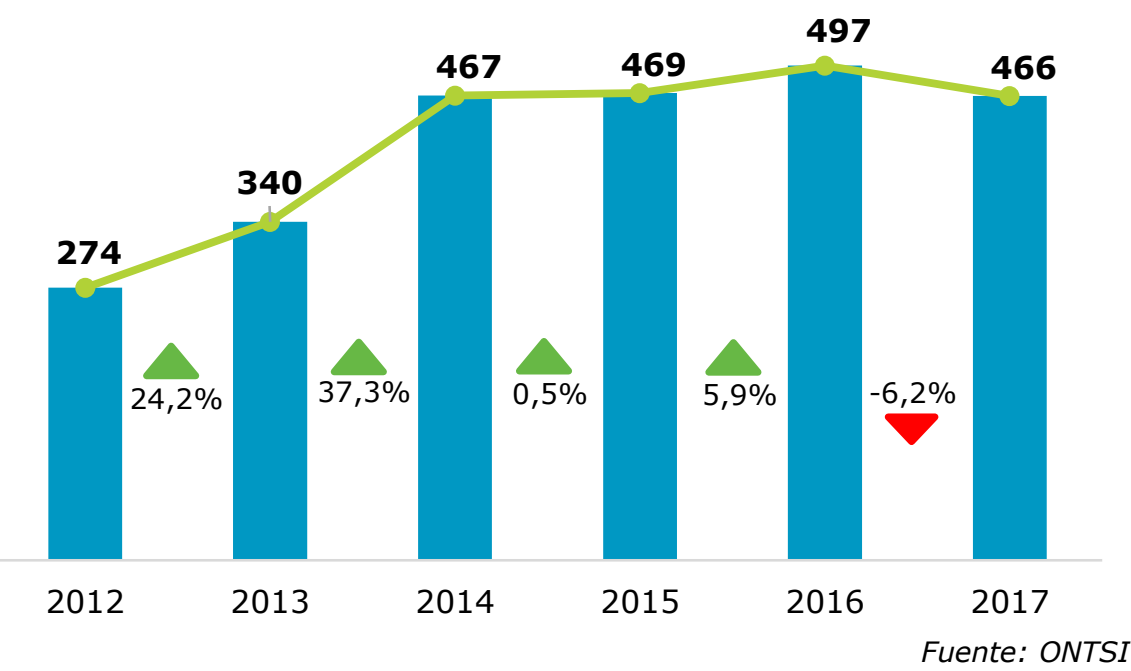

Volviendo a la cifra de negocio total de la rama de las actividades de exhibición cinematográfica, en este caso, diferenciando en función de los productos asociados a dicha rama, cabe señalar que el $67,2 \%$ de la cifra de negocio total procede de los servicios de exibición de películas, y el 32,8\% restante de los ingresos proviene de otros productos relacionados con la exhibición cinematográfica. 
Gráfico 45. Distribución del volumen de facturación de las actividades de exhibiciones cinematográficas por productos en España. 2017 (\% sobre la facturación total de la rama de actividad)

Servicios de exhibición de películas

Otros productos relacionados con la exhibición cinematográfica

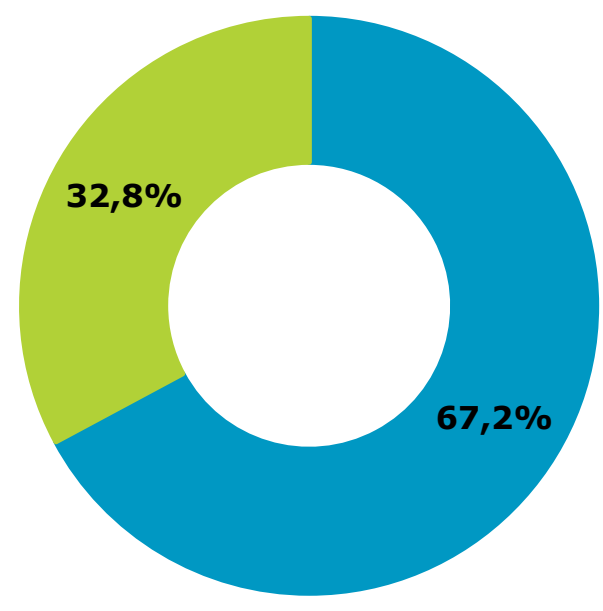

Fuente: ONTSI

En otro orden de cuestiones, el subsector de las actividades relacionadas con la exhibición cinematográfica registra un total de 453 empresas en el año 2017.

Por otra parte, con respecto al número de empleados totales del subsector, la cifra asciende en 2017 a las 6.874 personas ocupadas, de las cuales, tres cuartas partes $(75,2 \%)$ corresponden a la parte de negocio digital de las empresas del subsector ( 5.168 empleados, lo que significa un ligerísimo incremento con respecto a 2016, concretamente del $0,7 \%$ ).

De otro lado, la inversión total de las empresas del subsector de la exhibición cinematográfica registrada en 2017 desciende a los 247 millones de euros $(-4,6 \%$ menos con respecto a 2016), de los cuales el $32,8 \%$ corresponden a la parte de negocio digital ( 81 millones de euros).

Para finalizar este subapartado relativo a la rama de actividad exhibición cinematográfica, se ofrecen los datos que proporciona la

En 2018, el

$98,6 \%$ de

las salas de cine

en España

cuentan con

proyector

digital.
Asociación para la Investigación de Medios de Comunicación (AIMC), a través de su Censo de Salas de Cine, relativos a la evolución de la digitalización de las salas de cine. Ya a mediados de 2018, el 98,6\% de las salas de cine en España cuentan con proyector digital. De seguir así la tendencia, en pocos años se habrá completado el proceso de digitalización de las salas de cine.

Si bien el número de salas digitalizadas continúa creciendo, alcanzando una cifra de 3.469 en 2018 (un 1,2\% más con respecto a 2017), el total de salas de cine sigue descendiendo (3.518 en 2018) con una tasa de crecimiento compuesto agregado del $-1,2 \%$ 
para el periodo 2009-2018. Con respecto al número de salas preparadas para la proyección de películas en 3D, por primera vez desde 2009, se invierte la tendencia ascendente (946 salas en 2018 , es decir, un descenso del $-1,4 \%$ con respecto a las registradas en el año anterior.

Gráfico 46. Número de salas digitales en España. 2009 - 2018

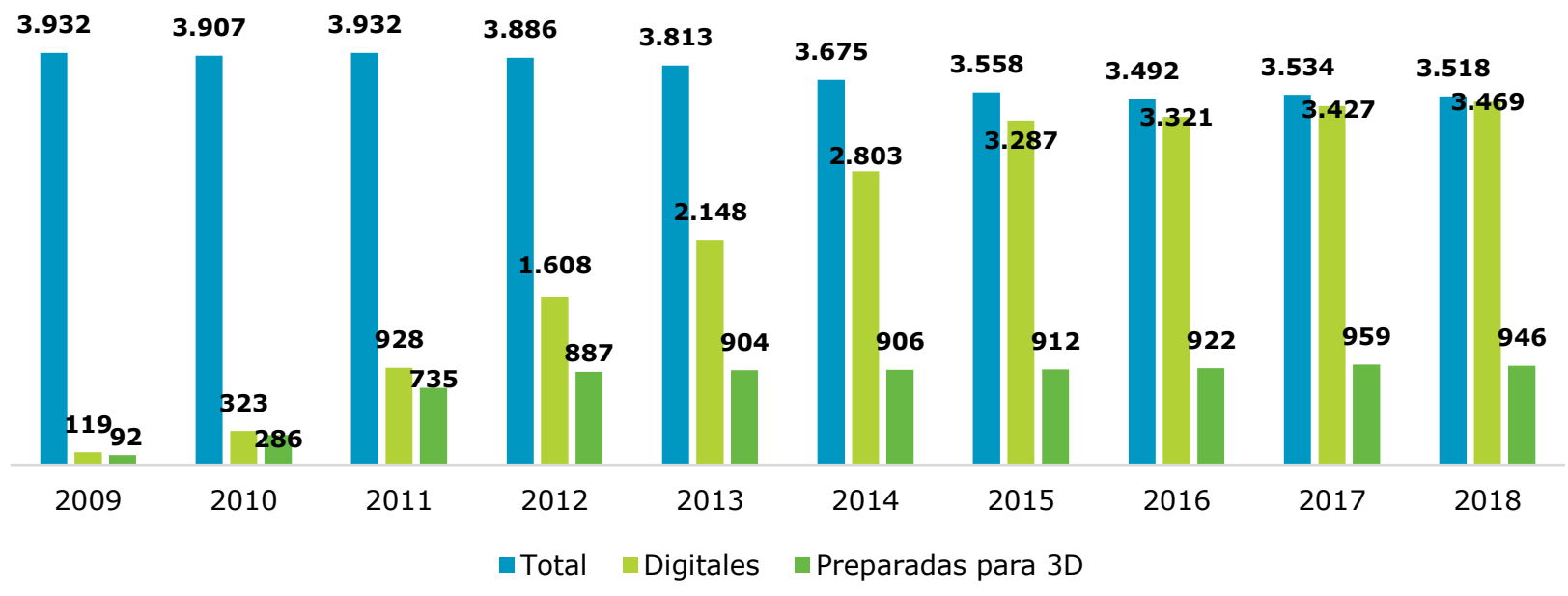

Fuente: AIMC, 2018. Datos de 2018 referidos al mes de abril

\section{CIFRA DE NEGOCIO} DIGITAL

\section{En 2017, la facturación}

digital de la rama de

Producción de

programas de TV

asciende a los

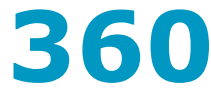

millones de euros

\subsubsection{Producción de programas de televisión}

En 2017, el volumen total de ingresos que registró el subsector relacionado con las actividades de producción de programas de televisión fue de 711 millones de euros (un 1,3\% de incremento con respecto al año anterior) creciendo por quinto año consecutivo. De esta cifra de negocio total, más de la mitad $(50,6 \%)$ corresponde a la parte de negocio digital, lo que se traduce en 360 millones de euros (un $13,9 \%$ más que en 2016 ).

Gráfico 47. Cifra de negocio digital de la rama de actividad de producción de programas de televisión, 2012-2017 (millones de euros)

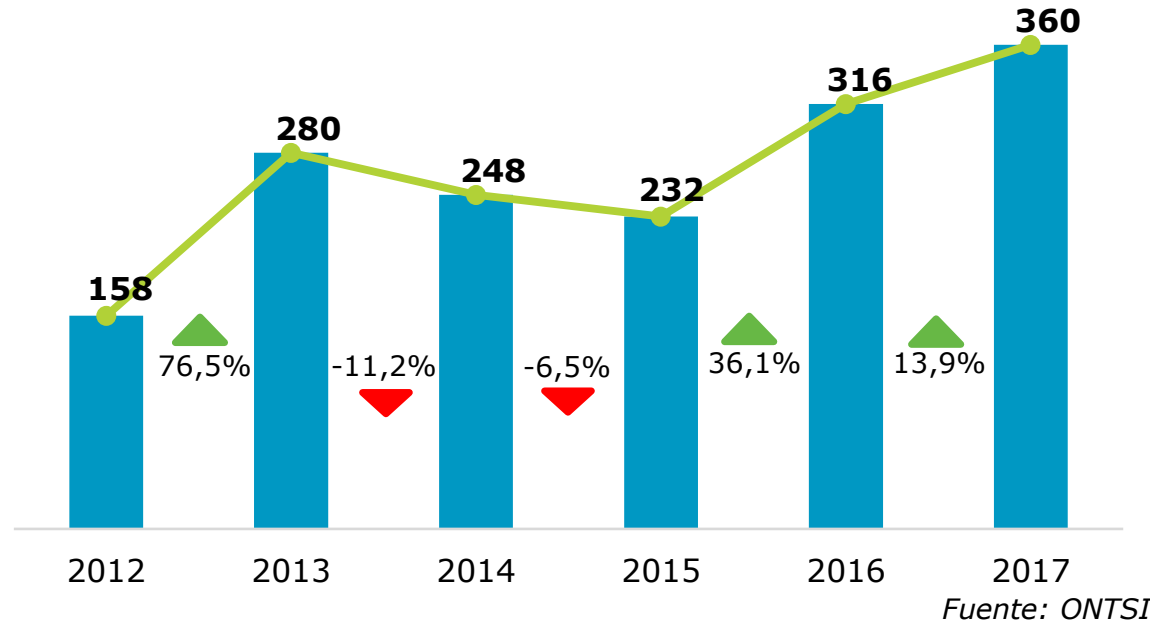


Más de la mitad de la facturación total del subsector se origina en los servicios de producción de otros programas de televisión

Distinguiendo por la tipología de productos asociada a las actividades de producción de programas de televisión, más de la mitad de la facturación total del subsector se origina en los servicios de producción de otros programas de televisión (54,3\%). Le sigue en volumen de negocio los originales de programas de televisión $(35 \%)$; y en una proporción bastante menor las ventas de espacio o tiempo publicitario en productos de cine, vídeo y televisión $(8,5 \%)$. El $2,1 \%$ restante de la cifra de negocio de este subsector procede de otros productos relacionados con la producción de programas de televisión.

Gráfico 48. Distribución del volumen de facturación por productos de las actividades de producción de programas de televisión en España, 2017 (\% sobre la facturación de la rama de actividad)

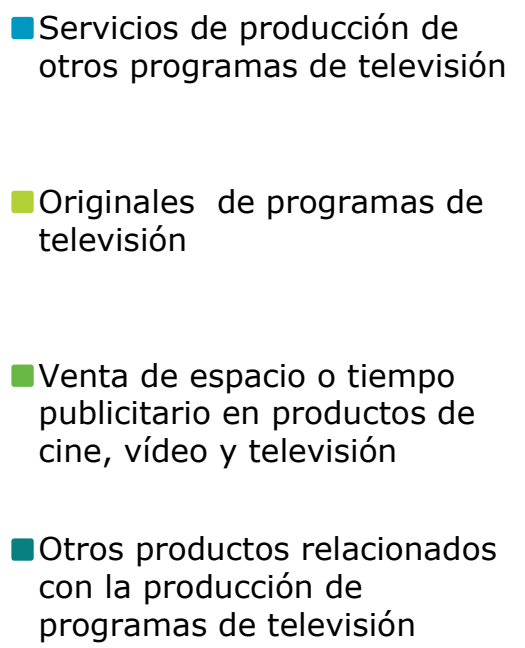

Servicios de producción de otros programas de televisión programas de televisión

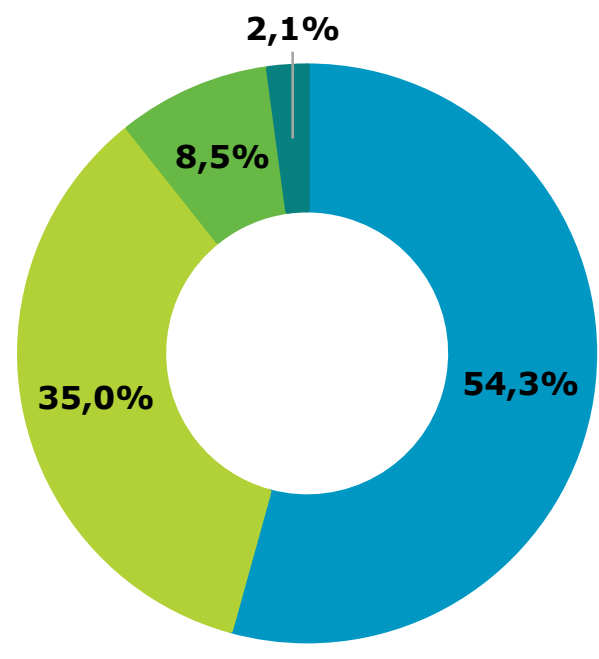

Fuente: ONTSI

Por otra parte, el número de empresas registrado en 2017 asciende a las 409, cifra que no volvía a registrarse desde el año 2014.

Igualmente, este subsector, en lo que se refiere al empleo total, registra unas cifras más que favorables. En 2017, se contabilizaron 8.987 empleos (un $10,4 \%$ más que en 2016). Del total de puestos de trabajo registrados, el $63,4 \%$ corresponde a la parte de negocio digital (5.695 empleos, un 9,7\% más que en 2016).

Finalmente, la inversión total realizada por parte de las empresas que pertenecen a esta rama de actividad cayó a los 37 millones de euros $(-31,3 \%$ menos que en 2016$)$. Solo un $8,3 \%$ de la inversión total corresponde a la parte de negocio digital ( 3 millones de euros). 


\section{CIFRA DE NEGOCIO DIGITAL}

En 2017, la facturación digital de la

distribución

cinematográfica y de video asciende a los

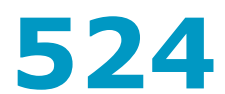

millones de euros

\subsubsection{Distribución cinematográfica y de vídeo}

En 2017, la rama de actividad relacionada con la distribución cinematográfica y de vídeo en España registra un volumen de facturación total que se mantiene por segundo año consecutivo en los 696 millones de euros, de los cuales el 75,2\% se corresponde con la parte de negocio digital (524 millones de euros).

Como puede comprobarse en la siguiente gráfica, el volumen de negocio digital de las empresas de distribución cinematográfica desde 2012 ha seguido una tendencia bastante irregular: en 2015, se produce un desplome de los ingresos siendo la tasa de crecimiento en dicho año del $-60,6 \%$. Sin embargo, en el último ejercicio se produce un crecimiento del $145,4 \%$, alcanzándose el mayor volumen de ingresos por parte del negocio digital de los últimos cinco años.

Gráfico 49. Cifra de negocio digital de la rama de actividad de distribución cinematográfica y de vídeo, 2012-2017 (millones de euros)

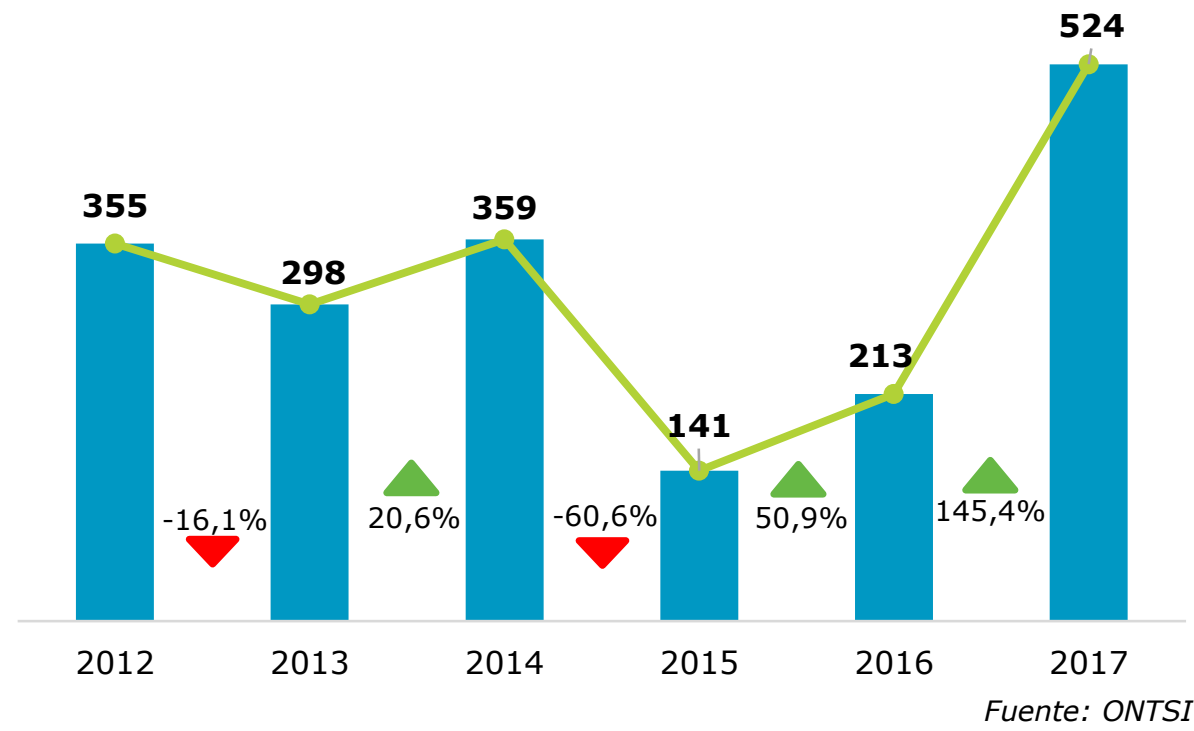

Distinguiendo por productos, de los 696 millones de euros de ingresos totales registrados por este subsector en 2017, casi el 68\% procede de los servicios de cesión de los derechos de las películas y de sus ingresos. Muy lejos de esta, ocupa la segunda posición otros servicios de distribución de programas de cine o vídeo $(13,8 \%)$; mientras que en tercera posición aparece la distribución de $\mathrm{VoD}$, que representa solamente un $6,3 \%$ de los ingresos totales de la rama de actividad. Por su parte, los ingresos por parte del streaming de películas y programas de TV sólo representan un 5,6\% de la facturación total del subsector. 
Gráfico 50. Distribución del volumen de facturación por productos de las actividades de distribución cinematográfica y de vídeo en España. 2017 (\% sobre la facturación total de la rama de actividad)

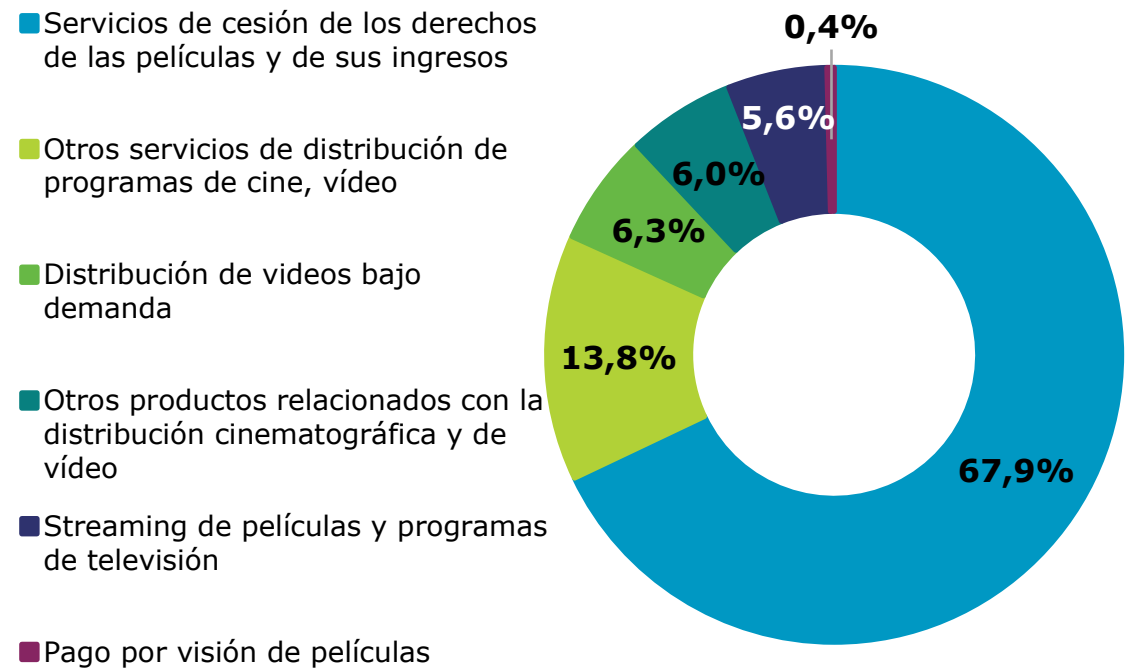

Fuente: ONTSI

En 2017, el $51,2 \%$ de los ingresos procedentes de la venta de productos de cine y vídeo a través de medios digitales procede de la distribución de VoD
Si se tiene en cuenta únicamente el total de ingresos procedentes de la venta de productos de cine y vídeo a través de medios digitales, en 2017 más de la mitad procede de la distribución de vídeos bajo demanda $(51,2 \%)$; el $45,6 \%$ procede de la distribución mediante streaming de películas y programas de TV. El 3,2\% restante corresponde al pago por visión de películas.

Por otro lado, con respecto al total de empresas dedicadas a la distribución cinematográfica y de vídeo en España se registra una cifra en 2017 de 203 empresas.

En lo que se refiere a las cifras de empleo, en 2017 este subsector registra un total de 1.085 empleados (un $8,1 \%$ más que en 2016). El $40,4 \%$ del total corresponde a la parte de negocio digital, con 439 empleados registrados, un 31,6\% más que en 2016.

Finalmente, se debe señalar que las empresas dedicadas a la distribución cinematográfica y de vídeo registran una cifra de inversión total de 120 millones de euros con una tasa de crecimiento con respecto al ejercicio del año anterior de $6,9 \%$. Solo un $23,5 \%$ de la inversión total se dedica a la parte de negocio digital (28 millones de euros ( 7 millones menos que en 2016). 


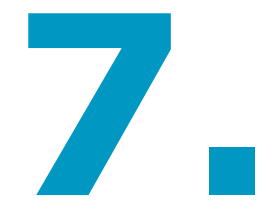

\section{EL SECTOR AUDIOVISUAL}
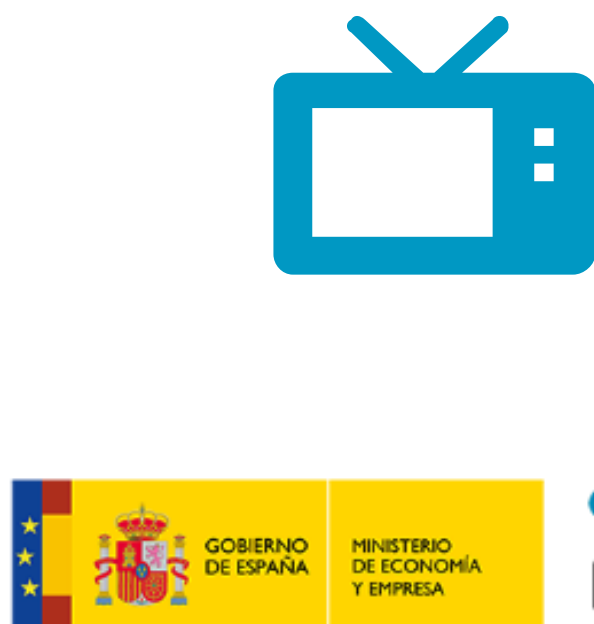

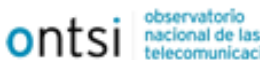

red.es 


\section{En 2017, el $85,6 \%$ de los hogares del mundo dispone de TV digital}

\section{El Sector Audiovisual}

\subsection{El mercado global audiovisual}

A continuación, se presentan los principales resultados relativos a la evolución del sector audiovisual, más concretamente, del sector de la televisión, con respecto a su nivel de digitalización y sus volúmenes de negocio en el mundo.

El sector audiovisual es uno de los más afectados por la transformación digital derivada del uso del canal Internet para el acceso a los contenidos. De este modo, se han multiplicado los soportes y los canales de acceso que permiten la reproducción automática en cualquier lugar y momento, y se ha multiplicado la oferta incrementando su disponibilidad adaptándose a las necesidades de los usuarios.

En la actualidad 1.639 millones de hogares en el mundo cuentan con algún tipo de televisor, representando el $82,3 \%$ sobre el total de hogares en el mundo. Las proyecciones estimadas de cara a los próximos años indican un ligero incremento de esta tipología de dispositivo en los hogares, siendo la tasa de crecimiento medio estimada para el período 2017-2021 de 1,2\%.

En 20171.402 millones de hogares a nivel mundial ya disponen de TV digital, lo que supone un $85,6 \%$ del total de hogares con televisión en el mundo. Las estimaciones calculadas por IDATE para los próximos cuatro años reflejan la progresiva desaparición de la televisión analógica en los hogares; la cifra proyectada para el año 2021 es 70 millones de hogares, representando tan sólo el 4,1\% de los hogares.

Gráfico 51. Evolución de la digitalización de la televisión en el mundo (millones de hogares)

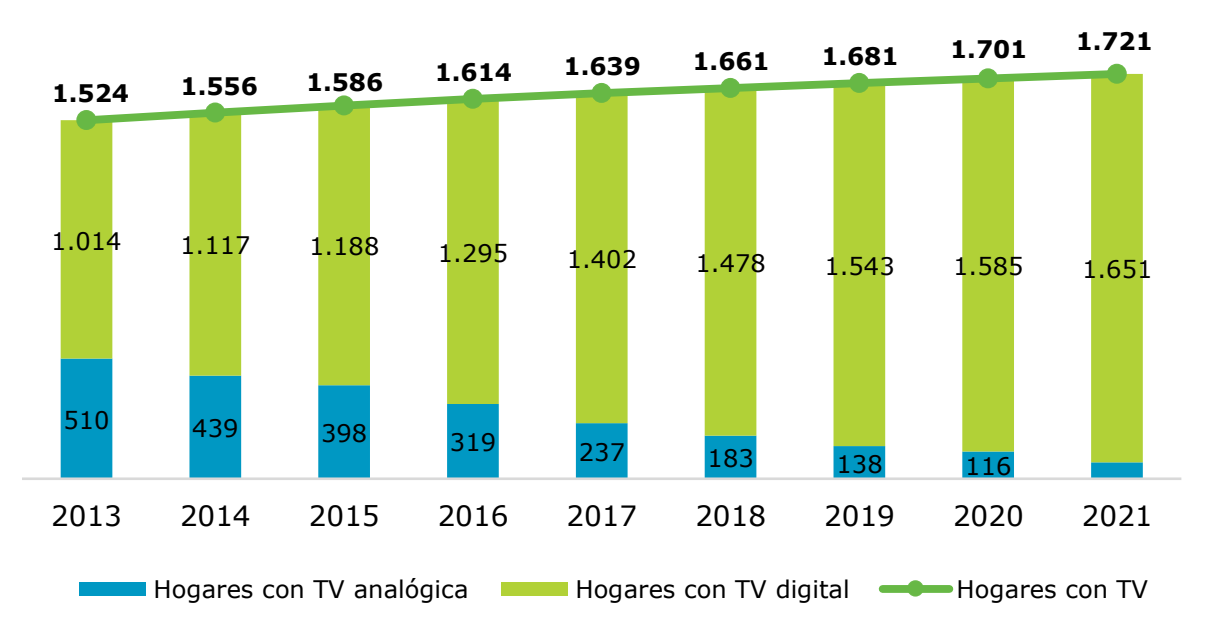

Fuente: IDATE, 2017a 
En 2017, el

$63,8 \%$ de los

hogares del mundo

dispone de

suscripciones a

TV de pago
Con respecto a la modalidad de acceso a los contenidos televisivos el número de hogares con solo TV en abierto desciende cada año, aunque muy ligeramente, evidenciando que cada vez son más los hogares que apuestan por la TV de pago. El número de hogares con suscripciones a TV de pago, desde 2013, supera al número de hogares con TV en abierto, alcanzando el $63,8 \%$ en 2017 . Se estima que en 2021 el $66,8 \%$ de los hogares dispondrá de TV de pago.

Gráfico 52. Evolución de los hogares con televisión en el mundo según modalidad de acceso a contenidos televisivos (millones de hogares)

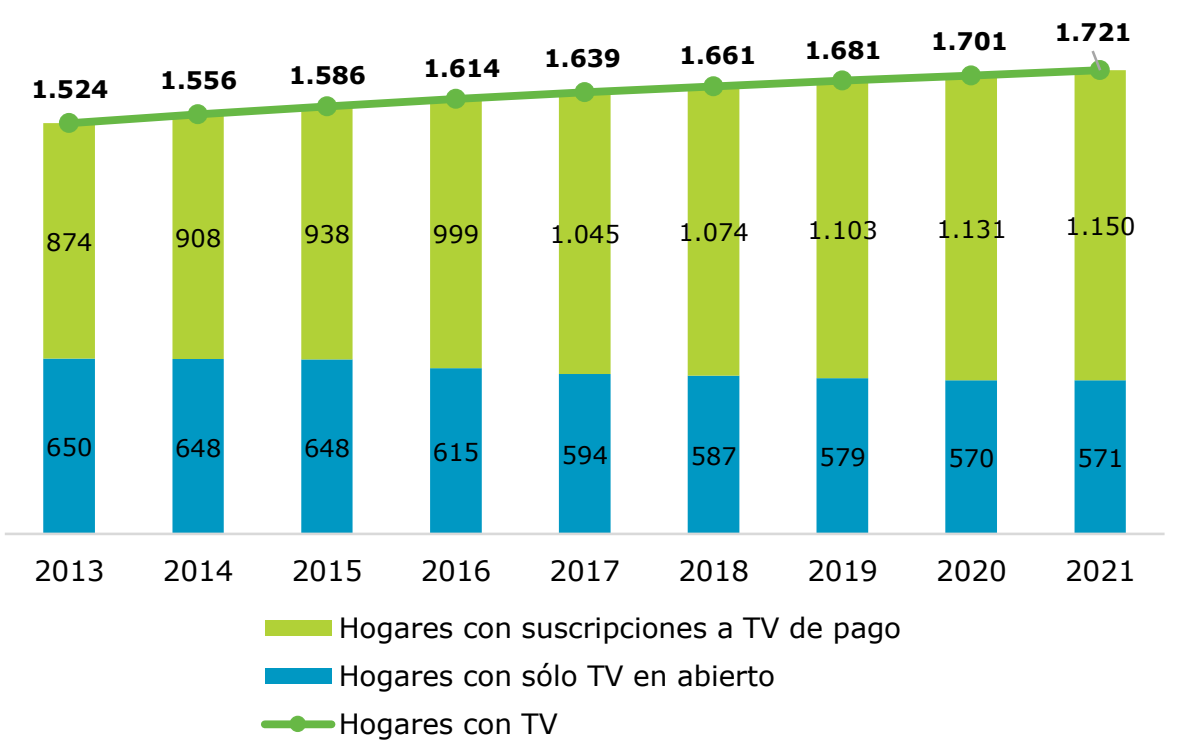

Fuente: IDATE, 2017a

Comparando entre las distintas regiones geográficas, Norteamérica destaca por ser la región donde mayor penetración existe de la televisión de pago, a pesar de la tendencia decreciente que viene experimentando desde 2014. Así, mientras que en 2013 el 86\% de los hogares contaba con suscripción a TV de pago, en 2017 el porcentaje de hogares que tienen contratado servicios de este tipo de TV ha caído al 78\%. Además, las proyecciones de IDATE indican que dentro de cinco años el porcentaje siga cayendo hasta el $70 \%$ para el continente norteamericano.

Por el contrario, la penetración de la televisión de pago en el resto de las regiones del mundo sigue una tendencia al alza. En 2017, el $66 \%$ de los hogares europeos cuenta con suscripciones a TV de pago; le siguen en importancia la región de Asia Pacífico (60\%), Latinoamérica (39\%) y, en último lugar, Oriente Medio y África (10\%). Igualmente, para estas cuatro regiones, las previsiones de IDATE son favorables en cuanto al incremento de las suscripciones de TV de pago en los hogares. 
Gráfico 53. Penetración de los servicios de suscripción a televisión de pago en las principales regiones $(\%$ de hogares)

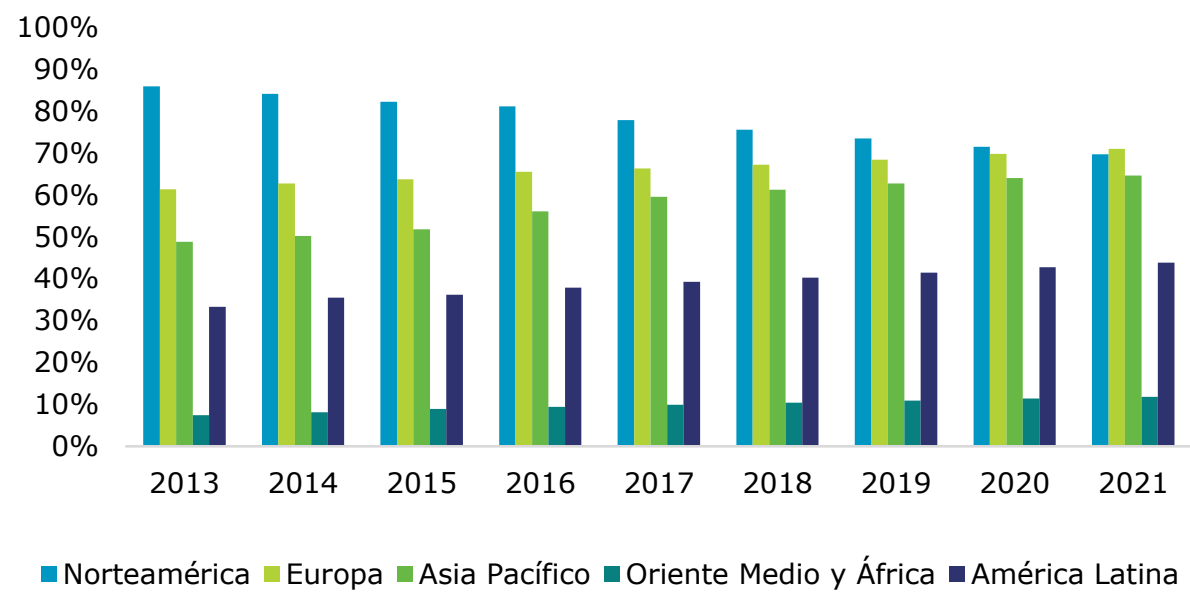

Continúa disminuyendo la presencia de la TV terrestre en los hogares del mundo, en favor de la TV por satélite o por cable
Fuente: IDATE, 2017a

De otro lado, la evolución de las diferentes redes de transmisión utilizadas por los hogares se mantiene constante. El número de hogares que disponen de TV por satélite, TV por cable y IPTV aumentan paulatinamente cada año, representando en 2017 un $29,9 \%, 35,4 \%$ y $12,6 \%$ respectivamente en relación con el total de hogares con TV. Al contrario, los hogares con TV terrestre disminuyen ligeramente su presencia mundial $(22,4 \%$ sobre el total de hogares con TV) en favor del resto de tecnologías mencionadas como, por ejemplo, la TV por satélite, de fácil instalación en regiones con dificultades geográficas a la hora de desplegar físicamente las nuevas redes de cable o fibra. Según las estimaciones calculadas por IDATE para el período 2017-2021 el mayor incremento proporcional lo experimentarán las tecnologías IPTV, siendo la tasa de crecimiento anual en promedio del $10 \%$.

Gráfico 54. Evolución del número de hogares por red de transmisión de la televisión a nivel mundial (millones de hogares)

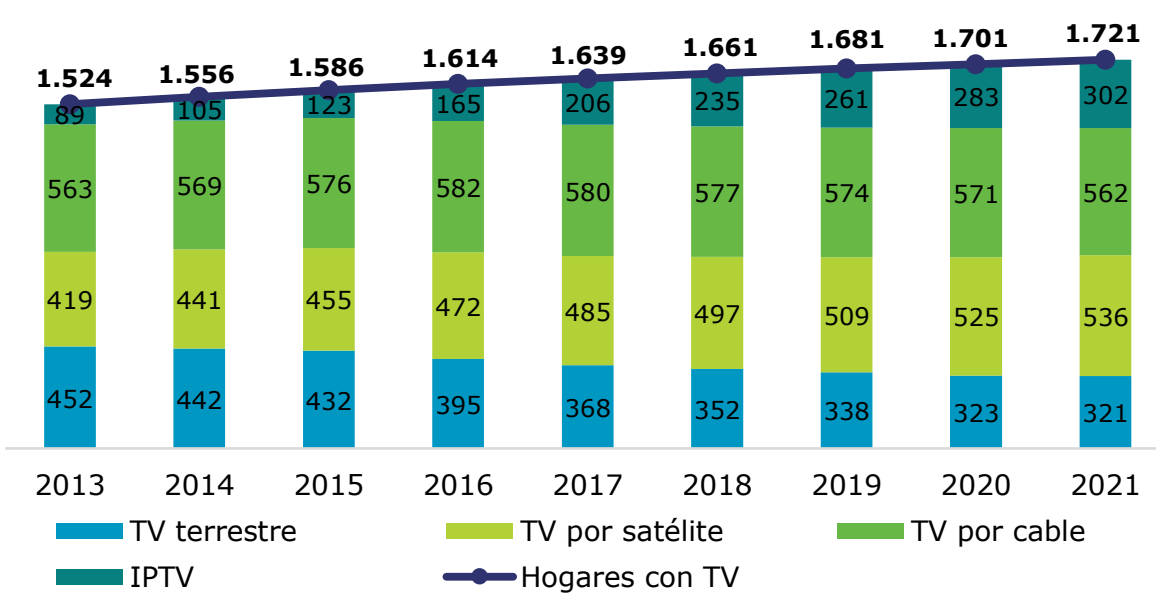

Fuente: IDATE, $2017 a$ 
El volumen de ingresos del

sector

audiovisual en el

mundo en el año

2017 asciende a

los 409 miles de

millones de

euros
En lo que se refiere a la evolución de los ingresos generados por el sector de la televisión en el mundo, se ha producido un ligero incremento durante el período 2013-2017. El volumen de ingresos en el año 2017 asciende a los 409 miles de millones de euros (un $1,9 \%$ más que durante el año anterior).

Diferenciando por regiones geográficas, Norteamérica se posiciona en primera posición generando los mayores ingresos, con un total de 158,4 miles de millones de euros. No obstante, se espera que durante los próximos años (2017-2021) experimente un retroceso de $-1,2 \%$. Asia Pacífico y Europa ingresan prácticamente lo mismo durante 2017, 101,9 y 102,8 miles de millones de euros respectivamente. Se espera que durante los próximos años ambas regiones geográficas crezcan ligeramente. América Latina y Oriente Medio y África obtienen unos ingresos televisivos muy por debajo del resto de las regiones mencionadas. En cambio, se estiman crecimientos más altos en los próximos años en estas dos regiones.

En términos relativos a la realidad demográfica de las principales regiones del mundo, igualmente Norteamérica genera el mayor volumen de ingresos per cápita, superando los 400 millones de euros durante el período 2013-2017. Muy lejos se encuentra Europa con 122 millones de euros per cápita para el año 2017.

Por otra parte, la digitalización ha permitido la consolidación de diferentes modalidades de ingreso (televisión en abierto con publicidad, subvenciones públicas y televisión de pago) que combinadas con un modelo de prestación de servicios (transmisión terrestre, satélite, cable e IPTV) generan un modelo de negocio.

En cuanto a la evolución de las cifras de negocio del sector audiovisual, los ingresos en el año 2017 han aumentado, un año más, hasta los 409 miles de millones de euros. Los proveedores de servicios audiovisuales obtienen sus principales ingresos a través de las siguientes vías:

- La publicidad, que supone el $42,3 \%$ de los ingresos de la televisión mundial en el año 2017 con una cifra total de 172,8 miles de millones de euros, un $1 \%$ más que en 2016 . Se espera que en los próximos años los ingresos procedentes de la publicidad continúen creciendo hasta llegar en 2021 a los 184,5 miles de millones de euros.

- Las subvenciones públicas, que representan el $9,1 \%$ del volumen de negocio de la televisión mundial en el año 2017 aportando un total de 37,4 miles de millones de euros, un $1,4 \%$ más que en 2016 . Las estimaciones calculadas por IDATE indican que en los próximos años los ingresos provenientes de las subvenciones públicas se incrementen hasta llegar a los 39,1 miles de millones de euros en 2021. 


\section{Las suscripciones de pago representan casi la mitad de los ingresos de la TV en el mundo en} 2017
- Las suscripciones de pago, que representan casi la mitad de los ingresos de la televisión en el mundo $(48,6 \%)$ de la televisión mundial en el año 2017 alcanzando un total de 198,5 miles de millones de euros, un 2,9\% más que en 2016. Se estima que en los próximos cuatro años los ingresos procedentes de las suscripciones de pago continúen creciendo hasta los 213,4 miles de millones de euros en 2021.

Gráfico 55. Evolución de los ingresos por modelo de negocio ligados a la televisión en el mundo (miles de millones de euros)

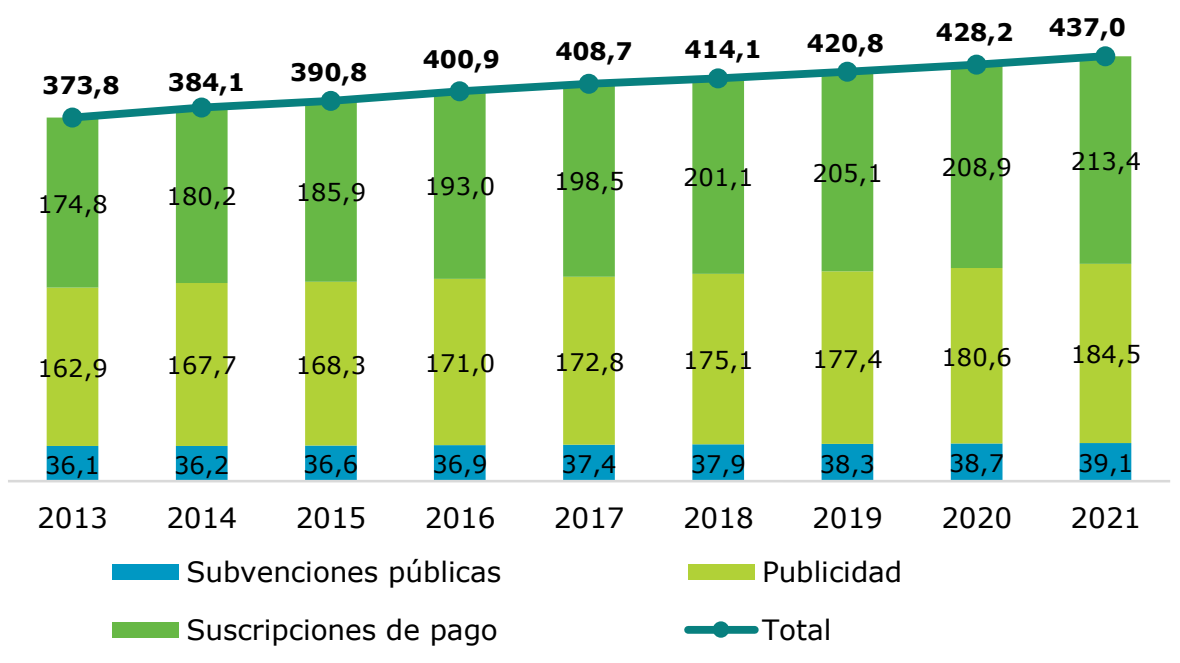

Fuente: IDATE, $2017 a$

Distinguiendo entre las principales regiones geográficas del mundo, la fotografía resultante es diferente en cuanto al peso proporcional que tienen los ingresos en función de su procedencia. De este modo, cabe destacar que en Europa el $26 \%$ de los ingresos de la televisión proceden de subvenciones públicas en el año 2017. Por el contrario, en el resto de las regiones, esta modalidad de ingresos apenas representa un 1\% (con la excepción de Asia Pacífico donde tan sólo alcanza un $9 \%$ ).

Norteamérica es la región donde mayor peso proporcional tienen los ingresos procedentes de las suscripciones de pago, representando el $59 \%$ del total. Le siguen Oriente Medio y África (58\%) y América Latina (52\%). Asia Pacífico es la región en la que la principal fuente generadora de ingresos televisivos es la publicidad, representando más de la mitad de los ingresos (52\%). 
Gráfico 56. Porcentaje de ingresos según modalidad con respecto al total en las principales regiones geográficas (porcentaje)

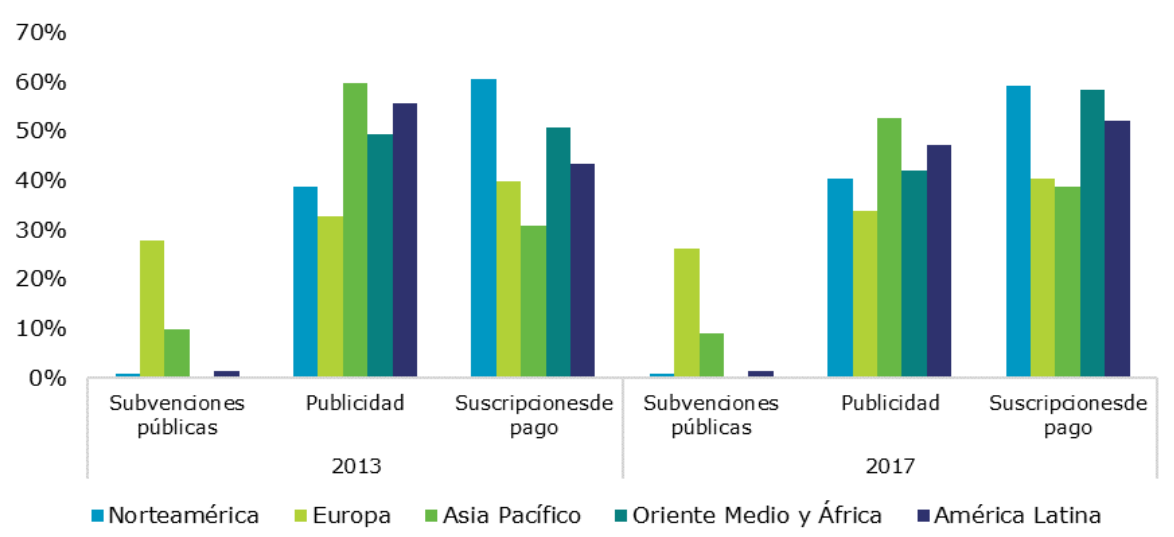

Fuente: Elaboración propia a partir de datos de IDATE

\subsection{El sector audiovisual en España}

\subsubsection{Cifra de negocio del sector audiovisual}

\section{CIFRA DE NEGOCIO}

La facturación de las actividades de programación y emisión de televisión se sitúa en

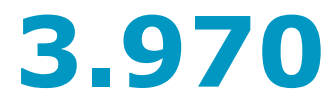

millones de euros en 2017
El volumen de ingresos procedente del sector de la televisión en España prosigue una evolución favorable iniciada en el año 2013. En 2017, se alcanza el máximo desde 2011, con una cifra de negocio de 3.970 millones de euros (un $7,7 \%$ más con respecto a los ingresos registrados el año anterior) ${ }^{9}$.

Diferenciando los ingresos en función de las diferentes modalidades de transmisión, la televisión terrestre continúa abarcando la mayor parte de la cifra de negocio del sector, si bien hasta 2016 abarcaba más de la mitad del volumen de negocio, en la actualidad pierde peso con respecto a otras modalidades en auge como la TV IP. La televisión terrestre representa en 2017 el 46,2\% de los ingresos (1.836 millones de euros, creciendo por cuarto año consecutivo).

Por su parte, el volumen de negocio de la TV IP crece a pasos agigantados a partir de 2014. En 2017, esta modalidad ya representa un $32,7 \%$ de los ingresos totales del sector de la televisión, con una cifra de 1.298 millones de euros (un 25,6\% más que el año anterior).

La televisión por satélite, por el contrario, continúa perdiendo volumen de negocio año tras año desde 2011, representando en 2017 solo un $13,2 \%$ de la cuota de mercado del sector de la televisión, siendo su cifra de negocio de 525 millones de euros. La tasa de crecimiento agregado para el período 2011-2017 de esta modalidad se sitúa en un $-8,9 \%$ anual.

\footnotetext{
${ }^{9}$ Los datos referidos a la cifra de negocio del sector audiovisual en España proceden de la Comisión Nacional de los Mercados y la Competencia (CNMC) estimados a partir de sus informes trimestrales.
} 
La televisión por cable mantiene una tendencia más o menos estable en cuanto a volumen de ingresos. Se pueden distinguir dos etapas para esta modalidad: la primera, desde 2011 hasta 2014, en la que descienden año a año sus ingresos a un ritmo pausado; y la segunda, desde 2015 hasta la actualidad en la que se revierte la tendencia, alcanzando en 2017 los 276 millones de euros y representando el $7 \%$ de los ingresos totales del sector de la televisión.

Otras modalidades de transmisión como la televisión online o la televisión móvil apenas llegan a representar el $1 \%$ en su conjunto del total de los ingresos del sector de la televisión.

Gráfico 57. Ingresos de la televisión por medio de transmisión. Evolución 2011-2017 (Millones de euros)

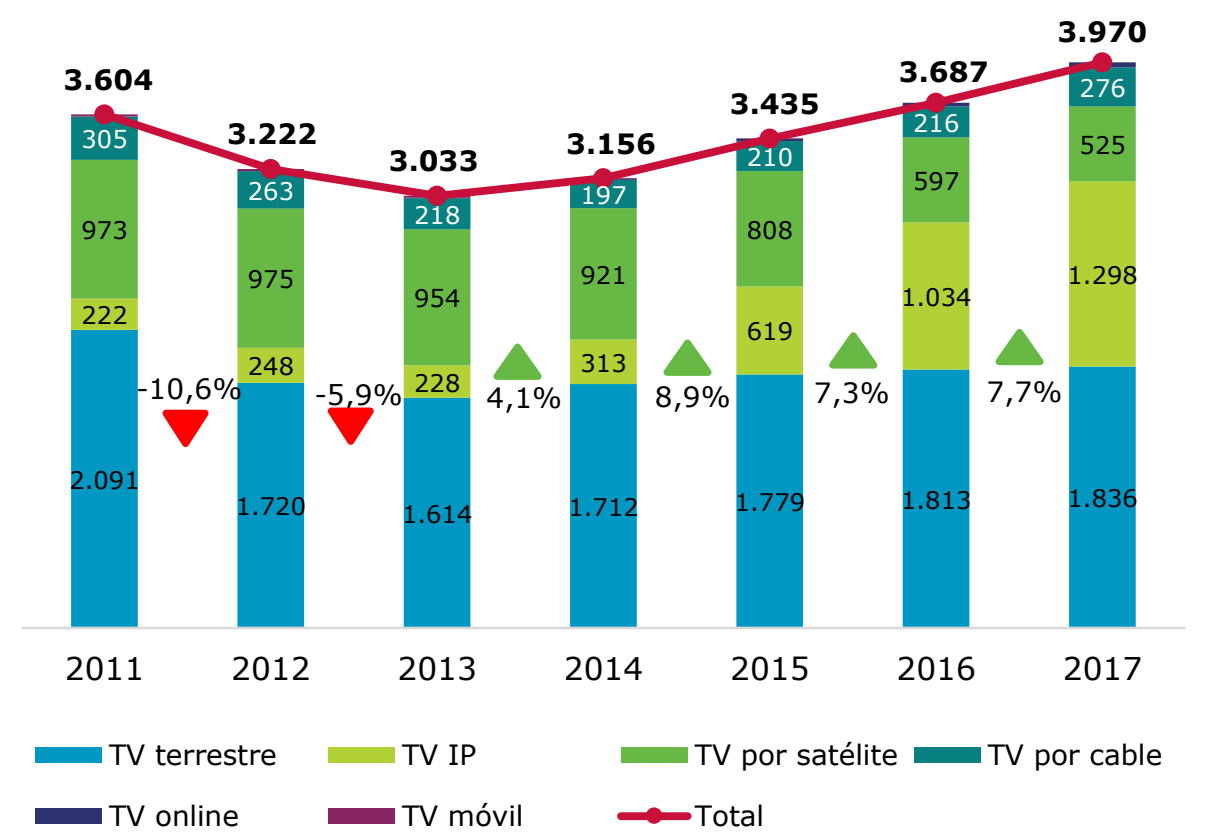

Fuente: CNMC, 2018 (datos estimados a partir de informes trimestrales)

Tomando en consideración solamente los ingresos generados por la televisión de pago, a partir de 2014 se invierte la tendencia negativa que se venía experimentando. En 2017, la cifra de negocio de la televisión de pago alcanza los 2.134 millones de euros (un 13,9\% más que en el año 2016, representando el mayor incremento de los últimos cuatro años). Además, cabe destacar el voluminoso incremento de la cifra de negocio que ha experimentado la TV IP a partir de 2015. Hasta entonces, más de la mitad de la cuota de mercado correspondía a la televisión por satélite, mientras que ya en 2017 representa la cuarta parte del total de ingresos de la televisión de pago. En la actualidad, la TV IP representa el $61 \%$ de los ingresos de la televisión de pago. 
Gráfico 58. Ingresos de la televisión de pago por medio de transmisión. Evolución 2011-2017 (Millones de euros)

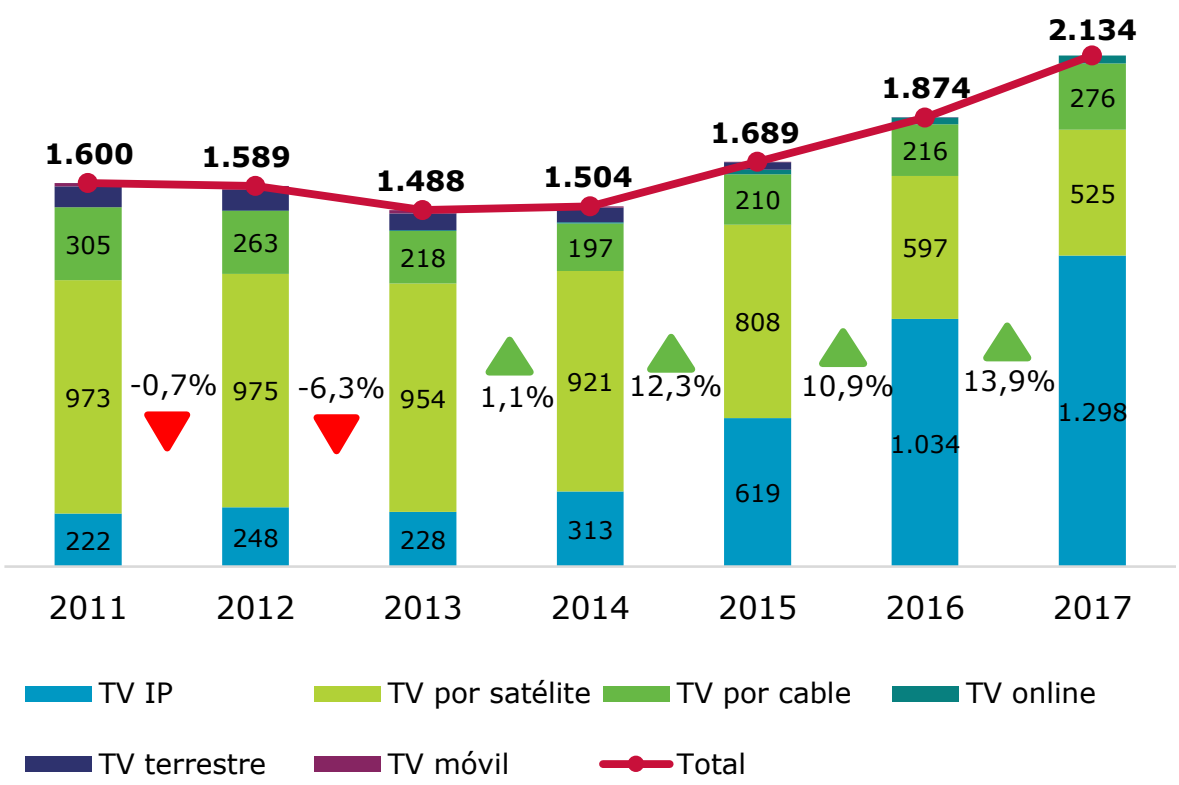

Fuente: CNMC, 2018 (datos estimados a partir de informes trimestrales)

\section{INVERSIÓN}

La inversión en publicidad por parte

del sector de la televisión se sitúa en

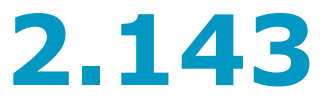

millones de euros en 2017

\subsubsection{Inversión publicitaria en el sector de la televisión}

Por cuarto año consecutivo se incrementa la cifra de inversión publicitaria en nuestro país, situándose en 2017 en los 2.143 millones de euros (solo un $1 \%$ más con respecto a 2016). Aunque la intensidad del crecimiento es menor cada año, se sigue evidenciando el buen estado de salud en la que se encuentra el sector, cuyas cifras de inversión están lejos de las alcanzadas durante los peores años de la crisis económica.

Según Infoadex (2018), el 90\% de la inversión publicitaria en televisión corresponde a las televisiones nacionales en abierto; un $5,3 \%$ a las televisiones autonómicas; y un $4,4 \%$ a los canales de pago. 
Gráfico 59. Inversión publicitaria en televisión en España. Evolución 2011 - 2017 (Millones de euros) $^{10}$

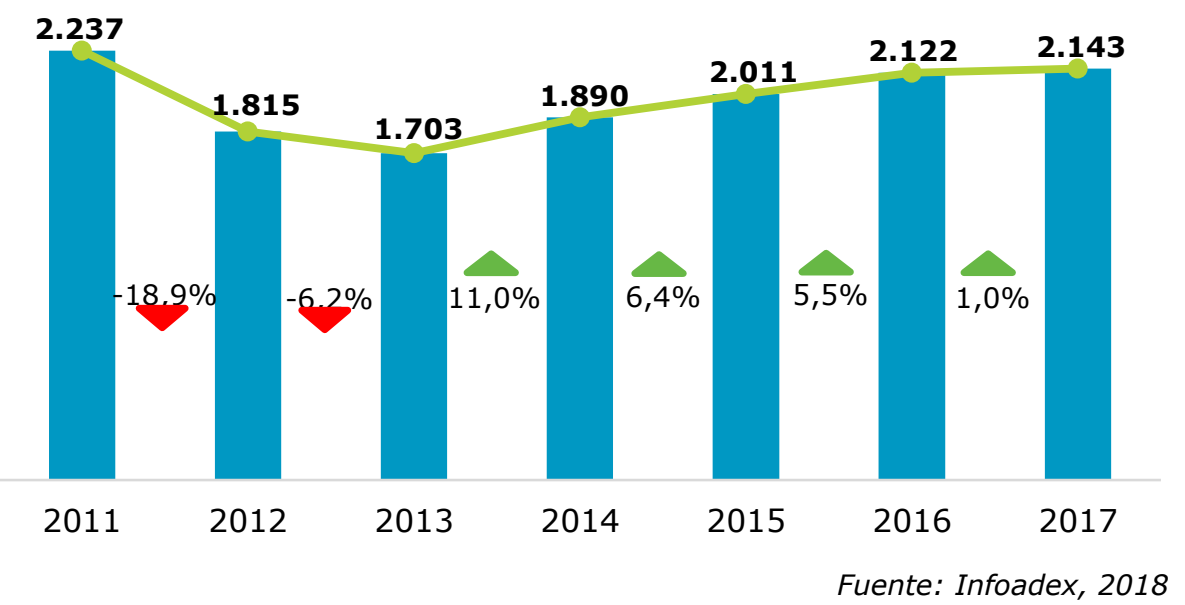

${ }^{10}$ Las cifras de inversión publicitaria en televisión en España se han extraído, para toda la serie histórica, de los informes que publica Infoadex anualmente. 


\section{$\bullet \bullet \bullet \bullet \bullet \bullet \bullet \bullet \bullet \bullet \bullet \bullet \bullet \bullet \bullet$}

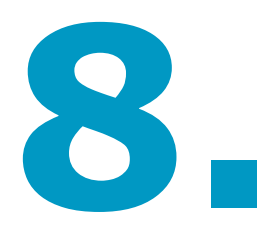

EL SECTOR DE LAS

PUBLICACIONES
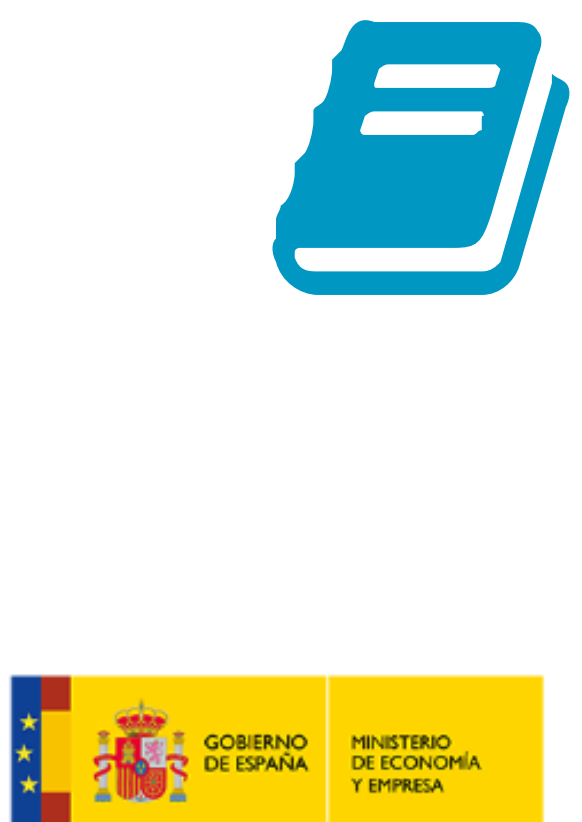

ontsi

red.es 


\section{El Sector de las publicaciones}

\subsection{El mercado global de las publicaciones}

Se presenta a continuación la evolución y las proyecciones previstas en los próximos años para el sector de las publicaciones en el mundo: por un lado, la evolución de los ingresos de la venta de libros electrónicos (ebook) y, por otro, la evolución de los ingresos generados por el sector de la prensa digital.

\section{El $11,5 \%$ de los ingresos por \\ ventas de libros en \\ el mundo procede de la venta de libros digitales}

\subsubsection{El libro electrónico en el mundo}

El sector de las publicaciones es todavía el sector con menor penetración de lo digital. Más concretamente en lo que se refiere a la publicación de libros, al contrario de como cabría pensar, la venta de libros en papel mantiene una cifra de negocios relativamente constante desde los últimos cinco años. Solamente en 2014 experimenta un ligero descenso con respecto al año anterior ($2,1 \%)$. Desde entonces, la cifra de negocio del libro en formato físico sigue una tendencia creciente aunque a unos ritmos muy bajos, y las previsiones de cara al periodo (2018-2022) tampoco indican un descenso significativo; de hecho, seguirá aumentando muy ligeramente, siendo la tasa de crecimiento medio anual para este período de $0,8 \%$. Todavía, en 2017 , la venta física de libros representa el $88,5 \%$ de los ingresos del sector del libro, con una cifra de 49 miles de millones de euros, un 1,1\% más que en 2016.

De otro lado, en el año 2013, el 9,3\% de los ingresos por ventas de libros en el mundo provenían de la venta de libros digitales o ebooks. Sin embargo, al contrario de como parecía preverse, cuatro años después, en 2017, ese porcentaje no ha aumentado de manera significativa, situándose en un $11,5 \%$. De hecho, las estimaciones para 2022 tampoco reflejan un crecimiento destacado, estableciéndose el porcentaje que representan los ingresos por parte de la venta de libros en formato electrónico en un 14,1\% sobre el total.

En 2017, el volumen de negocio de la venta de libros electrónicos en el mundo asciende a los 6,4 miles de millones de euros (un 9,4\% más que en 2016). Las estimaciones para los próximos cinco años indican un crecimiento de los ingresos por venta de ebooks del 5,5\% anual (IDATE, 2018a). 
Gráfico 60. Ingresos por ventas de libros en el mundo (miles de millones de euros)

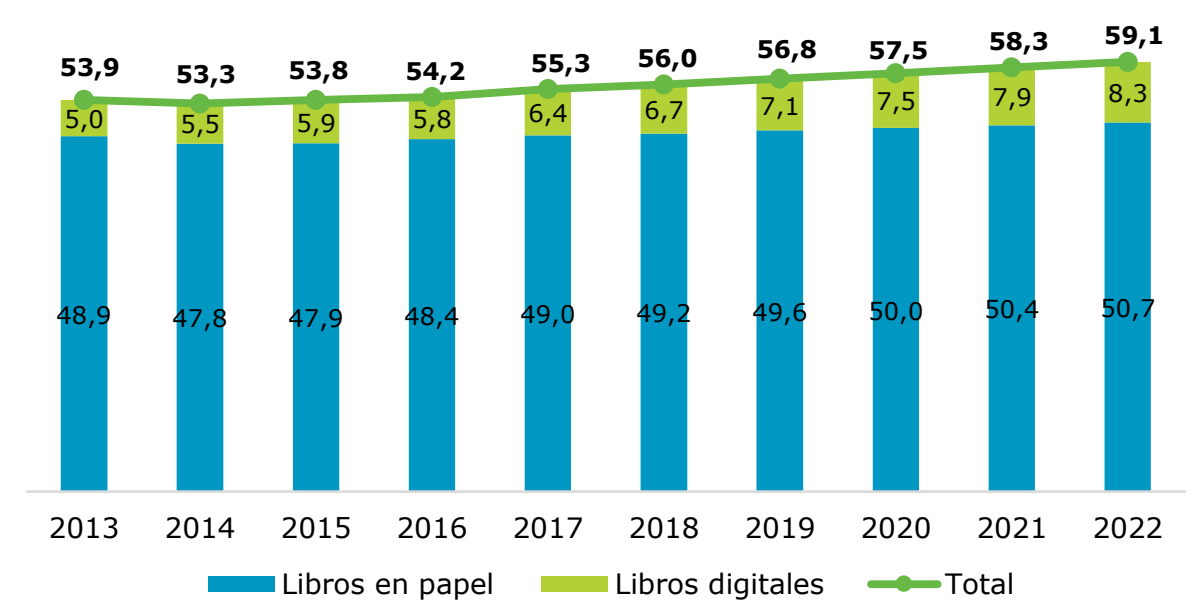

Fuente: IDATE, 2018a

Distinguiendo en función de las principales regiones del mundo, Norteamérica hasta el año 2015 representaba la región con mayores ingresos con respecto al total mundial. A partir de 2016 cambia la tendencia y es Asia Pacífico la región que se posiciona en cabeza. En 2017, Asia Pacífico engloba el 45,9\% del total de ingresos por ventas de libros electrónicos y Norteamérica el 33,8\%. Europa viene experimentando un crecimiento importante durante los últimos años y se espera que en 2022 represente el 21,5\%. Según las estimaciones para el período 2018-2022 América Latina y oriente Medio y África serán las regiones que mayor crecimiento experimentarán, aunque el porcentaje que representan con respecto al total de ingresos por ventas de ebooks es muy pequeño. Las tasas de crecimiento medio anual para estas regiones en los próximos años son las siguientes: Norteamérica (2,5\%), Europa (9\%), Asia Pacífico (4,5\%), Oriente Medio y África $(21,9 \%)$ y América Latina (35,5\%).

Por otro lado, en términos relativos a la población de estas regiones geográficas, el mayor volumen de ingresos per cápita en 2017 por

Se estima que Asia Pacífico sea en el futuro la región donde mayor porcentaje representen las ventas de libros digitales en comparación con el resto de regiones la venta de libros digitales le corresponde a Norteamérica con 5,9 millones de euros per cápita, cifra que ha descendido en $-32 \%$ con respecto al año 2013, año en el que se alcanza el máximo de la serie histórica. El resto de las regiones del mundo no llegan a superar el millón de euros per cápita, con la excepción de Europa a partir del año 2016.

Además, continuando desde la perspectiva geográfica, el peso proporcional que tienen los ingresos procedentes de la venta de libros digitales con respecto al total de ingresos de los sectores regionales difiere considerablemente entre unas regiones y otras. Durante el período 2013-2017 Norteamérica era la región en la que la venta de libros digitales tenía mayor peso con respecto a los ingresos de la venta total de libros, aunque ha experimentado un 
retroceso de 6 puntos porcentuales (del 21\% en 2013 al 15\% en 2017). Al contrario, en Asia Pacífico se viene incrementando paulatinamente la proporción de los ingresos de las ventas de libros digitales con respecto al total de ingresos del sector. No obstante, los porcentajes indicados en la siguiente ilustración reflejan que, tanto en la actualidad como en los próximos años, la venta de libros en papel continuará teniendo un peso muy importante y seguirá siendo la principal fuente de ingresos del sector en todas las regiones.

Gráfico 61. Porcentaje de los ingresos de la venta de libros en formato digital con respecto al total de ingresos del sector de la publicación de libros en cada una de las principales regiones

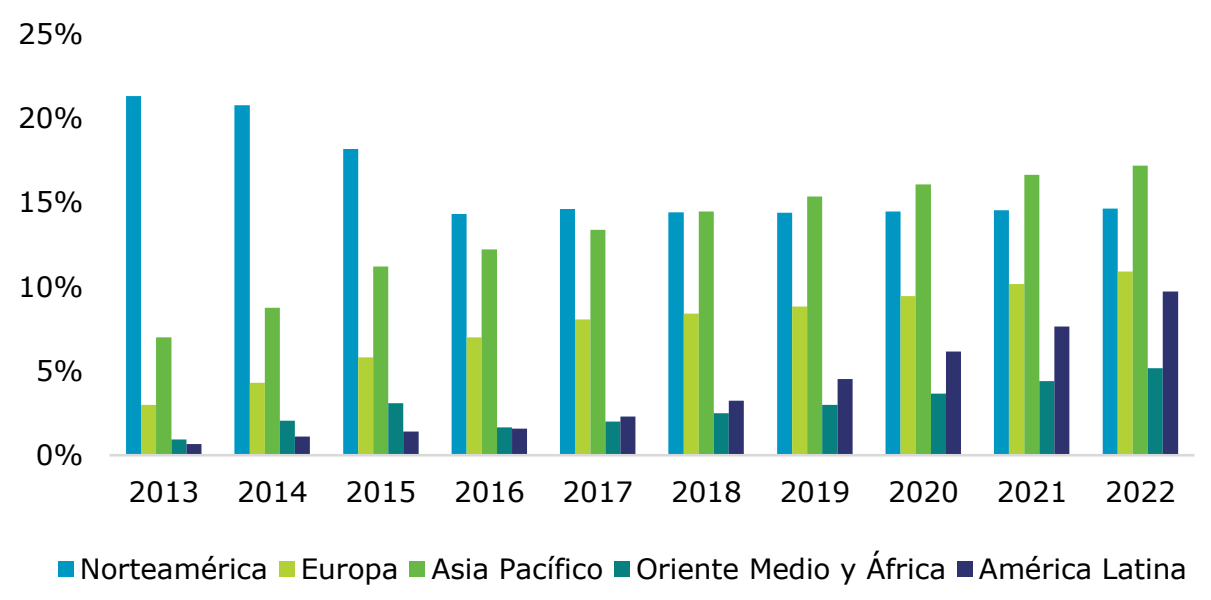

Fuente: Elaboración propia a partir de datos de IDATE

En 2017, la prensa en papel aun representa más del $90 \%$ de los ingresos totales del sector de la prensa escrita (113,5 miles de millones de euros)

\subsubsection{La prensa digital en el mundo}

Es evidente que el proceso de digitalización experimentado por el subsector de la prensa es relevante, aunque en la actualidad el volumen de ingresos que genera la prensa en formato físico (o en papel) supera enormemente a la prensa en formato digital.

Durante los últimos años los ingresos totales a nivel mundial generados por el sector de la prensa escrita siguen una tendencia a la baja (125,8 miles de millones de euros en 2017 , un $-1,7 \%$ con respecto al año anterior), debido fundamentalmente a la caída en los ingresos por parte de la prensa en formato físico. En 2017 la prensa en papel aun representa más del $90 \%$ de los ingresos totales del sector (113,5 miles de millones de euros).

En 2017, el volumen de negocio a nivel mundial de la prensa digital se cifra en 12,3 miles de millones de euros, un $8,6 \%$ más con respecto a 2016. Las previsiones de cara a los próximos años indican un incremento paulatino del volumen de negocio de la prensa digital, con una tasa de crecimiento medio anual para el período 2018-2022 del $11,7 \%$ anual. En 2022 se prevé que la prensa digital abarque 
aproximadamente el $18 \%$ de los ingresos de la prensa escrita (IDATE, 2018a).

Gráfico 62. Cifra de negocio de la prensa escrita en el mundo (miles de millones de euros)

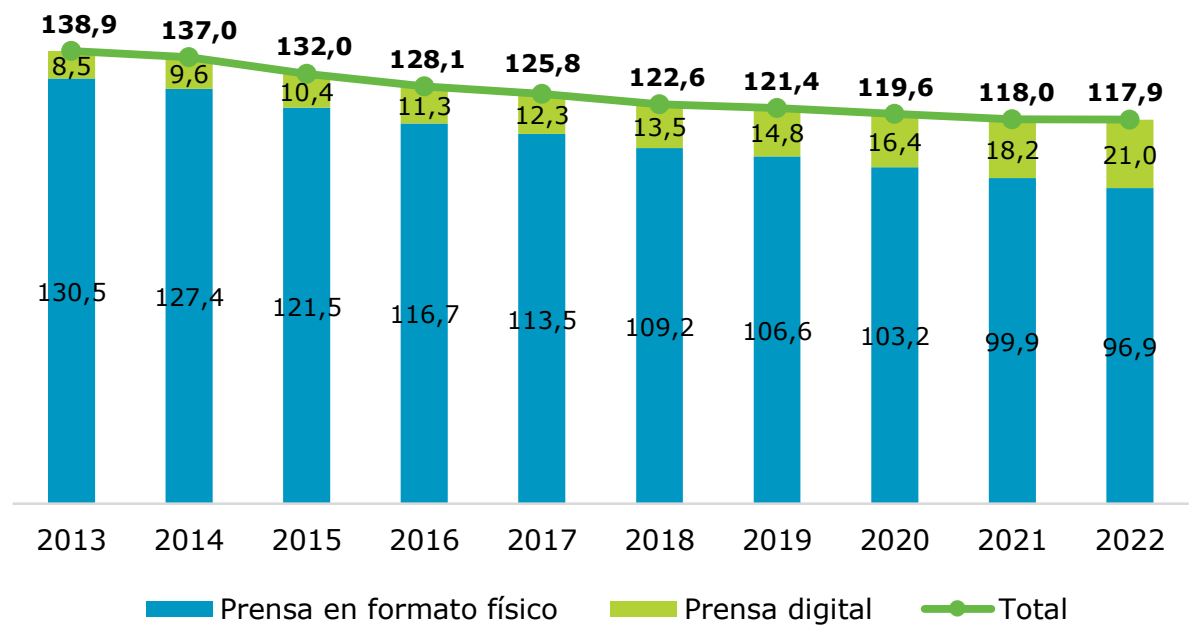

Fuente: IDATE, 2018a

Con respecto a las cifras absolutas de ingresos de la prensa digital para cada una de las regiones geográficas, el incremento paulatino es general en todas ellas. En relación con el total de ingresos mundial, Norteamérica es la región que mayores ingresos aporta (4,3 miles de millones de euros, lo que supone $34,9 \%$ sobre el total) en 2017. Con unas cifras similares, le siguen Asia Pacífico (3,9 miles de millones de euros) y Europa (3,3 miles de millones de euros) representando el $32,1 \%$ y el $27 \%$ sobre el total de ingresos del sector de la prensa digital en el mundo, respectivamente. La contribución de Oriente Medio y África y Latinoamérica al respecto apenas representa el $6 \%$ del total. Todas las regiones crecen en relación con al año anterior (IDATE, 2018a).

En términos relativos a la población de las regiones geográficas,

Las previsiones para los próximos años indican que poco a poco, aunque todavía lejos, la prensa digital irá ganando terreno a la prensa en papel, especialmente en Norteamérica y Latinoamérica Norteamérica genera los mayores ingresos per cápita con muchísima diferencia con respecto a las demás $(11,8$ millones de euros per cápita, en 2017). Muy por debajo aparece el continente europeo con una cifra de tan sólo 4 millones de euros per cápita. Del resto de regiones sólo América Latina logra superar el millón de euros por habitante de ingresos generados por la prensa digital.

Los ingresos procedentes de la prensa digital tienen mayor peso en Norteamérica ( $17 \%$ en 2017$)$ en comparación con el resto de las regiones del mundo. A partir de 2014 Latinoamérica se convierte en la segunda región donde, en términos proporcionales, mayor peso tiene la prensa digital. Las previsiones para los próximos años indican que poco a poco, aunque todavía lejos, la prensa en formato digital irá ganando terreno a la prensa en formato físico, especialmente en el caso norteamericano y latinoamericano, llegando a representar el $25 \%$ y el $20 \%$ del total de ingresos del sector para cada caso respectivamente. 


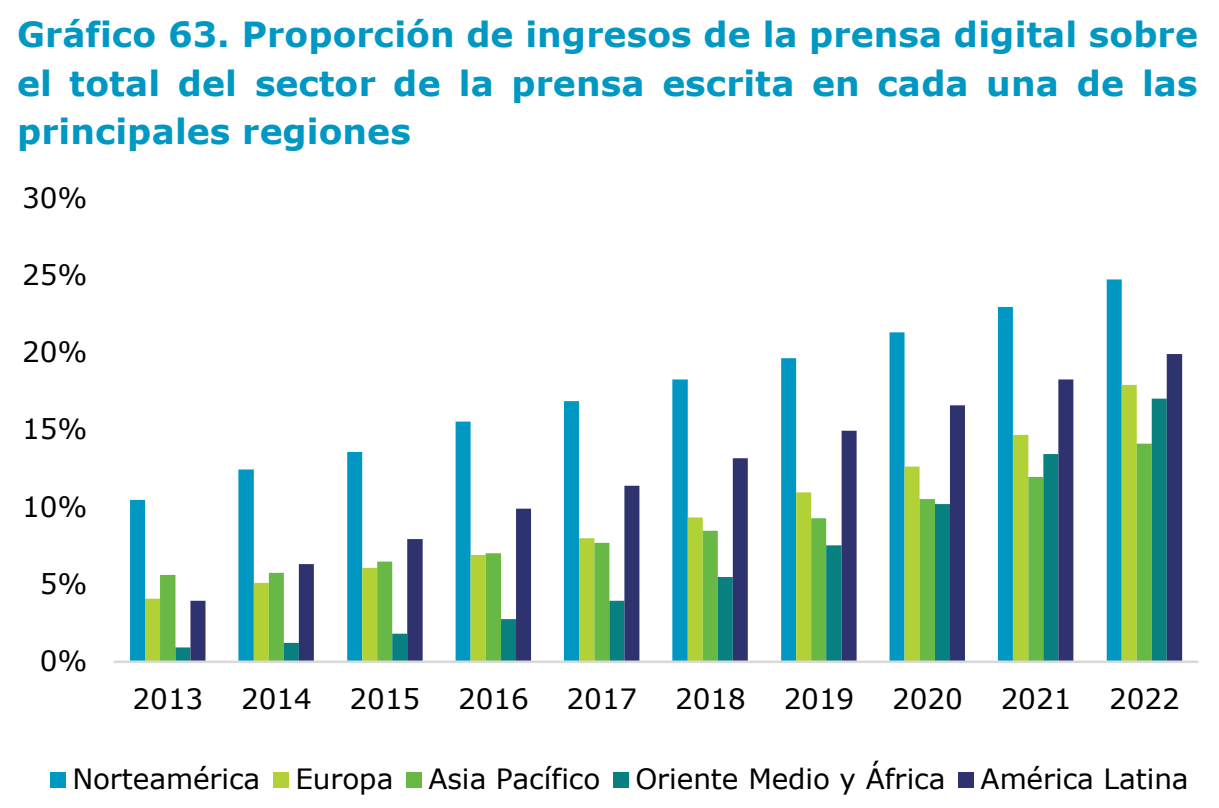

Fuente: Elaboración propia a partir de datos de IDATE

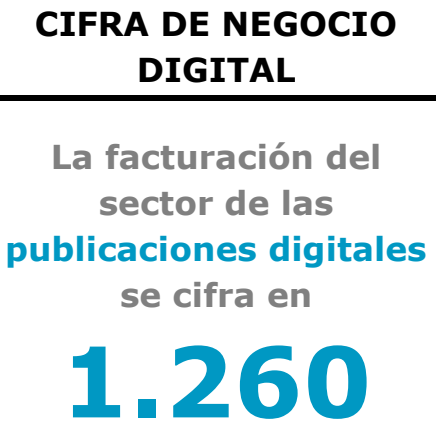

millones de euros en 2017

\subsection{El sector de las publicaciones en España}

El volumen de facturación total del sector de las publicaciones en España alcanza en 2017 los 5.497 millones de euros (-1,6\% menos con respecto a 2016). Mientras que la parte de negocio tradicional del sector sigue una tendencia negativa, llegando a los 4.237 millones de euros en 2017 ( $-14,5 \%$ en relación con el año anterior), desde 2014 el sector de las publicaciones en su dimensión digital evoluciona positivamente, experimentando un crecimiento especialmente intenso durante el último año La cifra de negocio digital del sector de las publicaciones en España asciende en 2017 a 1.260 millones de euros, un $74,3 \%$ más que en 2016, representando además el $22,9 \%$ del total de ingresos del sector de las publicaciones.

Todas las ramas de actividad ${ }^{11}$ pertenecientes al sector de las publicaciones, en su dimensión digital, igualmente han crecido considerablemente con respecto a 2016. Destaca la rama de edición de periódicos con un volumen de ingresos procedente del negocio digital de 534 millones de euros (un 78,4\% más que en 2016), superando por primera vez a la rama de edición de libros digitales (424 millones de euros). Igualmente destacan de manera notable la rama de otras actividades editoriales pasando de 42,6 millones de euros en 2016 a 187 millones en 2017; así como la rama de edición de revistas que incrementa su cifra de negocio digital en un $132,1 \%$ (112 millones de euros en 2017). Por su parte, la edición digital de

\footnotetext{
11 Las ramas de actividad que conforman el sector de las publicaciones son: edición de libros, edición de periódicos, edición de revistas, edición de directorios y guías de direcciones postales y otras actividades editoriales.
} 
El $42,4 \%$ de los ingresos del sector de las publicaciones digitales procede de la edición de periódicos digitales directorios y guías de direcciones postales tan solo alcanza los 2 millones de euros.

Gráfico 64. Cifra de negocio digital del Sector de las Publicaciones en España. 2012-2017 (millones de euros)

1.260

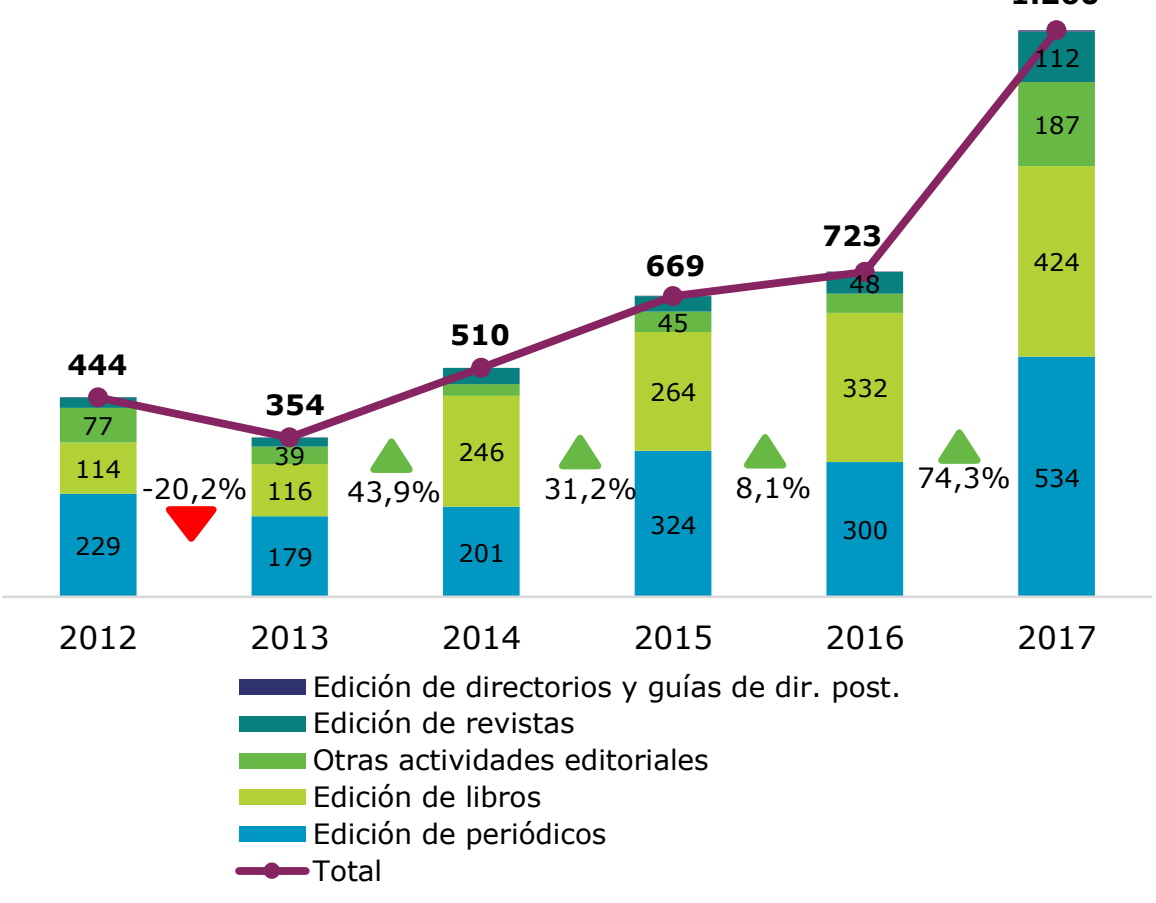

Fuente: ONTSI

Con respecto a la aportación de las diferentes ramas de actividad al total de ingresos del negocio digital del sector de las publicaciones la mayor parte procede de la edición de periódicos $(42,4 \%)$ del total, seguido de la rama dedicada a la edición de libros $(33,6 \%)$. La rama de otras actividades editoriales representa un $14,8 \%$. Residualmente, la edición de directorios y guías de direcciones postales tan sólo aporta un $0,2 \%$ de la cifra de negocio digital del sector de las publicaciones. 
Gráfico 65. Facturación del negocio digital por ramas de actividad del Sector Publicaciones en España en 2017 (\% sobre el total de facturación digital del sector)

Edición de periódicos

Edición de libros

- Otras actividades editoriales

Edición de revistas

Edición de directorios y guías de direcciones postales

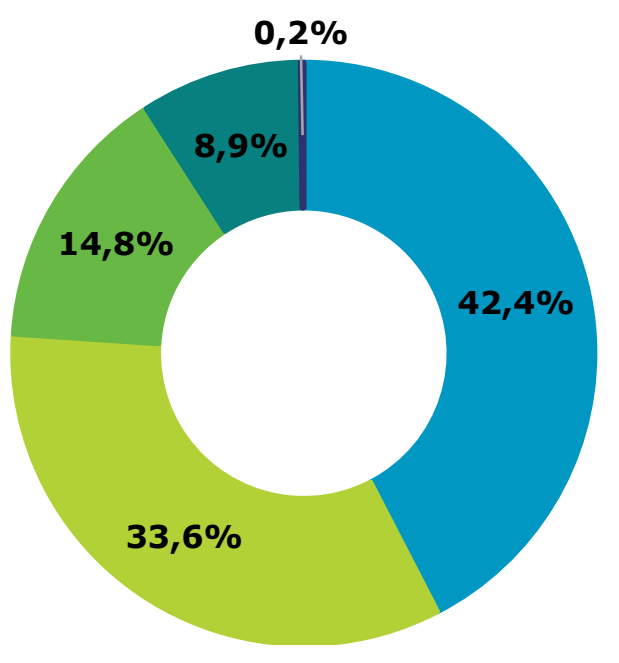

Fuente: ONTSI

El 39,2\% de las empresas del sector de publicaciones pertenece a la rama de edición de libros
En relación con la evolución del número de empresas del sector de las publicaciones, en 2017 se registra el peor dato desde el año 2012, descendiendo a las 3.182 empresas con una tasa de crecimiento con respecto al año 2016 de $-1,9 \%$. Distinguiendo en función de las ramas de actividad que se asocian a este sector, el $39,2 \%$ de las empresas pertenecen a la rama de edición de libros; el $25,1 \%$ a la de edición de periódicos; el $15,8 \%$ a la de edición de revistas; y en proporción similar, el $14,2 \%$, a otras actividades editoriales. El 5,8\% restante corresponde a las empresas de edición de directorios y guías de direcciones postales.

Gráfico 66. Porcentaje de empresas por rama de actividad del sector de las publicaciones en España en 2017 (\% sobre el total de empresas del sector)

Edición de libros

Edición de periódicos

Edición de revistas

- Otras actividades editoriales

Edición de directorios y guías de direcciones postales

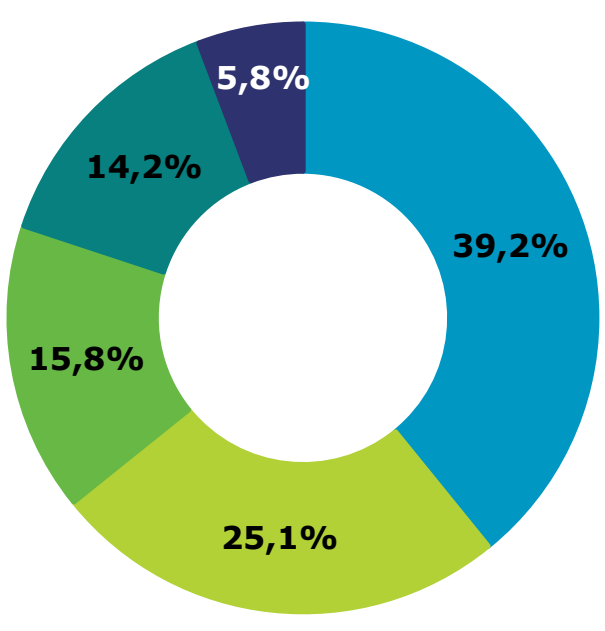

Fuente: ONTSI 


\section{El personal \\ ocupado en la parte de negocio digital crece por cuarto año consecutivo, un 40,6\% más con respecto a 2016}

En lo que se refiere a la evolución del empleo total en el sector de las publicaciones, se mantiene la evolución negativa que arrastra desde los últimos cinco años (en 2012 se alcanzaron los 37.099 empleos). En 2017, el total de personas ocupadas de este sector ha descendido a 33.786 (registrándose una tasa de crecimiento anual del $-2,8 \%$ con respecto a 2016 ).

Al contrario de lo que sucede con el empleo total del sector, que viene cayendo a un ritmo en promedio del $-1,9 \%$ anual desde 2012 (registrándose en 201733.786 empleos), el personal ocupado en la parte de negocio digital crece año tras año desde 2014, alcanzado en 2017 los 6.771 trabajadores (un 40,6\% más con respecto al año anterior). En 2017, el personal ocupado de la parte de negocio digital representa el $20 \%$ del total del empleo del sector de las publicaciones.

De esta parte del empleo del sector, el $35,3 \%$ se concentra en la rama de edición de periódicos, seguido de la edición de libros en similar proporción (35,2\%). El 15,6\% del empleo en el sector de publicaciones digitales se concentra en la rama de edición de revistas, y un $9,8 \%$ en la rama de edición de directorios y guías de direcciones postales. Por su parte, la rama clasificada como otras actividades editoriales tan sólo representa un $4,1 \%$ del empleo del sector en su dimensión digital.

Gráfico 67. Porcentaje de personal ocupado en la parte de negocio digital por rama de actividad del sector de las publicaciones en España en 2017 (\% sobre el total de empleados del sector en la parte de negocio digital)

Edición de periódicos
Edición de libros
Edición de revistas
Edición de directorios y guías
de direcciones postales
Otras actividades editoriales

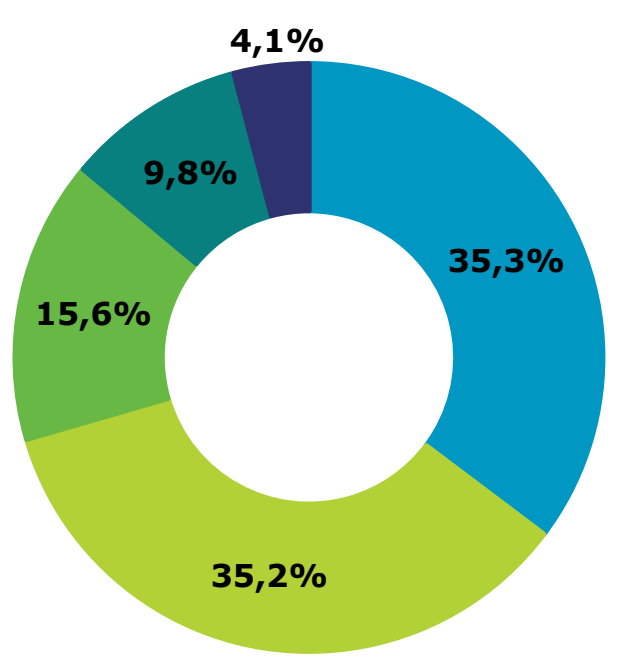

Fuente: ONTSI 


\section{Por primera vez desde 2012 la inversión en negocio digital del sector de las publicaciones desciende}

Para concluir esta visión general del sector de las publicaciones digitales en España, se debe mencionar que la inversión en negocio digital de las empresas del sector desciende por primera vez desde el año 2012. En 2017, la cifra desciende a los 179 millones de euros (con una tasa de crecimiento anual de $-22,3 \%$ con respecto a 2016). A su vez, en la actualidad la inversión en negocio digital de este sector solamente llega a representar un $10 \%$ de la inversión total.

Diferenciando según las ramas de actividad, más de la mitad de la inversión en negocio digital se concentra en la edición de periódicos $(53,5 \%)$; seguido de la edición de libros $(20,7 \%)$, la edición de directorios y guías de direcciones postales $(12,4 \%)$, otras actividades editoriales $(8,9 \%)$ y, en último lugar la edición de revistas $(4,5 \%)$.

Gráfico 68. Inversión de las actividades de edición en el negocio digital, 2017 (\% sobre el total de la inversión del sector)

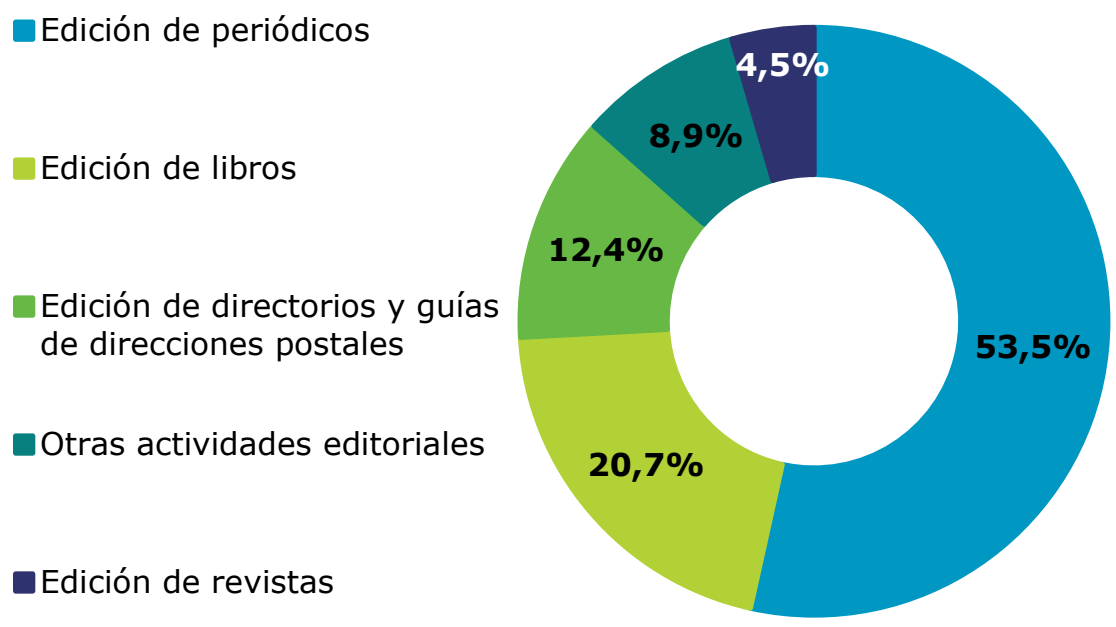

Fuente: ONTSI

\subsubsection{Edición de libros}

La rama de actividad dedicada a la edición de libros alcanza en 2017 una cifra de negocio de 2.436 millones de euros, de los cuales 424 millones de euros corresponden a la parte de negocio digital (cifra que representa el $17,4 \%$ de la facturación total de la rama de actividad). Los ingresos del negocio digital vienen experimentando desde el año 2012 un crecimiento continuado, siendo el periodo 2013-2014 en el que se produce el mayor incremento con una tasa de crecimiento anual del 112\%. En 2017 el volumen de negocio digital se incrementa en un $27,7 \%$ con respecto a 2016 . 
Gráfico 69. Cifra de negocio digital de la rama de edición de libros 2012-2017 (millones de euros)

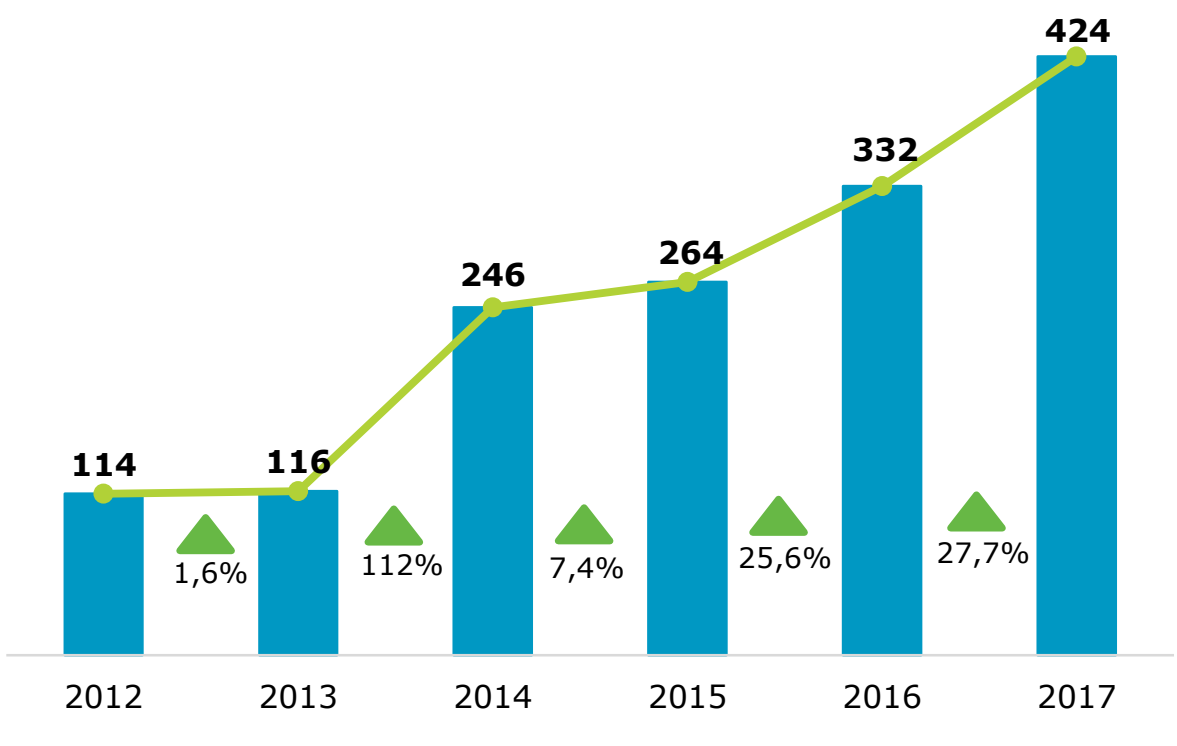

La contribución de los libros digitales a la facturación total de la rama de edición de libros continúa siendo muy escasa $(2,3 \%)$
Distinguiendo entre la tipología de productos asociada a la rama de edición de libros, en el año 2017 más de un tercio de la facturación total se asocia a las ventas de libros de texto (37\%). Destaca igualmente representando un $20,9 \%$ otros libros, folletos, prospectos y similares. Completa el podio en tercer lugar los libros profesionales, técnicos y académicos $(10,8 \%$ del volumen de facturación total). Cabe destacar la escasa contribución de los libros digitales a la facturación total de la rama de edición de libros $(2,3 \%)$.

Gráfico 70. Distribución del volumen de facturación por productos de las actividades de edición de libros en España. 2017 (\% sobre la facturación total de la rama de actividad)

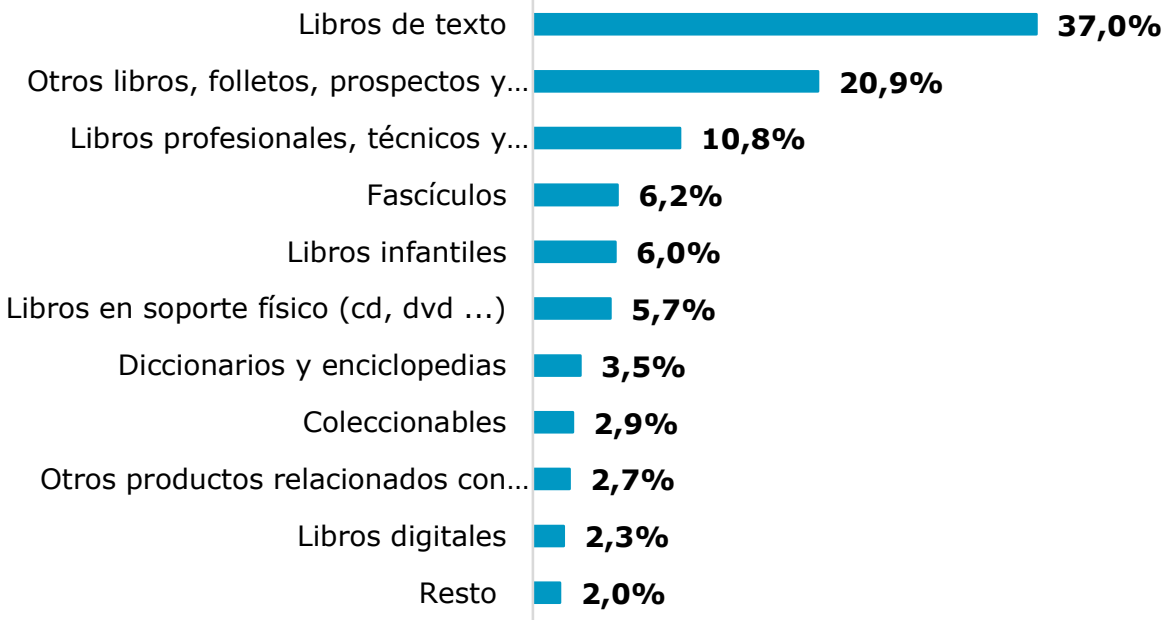

Fuente: ONTSI

Más allá de la evolución de la cifra de negocio de esta rama de actividad, igualmente se hace mención a la cuestión del número de 


\section{CIFRA DE NEGOCIO} DIGITAL

La facturación digital de la rama de edición de periódicos alcanza en 2017 los

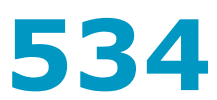

millones de euros empresas, el personal ocupado y la inversión de las empresas en negocio digital.

En lo que respecta al número de empresas, 2017 es el año en el que se registra el peor dato desde 2012, descendiendo a las 1.246, siendo la tasa de crecimiento anual con respecto a 2016 de $-3,1 \%$.

En cuanto al personal ocupado, el número de empleados correspondiente a la parte de negocio digital de la edición de libros crece por cuarto año consecutivo, registrándose en 2017 los 2.386 empleos (un $39,7 \%$ más en relación con el año anterior) representando el $18,7 \%$ del total del empleo de la rama de actividad. Por el contrario, en 2017, la cifra total de personal ocupado en el subsector de la edición de libros desciende a los 12.788 .

Por su parte, la inversión en negocio digital de las empresas de la rama de edición de libros desciende en 2017 a los 37 millones de euros $(-70,1 \%$ frente a 2016), representando tan solo una pequeñísima parte de la inversión total de la rama de actividad $(4,3 \%)$. Al contrario, la inversión total en edición de libros crece por segundo año consecutivo, situándose en 2017 en los 860 millones de euros (un $21,7 \%$ más con respecto a 2016).

\subsubsection{Edición de periódicos}

La rama de actividad del sector de publicaciones relacionada con la edición de periódicos alcanza en 2017 una cifra de negocio total de 1.700 millones de euros ( $-5,9 \%$ menos que en 2016$)$. De esta cifra total, el $31,4 \%$ procede del negocio digital, cuya cifra asciende a los 534 millones de euros (un $78,4 \%$ más que en el año anterior). De toda la serie histórica representada en la siguiente gráfica, en 2017 se produce el incremento más notable del volumen de negocio digital de la rama del sector.

Gráfico 71. Cifra de negocio digital de la rama de edición de periódicos 2012-2017 (millones de euros)

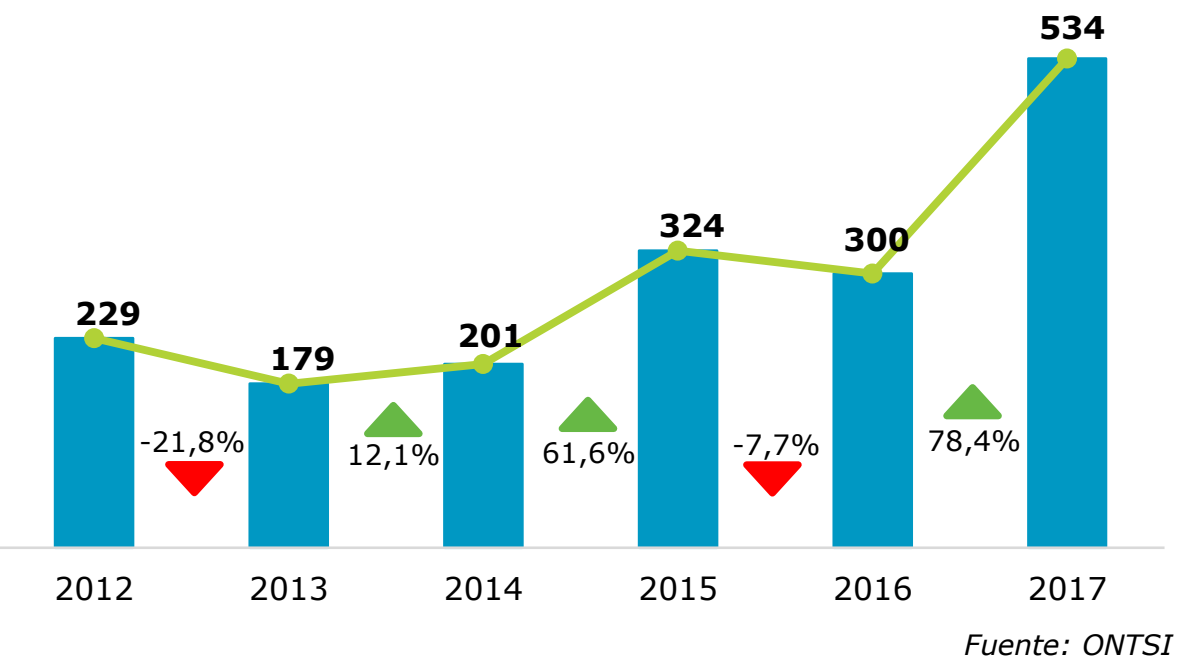


Del total de la facturación de la edición de periódicos, diferenciando en función de su tipología de productos asociada, el 38,6\% procede de los espacios publicitarios en periódicos impresos. En una proporción similar, los periódicos impresos representan el 37,6\% de la facturación digital de la edición de periódicos. En tercer lugar, aunque muy lejos de los anteriores, aparecen los espacios publicitarios en periódicos electrónicos que representan el 12,1\% del volumen de negocio de la edición de periódicos. Cabe destacar que las suscripciones a periódicos online tan sólo contribuyen en un $2,1 \%$ al cómputo de los ingresos totales.

Gráfico 72. Distribución del volumen de facturación por productos de las actividades de edición de periódicos en España. 2017 (\% sobre la facturación total de la rama de actividad)

Espacios publicitarios en
periódicos impresos
Periódicos impresos
Espacios publicitarios en
periódicos electrónicos
Otros productos relacionados
con la edición de periódicos
Promociones
Periódicos en internet
(suscripciones)
(suscripciones)

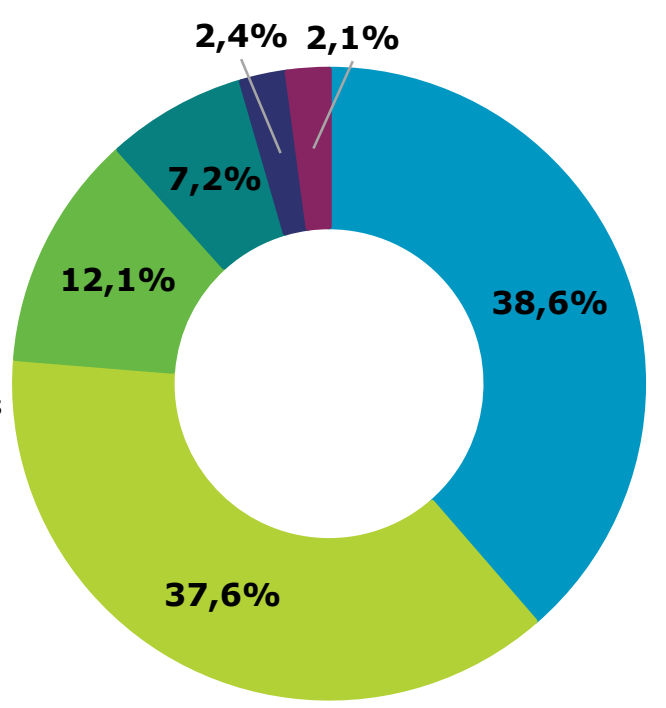

Fuente: ONTSI
El empleo dedicado a la parte de negocio digital de la edición de periódicos disminuye un

$$
-5,5 \% \text { con }
$$
respecto a 2016

El número de empresas pertenecientes a la rama de edición de periódicos desciende ligeramente a las 798 en 2017 (-1\% frente a 2016). Por su parte, la evolución total del empleo de la rama de actividad continúa con una tendencia negativa a pesar del ligero incremento que experimentó en 2015.

En 2017, el personal ocupado de la edición de periódicos cae a los 12.808 ( $-3,3 \%$ con respecto al año anterior). Igualmente, el número de empleados correspondiente a la parte de negocio digital disminuye por segundo año consecutivo, situándose en los 2.389 trabajadores $(-5,5 \%$ con respecto al año anterior), representando el $18,6 \%$ del empleo total de la rama de edición de periódicos.

La inversión de las empresas de edición de periódicos en la parte de negocio digital alcanza en 2017 los 96 millones de euros (un 4,5\% más que en 2016), representando un $15,6 \%$ de la inversión total de la rama de actividad. La cifra de inversión total de la edición de periódicos se incrementa por cuarto año consecutivo, alcanzando en 2017 los 612 millones de euros (27,9\% más que en el año anterior). 


\section{CIFRA DE NEGOCIO DIGITAL}

La facturación digital del sector Edición de revistas asciende en 2017 a

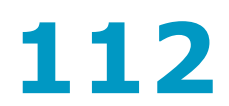

millones de euros

\subsubsection{Edición de revistas}

En 2017, la cifra de negocio total de la rama de actividad dedicada a la edición de revistas en España desciende a 775 millones de euros ( $-1,9 \%$ de decrecimiento con respecto a 2016$)$. De este volumen de negocio total casi el $20 \%$ procede del negocio digital, y cuya cifra se habría más que duplicado ascendiendo a los 112 millones de euros (un $132,1 \%$ más con respecto al año anterior). De toda la serie histórica representada en la siguiente gráfica, en relación con la evolución de la cifra de negocio digital de la edición de revistas, es el periodo 2016-2017 en el que se concentra el mayor incremento de los ingresos de la parte de negocio digital de la rama de actividad.

Gráfico 73. Cifra de negocio digital de la rama de edición de revistas 2012-2017 (millones de euros)

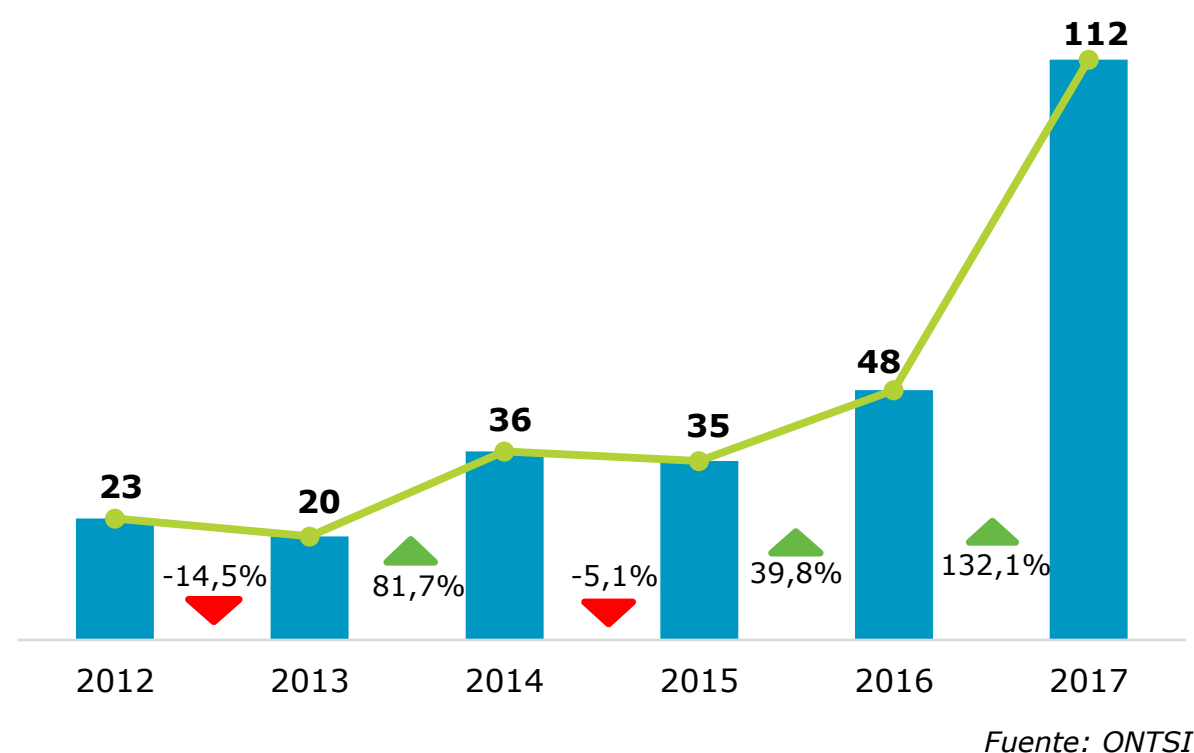

Diferenciando por tipo de productos, en 2017 más de la mitad de los ingresos totales de la rama de actividad de la edición de revistas procede de la venta de revistas impresas de carácter general $(50,3 \%)$, seguido de los espacios publicitarios en revistas impresas, los cuales generan el $18,7 \%$ de los ingresos. Por su parte, los productos distribuidos por medios digitales representan en su conjunto el $14 \%$ de los ingresos (un 9,2\% procede de los espacios publicitarios en revistas en internet, y un $4,8 \%$ procede de las suscripciones a revistas en internet). Si se tiene en cuenta únicamente estos dos últimos, asociados exclusivamente a la parte de negocio digital, el $65,6 \%$ de los ingresos procederían de los espacios publicitarios en revistas en internet, y el 34,3\% restante de las suscripciones a revistas en internet. 
Los productos de edición revistas distribuidos por medios digitales representan en su conjunto el $14 \%$ de los ingresos totales de la rama de actividad
Gráfico 74. Distribución del volumen de facturación de las actividades de edición de revistas en España. 2017 (\% sobre la facturación total de la rama de actividad)

Revistas impresas de interés
general
Espacios publicitarios en
revistas impresas
Revistas empresariales,
profesionales y académicas
Espacios publicitarios en
revistas en internet
Revistas en internet
(suscripciones)
Otras revistas impresas
Otros productos relacionados
con la edición de revistas
Servicios de cesión de los
derechos de uso de revistas

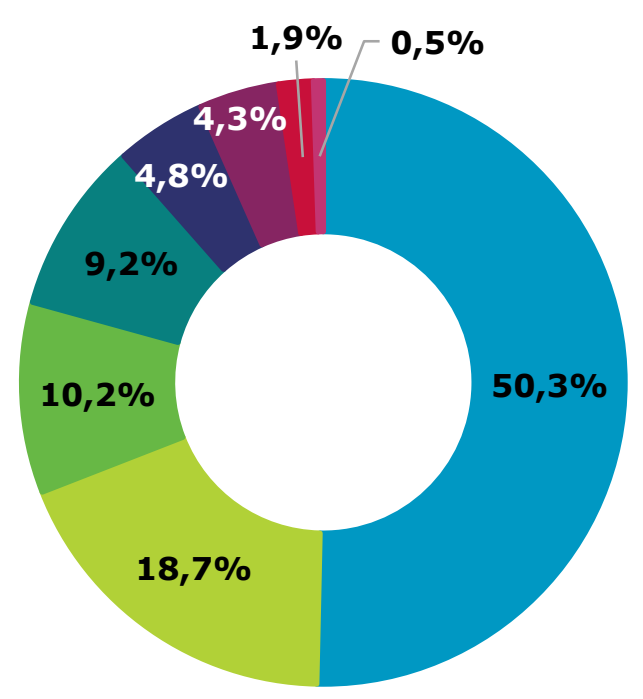

Fuente: ONTSI

Por otra parte, en 2017 el número de empresas dedicadas a la edición de revistas aumenta muy ligeramente hasta las 504 (0,4\% frente a 2016), a pesar de que la tendencia general que experimenta en los últimos cinco años es a la baja.

La cifra de empleo total de la rama de actividad continúa descendiendo paulatinamente desde 2015, registrándose una cifra de empleo en 2017 de 4.357 personas ocupadas. El 24,2\% del empleo en edición de revistas corresponde a la parte de negocio digital. A este respecto, se debe destacar que en el último año se ha producido un fortísimo incremento del personal ocupado en la edición de revistas digitales (128,4\% frente a 2016), alcanzándose en 2017 los 1.053 empleos.

Finalmente, en relación con las cifras de inversión registradas cabe señalar que presentan los menores volúmenes en comparación con los de las ramas de actividad anteriormente descritas. En 2017, se registra el mayor volumen de inversión desde 2012, alcanzando los 162 millones de euros (un 38,2\% más que en 2016), de los cuales solamente 8 millones de euros corresponden a la parte de negocio digital de la rama de actividad (5\%). 

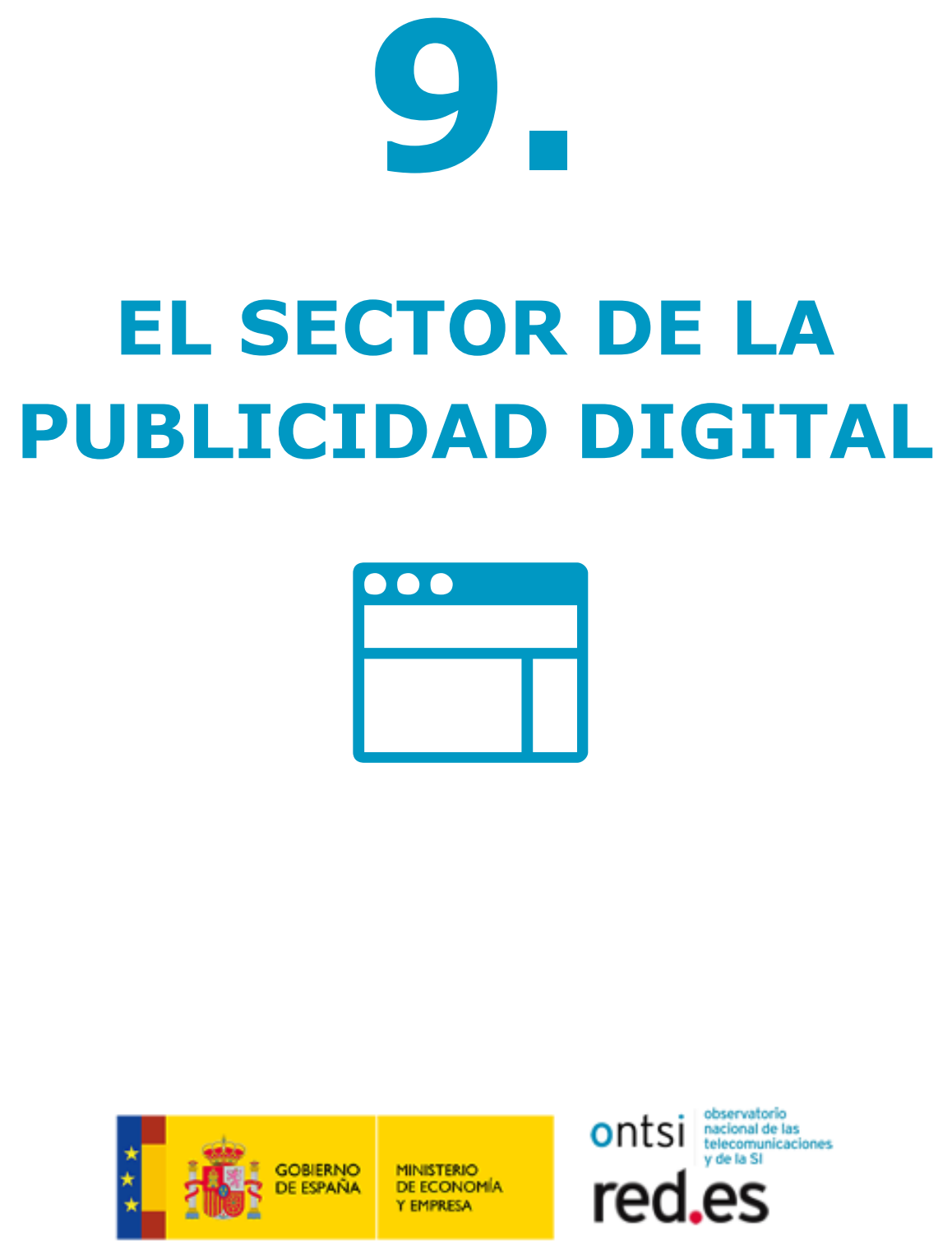

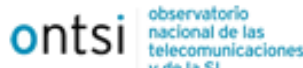

red.es 



\section{El Sector de la publicidad digital}

\subsection{El mercado global de la publicidad digital}

La cifra de ingresos de la publicidad en Internet en 2017 ascendió a 180.261 millones de euros
En este apartado se presentan las principales cifras relativas a los ingresos del sector de la publicidad online en función de sus tipologías, modelos existentes y su situación a nivel mundial.

En términos generales, se puede afirmar que el sector de la publicidad digital se encuentra en un buen momento, ya que viene creciendo de manera importante durante los últimos años tal y como refleja la evolución de las cifras de ingresos desde el año 2010. En seis años, los ingresos se triplicaron aproximadamente, pasando de 59.158 a 158.436 millones de euros en 2016. Ya en 2017 la cifra asciende a 180.261 millones de euros, un $13,8 \%$ más que en 2016 . Además, se espera un importante crecimiento en los próximos años (2017-2021), tal y como reflejan las estimaciones calculadas por IDATE con una tasa de crecimiento medio anual del 10,4\% (IDATE, 2017b).

Además, se puede afirmar que la situación en la que se encuentra el sector de la publicidad digital no se ha visto afectada por el constante crecimiento a nivel global que viene experimentando el uso de dispositivos de bloqueo de publicidad o ad blocking. Según el último informe disponible de PageFair (2017) sobre la situación en el mundo en cuanto al uso de adblockers se estima que el número de dispositivos de este tipo en 2017 es de 615 millones, de los cuales el $38,4 \%$ se asocian a ordenadores y el $61,8 \%$ a teléfonos móviles.

Diferenciando en función de los tipos de publicidad online existentes, los motores de búsquedas representan más de la mitad de todo el sector $(52,4 \%)$ en 2017 , con una cifra de ingresos total de 94.518 millones de euros. Le siguen los formatos gráficos de publicidad online representando el $41,3 \%$ del total $(74.370$ millones de euros de ingresos; y en menor medida otras tipologías que tan sólo representan un $6,3 \%$ de la facturación total del sector (11.372 millones de euros). Todas estas modalidades crecen respecto a 2016 y se espera la misma tendencia entre 2017 y 2021 (IDATE, 2017b).

De otro lado, IDATE (2018b), estima que el mercado de la publicidad digital en el mundo experimentará un fuerte incremento en sus ingresos (alcanzado los 268 miles de millones de euros en 2021) gracias a la creciente madurez de la publicidad programática y la popularidad de los contenidos que se distribuyen a través de las redes sociales, el vídeo y los dispositivos móviles. 
Gráfico 75. Ingresos por tipo de publicidad online (millones de euros)

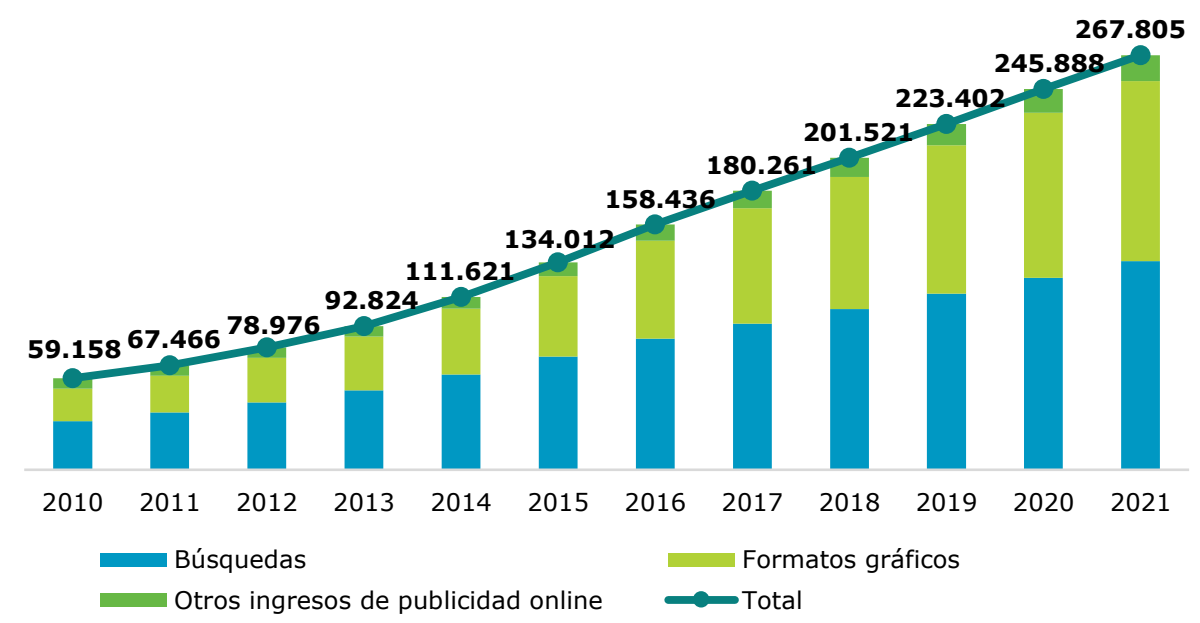

Fuente: IDATE, $2017 \mathrm{~b}$

Norteamérica se posiciona como la región con más ingresos procedentes de la publicidad digital
Distinguiendo por regiones geográficas, Norteamérica cuenta con la mayor cifra de ingresos procedente de la publicidad online (65.766 millones de euros, un 16,2\% más que en el año 2016), representando el $36,5 \%$ de toda la publicidad online a nivel global.

Asia Pacífico obtiene unos ingresos muy similares a los experimentados por el sector norteamericano, con una cifra en 2017 de 63.981 millones de euros. Europa registra un volumen de negocio de 43.283 millones de euros. América Latina y Oriente Medio y África que en la actualidad representan en torno al $4 \%$ en su conjunto de toda la publicidad online. Las previsiones de futuro son favorables para todas las regiones geográficas, especialmente para Oriente Medio y África con una tasa de crecimiento medio anual del $15,3 \%$.

Vinculando el total de los ingresos procedentes de la publicidad online a la realidad demográfica de cada región, destaca Norteamérica significativamente con respecto al resto de las regiones con unos ingresos de 181,5 millones de euros per cápita en 2017. Por el contrario, Asia Pacífico que en términos absolutos representaba casi un tercio de los ingresos totales de la publicidad online a nivel mundial, en 2017 tan sólo genera 15,5 millones de euros per cápita.

Como apuntes finales a la situación del mercado global de la publicidad digital, según IDATE (2018b), en la actualidad, más de la mitad de este mercado se reparte entre dos grandes competidores: Facebook, que principalmente domina el mercado de la publicidad en formatos gráficos, y Google, que domina el mercado de la publicidad mediante búsquedas. Lejos de estos dos grandes aparecen otros dos competidores: Baidu y Microsoft que luchan por controlar el resto.

Además, la publicidad programática constituirá en el futuro el motor tecnológico clave para el crecimiento del sector de la publicidad digital: esto es, la automatización del proceso de toma de decisiones 
de compra de espacio publicitario, en combinación con el retargeting (que consiste en impactar con publicidad a los usuarios que con anterioridad han interactuado con una marca determinada, es decir, se muestra a los usuarios anuncios de sitios que ya han visitado), que puede utilizarse dentro de la publicidad en formatos gráficos, e incorporándose a la publicidad a través de redes sociales, vídeo y dispositivos móviles, incluso a los mercados de publicidad televisiva tradicional.

En relación con esto último, se prevé que Amazon juegue un papel importante de cara al futuro del sector de la publicidad digital dada la enorme base de datos de registro de compra de usuarios que posee, al contrario que sus competidores. Además, cada vez más usuarios eligen Amazon para realizar búsquedas relacionadas con productos en lugar de Google, por lo que el valor de su base de datos no hace más que aumentar. Todo esto, unido al éxito de sus altavoces inteligentes (Alexa y Echo), le permiten obtener más datos personales, junto con la adquisición de la cadena de supermercados norteamericana Whole Foods (expandiéndose así al comercio minorista), no hacen sino incrementar su potencial publicitario (IDATE, 2018).

\subsection{El mercado de la publicidad digital en España}

\subsubsection{Inversión en publicidad digital en España}

La inversión publicitaria en medios digitales no ha parado de crecer

INVERSIÓN EN PUBLICIDAD DIGITAL

La inversión en

Publicidad Digital

alcanza una cifra de

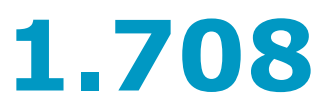

millones de euros en 2017 desde el año 2013. Entre los años 2014 y 2016 se producen los mayores incrementos en las cifras de inversión publicitaria en este tipo de medios, con unos incrementos anuales que rondaban el $21 \%$. Igualmente, ya en 2017 la cifra se ha incrementado con respecto al año anterior en un 9,1\%, alcanzándose un volumen de inversión de 1.708 millones de euros (IAB Spain, 2018).

Gráfico 76. Inversión en publicidad digital en España: Evolución 2011-2017 (millones de euros)

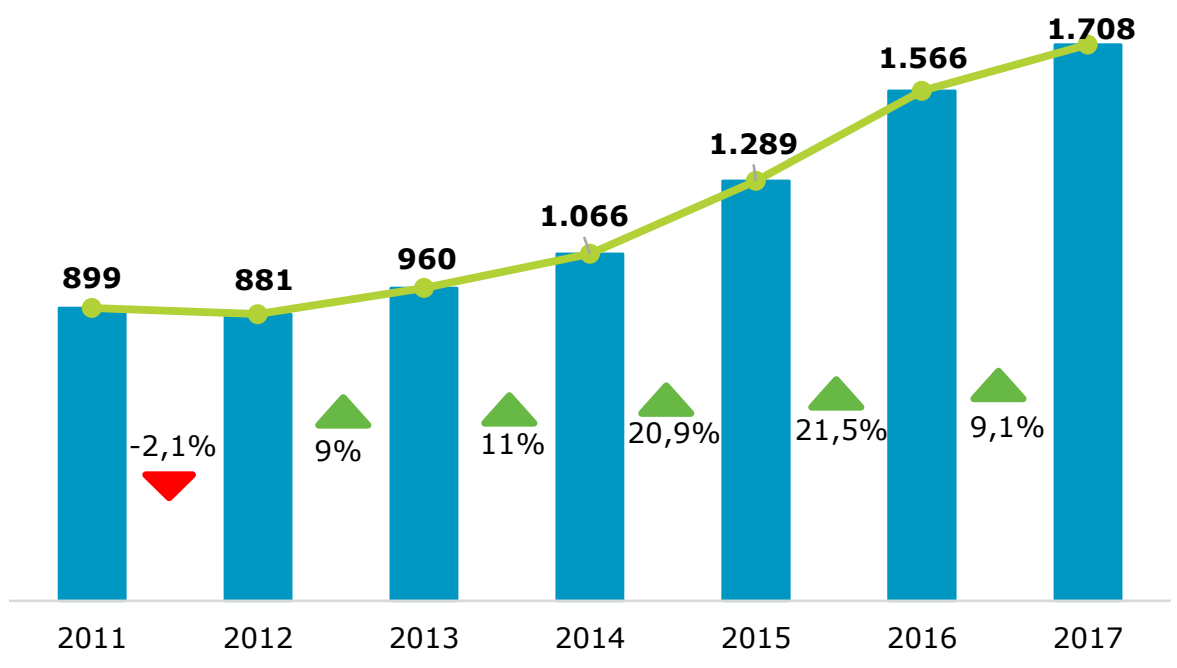

Fuente: IAB Spain, 2018a 


\section{La distribución de la inversión publicitaria digital se reparte en su mayoría en el canal Desktop \& Mobile (97\% del total de inversión publicitaria)}

La inversión publicitaria total en medios digitales constituye el agregado de la inversión procedente de los siguientes canales: Desktop \& Mobile (la publicidad registrada a través de ordenadores de sobremesa, y la publicidad a través de dispositivos inalámbricos e interactivos como los teléfonos móviles, PDAs, etc.); Digital Signage (también llamada señalización digital dinámica, basada en la emisión de contenidos publicitarios dinámicos, personalizados y, en ocasiones, interactivos mediante tecnología IP, tanto en interiores como en exteriores, a través de pantallas en sustitución a los carteles tradicionales); y Audio Online (la publicidad relacionada con contenidos de audio en Internet).

En 2017, la inversión en España en publicidad digital en Desktop \& Mobile representa el $97 \%$ del total ( 1.657 millones de euros, lo que significa un aumento del $8,6 \%$ con respecto a 2016). Un $2,7 \%$ de la inversión en publicidad digital corresponde a la señalización digital dinámica (46 millones de euros), y el 0,2\% restante corresponde al Audio Online con tan sólo 5,8 millones de euros).

No obstante, se debe señalar que en el último estudio sobre inversión publicitaria para el año 2017 de IAB Spain no se considera dentro del agregado de la inversión en publicidad digital la inversión relacionada con la TV conectada. En el año 2016 esta modalidad representaba tan sólo un $0,3 \%$ con apenas 4,9 millones de euros.

Por último, se debe destacar que, de la inversión publicitaria total en España, la publicidad digital sigue manteniendo la segunda posición (representando un $31 \%$ de la inversión total en publicidad, dos puntos porcentuales más que en 2016) solo por detrás de la televisión que abarca el 38,9\%. Continúan representando una parte proporcional mucho menor la inversión publicitaria en otros medios como los diarios $(10,3 \%)$ o la radio $(8,4 \%)$.

Gráfico 77. Distribución de la inversión publicitaria total por medios en 2017 en España (\%)

Televisión
Publicidad Digital
Diarios
Radio
Exterior
Devistas
Dine
Dominicales

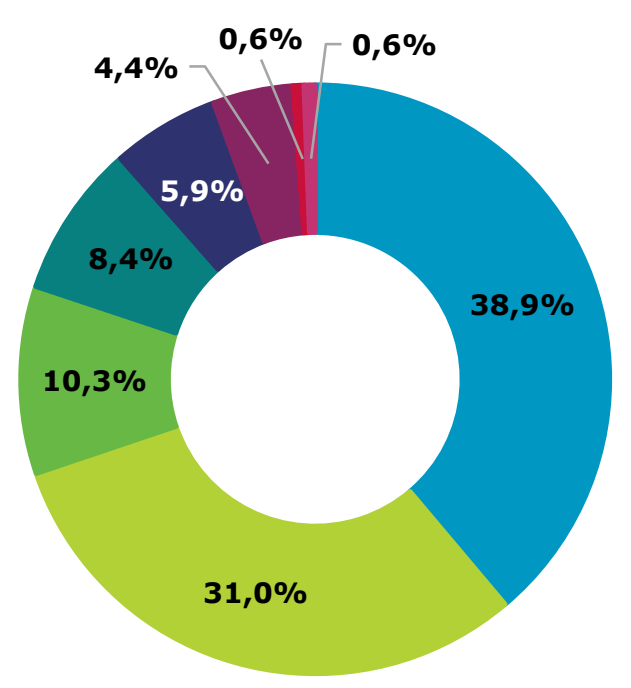

Fuente: IAB Spain, 2018a 


\section{$\bullet \bullet \bullet \bullet \bullet \bullet \bullet \bullet \bullet \bullet \bullet \bullet \bullet \bullet$}

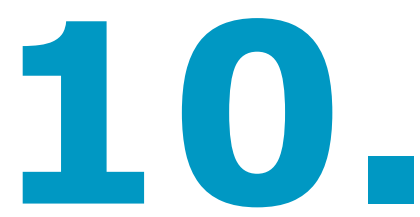

\section{OTROS SECTORES DE CONTENIDOS DIGITALES

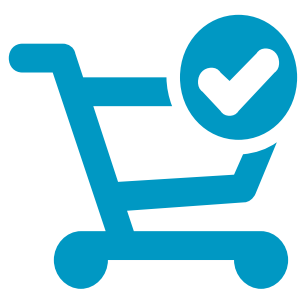




\section{Otros sectores de contenidos digitales}

\subsection{Deportes electrónicos (e-Sports)}

Se estima que el mercado global de los e-sports alcance en 2018 una cifra de negocio de 1,2 miles de millones de euros
El sector de los deportes electrónicos ha irrumpido con fuerza en la contribución al crecimiento del sector de los contenidos digitales, concretamente en el sector de los videojuegos. Se erige, además, como un activo de una importancia crucial para que un videojuego tenga éxito (manteniendo su audiencia y prolongando su ciclo de vida), a la vez que proporciona ingresos adicionales al sector del videojuego.

Según IDATE (2018b), se estima que en 2018 el mercado global de los deportes electrónicos alcance los 1,2 miles de millones de euros, y que seguirá creciendo en los próximos cuatro años a un ritmo del $32,7 \%$ anual en promedio, pudiendo alcanzar en 2022 una cifra de negocio de 3,8 miles de millones de euros.

Por otra parte, el sector de los e-sports se estructura alrededor de cuatro segmentos que configuran su modelo de ingresos: derechos de autor y licencias; venta de entradas para eventos y merchandising; patrocinio y publicidad; y apuestas.

Se estima, en la actualidad, que la mayor parte de los ingresos del sector de los e-sports proceda de los patrocinios y la publicidad, representando el 64,2\% (796 millones de euros). Le sigue en importancia, aunque en menor proporción, los ingresos procedentes de las apuestas, estimadas en 187 millones de euros $(15,1 \%$ de los ingresos del sector). Se prevé para los próximos años un crecimiento importante de esta fuente de ingresos, a un ritmo en promedio del $60 \%$ anual hasta 2022 . Las licencias y derechos de autor representan $13,6 \%$ del volumen de negocio (168 millones de euros); y representando el $7,1 \%$ de los ingresos aparece la venta de entradas para la asistencia a eventos, torneos, etc. y de merchandising, que se estima que alcance en 2018 los 88 millones de euros. Ésta última se prevé que tenga especial relevancia en el continente asiático (IDATE, 2018b).

En el caso de España, en la actualidad se habla de una consolidación del sector y de su fuerte penetración en nuestro país, donde ya se han constituido organismos como la Liga de Videojuegos Profesional (LVP) o la Electronic Sports League (ESL) que han establecido acuerdos con grandes empresas para el fortalecimiento de su presencia. Además, estas ligas están fomentando la creación de diferentes equipos focalizados en distintos videojuegos, lo que supone el involucramiento de marcas en los patrocinios de los equipos y en la organización de eventos, aunque todavía se desconoce su potencial (IAB Spain, 2018b).

\subsection{Redes Sociales}

La función de las redes sociales se ha afianzado en el universo digital, ya que facilitan a los usuarios compartir noticias, crear y 


\section{Las estimaciones} para los próximos años indican crecimientos importantes en el sector de las redes sociales compartir contenido propio, jugar online y acceder a servicios multimedia, por poner algunos ejemplos. Aprovechando toda la actividad que se genera en las redes sociales, las marcas buscan interactuar con los clientes con el objetivo de vender sus productos y servicios.

Las redes sociales suponen también una importante fuente de ingresos, que provienen de dos modelos de negocio diferente: en primer lugar, la publicidad, que se caracteriza por el alto grado de personalización. Mediante el análisis del comportamiento de los clientes y la aplicación de técnicas de Big Data, las marcas obtienen conocimiento de los usuarios a través de sus perfiles en redes sociales permitiendo segmentar con precisión y exactitud el público objetivo de sus futuras campañas. Y, en segundo lugar, la venta de servicios y bienes virtuales.

Los ingresos provenientes de las redes sociales a nivel mundial se sitúan en el año 2017 en 38.508 millones de euros, un 13,6\% más que en el año 2016. Las estimaciones para los próximos años indican crecimientos importantes en el sector de las redes sociales. La tasa de crecimiento medio anual entre 2017 y 2021 asciende a 9,8\%. Además, el 52,2\% de la facturación de las redes sociales se debió a los ingresos procedentes de la publicidad, mientras que el $47,8 \%$ restante a los ingresos por ventas de bienes y servicios. Se estima que para el año 2021 los ingresos procedentes de la publicidad supongan el 60,2\% del total de los ingresos (IDATE, 2017b).

Asia Pacífico y Norteamérica son las regiones geográficas con mayores ingresos procedentes de redes sociales registrando una cifra de negocio de 16.875 y 13.231 millones de euros respectivamente. Ambas crecen respecto a 2016, Norteamérica incrementa sus ingresos en redes sociales un $17,1 \%$ y Asia Pacifico hace lo propio en un $9,7 \%$. Estas dos regiones conjuntamente acumulan el $78,2 \%$ de los ingresos totales en redes sociales. En el caso de Europa, el volumen de negocio es de 6.589 millones de euros, habiendo experimentado un crecimiento del $8,9 \%$ con respecto a 2016. La tasa de crecimiento medio anual para el período 2017-2021 en el continente europeo es del 9,5\%. Latinoamérica y Oriente Medio y África no presentan todavía unos volúmenes de ingresos destacables provenientes de las redes sociales. Ambas regiones conjuntamente apenas llegan a englobar el $5 \%$ de los ingresos totales. No obstante, se estima que la tasa promedio de crecimiento anual en el periodo comprendido entre 2017 y 2021 para ambas regiones será superior al de otras regiones más consolidadas ( $14,9 \%$ en el caso de Latinoamérica y $16,9 \%$, en el caso de Oriente Medio y África).

Con respecto a España, el volumen de negocio de las redes sociales igualmente viene experimentando un notable crecimiento sin cesar desde el año 2010. En la actualidad, el sector alcanza los 289 millones de euros (un $9,6 \%$ más que en 2016 ) y se estima una tasa de crecimiento compuesto anual del 6,4\% hasta el año 2021 , en el 
que se estima que se alcancen los 370 millones de euros (IDATE, 2017b). 


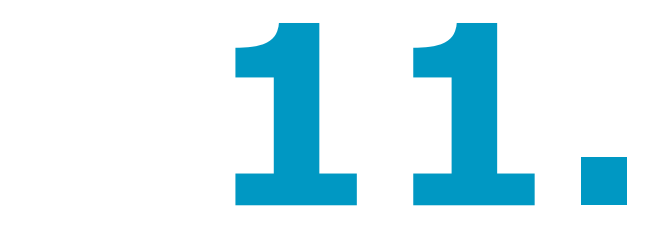

\section{CONCLUSIONES}

$$
\text { 阅 }
$$

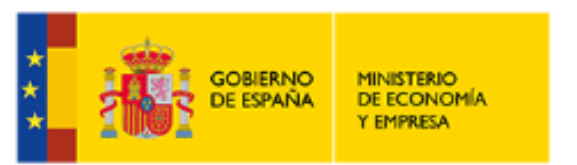

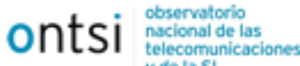

red.es 


\section{Conclusiones}

En este apartado se especifican los aspectos más relevantes relativos a la evolución de la industria de los contenidos digitales y de sus sectores asociados, tanto desde una perspectiva global como nacional.

A nivel mundial el proceso de digitalización continúa su tendencia creciente especialmente en los sectores de los videojuegos, el vídeo y la música, los cuales presentan unas tasas de digitalización en 2017 del 88\%, 68\% y 66\%, respectivamente.

En España, la tasa de digitalización de la industria de contenidos se incrementa en 4,1 puntos porcentuales, volviendo a valores muy similares a los registrados antes de 2016. En 2017, el $54 \%$ de sus ingresos proceden de la parte de negocio digital.

En lo que respecta al sector del videojuego, los juegos para dispositivos móviles y tablets poco a poco se van convirtiendo en el segmento líder; al mismo tiempo que los desarrolladores y fabricantes de videoconsolas están orientando su estrategia de distribución de software hacia un modelo completamente digital. Estos hechos explicarían en parte la creciente digitalización experimentada por el sector, tanto a nivel global como nacional. Así, en 2017, la industria del videojuego global asciende a los 86,5 miles de millones de euros contribuyendo únicamente a este incremento los ingresos procedentes de las ventas digitales. En España, este sector ha incrementado sus ingresos en un 15,6\% con respecto a 2016 (713 millones de euros). Además, se prevé que dentro de cuatro años los ingresos por ventas en formato físico en el mundo apenas representen el $4 \%$.

Por otro lado, el proceso de digitalización del sector de la música a nivel global sigue una tendencia muy similar a la del videojuego. En 2017, su cifra de negocio total ha ascendido a los casi 15.000 millones de euros, gracias al incremento de las ventas digitales que han crecido un $32 \%$ más con respecto al año anterior; mientras que en España los ingresos de la música digital crecen un $50,3 \%$ más. Este notable crecimiento del sector se debe fundamentalmente a que, en la actualidad, cobra mayor importancia la distribución de los productos mediante suscripciones online y los servicios de streaming (que ya representa en torno al $60 \%$ de la facturación de la música digital en el mundo). En España, la música en streaming aporta el $47,5 \%$ de los ingresos totales de la música digital.

De forma similar, el crecimiento exponencial de los ingresos del sector del vídeo en su dimensión de negocio digital a nivel global se debe al importante papel que tienen las suscripciones a servicios de vídeo, que representan en la actualidad cerca del $60 \%$ de los ingresos procedentes del negocio digital. En España, más de la mitad de los ingresos procedentes de la venta de productos de cine y vídeo a través de medios digitales procede de la distribución de vídeo bajo demanda.

De otro lado, el sector de la televisión estaría experimentando un proceso de reinvención en lo que se refiere a los vínculos que mantiene con el sector de la publicidad, con el fin de ofrecer a los anunciantes ventajas similares a las que ofrece Internet. En relación con esto, tiene una importancia especial el desarrollo de la televisión programática, que consiste en la aplicación de tecnología a la publicidad para encontrar audiencias y perfiles más sofisticados y efectivos, ofreciendo los mismos anuncios publicitarios a todos los espectadores que ven el mismo programa de televisión, y permitiendo a los anunciantes apuntar a aquellos programas cuyos espectadores coinciden más con su consumidor objetivo ideal. La televisión programática cobra especial importancia en Estados Unidos, donde crece rápidamente, aunque también avanza progresivamente en países como Reino Unido, Alemania y Australia. 
Para el desarrollo y despegue de la TV programática jugarán en el futuro un papel muy importante la generalización de la adopción de diferentes dispositivos que permiten conectar la TV a Internet (por ejemplo, los STB), la capacidad de los agentes interesados en llegar a acuerdos sobre estándares tecnológicos y nuevas herramientas para la medición de audiencias, la aparición de nuevos modelos de negocio que se adapten a la nueva relación entre los agentes del mercado, el desarrollo de normativa regulatoria, y el alcance de mayores grados de transparencia en la utilización de datos, fundamentalmente.

Además, la publicidad programática constituirá en el futuro el motor tecnológico clave para el crecimiento del sector de la publicidad digital: esto es, la automatización del proceso de toma de decisiones de compra de espacio publicitario, en combinación con el retargeting (es decir, impactar con publicidad a los usuarios que con anterioridad han interactuado con una marca determinada). No obstante, el sector de la publicidad digital a nivel mundial crece incesantemente y se espera que lo siga haciendo durante los próximos años. En España, además, las cifras de inversión crecen año a año, desde 2012 a un ritmo en promedio del $14,2 \%$ anual.

Dentro del sector audiovisual, la televisión lineal continúa perdiendo terreno en favor del vídeo online (OTT). La rápida adopción del acceso a Internet de alta velocidad (tanto fijo como móvil), la TV conectada y las STB, se ha traducido en un crecimiento para los ingresos generados por el consumo de vídeo OTT.

En España, el volumen de negocio de la TV IP viene creciendo a pasos agigantados en los últimos años, desbancando del primer puesto a la TV por satélite, que dominaba el mercado de la TV de pago hasta 2015. La TV IP es ya la principal modalidad de acceso a contenido audiovisuales (en sólo tres años ha pasado de aglutinar un poco más del $20 \%$ de los ingresos a representar más del $60 \%$ de los ingresos de la TV de pago). En la actualidad, esta modalidad representa un tercio de los ingresos totales del sector de la televisión en España.

Por el contrario, tanto el sector de las publicaciones de libros como el de la prensa siguen resistiéndose en la transición hacia el mundo digital, cuyas tasas de digitalización son del $11 \%$ y del $10 \%$, respectivamente. Las cifras de ingresos de la venta de libros digitales a nivel mundial siguen una tendencia al alza durante los últimos años, aunque a un ritmo de crecimiento bastante bajo.

Aunque este tipo de ventas continúan siendo escasas, cabe destacar que la venta de libros en formato físico a través de comercio electrónico se incrementa de forma masiva a expensas de la venta tradicional en librería. En el caso de España, la contribución de los libros digitales a la facturación total de la rama de actividad de edición de libros continúa siendo muy baja. Las razones que se dan para explicar el fenómeno de la baja digitalización de esta rama de actividad, en términos generales, se atribuyen no solo a la fidelidad de los lectores al formato tradicional en papel, sino también a la escasa competitividad de los precios de los productos según su modalidad de distribución (digital o tradicional en papel), así como la relativa ausencia en el sector a nivel internacional de grandes compañías proveedoras de servicios de suscripción similares a las existentes en los sectores del vídeo o la música.

En definitiva, en el marco de la coyuntura económica actual, se puede confirmar el buen momento que está experimentando la industria de los contenidos digitales, en términos generales, tanto en España como en el mundo. Los indicadores analizados a lo largo del presente documento corroboran este hecho para todos los sectores que conforman esta industria, fundamentalmente en la dimensión del volumen de ingresos por ventas digitales: en el mundo destaca el crecimiento de la música, el vídeo y los videojuegos; en España, las publicaciones, la música y el vídeo. 
Además, las previsiones de cara al futuro a nivel mundial señalan la progresiva desaparición de las ventas en formato físico en todos los sectores, con una única excepción: el sector de las publicaciones, tanto en la rama de edición de libros, como en la de la prensa escrita, en el cual los ingresos por parte de las ventas físicas seguirán representando en los próximos años más del $80 \%$. 


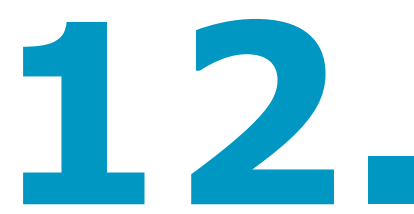

\section{NOTA METODOLÓGICA}

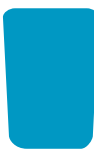

$\longrightarrow$ 


\section{Nota metodológica}

\subsection{Nota general}

El informe ha sido elaborado por los equipos de Estudios e Indicadores del ONTSI, con los servicios de apoyo y asesoramiento de Asesores y Consultores en Administraciones Públicas, SL.

En la elaboración del informe se han tenido en cuenta como fuentes principales las siguientes:

- Encuesta a las empresas del Sector de las Telecomunicaciones, de las Tecnologías de la Información y los Contenidos 2017. ONTSI, 2018.

- Informe Media Strategies: The content industry's fundamentals and new trends elaborado por IDATE para el ONTSI.

- Estadísticas anuales del sector audiovisual elaboradas por la Comisión Nacional de los Mercados y la Competencia. Los datos incluidos en el informe sobre la cifra de negocios y la inversión del sector audiovisual proceden de los informes trimestrales de 2017 de la CNMC.

\subsection{Ficha técnica y metodología de la encuesta a las empresas del sector de contenidos}

En línea con la recomendación de la OCDE de componer un espacio metodológico completo y homogéneo en la industria de los contenidos y servicios audiovisuales, el ONTSI ha considerado conveniente agregar las actividades de contenidos: publicación de libros, actividades cinematográficas, actividades de grabación de sonido y otros servicios de información con las de prestación de servicios audiovisuales que publica la Comisión Nacional de los Mercados y de la Competencia.

\begin{tabular}{|c|c|}
\hline & Clasificación del sector de los Contenidos y de los Servicios Audiovisuales \\
\hline CNAE 2009 & Publicación de libros, periódicos y otras actividades de publicación \\
\hline 5811 & Edición de libros \\
\hline 5813 & Edición de directorios y guías de direcciones postales \\
\hline 5814 & Edición de periódicos \\
\hline 5819 & Otras actividades editoriales \\
\hline CNAE 2009 & Actividades cinematográficas, de vídeo y de programas de televisión \\
\hline 5912 & Actividades de post-producción cinematográfica, de vídeo y de programas de televisión \\
\hline 5914 & Actividades de exhibición cinematográfica \\
\hline 5915 & Actividades de producción cinematográfica y de vídeo \\
\hline 5916 & Actividades de producción de programas de televisión \\
\hline 5917 & Actividades de distribución cinematográfica y de vídeo \\
\hline 5918 & Actividades de distribución de programas de televisión \\
\hline CNAE 2009 & Actividades de grabación de sonido y edición musical \\
\hline 5920 & Actividades de grabación de sonido y edición musical \\
\hline CNAE 2009 & Actividades de programación y emisión de radio y televisión \\
\hline 6010 & Actividades de radiodifusión \\
\hline 6020 & Actividades de programación y emisión televisión \\
\hline CNAE 2009 & Otros servicios de información \\
\hline 6391 & Actividades de agencias de noticias \\
\hline 6399 & Otros servicios de información \\
\hline
\end{tabular}


Para complementar la industria de contenidos digitales, el informe, al igual que en sus ediciones anteriores, incorpora el análisis de los sectores de videojuegos y publicidad digital, ofreciendo así una panorámica más completa del sector.

En 2017, el sector de los contenidos y servicios audiovisuales estaba formado por 9.785 empresas. Este dato es suministrado por la Tesorería General de la Seguridad Social al ONTSI en base a los CNAE considerados en la tabla anterior. No se dispone del número de empresas de publicidad y de videojuegos.

La ficha técnica correspondiente al estudio del sector TICC, que engloba al sector de Contenidos, es la siguiente:

- Universo: el universo de empresas es de 14.452 (a partir de datos del Registro Mercantil).

- Ámbito: Península, Baleares, Canarias, Ceuta y Melilla.

- Muestra: el objetivo del estudio fue la actividad económica de las empresas, que se encuentran operativas de 2011 a 2016. Se trabajó con los resultados de las cuentas no consolidadas para poder separar de una manera más certera las cifras por ramas de actividad. La muestra seleccionada es de 3.851 unidades y la muestra efectiva es de 2.533 unidades. Para el caso del sector de los Contenidos, la muestra fue de 1.086 empresas, y la muestra efectiva alcanzó 697 empresas.

- Técnica: captación de datos online.

- Trabajo de campo: la recogida de información tiene una duración de 3 meses y se realiza entre marzo y junio.

- Error muestral: el margen de error de la muestra total, para las condiciones estadísticas convencionales $(p=q=50 \%$ ) y para un intervalo de confianza del $95 \%$ es de $\pm 0,02$ con una tasa de respuesta del $66 \%$. Para contenidos el error oscila entre un $\pm 0,04$ con una tasa de respuesta del $-64 \%$.

Con el fin de profundizar en el conocimiento de la industria de los contenidos digitales, el ONTSI solicitó en la encuesta dirigida a las empresas de contenidos y servicios audiovisuales, la desagregación del porcentaje digital de facturación, el porcentaje digital del empleo y de la inversión.

El concepto de porcentaje digital recoge la parte de los ingresos que corresponde a bienes y/o servicios que proporcionan contenidos con información en formato digital o electrónico. De acuerdo con lo anteriormente expuesto, los productos incluyen las publicaciones, películas, vídeos, programas de TV y radio, música, videojuegos, software, y contenidos relacionados con la educación, servicios de información financiera y los distintos formatos de publicidad online o de publicidad para soportes móviles. Se consideran digitales tanto los contenidos distribuidos sin soporte físico como los contenidos digitales distribuidos o comercializados en formato digital sobre soporte físico (CD, DVD, pendrive, etc.)

Además, se incluyen los contenidos digitales o electrónicos de nuevos tipos de servicios web accesibles en línea como por ejemplo servicios de noticias, información, juegos, servicios de información financiera, servicios relacionados con la educación, servicios de reproducción de música, vídeo bajo demanda, publicidad online, videojuegos online, etc.

A efectos de esta encuesta se define contenido como "un mensaje o una información organizada, accesible para las personas mediante su compra o acceso por cualquier vía: en soporte físico, a través de Internet, por otros medios electrónicos, vía medios de comunicación y otras actividades relacionadas con los medios". 


\subsection{Fórmula para las tasas de crecimiento compuesto anual}

Las tasas de crecimiento compuesto anual se han calculado siguiendo la fórmula que se indica a continuación, siendo " $n$ " el número de años entre los dos años a calcular:

$$
\mathrm{TCCA}=100 *((\text { Valor futuro/ Valor previo }) \wedge(1 /(n-1))-1)
$$

\subsection{Estimaciones de evolución futura}

Se han empleado datos cuantitativos procedentes de fuentes secundarias cuando estaban disponibles. Adicionalmente, se han realizado comentarios cualitativos propios del ONTSI en base a las tendencias observadas.

\subsection{Aclaraciones Sectoriales}

En el sector de los videojuegos se combinan dos fuentes de datos externas a la hora de describir su evolución. Por un lado, se presenta la cifra de negocio obtenida por las empresas españolas desarrolladoras de videojuegos, dato obtenido de la nota de prensa "La industria española del videojuego consolida las buenas expectativas de crecimiento" publicada por la Asociación Española de Empresas Desarrolladoras de Videojuegos y Software de Entretenimiento (DEV). Por otro lado, se recoge la facturación por venta de videojuegos en soporte físico proporcionado por la Asociación Española de Videojuegos (AEVI) en su Anuario del Videojuego 2018. 


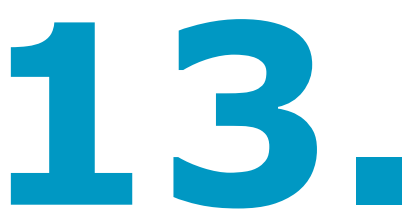

\section{GLOSARIO DE TÉRMINOS}

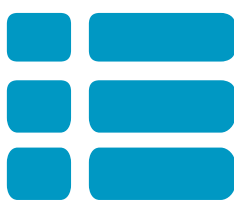




\section{Glosario de términos}

- ADE: Agenda Digital para España.

- Ad-Blocker: programa informático que permite filtrar o bloquear la publicidad inserta en páginas web.

- AEVI: Asociación Española de Videojuegos.

- AIMC: Asociación para la Investigación de Medios de Comunicación.

- Banda ancha: conexión a Internet capaz de transmitir información a gran velocidad.

- BYOD: del inglés Bring Your Own Device.

- CAGR: del inglés Compound Annual Growth Rate.

- CD: del inglés Compact Disc (disco compacto).

- CNAE: Clasificación Nacional de Actividades Económicas.

- CNMC: Comisión Nacional de los Mercados y Competencia.

- Desktop \& Mobile: publicidad registrada a través de ordenadores de sobremesa, y la publicidad a través de dispositivos inalámbricos e interactivos como los teléfonos móviles, PDAs, etc.

- DG GROW: Dirección General de Mercado Interior, Industria, Emprendimiento y Pymes de la Comisión Europea.

- Digital Signage: publicidad basada en la emisión de contenidos publicitarios dinámicos, personalizados $\mathrm{y}$, en ocasiones, interactivos mediante tecnología IP, tanto en interiores como en exteriores, a través de pantallas en sustitución a los carteles tradicionales.

- Digitalización de las salas: proceso de adaptación de las salas de cine a la emisión de películas en formato digital.

- DEV: Asociación Española de Empresas Productoras y Desarrolladoras de Videojuegos y Software de Entretenimiento.

- DOCSIS 3.1: Estándar que define los requisitos de operaciones y comunicaciones en las redes de cable.

- DVD: del inglés Digital Video Disc (disco digital de vídeo).

- Enlaces patrocinados: enlaces embebidos en los motores de búsqueda por los que el patrocinador paga cierta cantidad. Aparecen en las posiciones destacadas del buscador.

- Exabyte: unidad de almacenamiento equivalente a 2 elevado a 60 bytes 0 1.000.000.000 de gigabytes.

- FTTx: del inglés Fiber to the $x$. Término genérico para denominar cualquier acceso de banda ancha sobre fibra óptica que sustituya total o parcialmente el cobre del bucle de acceso. El término FTTx engloba las distintas configuraciones desplegadas (FTTB, FTTH, FTTN, FTTC, etc.).

- FTTB: del inglés Fiber to the Basement. La fibra óptica llega hasta la acometida del edificio. Normalmente termina en un punto de distribución intermedio en el interior o en las inmediaciones del edificio de los abonados.

- FTTN: Fiber to the Node. O fibra hasta el nodo. La fibra termina en una central del operador de telecomunicaciones que presta el servicio. Normalmente suele estar más lejos de los abonados que en FTTH y FTTB.

- FTTC: del inglés Fiber to the Curb. Similar a FTTN, pero la cabina o armario de telecomunicaciones está más cerca del usuario, normalmente a menos de 300 metros.

- FTTdp: del inglés Fiber to the distribution point.

- FTTH: del inglés Fiber to the Home. O fibra hasta el hogar (la fibra óptica llega hasta el interior de la misma casa u oficina del abonado.

- Freemium o Free to Play: es un modelo de negocio que ofrece servicios básicos de 
forma gratuita y cobra por otros servicios o funcionalidades más avanzadas.

- HFC: del inglés Hybrid Fibre Coaxial. Término que define una red de fibra óptica que incorpora tanto fibra óptica como cable coaxial para crear una red de banda ancha.

- HDMI: del inglés High Definition Multimedia Interface.

- IAB: Internet Advertising Bureau.

- IDATE: Institut de l'audiovisuel et des télécommunications en Europe. Uno de los principals think tank europeos en materia de economía digital.

- IFPI: International Federation of the Phonographic Industry

- INE: Instituto Nacional de Estadística.

- Juego social: género de videojuegos que engloba los siguientes: preguntas, canto, baile, instrumentos musicales y fiesta.

- Juegos bajo demanda: término empleado para los videojuegos que se encuentran en una plataforma, generalmente "en la nube", desde la cual los usuarios pueden consumirlos cuándo y dónde ellos deseen, también es conocido con el término anglosajón game on demand.

- Juegos "en la nube": modelo de negocio del sector de los videojuegos que ofrece el uso de los programas de forma remota mediante un dispositivo, ejecutándose dicho programa en los servidores externos y transmitiendo los datos vía Internet al dispositivo del usuario, también es conocido con el término anglosajón cloud gaming.

- Juegos Masivos online: aquellos juegos en los que hay varios participantes conectados en tiempo real a través de Internet, también es conocido con el término anglosajón massive multiplayer online.

- Juegos personalizados: formato publicitario en los videojuegos para la promoción de marcas por medio del uso de la propia marca como elemento central del juego, también es conocido con el término anglosajón adgames.

- LTE: del inglés Long Term Evolution. También conocido como 4G, es la evolución de las redes 3,5G de comunicaciones móviles. Las características de estas redes las hacen idóneas para soportar los servicios móviles del futuro al poder proporcionar, en determinadas condiciones, servicios de transmisión de datos con velocidades de pico superiores a los 100 Mbps.

- LOPD: Ley Orgánica de Protección de Datos.

- Mbps: Megabit por segundo.

- MoU: en sus siglas en inglés, Memorandum of Understanding (Memorando de Entendimiento).

- Música "en la nube": modelo híbrido entre el streaming y subida o descarga de archivos de música para su consumo y/o almacenamiento.

- OCDE: en inglés Organisation for Economic Co-operation and Development (OECD). Organización para la Cooperación y el Desarrollo Económico.

- ONTSI: Observatorio Nacional de las Telecomunicaciones y de la Sociedad de la Información.

- OTT: del inglés Over the Top. Término utilizado para designar servicios prestados en Internet que utilizan las redes de comunicaciones para la relación con los usuarios.

- Pago por descarga: modalidad de negocio que se basa en el pago por la descarga de contenidos adicionales para el juego, también conocida con el término anglosajón item selling.

- PPV: del inglés Pay Per View (Pago Por Vísión). Modelo de explotación de contenidos audiovisuales en el que los usuarios deben pagar una cantidad para poder visualizarlos.

- Paywall: término inglés utilizado para designar el modelo de negocio de la prensa por el cual el usuario que quiere acceder a una noticia se encuentra con una pantalla invitándole a suscribirse al medio para poder continuar.

- PC: del inglés Personal Computer (ordenador personal). 
- Publicidad programática: tipo de publicidad digital en la que el anunciante compra audiencias y no espacios como en la publicidad tradicional, basada en el Big Data para segmentar la audiencia y ofrecer la publicidad a un público objetivo.

- Realidad aumentada: tecnología que mezcla la visión del mundo real con elementos virtuales. Se diferencia de la realidad virtual en que no se aísla de la realidad, sino que se adapta a ella.

- Redes NGA: del inglés Next Generation Access. Redes de banda ancha ultrarrápida.

- Retargeting: impactar con publicidad a los usuarios que con anterioridad han interactuado con una marca determinada.

- RGPD: Reglamento General de Protección de Datos.

- Roaming: itinerancia de datos. Servicio que ofrecen a sus clientes los operadores de usar el servicio en una red móvil diferente de la suya, por lo general fuera del territorio nacional.

- SEAD: Secretaría de Estado para el Avance Digital.

- STB: del inglés Set Top Box. Decodificador.

- Streaming: distribución de contenidos tanto de audio como de vídeo mediante acceso sin descarga a través de Internet.

- Suscripción: modalidad de pago por el uso de servicios a través de una cuota.

- Tableta digital o tablet: dispositivo portátil similar a un ordenador portátil, pero de menor dimensión, integrado en una pantalla táctil que permite la interacción con el mismo.

- TDT: Televisión Digital Terrestre.

- Televisión IP (TV-IP): del inglés Internet Protocol Television (IP-TV), es un sistema de distribución de televisión basado en el protocolo IP, suministrado en la mayoría de los casos por los mismos proveedores de Internet.

- TIC: Tecnologías de la Información y la Comunicación.

- VAB: Valor Añadido Bruto.

- VABpm: Valor Añadido Bruto a precios de mercado.

- VDSL: del inglés Very high-bit-rate Digital Subscriber Line (línea de abonado de muy alta tasa de transferencia). Se trata de una tecnología de acceso a internet de banda ancha perteneciente a la familia de tecnologías XDSL que transmiten los impulsos sobre el cable de par trenzado de la línea telefónica convencional.

- Vídeo bajo demanda: del inglés video on demand (VoD).

- VR: del inglés Virtual Reality. 


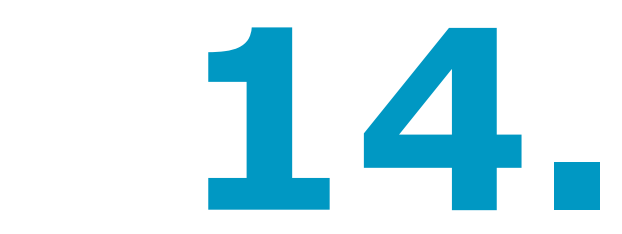

BIBLIOGRAFÍA
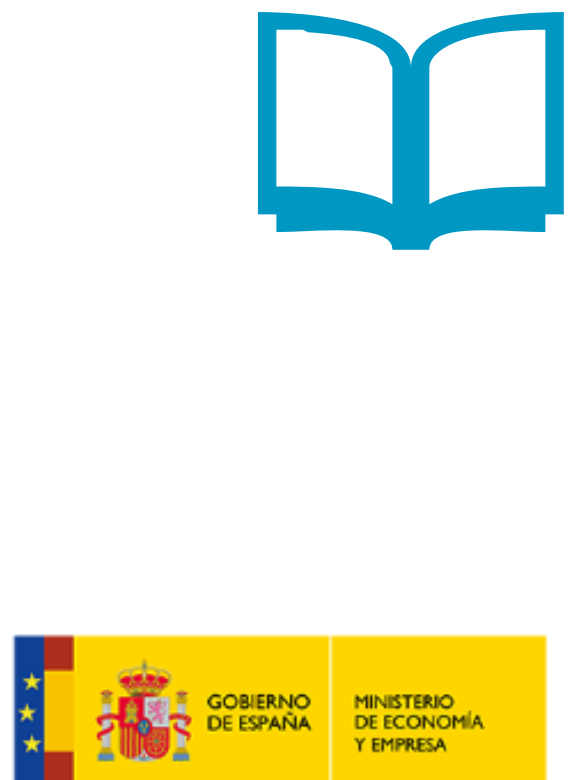

ontsi red.es 


\section{Bibliografía}

- Asociación Española de Videojuegos (AEVI) (2018), Anuario de la industria del Videojuego.

- Asociación para la Investigación de Medios de Comunicación (AIMC) (2018), Censo de Salas de Cine.

- BuzzAngle (2018) Music U.S. Report 2017.

- CISCO (2018), Cisco Visual Networking Index: Forecast and Methodology, 2017-2022, https://www.cisco.com/c/en/us/solutions/collateral/service-provider/visual-networkingindex-vni/white-paper-c11-741490.pdf

- Comisión Europea (CE) (2018), Connectivity. Broadband markets developments in the $E U$.

- Comisión Nacional de los Mercados y la Competencia (CNMC) (2018), Informe Económico Sectorial de las Telecomunicaciones y el Audiovisual 2018, Datos trimestrales.

- DEV (2018), Libro blanco del desarrollo español de los videojuegos 2017.

- Eurostat, Database.

- IAB Spain (2016), FAQ's Reglamento Europeo de Protección de Datos.

- IAB Spain (2018a), Inversión Publicitaria en Medios Digitales, https://iabspain.es/wpcontent/uploads/inversin-publicitaria-medios-digitales 2017 vreducida.pdf

- IAB Spain (2018b), Top tendencias digitales 2018.

- IAB Spain (2018c), Estudio Anual Vídeo Online 2018.

- IDATE (2017a), World TV \& Video Services Markets.

- IDATE (2017b), World OTT Markets.

- IDATE (2017c), World FTTx Market.

- IDATE (2017d), World LTE Markets - 5G Initiatives \& MBB Spectrum.

- IDATE (2018a), World Digital Content Markets.

- IDATE (2018b), Media Strategies: The content industry's fundamentals and new trends.

- IFPI (2018), Global Music Report 2018.

- INE, Encuesta sobre equipamiento y uso de las TIC en los hogares 2018.

- Infoadex (2018), Estudio Infoadex de la inversión publicitaria en España 2018.

- ONTSI (2017), Informe anual del sector de los contenidos digitales en España 2017.

- ONTSI (2018), LXI Oleada del Panel Hogares. Las TIC en los hogares españoles (1T/2018).

- Pagefair (2017), The state of the blocked web. Global Adblock Report 2017.

- Secretaría de Estado para el Avance Digital (SEAD) (2018), Informe de cobertura de banda ancha en España en el año 2017. 


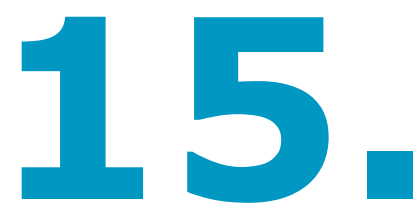

\section{ÍNDICE DE GRÁFICOS}
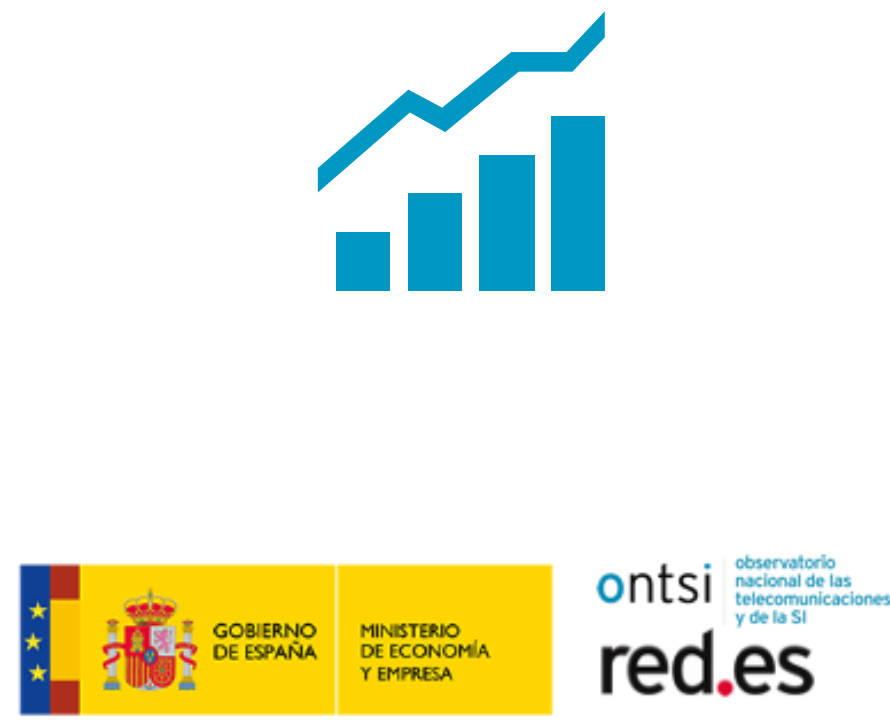


\section{5 Índice de gráficos}

GRÁFICO 1. EquipaMiENTO DE PRODUCTOS TIC EN LOS HOGARES ESPAÑOLES, 2018 (\% DE

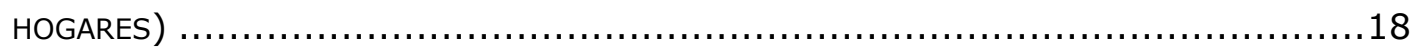

GRÁFICO 2. PRINCIPALES DISPOSITIVOS DE ACCESO A INTERNET (\% DE INTERNAUTAS) ..........18

GRÁFICO 3. PRINCIPALES DISPOSITIVOS PARA EL CONSUMO DE VÍDEO ONLINE (\% DE USUARIOS DE

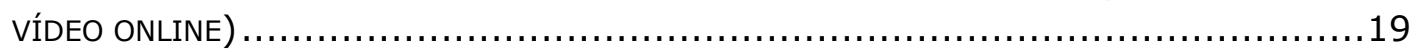

GRÁFICO 4. CoberTURA DE REDES NGA EN ESPAÑA VS. UE28 (\% HOGARES) ..................21

GRÁFICO 5. COBERTURA DE REDES DE BANDA ANCHA ULTRARRÁPIDA EN ESPAÑA POR TECNOLOGÍA

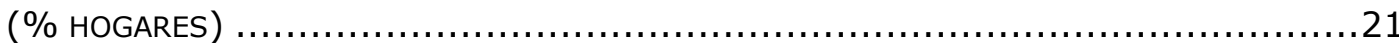

GRÁFICO 6. EVOLUCIÓN ESPERADA DEL TRÁFICO IP 2017-2022 (EXABYTES/MES) ................23

GRÁFICO 7. DISTRIBUCIÓN DEL TRÁFICO IP GENERADO POR LOS CONSUMIDORES POR TIPO DE

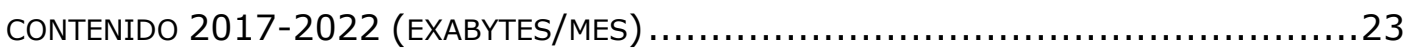

GRÁFICO 8. EVOLUCIÓN DE LOS USUARIOS EUROPEOS QUE UTILIZAN DIARIAMENTE INTERNET ....24

GRÁFICO 9. EVOLUCIÓN DE LOS PRINCIPALES USOS DE INTERNET RELACIONADOS CON EL CONSUMO DE CONTENIDOS DIGITALES EN LA UE-28, 2013-2017 (\% USUARIOS QUE HAN ACCEDIDO A

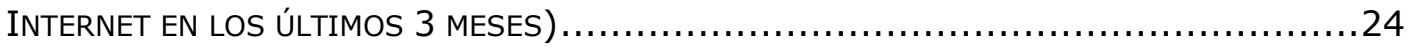

GRÁFICO 10. PRINCIPALES USOS DE INTERNET RELACIONADOS CON EL CONSUMO DE CONTENIDOS DIGITALES EN LA UE-28 (\% USUARIOS QUE HAN ACCEDIDO A INTERNET EN LOS ÚLTIMOS 3

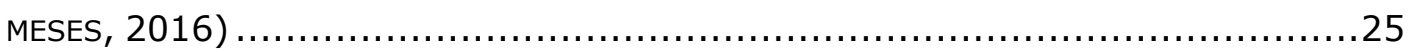

GRÁFICO 11. CifRA DE NEGOCIO DE LA INDUSTRIA DE LOS CONTENIDOS DIGITALES EN EL PERIODO

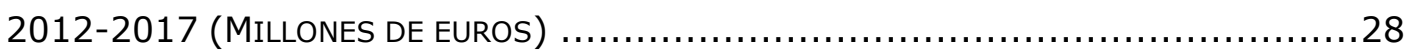

GRÁFICO 12. DESGLOSE DE LA FACTURACIÓN DE LA INDUSTRIA DE LOS CONTENIDOS DIGITALES POR SECTORES EN EL AÑO 2017 (\%/TOTAL) ......................................... 29

GRÁFICO 13. TASA DE DIGITALIZACIÓN POR SECTORES. AÑo 2017 (\%/TOTAL) ..................30

GRÁFICO 14. NÚMERO DE EMPRESAS DE LA INDUSTRIA DE LOS CONTENIDOS. 2012-2017 ......31

GRÁFICO 15. DESGLOSE DEL NÚMERO DE EMPRESAS DE LA INDUSTRIA DE LOS CONTENIDOS POR

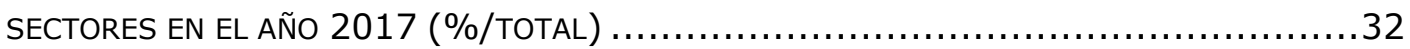

GRÁFICO 16. NúMERO DE EMPLEADOS EN LA INDUSTRIA DE LOS CONTENIDOS DIGITALES. 20122017

GRÁFICO 17. EMPLEO DEDICADO A LA INDUSTRIA DE LOS CONTENIDOS DIGITALES POR RAMA.

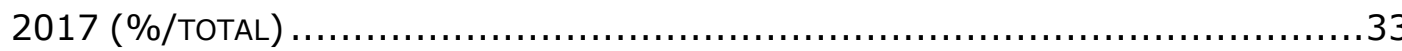

GRÁFICO 18. INVERSIÓN EN EL NEGOCIO DIGITAL DE LA INDUSTRIA DE LOS CONTENIDOS. 2017

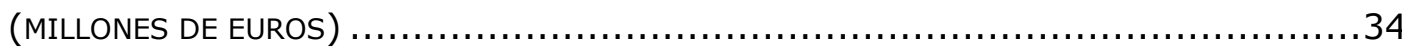

GRÁFICO 19. INVERSIÓN EN EL NEGOCIO DIGITAL DE LA INDUSTRIA DE LOS CONTENIDOS

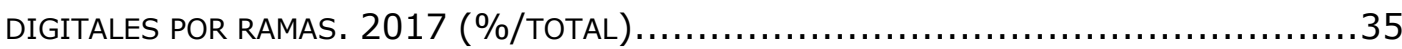

GRÁFICO 20. INGRESOS POR VENTA DE VIDEOJUEGOS EN EL MUNDO (MILES DE MILLONES DE EUROS).

GRÁFICO 21. FACTURACIÓN DE LA INDUSTRIA ESPAÑOLA DE DESARROLLO DE VIDEOJUEGOS,

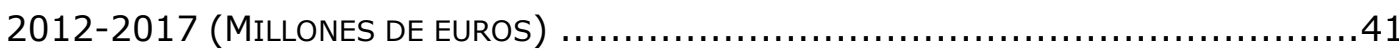

GRÁFICO 22. INGRESOS POR VENTA FÍSICA DE VIDEOJUEGOS (SOFTWARE) EN ESPAÑA. EVOLUCIÓN

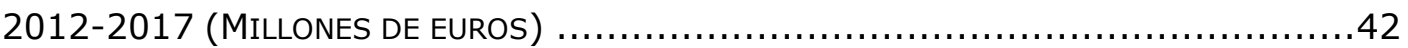

GRÁfico 23. VideOJUEGOS (SOFTWARE) VENDIDOS EN ESPAÑA. EVOlUCIÓN 2012-2017 (MilLONES DE UNIDADES)

GRÁFICO 24. DISTRIBUCIÓN DE LA CIFRA DE NEGOCIO DE PRODUCTOS RELACIONADOS CON EL SECTOR DE LOS VIDEOJUEGOS EN ESPAÑA, 2017 (\% SOBRE EL TOTAL) ...................43

GRÁFICO 25. INGRESOS POR VENTA DE DISCOS EN EL MUNDO (MILES DE MILLONES DE EUROS).. 45

GRÁFICO 26. INGRESOS POR VENTA DE DISCOS EN EL MUNDO SEGÚN IFPI (MILES DE MILLONES DE EUROS) 
GRÁFICO 27. INGRESOS DEL SECTOR DE LA MÚSICA (VENTAS DIGITALES) SEGÚN ORIGEN (MILES

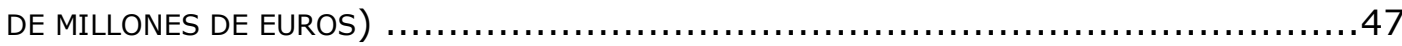

GRÁFICO 28. FACTURACIÓN DEL NEGOCIO DIGITAL DE LA MÚSICA EN ESPAÑA: 2012-2017

(MILLONES DE EUROS)

GRÁFICO 29. DiSTRIBUCIÓN EN PRODUCTOS DE LA FACTURACIÓN DEL SECTOR DE LA MÚSICA EN ESPAÑA 2017 (\%/TOTAL)

GRÁFICO 30. DISTRIBUCIÓN DE LA FACTURACIÓN POR COMERCIALIZACIÓN ONLINE DE MÚSICA EN ESPAÑA 2017 (\% SOBRE EL TOTAL DE LA FACTURACIÓN POR COMERCIALIZACIÓN ONLINE) .50

GRÁFICO 31. EVOLUCIÓN DE INGRESOS DE VÍDEO EN SOPORTE FÍSICO Y DIGITAL A NIVEL MUNDIAL

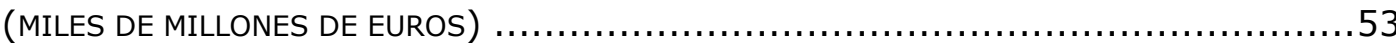

GRÁFICO 32. EVOLUCIÓN DE LOS INGRESOS POR VENTA, ALQUILER Y SUSCRIPCIONES DE VÍDEO EN SOPORTE DIGITAL A NIVEL MUNDIAL (MILES DE MILLONES DE EUROS) $\ldots \ldots \ldots \ldots \ldots \ldots \ldots \ldots \ldots$

GRÁFICO 33. EVOLUCIÓN DE LOS INGRESOS POR VENTA, ALQUILER Y SUSCRIPCIONES DE VÍDEO EN SOPORTE DIGITAL A NIVEL MUNDIAL (MILES DE MILLONES DE EUROS) $\ldots \ldots \ldots \ldots \ldots \ldots \ldots \ldots \ldots$

GRÁFICO 34. EVOLUCIÓN DE LOS INGRESOS DE LOS SERVICIOS DE VÍDEO BAJO DEMANDA EN EL

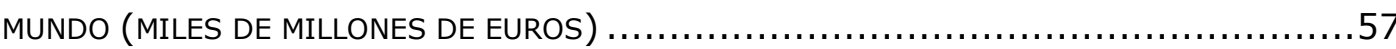

GRÁFICO 35. FACTURACIÓN DIGITAL DEL CINE Y VÍDEO EN ESPAÑA: 2012-2017 (MilLONES DE

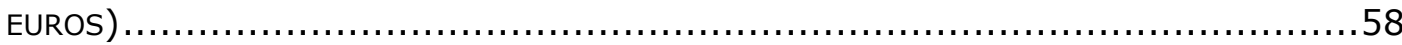

GRÁFICO 36. FACTURACIÓN DEL NEGOCIO DIGITAL DE ACTIVIDADES CINEMATOGRÁFICAS, DE VÍDEO Y DE PROGRAMAS DE TELEVISIÓN EN ESPAÑA. 2017 (\% SOBRE LA FACTURACIÓN DIGITAL DEL SECTOR)

GRÁFICO 37. PORCENTAJE DE EMPRESAS POR RAMA DE ACTIVIDAD DEL SECTOR DE CINE Y DE VÍDEO EN ESPAÑA EN 2017 (\% SOBRE EL TOTAL DE EMPRESAS DEL SECTOR)

GRÁFICO 38. PORCENTAJE DE PERSONAL OCUPADO EN LA PARTE DE NEGOCIO DIGITAL POR RAMA DE ACTIVIDAD DEL SECTOR DE CINE Y DE VÍDEO EN ESPAÑA EN 2017 (\% SOBRE EL TOTAL DE

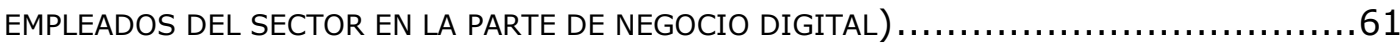

GRÁFICO 39. INVERSIÓN DIGITAL DEL SECTOR DE CINE Y VÍDEO, 2017 (\% SOBRE EL TOTAL DE LA INVERSIÓN DEL SECTOR DEDICADA AL NEGOCIO DIGITAL) ..............................62

GRÁFICO 40. CifRA DE NEGOCIO DIGITAL DE LA RAMA DE ACTIVIDAD DE PRODUCCIÓN CINEMATOGRÁFICA Y DE VÍDEO $2012-2017$ (MILLONES DE EUROS) $\ldots \ldots \ldots \ldots \ldots \ldots \ldots \ldots \ldots$

GRÁFICO 41. DISTRIBUCIÓN DEL VOLUMEN DE FACTURACIÓN POR PRODUCTOS DE LAS ACTIVIDADES DE PRODUCCIÓN CINEMATOGRÁFICA Y DE VÍDEO EN ESPAÑA. 2017 (\% SOBRE LA FACTURACIÓN DE LA RAMA DE ACTIVIDAD)

GRÁFICO 42. CifRA DE NEGOCIO DIGITAL DE LA RAMA DE ACTIVIDAD DE POST-PRODUCCIÓN CINEMATOGRÁFICA, DE VÍDEO Y DE PROGRAMAS DE TELEVISIÓN 2012-2017 (MILLONES DE EUROS)

GRÁFICO 43. DISTRIBUCIÓN DEL VOLUMEN DE FACTURACIÓN POR PRODUCTOS DE LAS ACTIVIDADES DE POST-PRODUCCIÓN CINEMATOGRÁFICA, DE VÍDEO Y DE PROGRAMAS DE TELEVISIÓN EN ESPAÑA. 2017 (\% SOBRE LA FACTURACIÓN DIGITAL DE LA RAMA DE ACTIVIDAD) ...........65

GRÁFICO 44. CifRA DE NEGOCIO DIGITAL DE LA RAMA DE ACTIVIDAD DE EXHIBICIÓN CINEMATOGRÁFICA, 2012-2017 (MILLONES DE EUROS) …...........................66

GRÁFICO 45. DISTRIBUCIÓN DEL VOLUMEN DE FACTURACIÓN DE LAS ACTIVIDADES DE EXHIBICIONES CINEMATOGRÁFICAS POR PRODUCTOS EN ESPAÑA. 2017 (\% SOBRE LA FACTURACIÓN TOTAL DE LA RAMA DE ACTIVIDAD)

GRÁFICO 46. NÚMERO DE SALAS DIGITALES EN ESPAÑA. 2009 - 2018

GRÁFICO 47. CiFRA DE NEGOCIO DIGITAL DE LA RAMA DE ACTIVIDAD DE PRODUCCIÓN DE PROGRAMAS DE TELEVISIÓN, 2012-2017 (MILLONES DE EUROS)

GRÁFICO 48. DISTRIBUCIÓN DEL VOLUMEN DE FACTURACIÓN POR PRODUCTOS DE LAS ACTIVIDADES DE PRODUCCIÓN DE PROGRAMAS DE TELEVISIÓN EN ESPAÑA, 2017 (\% SOBRE LA FACTURACIÓN DE LA RAMA DE ACTIVIDAD) 
GRÁfiCo 49. CifRA DE NEGOCIO DIGITAL DE LA RAMA DE ACTIVIDAD DE DISTRIBUCIÓN CINEMATOGRÁFICA Y DE VÍDEO, 2012-2017 (MILLONES DE EUROS) …....................70

GRÁFICO 50. DISTRIBUCIÓN DEL VOLUMEN DE FACTURACIÓN POR PRODUCTOS DE LAS ACTIVIDADES DE DISTRIBUCIÓN CINEMATOGRÁFICA Y DE VÍDEO EN ESPAÑA. 2017 (\% SOBRE LA

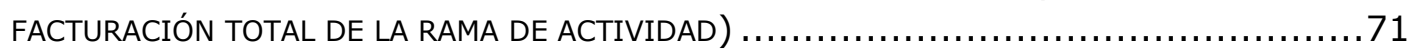

GRÁFICO 51. EVOLUCIÓN DE LA DIGITALIZACIÓN DE LA TELEVISIÓN EN EL MUNDO (MILLONES DE

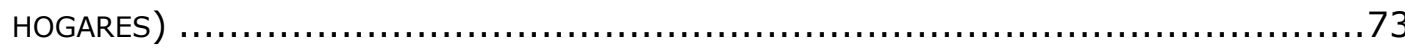

GRÁFICO 52. EVOLUCIÓN DE LOS HOGARES CON TELEVISIÓN EN EL MUNDO SEGÚN MODALIDAD DE ACCESO A CONTENIDOS TELEVISIVOS (MILLONES DE HOGARES) ......................... 74

GRÁFICO 53. PENETRACIÓN DE LOS SERVICIOS DE SUSCRIPCIÓN A TELEVISIÓN DE PAGO EN LAS

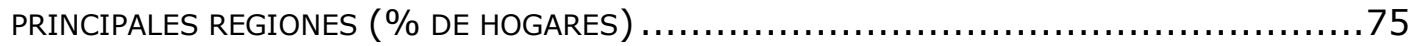

GRÁFICO 54. EVOLUCIÓN DEL NÚMERO DE HOGARES POR RED DE TRANSMISIÓN DE LA TELEVISIÓN

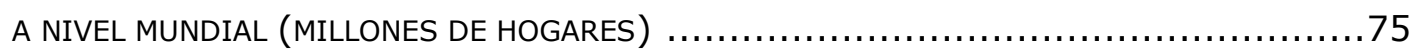

GRÁFICO 55. EVOLUCIÓN DE LOS INGRESOS POR MODELO DE NEGOCIO LIGADOS A LA TELEVISIÓN

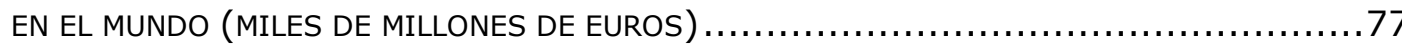

GRÁFICO 56. PORCENTAJE DE INGRESOS SEGÚN MODALIDAD CON RESPECTO AL TOTAL EN LAS

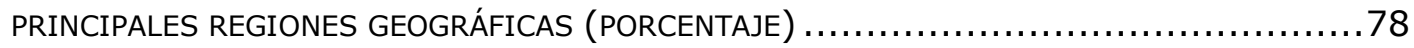

GRÁFICO 57. INGRESOS DE LA TELEVISIÓN POR MEDIO DE TRANSMISIÓN. EVOLUCIÓN 2011-2017 (MILLONES DE EUROS)

GRÁFICO 58. INGRESOS DE LA TELEVISIÓN DE PAGO POR MEDIO DE TRANSMISIÓN. EVOLUCIÓN

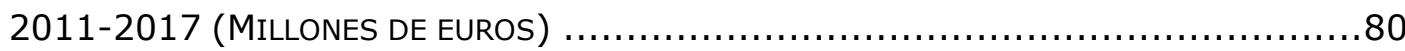

GRÁFICO 59. INVERSIÓN PUBLICITARIA EN TELEVISIÓN EN ESPAÑA. EVOLUCIÓN 2011 - 2017 (MILLONES DE EUROS)

GRÁFICO 60. INGRESOS POR VENTAS DE LIBROS EN EL MUNDO (MILES DE MILLONES DE EUROS). 84

GRÁFICO 61. PORCENTAJE DE LOS INGRESOS DE LA VENTA DE LIBROS EN FORMATO DIGITAL CON RESPECTO AL TOTAL DE INGRESOS DEL SECTOR DE LA PUBLICACIÓN DE LIBROS EN CADA UNA

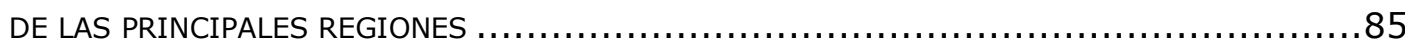

GRÁFICO 62. CifRA DE NEGOCIO DE LA PRENSA ESCRITA EN EL MUNDO (MILES DE MILLONES DE EUROS).

GRÁFICO 63. PROPORCIÓN DE INGRESOS DE LA PRENSA DIGITAL SOBRE EL TOTAL DEL SECTOR DE LA PRENSA ESCRITA EN CADA UNA DE LAS PRINCIPALES REGIONES $\ldots \ldots \ldots \ldots \ldots \ldots \ldots \ldots . \ldots \ldots \ldots$

Gráfico 64. Cifra de Negocio digital del Sector de las Publicaciones en España. 20122017 (MILLONES DE EUROS)

GRÁFICO 65. FACTURACIÓN DEL NEGOCIO DIGITAL POR RAMAS DE ACTIVIDAD DEL SECTOR PUBLICACIONES EN ESPAÑA EN 2017 (\% SOBRE EL TOTAL DE FACTURACIÓN DIGITAL DEL SECTOR)

GRÁFICO 66. PORCENTAJE DE EMPRESAS POR RAMA DE ACTIVIDAD DEL SECTOR DE LAS PUBLICACIONES EN ESPAÑA EN 2017 (\% SOBRE EL TOTAL DE EMPRESAS DEL SECTOR) ......89

GRÁFICO 67. PORCENTAJE DE PERSONAL OCUPADO EN LA PARTE DE NEGOCIO DIGITAL POR RAMA DE ACTIVIDAD DEL SECTOR DE LAS PUBLICACIONES EN ESPAÑA EN 2017 (\% SOBRE EL TOTAL DE EMPLEADOS DEL SECTOR EN LA PARTE DE NEGOCIO DIGITAL) $\ldots \ldots \ldots \ldots \ldots \ldots \ldots \ldots \ldots \ldots$

GRÁFICO 68. INVERSIÓN DE LAS ACTIVIDADES DE EDICIÓN EN EL NEGOCIO DIGITAL, 2017 (\%

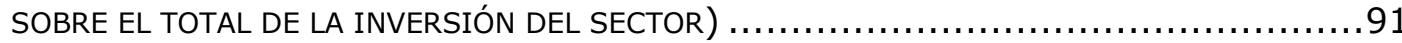

GRÁFICO 69. CifRA DE NEGOCIO DIGITAL DE LA RAMA DE EDICIÓN DE LIBROS 2012-2017 (MILLONES DE EUROS)

GRÁFICO 70. DISTRIBUCIÓN DEL VOLUMEN DE FACTURACIÓN POR PRODUCTOS DE LAS ACTIVIDADES DE EDICIÓN DE LIBROS EN ESPAÑA. 2017 (\% SOBRE LA FACTURACIÓN TOTAL DE LA RAMA DE ACTIVIDAD)

GRÁfiCo 71. CifRA DE NEGOCIO DIGITAL DE LA RAMA DE EDICIÓN DE PERIÓdiCOS 2012-2017 (MILLONES DE EUROS) 
GRÁFICO 72. DISTRIBUCIÓN DEL VOLUMEN DE FACTURACIÓN POR PRODUCTOS DE LAS ACTIVIDADES DE EDICIÓN DE PERIÓDICOS EN ESPAÑA. 2017 (\% SOBRE LA FACTURACIÓN TOTAL DE LA

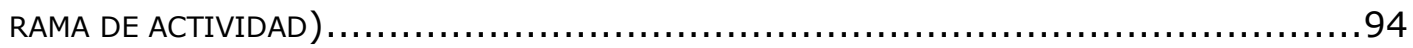

GRÁFICO 73. CiFRA DE NEGOCIO DIGITAL DE LA RAMA DE EDICIÓN DE REVISTAS 2012-2017

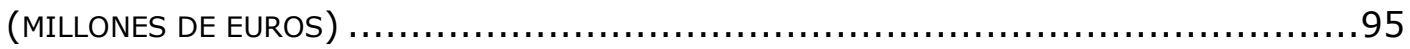

GRÁFICO 74. DISTRIBUCIÓN DEL VOLUMEN DE FACTURACIÓN DE LAS ACTIVIDADES DE EDICIÓN DE REVISTAS EN ESPAÑA. 2017 (\% SOBRE LA FACTURACIÓN TOTAL DE LA RAMA DE ACTIVIDAD)

GRÁFICO 75. INGRESOS POR TIPO DE PUBLICIDAD ONLINE (MILLONES DE EUROS) .96

GRÁFICO 76. INVERSIÓN EN PUBLICIDAD DIGITAL EN ESPAÑA: EVOLUCIÓN 2011-2017 (MILLONES DE EUROS) 100

GRÁFICO 77. DISTRIBUCIÓN DE LA INVERSIÓN PUBLICITARIA TOTAL POR MEDIOS EN 2017 EN ESPAÑA (\%) 101 102 